IVONETE ROSSI BAUTITZ

\title{
DEGRADAÇÃO DE FÁRMACOS POR PROCESSO FOTO-FENTON E FERRO METÁLICO
}

Tese apresentada ao instituto de Química, Universidade Estadual Paulista, como parte dos requisitos para obtenção do título de doutor em Química

Orientadora: Profa. Dra. Raquel Fernandes Pupo Nogueira 


\section{Bautitz, Ivonete Rossi}

B352d Degradação de fármacos por processo foto-Fenton e ferro metálico / Ivonete Rossi Bautitz. - Araraquara : [s.n], 2010

170 f. : il.

Tese (doutorado) - Universidade Estadual Paulista, Instituto de Química Orientador: Raquel Fernandes Pupo Nogueira

1. Química analítica. 2. Fármacos. 3. Foto-Fenton. 4. Processos oxidativos avançados. I. Título. 


\title{
IVONETE ROSSI BAUTITZ
}

\author{
Tese apresentada ao Instituto de \\ Quimica, Universidade Estadual \\ Paulista, como parte dos requisitos para \\ obtenção do título de Doutor em \\ Química.
}

Araraquara, 26 de fevereiro de 2010 .

\section{BANCA EXAMINADORA}

Raquel F. Pupso tho gumis

Prof $^{\mathrm{a}} \mathrm{Dr}^{\mathrm{a}}$ Raquel Fernandes Pupo Nogueira (Orientadora) Instituto de Química - UNESP, Araraquara

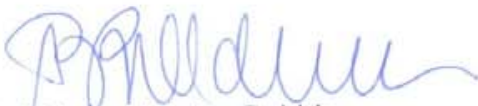

Prof $^{\mathrm{a}} \mathrm{Dr}^{\mathrm{a}}$ Maria Valnice Boldrin

Instituto de Química - UNESP, Araraquara

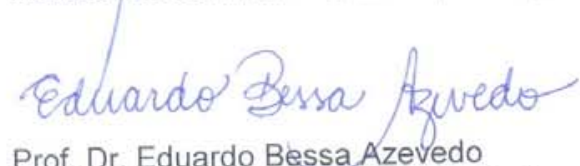

Instituto de Química - USP, São Carlos

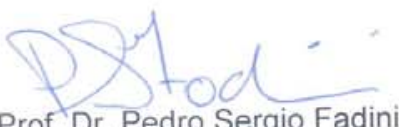

Prof. Dr. Pedro Sergio Fadin

Universidade Federal de São Carlos - UFSCar, Säo Carlos

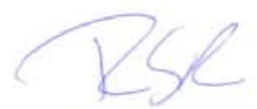

Prof. Dr. Renato Sanches Freire

Instituto de Química - USP, São Paulo 


\section{DADOS CURRICULARES}

\section{DADOS PESSOAIS}

Nome: Ivonete Rossi Bautitz

Filiação: Antonio Piazza Rossi e Maria Salla Rossi

Naturalidade: Catanduvas-PR

Nacionalidade: Brasileira

e-mail: i.rossi@hotmail.com

2 FORMAÇÃO ACADÊMICA

\subsection{LICENCIATURA EM QUÍMICA}

Curso de licenciatura concluído em 16 de agosto de 2003, nas Faculdades Integradas de Palmas - PR (FACIPAL).

\subsection{MESTRADO EM QUÍMICA}

Curso de Pós-graduação em Química, Área de Concentração: Química Analítica, concluído em 20 de junho de 2006 no Instituto de Química de Araraquara - UNESP (Universidade Estadual Paulista Júlio de Mesquita Filho).

\subsection{DOUTORADO EM QUÍMICA}

Curso de Pós-graduação em Química, Área de Concentração: Química Analítica, concluído em 26 de fevereiro de 2010 no Instituto de Química de Araraquara - UNESP (Universidade Estadual Paulista Júlio de Mesquita Filho). 
3 TRABALHOS CIENTÍFICOS PUBLICADOS

FONSECA, J. C. L.; SILVA, M. R. A.; BAUTITZ, I. R.; NOGUEIRA, R. F. P.; MARCHI, M. R. R. Avaliação da confiabilidade analítica das determinações de Carbono Orgânico Total (COT). Eclética Química. , v. 31, p. 47-52, 2006.

BAUTITZ, I. R.; NOGUEIRA, R. F. P. Degradation of tetracycline by photo-Fenton process - Solar irradiation and matrix effects. Journal of Photochemistry and Photobiology A: Chemistry, v. 187, p. 33-39, 2007.

MELO, S. A. S.; BAUTITZ, I. R.; NOGUEIRA, R. F. P. Monitoring pharmaceuticals photo-Fenton degradation process by using solid phase extraction and liquid chromatography. Analytical Letters, v. 41, p. 1682-1690, 2008.

MELO, S. A. S.; TROVÓ, A. G.; BAUTITZ, I. R.; NOGUEIRA, R. F. P. Degradação de fármacos residuais por processos oxidativos avançados. Quimica. Nova, v. 32, p. 188197, 2009.

4 TRABALHO CIENTÍFICO ACEITO PARA PUBLICAÇÃO

BAUTITZ, I. R., NOGUEIRA, R. F. P. Photodegradation of lincomycin and diazepam in sewage treatment plant effluent by photo-Fenton process. Catalysis Today. 
Dedico esse trabalho àqueles que, com carinho e compreensão, incentivaram-me a continuar na luta quando a desistência parecia ser a única saída. Afinal, essa é a chegada de um caminho cheio de derrotas e vitórias, vencidas e comemoradas uma a uma, com a ajuda destes que são o meu refúgio e a minha fortaleza:

Meu esposo Emerson

Minha mãe Maria e meu pai Antonio

Minha irmãs Valdete e Janete

Meus sobrinhos Aline e Ricardo

Meus sogros $\mathcal{N}$ air e $\mathcal{N}$ eri 


\section{AGRADECIMENTOS}

A Deus... pela vida, pela saúde, sabedoria e discernimento para superar cada obstáculo encontrado no caminho.

A meu Esposo Emerson...por estar sempre presente.

Aos meus pais...pela ajuda contínua, pelo zelo constante, pela torcida sempre...

A família Rossi...pelo incentivo e apoio.

A família Bautitz...por ter me acolfido e me ajudado desde o início dessa luta.

A minha orientadora Raquel...por todas as experiências vivenciadas durante esse período que me proporcionaram além de conhecimento científico, crescimento pessoal, pois com seu exemplo de amizade, honestidade e responsabilidade soube sempre indicar o melhor caminho.

Aos amigos do laboratório que compartilharam cada resultado que obtive e suportaram os dias de desânimo e de lamentações: Adriana, Ana Paula, Daniely, João, Jorge, Mariana, Michele e Nicole; E aqueles que já voaram: Alam, Janaina, Milady, Mirela e Ricardo, mas que deixaram muitas saudades...

Aos meus amigos Marcus Vinícius, Ana, Mara Nilza, Henrique e Ivan que sempre terão minha gratidão por serem os primeiros facilitadores dessa caminhada.

Aos amigos conquistados em Araraquara: Onilde e Antonio Comin.

A professora Valnice pela disponibilização do cromatógrafo. 
A todos os funcionários do Instituto de Química.

Ao DAAE pela coleta das amostras de efluente de estação de tratamento de esgoto.

A FAPESP pela bolsa concedida.

Neste trabalho

Alguns colaboraram o tempo todo

Outros em algum intervalo de tempo

Também houve aqueles que em um breve momento

brindaram-me com uma idéia, uma pergunta ou

simplesmente um sorriso.

Agradeço a todos. 
Nas grandes 6atalhas da vida, o primeiro passo para a vitória é o desejo de vencer!

(Mahatma Gandhi) 


\section{RESUMO}

A contaminação de compartimentos aquáticos com resíduos de fármacos é frequentemente relatada na literatura. Fármacos residuais de várias classes

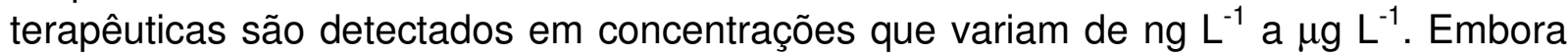
estes resíduos sejam encontrados em baixas concentrações, alguns estudos relatam a ocorrência de efeitos adversos a organismos aquáticos. Portanto, faz-se necessário o estudo de processos que promovam a degradação destes contaminantes emergentes. Nesse contexto, foi avaliada neste trabalho a eficiência do processo foto-Fenton na degradação dos fármacos diazepam, propranolol e lincomicina e também a eficiência de reações baseadas em ferro metálico para a degradação de diazepam. O monitoramento da concentração dos fármacos foi feito por meio da técnica de Cromatografia Líquida de Alta Eficiência com detector de arranjo de diodos (CLAE-UV) e a remoção da matéria orgânica foi avaliada por análises de Carbono Orgânico Total (COT). O processo foto-Fenton foi eficiente na degradação dos fármacos, pois promoveu total oxidação em aproximadamente 8 minutos de tratamento e mais de $80 \%$ de remoção de COT após 60 minutos, sob lâmpada de luz negra. Sob radiação solar, a oxidação dos três fármacos estudados ocorreu em aproximadamente 5 minutos de tratamento, além de um percentual de mais de $90 \%$ de remoção de COT alcançado em 60 minutos. Tanto sob radiação solar quanto sob lâmpada de luz negra, a espécie de ferro que promoveu maior degradação foi $\mathrm{FeOx}\left(0,20 \mathrm{mmol} \mathrm{L}^{-1}\right)$, e das concentrações de $\mathrm{H}_{2} \mathrm{O}_{2}$ avaliadas $\left(1,0,5,0,10,0 \mathrm{mmol} \mathrm{L}^{-1}\right)$, as concentrações 5,0 e $10,0 \mathrm{mmol} \mathrm{L}^{-1}$ promoveram os melhores índices de degradação. A avaliação da interferência da matriz efluente de estação de tratamento de esgoto (ETE), onde normalmente os fármacos residuais são encontrados, demonstrou que a oxidação dos fármacos não foi prejudicada na presença dessa matriz. Entretanto, 10\% a menos de remoção de COT foi observado para o fármaco lincomicina, comparado à remoção obtida em água deionizada. A avaliação dos intermediários de degradação formados durante o processo foto-Fenton demonstrou que os primeiros compostos formados pela oxidação são compostos hidroxilados, com a entrada de uma e duas hidroxilas no caso de diazepam e de até sete hidroxilas no caso do propranolol. Apenas um intermediário monohidroxilado do fármaco lincomicina foi identificado. O processo $\mathrm{Fe}$ o/EDTA $/ \mathrm{O}_{2}$ avaliado para a degradação de diazepam promoveu a oxidação do fármaco em 60 minutos e $60 \%$ de remoção de COT após 2 horas de tratamento. Esse processo, embora tenha apresentado menores índices de degradação comparado ao processo foto-Fenton, apresenta algumas vantagens, como por exemplo, o aproveitamento de rejeitos industriais de ferro, a geração in situ de $\mathrm{H}_{2} \mathrm{O}_{2}$, bem como a não necessidade de ajuste de $\mathrm{pH}$ devido ao tamponamento entre $\mathrm{pH}$ 5-6 promovido pelo sistema. Entretanto, a adição de EDTA ao sistema apresenta-se como uma desvantagem por tratar-se de uma substância tóxica. Intermediários hidroxilados de diazepam foram identificados também durante a degradação pelo sistema $\mathrm{Fe} / \mathrm{EDTA} / \mathrm{O}_{2}$ o que mostra que o oxidante formado neste processo dever ser o mesmo formado no processo fotoFenton.

Palavras-chave: fármacos, foto-Fenton, ferro metálico, processos oxidativos avançados. 


\begin{abstract}
Contamination of the aquatic environment with pharmaceutical residues is frequently reported in the literature. Pharmaceutical residues of several therapeutical classes are detected in concentrations that vary from $\mathrm{ng} \mathrm{L}^{-1}$ to $\mu \mathrm{g} \mathrm{L}^{-1}$. Although these residues were found in low concentrations, some studies reported the occurrence of adverse effects to aquatic organisms. Therefore, the study of processes that promote the degradation of these emerging pollutants becomes necessary. In this context, the efficiency of the photo-Fenton process in the degradation of the pharmaceuticals diazepam, propranolol and lincomycin and also the efficiency of reactions based on metallic iron for the degradation of diazepam was evaluated in this work. The monitoring of the pharmaceuticals concentration was carried out using High Performance Liquid Chromatography with diode array detector (HPLC-UV) and the removal of the organic matter concentration was evaluated by Total Organic Carbon (TOC) analysis. The photo-Fenton process was efficient for the degradation of the pharmaceuticals since it promoted total oxidation after approximately 8 minutes treatment and more than $80 \%$ of TOC removal after 60 minutes under black light radiation. Under solar radiation, the oxidation of the three pharmaceuticals studied occurred after approximately 5 minutes and more than $90 \%$ of TOC removal was achieved in 60 minutes. FeOx $\left(0,20 \mathrm{mmol} \mathrm{L}^{-1}\right)$ promoted higher degradation not only under solar but also under blacklight radiation. Among the $\mathrm{H}_{2} \mathrm{O}_{2}$ concentrations evaluated $\left(1,0,5,0,10,0 \mathrm{mmol} \mathrm{L}^{-1}\right)$, the concentrations of 5,0 and $10,0 \mathrm{mmol} \mathrm{L}^{-1}$ promoted higher degradation. The evaluation of the interference of the matrix effluent of sewage treatment plant (STP), where the pharmaceutical residues are normally found, demonstrated that the oxidation of the pharmaceuticals was not hindered in the presence of this matrix. However, $10 \%$ lower TOC removal was observed for lincomycin, compared to the removal achieved in deionized water. The evaluation of the degradation intermediates generated during the photo-Fenton process demonstrated that the first compounds formed are hydroxylated compounds, with the entrance of one or two hydroxyl groups in the case of diazepam and seven hydroxyl groups in the case of propranolol. Only a monohydroxylated intermediate of the lincomycin was identified. The $\mathrm{Fe}-/ \mathrm{EDTA} / \mathrm{O}_{2}$ process evaluated for the degradation of diazepam promoted the oxidation of the pharmaceutical after 60 minutes and $60 \%$ TOC removal after 2 hours treatment. Although this process presented lower degradation compared to the photo-Fenton process, it presents some advantages, as for example, the possibility of reuse of an industrial iron residue, the in situ generation of $\mathrm{H}_{2} \mathrm{O}_{2}$, besides the fact that $\mathrm{pH}$ adjustment is not necessary due to the self-buffering of the system between $\mathrm{pH} 5-6$. However, the addition of EDTA to the system is a disadvantage for being a toxic substance. Hydroxylated intermediates of diazepam were also identified during degradation by $\mathrm{Fe}-/ \mathrm{EDTA} / \mathrm{O}_{2}$ system, what showed that the oxidant formed in this process may be the same as formed in the photo-Fenton process.
\end{abstract}

Keywords: pharmaceuticals, photo-Fenton, iron metallic, advanced oxidation processes 


\section{LISTA DE LEGENDAS DAS FIGURAS}

Figura 1. Fontes de resíduos de fármacos no ambiente.

Figura 2. Especiação de $\mathrm{Fe}(\mathrm{II})$ em água em função do pH. (Adaptado de Pignatello et al., 2006).

Figura 3. (A) Especiação das espécies de $\mathrm{Fe}(\mathrm{III})$ em água $\left(\mathrm{Fe}(\mathrm{III})=1 \times 10^{-3}\right.$ mol L ${ }^{-1}$; Força iônica $\left.0,1 \mathrm{~mol} \mathrm{~L}^{-1} ; 25^{\circ} \mathrm{C}\right)$. As linhas tracejadas referem-se as regiões supersaturadas com $\mathrm{Fe}(\mathrm{III})(\mathrm{OH})_{3}$. (adaptado de GALLARD; LAAT; LEGUBE, 1999). (B) Espectro de absorção de $\mathrm{Fe}(\mathrm{III})$ monomérico e das espécies de hidroxocomplexos de Fe(III) (adaptado de SAFARZADEH-AMIRI; BOLTON; CARTER, 1996b)

Figura 4. Representação de uma barreira reativa permeável. Fonte: USEPA

Figura 5. Estrutura molecular do fármaco diazepam (massa molar 284,7 g $\left.\mathrm{mol}^{-1}\right)$.

Figura 6. Estrutura molecular do fármaco cloridrato de propranolol (massa molar 259,3 $\mathrm{g} \mathrm{mol}^{-1}$ ).

Figura 7. Estrutura molecular do fármaco cloridrato de lincomicina (massa molar 443,0 $\mathrm{g} \mathrm{mol}^{-1}$ )

Figura 8. Representação esquemática do reator utilizado nos experimentos de fotodegradação

Figura 9. Reator utilizado para fotodegradação dos fármacos sob radiação solar.

Figura 10. Sistema de degradação baseado em ferro metálico do fármaco diazepam

Figura 11. Espectro de absorção no UV-vis de diazepam (A), propranolol (B) e lincomicina (C) em água deionizada. Concentração dos fármacos $[D Z P]=[P P N]=5,0 \mathrm{mg} \mathrm{L}^{-1} ;[\mathrm{LCM}]=25,0 \mathrm{mg} \mathrm{L}^{-1}$.

Figura 12. Curvas analíticas preparadas com soluções padrão com concentrações de 0,0976 a $25,0 \mathrm{mg} \mathrm{L}^{-1}$ para o fármaco DZP (A) 
concentrações de 0,937 a $30,0 \mathrm{mg} \mathrm{L}^{-1}$ para o PPN (B) e de 0,390 a $25,0 \mathrm{mg} \mathrm{L}^{-1}$ para a LCM

Figura 13. Gráfico da razão sinal/concentração versus concentração em escala logarítmica para o fármaco DZP (A), PPN (B), e LCM (C)

Figura 14. Influência da utilização de ferro livre ou complexado na oxidação de DZP (A), e na remoção de COT (B), sob radiação de lâmpada de luz negra. Condições iniciais: $[\mathrm{DZP}]=25,0 \mathrm{mg} \mathrm{L}^{-1} ;[\mathrm{FeOx}]=$ $\left[\mathrm{Fe}\left(\mathrm{NO}_{3}\right)_{3}\right]=0,20 \mathrm{mmol} \mathrm{L}^{-1} ;\left[\mathrm{H}_{2} \mathrm{O}_{2}\right]=5,0 \mathrm{mmol} \mathrm{L}^{-1}$. Fenton térmico $=\left[\mathrm{FeSO}_{4}\right]=0,20 \mathrm{mmol} \mathrm{L}^{-1} ;\left[\mathrm{H}_{2} \mathrm{O}_{2}\right]=5,0 \mathrm{mmol} \mathrm{L}^{-1}$; sem irradiação.

Figura 15. Influência da concentração de $\mathrm{H}_{2} \mathrm{O}_{2}$ na oxidação de DZP (A), e na remoção de COT $(B)$ sob radiação de lâmpada de luz negra. Condições iniciais: $[\mathrm{DZP}]=25,0 \mathrm{mg} \mathrm{L}^{-1} ;[\mathrm{FeOx}]=\left[\mathrm{Fe}\left(\mathrm{NO}_{3}\right)_{3}\right]=$ $0,20 \mathrm{mmol} \mathrm{L}^{-1}$

Figura 16. Consumo de $\mathrm{H}_{2} \mathrm{O}_{2}$ durante fotodegradação de DZP. Influência das espécies de ferro (A), e da concentração de $\mathrm{H}_{2} \mathrm{O}_{2}$ (B). Condições iniciais: $[\mathrm{DZP}]=25,0 \mathrm{mg} \mathrm{L}^{-1}$; $[\mathrm{FeOX}]=0,20 \mathrm{mmol} \mathrm{L}^{-1}$; $\left[\mathrm{H}_{2} \mathrm{O}_{2}\right]=5,0 \mathrm{mmol} \mathrm{L}^{-1}$ (para o gráfico $\mathrm{A}$ ).

Figura 17. Influência da utilização de ferro livre ou complexado na oxidação de PPN (A), e na remoção de COT (B), sob radiação de lâmpada de luz negra. Condições iniciais: $[\mathrm{PPN}]=25,0 \mathrm{mg} \mathrm{L}^{-1} ;[\mathrm{FeOx}]=$ $\left[\mathrm{Fe}\left(\mathrm{NO}_{3}\right)_{3}\right]=0,20 \mathrm{mmol} \mathrm{L}^{-1} ;\left[\mathrm{H}_{2} \mathrm{O}_{2}\right]=5,0 \mathrm{mmol} \mathrm{L}^{-1}$. Fenton térmico $=\left[\mathrm{FeSO}_{4}\right]=0,20 \mathrm{mmol} \mathrm{L}^{-1} ;\left[\mathrm{H}_{2} \mathrm{O}_{2}\right]=5,0 \mathrm{mmol}^{-1}$; sem irradiação.

Figura 18. Influência da concentração de $\mathrm{H}_{2} \mathrm{O}_{2}$ na oxidação de PPN $(A)$, e na remoção de COT $(\mathrm{B})$, sob radiação de lâmpada de luz negra. Condições iniciais: $[\mathrm{PPN}]=25,0 \mathrm{mg} \mathrm{L}^{-1} ;[\mathrm{FeOx}]=\left[\mathrm{Fe}\left(\mathrm{NO}_{3}\right)_{3}\right]=$ $0,20 \mathrm{mmol} \mathrm{L}^{-1}$

Figura 19. Consumo de $\mathrm{H}_{2} \mathrm{O}_{2}$ durante fotodegradação de PPN. Influência das espécies de ferro (A), e da concentração de $\mathrm{H}_{2} \mathrm{O}_{2}$ (B). Condições iniciais: $[\mathrm{PPN}]=25,0 \mathrm{mg} \mathrm{L}^{-1} ;[\mathrm{FeOx}]=0,20 \mathrm{mmol} \mathrm{L}^{-1}$; $\left[\mathrm{H}_{2} \mathrm{O}_{2}\right]=5,0 \mathrm{mmol} \mathrm{L}^{-1}$ (para o gráfico $\mathrm{A}$ ) 
Figura 20. Influência da utilização de ferro livre ou complexado na oxidação de LCM (A), e na remoção de COT (B), sob radiação de lâmpada de luz negra. Condições iniciais: $[\mathrm{LCM}]=25,0 \mathrm{mg} \mathrm{L}^{-1}$; $[\mathrm{FeOX}]=$ $\left[\mathrm{Fe}\left(\mathrm{NO}_{3}\right)_{3}\right]=0,20 \mathrm{mmol} \mathrm{L}^{-1} ;\left[\mathrm{H}_{2} \mathrm{O}_{2}\right]=5,0 \mathrm{mmol} \mathrm{L}^{-1}$. Fenton térmico $=\left[\mathrm{FeSO}_{4}\right]=0,20 \mathrm{mmol} \mathrm{L}^{-1} ;\left[\mathrm{H}_{2} \mathrm{O}_{2}\right]=5,0 \mathrm{mmol} \mathrm{L}^{-1}$; sem irradiação.

Figura 21. Influência da concentração de $\mathrm{H}_{2} \mathrm{O}_{2}$ na oxidação de LCM (A), e na remoção de COT $(\mathrm{B})$, sob radiação de lâmpada de luz negra. Condições iniciais: $[\mathrm{LCM}]=25,0 \mathrm{mg} \mathrm{L}^{-1} ;[\mathrm{FeOx}]=\left[\mathrm{Fe}\left(\mathrm{NO}_{3}\right)_{3}\right]=$ $0,20 \mathrm{mmol} \mathrm{L}^{-1}$

Figura 22. Consumo de $\mathrm{H}_{2} \mathrm{O}_{2}$ durante fotodegradação de LCM. Influência das espécies de ferro (A), e da concentração de $\mathrm{H}_{2} \mathrm{O}_{2}$ (B). Condições iniciais: $[\mathrm{LCM}]=25,0 \mathrm{mg} \mathrm{L}^{-1} ;[\mathrm{FeOx}]=0,20 \mathrm{mmol} \mathrm{L}^{-1}$; $\left[\mathrm{H}_{2} \mathrm{O}_{2}\right]=5,0 \mathrm{mmol} \mathrm{L}^{-1}$ (para o gráfico $A$ ).

Figura 23. Influência da utilização de ferro livre ou complexado na oxidação de DZP (A), PPN (C) e LCM (E), e na remoção de COT de DZP (B), PPN (D) e LCM (F) sob radiação solar. Condições iniciais: $[\mathrm{DZP}]=[\mathrm{PPN}]=[\mathrm{LCM}]=25,0 \mathrm{mg} \mathrm{L}^{-1} ;[\mathrm{FeOx}]=\left[\mathrm{Fe}\left(\mathrm{NO}_{3}\right)_{3}\right]=0,20$ $\mathrm{mmol} \mathrm{L}^{-1} ;\left[\mathrm{H}_{2} \mathrm{O}_{2}\right]=5,0 \mathrm{mmol} \mathrm{L}^{-1}$

Figura 24. Consumo de $\mathrm{H}_{2} \mathrm{O}_{2}$ durante fotodegradação de DZP (A), PPN (B) e LCM (C) sob radiação solar. Influência das espécies de ferro e da reposição de $\mathrm{H}_{2} \mathrm{O}_{2}$. Condições iniciais: $[\mathrm{DZP}]=[\mathrm{PPN}]=[\mathrm{LCM}]$ $=25,0 \mathrm{mg} \mathrm{L}^{-1} ;[\mathrm{FeOx}]=\left[\mathrm{Fe}\left(\mathrm{NO}_{3}\right)_{3}\right]=0,20 \mathrm{mmol} \mathrm{L}^{-1} ;\left[\mathrm{H}_{2} \mathrm{O}_{2}\right]=5,0$ mmol L-1; com reposição de mais $1,36 \times 10^{-3} \mathrm{~mol} \mathrm{H}_{2} \mathrm{O}_{2}$ aos 30 minutos

Figura 25. Influência da matriz na oxidação de DZP (A), e na remoção de COD (B) sob lâmpada de luz negra. Condições iniciais: [DZP] = $25,0 \mathrm{mg} \mathrm{L}^{-1} ;[\mathrm{FeOx}]=0,20 \mathrm{mmol} \mathrm{L}^{-1} ;\left[\mathrm{H}_{2} \mathrm{O}_{2}\right]=5,0 \mathrm{mmol} \mathrm{L}^{-1}$ reposicão $\mathrm{H}_{2} \mathrm{O}_{2}$ (adição de $1,23 \times 10^{-3} \mathrm{~mol}$ em 30 minutos e mais $0,0035 \times 10^{-3} \mathrm{~mol}$ em $\left.105 \mathrm{~min}\right)$. EFL - efluente.

Figura 26. Fotodegradação do efluente (EFL) sob radiação de lâmpada de luz negra- Condições iniciais: $[\mathrm{FeOx}]=0,20 \mathrm{mmol} \mathrm{L}^{-1} ;\left[\mathrm{H}_{2} \mathrm{O}_{2}\right]=$ 
$5,0 \mathrm{mmol} \mathrm{L}^{-1}$. Fotodegradação do efluente $(\mathrm{EFL})$ - sem carbono inorgânico $(\mathrm{Cl})$ e com reposição de reagentes. Condições iniciais: $[\mathrm{FeOx}]=0,20 \mathrm{mmol} \mathrm{L}^{-1} ;\left[\mathrm{H}_{2} \mathrm{O}_{2}\right]=5,0 \mathrm{mmol} \mathrm{L}^{-1}$ com reposicões (FeOx - 8,18 x $10^{-5} \mathrm{~mol}$ aos 90 min.; $\mathrm{H}_{2} \mathrm{O}_{2}-1,19 \times 10^{-3} \mathrm{~mol}$ em 120 minutos)

Figura 27. Influência da matriz na oxidação de LCM (A), e na remoção de COD (B) sob radiação artificial. Carbono inorgânico retirado antes dos experimentos. Condições iniciais: $[\mathrm{LCM}]=25,0 \mathrm{mg} \mathrm{L}^{-1}$; $[\mathrm{FeOx}]=0,20 \mathrm{mmol} \mathrm{L}^{-1} ;\left[\mathrm{H}_{2} \mathrm{O}_{2}\right]=5,0 \mathrm{mmol} \mathrm{L}^{-1}$ - Experimento com reposição de reagentes (adição de $8,18 \times 10^{-5} \mathrm{~mol} \mathrm{FeOx}$ aos 90 min.; $1,19 \times 10^{-3} \mathrm{~mol}$ de $\mathrm{H}_{2} \mathrm{O}_{2}$ aos 120 minutos de tratamento). EFL - efluente.

Figura 28. Cromatograma de íons totais (TIC) da amostra retirada do experimento de degradação de DZP por processo foto-Fenton aos 5 minutos de tratamento. Condições iniciais: DZP $=25 \mathrm{mg}$ $\mathrm{L}^{-1} ; \mathrm{FeOx}=0,1 \mathrm{mmol} \mathrm{L}^{-1} ; \mathrm{H}_{2} \mathrm{O}_{2}=10 \mathrm{mmol} \mathrm{L}^{-1}$

Figura 29. Cromatograma obtido por CLAE-UV da amostra retirada do experimento de degradação de DZP por processo foto-Fenton aos 5 minutos de tratamento. Condições iniciais: DZP $=25 \mathrm{mg}$ $\mathrm{L}^{-1} ; \mathrm{FeOx}=0,1 \mathrm{mmol} \mathrm{L}^{-1} ; \mathrm{H}_{2} \mathrm{O}_{2}=10 \mathrm{mmol} \mathrm{L}^{-1}$

Figura 30. Cromatograma de íons totais (TIC) do branco experimental com adição de catalase para interrupção da reação de Fenton. Condições iniciais: $\mathrm{FeOx}=0,1 \mathrm{mmol} \mathrm{L}{ }^{-1} ; \mathrm{H}_{2} \mathrm{O}_{2}=10 \mathrm{mmol} \mathrm{L}^{-1}$; amostra retirada do experimento aos 5 minutos de tratamento.

Figura 31. Espectro de massas do padrão de DZP (A) e sua respectiva fragmentação (MSMS) (B).

Figura 32. Cromatograma pelo pico base (BPI) da amostra retirada do experimento de fotodegradação de DZP aos 5 minutos de tratamento por processo foto-Fenton. Condições experimentais: $\mathrm{FeOx}=0,10 \mathrm{mmol} \mathrm{L}^{-1} ; \mathrm{H}_{2} \mathrm{O}_{2}=1,0 \mathrm{mmol} \mathrm{L}^{-1} ; \mathrm{pH} 2,5$

Figura 33. Espectro de massas dos compostos $D_{1}(A) ; D_{5}(B)$ e $D_{6}(C)(m / z$ 
301), formados durante a degradação de DZP por processo fotoFenton.

Figura 34. Fragmentação (MSMS) dos isômeros que apresentaram relação massa/carga 301, formados durante a degradação de DZP por processo foto-Fenton. A- Isômero $D_{5}$, B- Isômero $D_{1}$ e $D_{6}$ (formados pela entrada de uma hidroxila)

Figura 35. Espectro de massas dos compostos $D_{2}(A) ; D_{3}(B)$ e $D_{4}(C)(m / z$ $317)$, formados durante a degradação de DZP por processo fotoFenton.

Figura 36. Fragmentação (MSMS) dos isômeros $D_{2}, D_{3}, D_{4}$, que apresentaram relação $\mathrm{m} / \mathrm{z} 317$, formados durante a degradação de DZP por processo foto-Fenton

Figura 37. Espectro de massas do padrão de PPN (A) e sua respectiva fragmentação (MSMS) (B)

Figura 38. Cromatograma pelo pico base (BPI) da amostra retirada do experimento de fotodegradação de PPN aos 2 minutos (A) e aos 15 minutos (B).

Figura 39. Cromatograma pelo pico base $(\mathrm{BPI})$ referente à amostra retirada do experimento de fotodegradação de PPN aos 20 minutos (A) e branco do experimento (B).

Figura 40. Espectros de massas referentes aos intermediários de degradação do $P P N P_{1}(A)$ e $P_{2}(B)$.

Figura 41. Cromatograma pelo pico base (BPI) obtido para as amostras 0 (A), 2 (B) e 8 (C) minutos de degradação de LCM por processo foto-Fenton.

Figura 42. Espectro de massas do padrão de LCM (A) e sua respectiva fragmentação (MSMS) (B)

Figura 43. Cromatograma de íons totais (TIC) da amostra retirada do experimento de fotodegradação de LCM aos 2 minutos de tratamento $(A)$ e espectro de massas do $C_{1}(B)$

Figura 44. Remoção de DZP por meio do sistema ferro metálico 
nanoparticulado. Condição inicial: $[\mathrm{DZP}]=21-26 \mathrm{mg} \mathrm{L}^{-1} ;\left[\mathrm{Fe}^{\circ}\right]=3$

$\mathrm{g} \mathrm{L}^{-1}$. Agitação magnética.

Figura 45. Reações possíveis no sistema $\mathrm{Fe}^{\circ} / \mathrm{O}_{2}$ (KEENAN; SEDLAK, 2008a).

Figura 46. Remoção de DZP pelo sistema $\mathrm{Fe} / / E D T A / \mathrm{O}_{2}$. (A) remoção de $\operatorname{COD}(B)$, monitoramento do $\mathrm{pH}(\mathrm{C})$. Condição inicial: $[\mathrm{DZP}]=15-$ $23 \mathrm{mg} \mathrm{L}^{-1}$; Com borbulhamento de ar e agitação magnética. ( $\mathrm{Fe}^{-}$ nanoparticulado)

Figura 47. Influência da concentração e pré-tratamento de $\mathrm{Fe}^{-}$ microparticulado na oxidação de DZP $(A)$ e remoção de $\operatorname{COD}(B)$. Condições experimentais: $[\mathrm{DZP}]=25 \mathrm{mg} \mathrm{L}^{-1}$; $\left[\right.$ EDTA] $=119 \mathrm{mg} \mathrm{L}^{-}$ 1; borbulhamento de ar; agitação mecânica; lavagem de $\mathrm{Fe}^{\circ} \mathrm{HCl}$ $1,0 \mathrm{~mol} \mathrm{~L}^{-1}$

Figura 48. Influência do ácido usado no pré-tratamento das micropartículas de $\mathrm{Fe}^{-}$na oxidação de DZP (A) e remoção de $\operatorname{COD}(\mathrm{B})$. Condições experimentais:[DZP] $=25 \mathrm{mg} \mathrm{L}^{-1} ;\left[\mathrm{Fe}^{0}\right]=25 \mathrm{~g} \mathrm{~L}^{-1}$; [EDTA] $=119 \mathrm{mg} \mathrm{L}^{-1}$, borbulhamento de ar; agitação mecânica.....

Figura 49. Influência da concentração de EDTA na oxidação de DZP (A) e remoção de COD (B). Condições experimentais: $[D Z P]=25 \mathrm{mg}$ $\mathrm{L}^{-1} ;$ [ $\mathrm{Fe}^{-0}$ microparticulado] $=25 \mathrm{~g} \mathrm{~L}^{-1}$, borbulhamento de ar; agitação mecânica; lavagem de $\mathrm{Fe}^{\mathrm{o}}$ : $\mathrm{H}_{2} \mathrm{SO}_{4} 1,0 \mathrm{~mol} \mathrm{~L}^{-1}$

Figura 50. Influência do $\mathrm{Fe}$ - na oxidação de $\operatorname{DZP}(\mathrm{A})$ e remoção de $\mathrm{COD}(\mathrm{B})$.

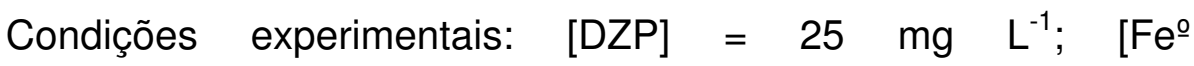
microparticulado $]=25 \mathrm{~g} \mathrm{~L}^{-1} ;\left[\mathrm{Fe}^{2+}\right]=5 \mathrm{~g} \mathrm{~L}^{-1} ;$ [EDTA $]=119 \mathrm{mg} \mathrm{L}^{-1}$; borbulhamento de ar; agitação mecânica; lavagem de $\mathrm{Fe}^{\circ}$ : $\mathrm{H}_{2} \mathrm{SO}_{4}$ $1,0 \mathrm{~mol} \mathrm{~L}^{-1}$ 132

Figura 51. Monitoramento de $\mathrm{pH}$ durante degradação de DZP no sistema $\mathrm{Fe}^{\circ}$. Condições experimentais: $[\mathrm{DZP}]=25 \mathrm{mg} \mathrm{L}^{-1}$; $\left[\mathrm{Fe}^{\circ}\right.$ microparticulado $]=25 \mathrm{~g} \mathrm{~L}^{-1}$, [EDTA] $=119 \mathrm{mg} \mathrm{L}^{-1}$. 134

Figura 52. Influência de $\mathrm{O}_{2}$ na remoção de DZP. Condições experimentais: $[\mathrm{DZP}]=25 \mathrm{mg} \mathrm{L}^{-1} ;\left[\mathrm{Fe}^{-0}\right.$ microparticulado $]=25 \mathrm{~g} \mathrm{~L}^{-1}$, [EDTA $]=119$ 
$\mathrm{mg} \mathrm{L}^{-1}$; borbulhamento de $\mathrm{N}_{2}$

Figura 53. Cromatogramas obtidos por CLAE-UV referentes à amostra retirada do experimento Fenton aos 2 minutos e do experimento $\mathrm{Fe}$-/EDTA $/ \mathrm{O}_{2}$ aos 120 minutos. Fenton - Condições iniciais: [DZP] $=25,0 \mathrm{mg} \mathrm{L}^{-1} ;\left[\mathrm{FeSO}_{4}\right]=0,10 \mathrm{mmol} \mathrm{L}^{-1} ;\left[\mathrm{H}_{2} \mathrm{O}_{2}\right]=1,0 \mathrm{mmol} \mathrm{L}^{-1} ; \mathrm{pH}$ 2,5. Sistema ferro metálico - $[\mathrm{DZP}]=25 \mathrm{mg} \mathrm{L}^{-1} ;\left[\mathrm{Fe}^{-0}\right]=25 \mathrm{~g} \mathrm{~L}^{-1}$, borbulhamento de ar.

Figura 54. Cromatograma referente aos intermediários formados durante a degradação de DZP pelo $\mathrm{Fe}^{-}$- amostra retirada do experimento aos 120 minutos (A) e intermediários formados durante 0 processo foto-Fenton amostra retirada do experimento aos 5 minutos de experimento $(B)$

Figura 55. Espectros de massas dos intermediários $D_{7}(A) ; D_{8}(B) ; D_{9}(C)$; $D_{10}(D) ; D_{11}(E) ; D_{12}(F) ; D_{13}(G) ; D_{14}(H)$ formados durante degradação de DZP pelo sistema $\mathrm{Fe}^{\circ}$. 


\section{LISTA DE LEGENDAS DAS TABELAS}

Tabela 1. Ocorrência e concentração de fármacos detectados em diferentes países

Tabela 2. Potencial padrão de redução $\left(\mathrm{E}^{\circ}\right)$ de alguns oxidantes versus eletrodo normal de hidrogênio (ENH).

Tabela 3. Degradação de fármacos por Processos Oxidativos Avançados

Tabela 4. Concentração inicial dos fármacos nos experimentos de degradação

Tabela 5. Concentração inicial dos reagentes utilizados no sistema de degradação com $\mathrm{Fe}^{\mathrm{o}}$

Tabela 6. Equações das curvas analíticas, intervalo de linearidade, coeficientes de correlação (R), limite de detecção (LD) e de quantificação (LQ) para os fármacos estudados.

Tabela 7. Recuperação de PPN em água com cartuchos Sep-Pack C18..... 72

Tabela 8. Recuperação de PPN em água, eluição com metanol - 1\%TFA..... 72

Tabela 9. Monitoramento da concentração de DZP após adição de catalase.

Tabela 10. Intermediários de degradação de DZP formados por processo foto-Fenton.

Tabela 11. Intermediários formados durante degradação de DZP por processo foto-Fenton e ferro metálico 


\section{LISTA DE ABREVIATURAS E SIGLAS}

BPI Base peak intensity

CetesB Companhia Ambiental do Estado de São Paulo

Cl Carbono inorgânico

CLAE-EM Cromatografia Líquida de alta eficiência acoplada à espectrometria de massas

CLAE-UV Cromatografia líquida de alta eficiência acoplado ao detector de arranjo de diodos

COD Carbono orgânico dissolvido

CONAMA Conselho Nacional de Meio Ambiente

COT Carbono orgânico total

CT Carbono total

DAAE Departamento Autônomo de Água e Esgotos

DZP Diazepam

EDTA Ácido etilenodiaminotetraacético

EFS Extração em fase sólida

ENH Eletrodo normal de hidrogênio

ETE Estação de tratamento de esgoto

FeOx Ferrioxalato de potássio

LCM Lincomicina

LD Limite de detecção

LNLS Laboratório Nacional de Luz Síncrotron

LQ Limite de quantificação

MM Massa Molar

POA Processos Oxidativos Avançados

PPN Propranolol

TIC Total íon current

TR Tempo de retenção

USEPA Agência de Proteção Ambiental dos Estados Unidos

UV Ultravioleta

Vis Visível 


\section{SUMÁRIO}

1 INTRODUÇÃO

1.1 Contaminação ambiental........................................................................ 23

1.2 Contaminação de ambientes aquáticos por resíduos de fármacos.............. 24

1.2.1 Ocorrência de resíduos de fármacos em ambientes aquáticos........................ 24

1.2.1.1 Resíduos de fármacos em ambientes aquáticos no Brasil.......................... 26

1.2.2 Fontes de resíduos de fármacos em ambientes aquáticos............................... 27

1.2.3 Efeitos de resíduos de fármacos nos organismos.......................................... 30

1.3 Processos Oxidativos Avançados (POA) .............................................. 33

1.3.1 Histórico.................................................................................... 33

1.3.2 Fundamentos dos Processos Oxidativos Avançados..................................... 34

1.3.3 Processo Fenton e foto-Fenton............................................................. 37

1.3.4 Degradação de fármacos por Processos Oxidativos Avançados.................... 42

1.4 Sistema de degradação de contaminantes baseado em Ferro Metálico $\left(\mathrm{Fe}^{\mathrm{O}}\right)$.

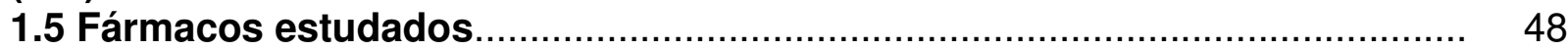

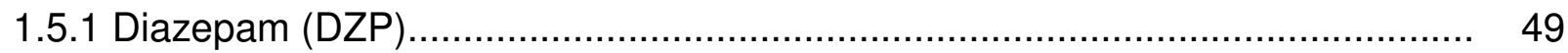

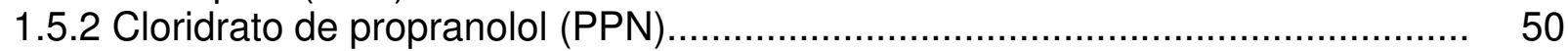

1.5.3 Cloridrato de lincomicina (LCM) .......................................................... 50

2 OBJETIVOS

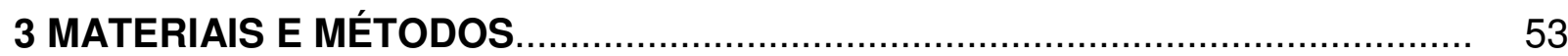

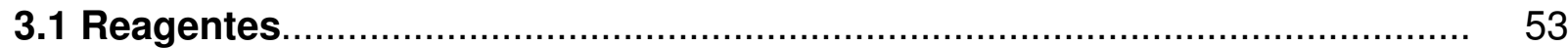

3.2 Preparo das soluções...................................................................... 53

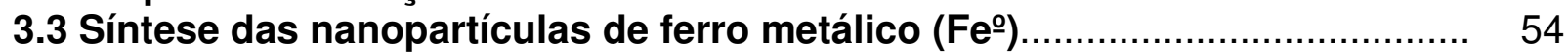

3.4 Degradação dos fármacos....................................................................... 55

3.4.1 Processo foto-Fenton com radiação artificial (lâmpada de luz negra)............... 55

3.4.2 Processo foto-Fenton com radiação solar................................................... 56

3.4.3 Sistema de degradação do fármaco diazepam baseado em ferro metálico $\left(\mathrm{Fe}^{\mathrm{o}}\right)$.......

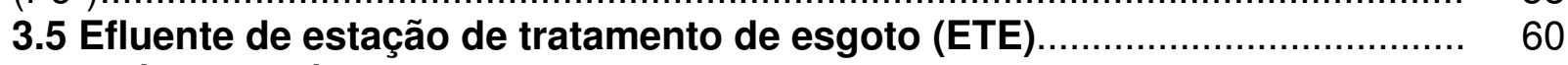

3.6 Análises Químicas................................................................................. 61

3.6.1 Determinação de Carbono Orgânico Total (COT) ........................................ 61

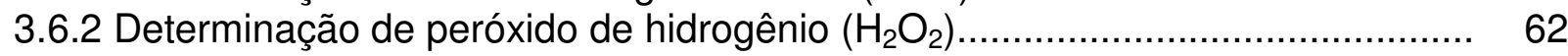

3.6.2.1 Determinação de $\mathrm{H}_{2} \mathrm{O}_{2}$ residual nos experimentos foto-Fenton - método do metavanadato de amônio.

3.6.2.2 Determinação de $\mathrm{H}_{2} \mathrm{O}_{2}$ gerado no sistema de degradação baseado em ferro metálico - método da DPD.

3.6.3 Cromatografia Líquida de Alta eficiência acoplada ao detector de arranjo de diodos (CLAE-UV)...

3.6.4 Cromatografia Líquida de Alta Eficiência acoplada à espectrometria de massas (CLAE-EM)..... 
4.1 Avaliação da confiabilidade analítica do método de determinação dos fármacos

4.2 Degradação dos fármacos mediada pelo processo foto-Fenton................... 71

4.2.1 Procedimentos testados para interromper a reação de Fenton......................... 71

4.2.1.1 Extração em fase sólida (EFS)......................................................... 71

4.2.1.2 Enzima catalase...................................................................... 73

4.2.2 Fotodegradação de diazepam por processo foto-Fenton sob radiação artificial (lâmpada de luz negra).

4.2.3 Fotodegradação de propranolol por processo foto-Fenton sob radiação artificial (lâmpada de luz negra).

4.2.4 Fotodegradação de lincomicina por processo foto-Fenton sob radiação artificial (lâmpada de luz negra).

4.2.5 Fotodegradação dos fármacos sob radiação solar.

4.2.6 Fotodegradação dos fármacos em efluente de estação de tratamento de esgoto (ETE)

4.2.7 Identificação dos intermediários formados durante a degradação dos fármacos por processo foto-Fenton pela técnica de Cromatografia Líquida de Alta Eficiência acoplada à espectrometria de massas (CLAE-EM).

4.2.7.1 Intermediários de degradação do fármaco diazepam.....................................

4.2.7.2 Intermediários de degradação do fármaco propranolol...................................

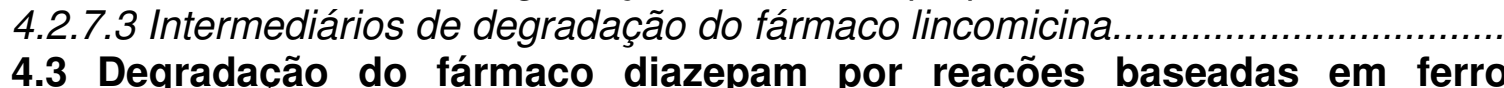
metálico $\left(\mathrm{Fe}^{\mathrm{o}}\right)$

4.3.1 Degradação de DZP com ferro nanoparticulado............................................. 120

4.3.2 Degradação de DZP com ferro microparticulado......................................... 125

4.3.2.1 Influência da lavagem das micropartículas de $\mathrm{Fe}^{\circ}$ e da concentração de $\mathrm{Fe}^{\circ}$ e EDTA.

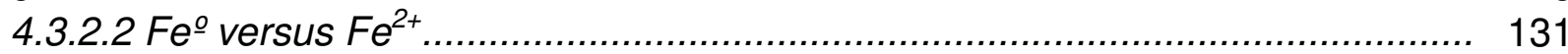

4.3.2.3 Influência do $\mathrm{pH}$ e $\mathrm{O}_{2}$ no sistema Fe $\mathrm{o}$ EDTA................................................... 134

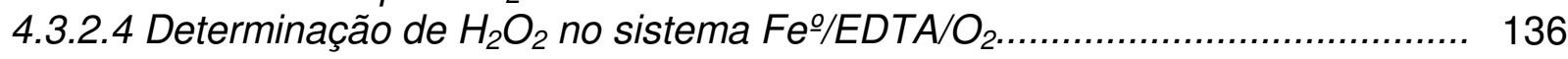

4.3.3 Comparação da degradação do fármaco diazepam obtida pelo processo fotoFenton e pelo sistema $\mathrm{Fe} / \mathrm{EDTA} / \mathrm{O}_{2}$ e dos intermediários formados durante os dois processos.

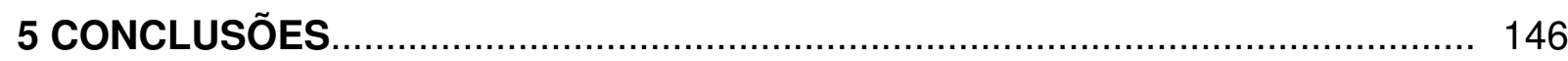

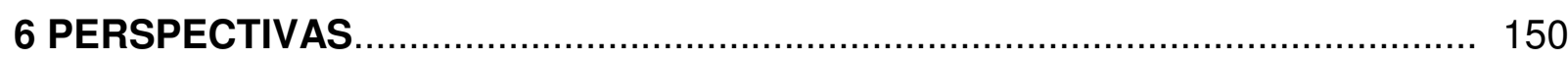

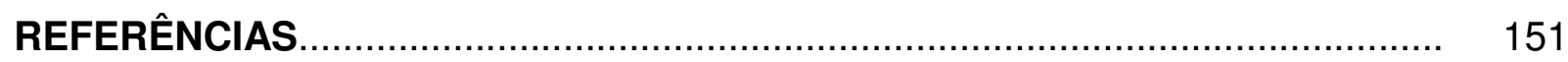

ANEXO 


\section{INTRODUÇÃO}

\subsection{Contaminação ambiental}

O avanço tecnológico impulsionado pelo crescimento populacional e pelo modelo econômico atual levou ao desenvolvimento de inúmeros produtos químicos. Entretanto, após servirem aos seus propósitos, muitas dessas substâncias consideradas tóxicas, acabam, por vários motivos, contaminando o ambiente.

A preocupação com a contaminação das águas se justifica uma vez que todas as formas de vida são dependentes da disponibilidade de água. Considerando que mais de $97 \%$ da água do planeta é salgada e que do percentual de água doce apenas $0,01 \%$ está disponível para as atividades humanas, pois o restante está na forma de geleiras, é compreensível que os compartimentos aquáticos tenham merecido grande atenção nas últimas décadas no que diz respeito à sua preservação.

A Agência de Proteção Ambiental dos Estados Unidos (USEPA), baseada em dados toxicológicos, listou 126 poluentes prioritários, dentre os quais estão pesticidas, bifenilas policloradas e metais tóxicos (USEPA, 2009a). Segundo a Companhia Ambiental do Estado de São Paulo (CETESB), esses poluentes aportam em ambientes aquáticos principalmente por meio de efluentes domésticos e industriais e pela carga difusa urbana e agrícola (poluentes advindos da drenagem destas áreas: fertilizantes, pesticidas, material em suspensão, etc) (CETESB, 2009).

A contaminação das águas por esses poluentes é conhecida de longa data, entretanto, a contaminação por substâncias em baixas concentrações, como é o caso de resíduos de fármacos, tem despertado o interesse da comunidade científica mais 
recentemente. A ocorrência, as possíveis fontes e os efeitos causados pelos fármacos residuais serão abordados nos próximos itens.

\subsection{Contaminação de ambientes aquáticos por resíduos de fármacos}

A contaminação de ambientes aquáticos por diversos poluentes desperta preocupação devido à importância da água para os seres vivos. O constante monitoramento de ambientes aquáticos aliado ao desenvolvimento de técnicas analíticas mais sensíveis possibilitou a detecção de micropoluentes tais como produtos de higiene pessoal, desreguladores endócrinos e resíduos de fármacos encontrados em baixas concentrações (ng L $\mathrm{L}^{-1}$ a $\mu \mathrm{g} \mathrm{L}^{-1}$ ). Esses micropoluentes, também chamados de poluentes emergentes, estão despertando o interesse da comunidade científica pois ainda não se tem muito conhecimento sobre as implicações destas substâncias no ambiente (KÜMMERER, 2004).

\subsubsection{Ocorrência de resíduos de fármacos em ambientes aquáticos}

A ocorrência de fármacos no ambiente foi relatada já em 1976 por Garrison e colaboradores que detectaram a presença de ácido clofíbrico em efluentes de estação de tratamento de esgotos (ETE) nos Estados Unidos da América (EUA) (GARISSON, 1976, apud FENT; WESTON; CAMINADA, 2006). Atualmente a USEPA mantém um sítio com informações sobre resíduos de fármacos e produtos de higiene pessoal no qual está disponível um documento que contém 8882 (Dezembro/2009) referências de 
literatura relevante sobre fontes, ocorrência, efeitos e degradação/remoção destes micropoluentes (USEPA, 2009b).

Fármacos de várias classes terapêuticas foram detectados em diferentes regiões do mundo em concentrações que variaram de $\mathrm{ng} \mathrm{L}^{-1}$ a $\mu \mathrm{g} \mathrm{L}^{-1}$ (Tabela 1).

Tabela 1. Ocorrência e concentração de fármacos detectados em diferentes países.

\begin{tabular}{|c|c|c|c|}
\hline Fármaco & $\begin{array}{c}\text { Concentração } \\
\text { média } \\
\left(\mu \mathrm{g} \mathrm{L}^{-1}\right)\end{array}$ & Matriz/País & Referência \\
\hline Amoxicilina $^{1}$ & 0,013 & Esgoto bruto/tália & Castiglioni et al., 2006 \\
\hline Atenolol $^{2}$ & 0,30 & Esgoto bruto/Suécia & Bendz et al., 2005 \\
\hline Bezafibrato $^{3}$ & 1,2 & Esgoto bruto/Brasil & Stumpf et al., 1999 \\
\hline Carbamazepina $^{4}$ & 1,0 & Efluente ETE/Grécia & Andreozzi et al., 2003 \\
\hline Cetoprofeno ${ }^{5}$ & 0,20 & Efluente ETE/Alemanha & Ternes, 1998 \\
\hline Diclofenaco $^{5}$ & 0,35 & Esgoto bruto/Finlândia & Lindqvist et al., 2005 \\
\hline Diazepam $^{4}$ & 0,053 & Efluente ETE/Alemanha & Ternes et al., 2001 \\
\hline $17 \alpha$-etinilestradiol ${ }^{6}$ & 0,073 & Água superficial/EUA & Kolpin et al., 2002 \\
\hline Ibuprofeno ${ }^{5}$ & 0,79 & Efluente ETE/Canadá & Gagné et al., 2006 \\
\hline Lincomicina $^{1}$ & 0,013 & Efluente ETE/Taiwan & Lin et al., 2008 \\
\hline Propranolol $^{2}$ & 0,030 & Efluente ETE/Suécia & Bendz et al., 2005 \\
\hline Naproxeno ${ }^{5}$ & 4,7 & Esgoto bruto/ Espanha & Santos et al., 2005 \\
\hline Sulfametoxazol ${ }^{1}$ & 0,05 & Água superficial/EUA & Stackelberg et al., 2004 \\
\hline Tetraciclina $^{1}$ & 0,010 & Água superficial/Itália & Calamari et al., 2003 \\
\hline
\end{tabular}

Como pode se observado na Tabela 1 os resíduos de fármacos foram detectados em vários compartimentos incluindo águas superficiais, efluentes de ETE e 
esgoto bruto. Porém, existem trabalhos na literatura sobre a ocorrência de fármacos residuais também em água potável (BENOTTI et al., 2009; SEGURA et al., 2009; TERNES, 2001), em águas subterrâneas (DÍAZ-CRUZ; BARCELÓ, 2008; LINDSEY; MEYER; THURMAN, 2001) e em lodos e sedimentos (JELIC; PETROVIC; BARCELÓ, 2009; SARMAH; MEYER; BOXALL, 2006). Fármacos residuais foram encontrados também no ártico (KALLENBORN et al., 2008 apud KÜMMERER, 2009).

\subsubsection{Resíduos de fármacos em ambientes aquáticos no Brasil}

No Brasil, um dos primeiros trabalhos publicados sobre a ocorrência de fármacos em ambientes aquáticos é de Stumpf e colaboradores (1999) que detectaram a presença de fármacos em efluentes de ETE em concentrações que variaram de 0,1 a $1,0 \mu \mathrm{g} \mathrm{L}^{-1}$ e 0,02 a $0,04 \mu \mathrm{g} \mathrm{L}^{-1} \mathrm{em}$ águas superficiais. Neste mesmo trabalho foi avaliada a eficiência de remoção destes fármacos em ETE, a qual variou entre 12 e 90\%. Em outro trabalho publicado no mesmo ano, os hormônios $17 \beta$ - estradiol e estrona foram detectados em efluentes de ETE com concentrações médias de 0,021 e $0,040 \mu \mathrm{g} \mathrm{L}^{-1}$ (TERNES et al., 1999).

Atualmente existem grupos de pesquisa brasileiros monitorando esses micropoluentes em água, com alguns dados de ocorrência de fármacos em águas superficiais (SODRÉ et al., 2007), em água potável (SODRÉ; LOCATELLI; JARDIM, 2010) e em efluentes hospitalares (SOUZA et al., 2009). Entretanto, esse monitoramento ainda é muito restrito visto a extensão territorial do Brasil. Além disso, considerando o déficit brasileiro em saneamento básico, é possível estimar que é 
preocupante o quadro de contaminação das águas brasileiras por resíduos de fármacos uma vez que esgotos são lançados in natura nos corpos d'água.

\subsubsection{Fontes de resíduos de fármacos em ambientes aquáticos}

Existem várias rotas de entrada de resíduos de fármacos no ambiente, que vão desde esgoto doméstico, agricultura, aquicultura e até cemitérios. A Figura 1 ilustra as possíveis fontes de contaminação do ambiente por esses resíduos.

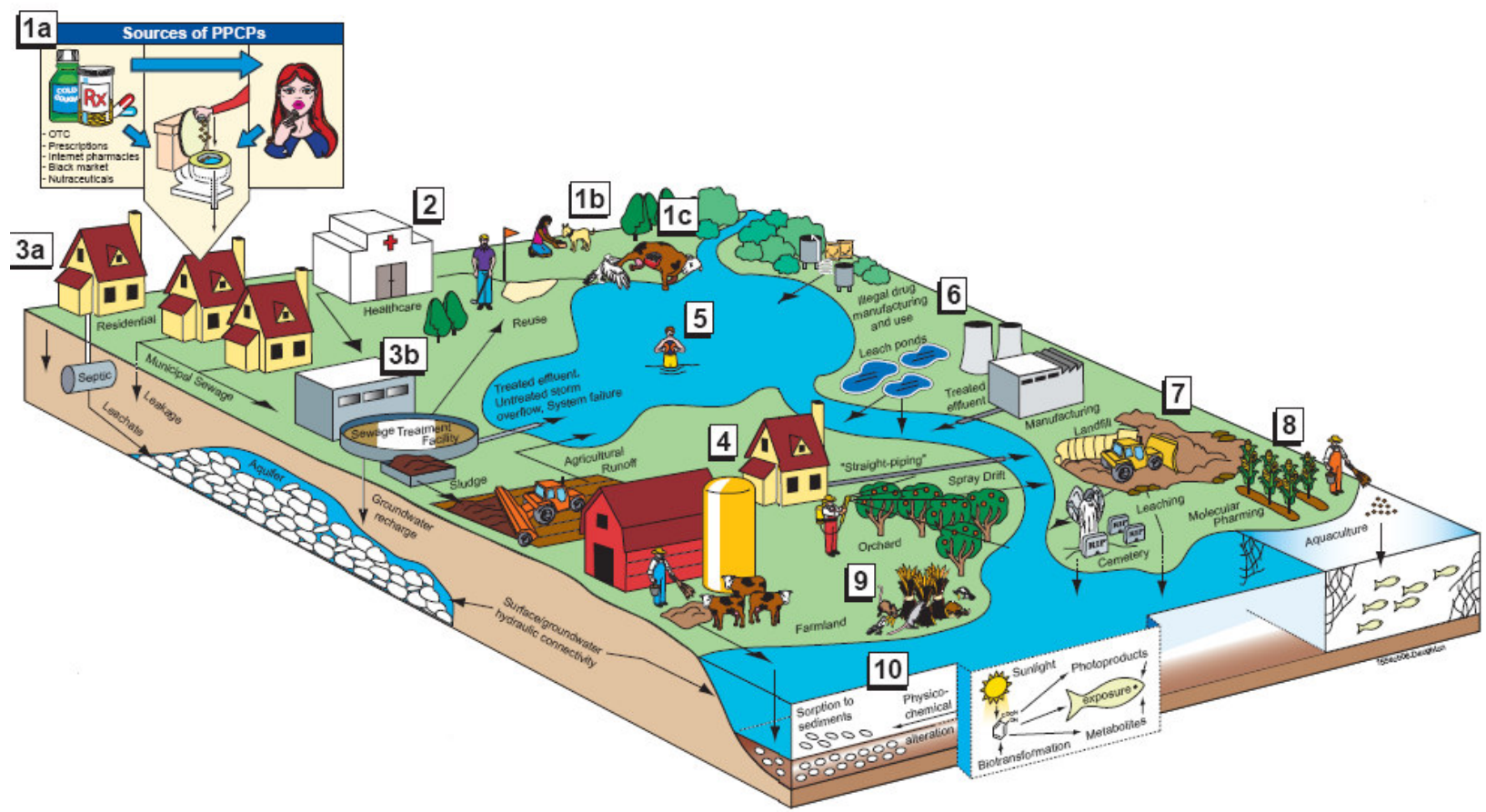

Figura 1. Fontes de resíduos de fármacos no ambiente.

Legenda: 1a- medicina humana: excreção/disposição inadequada; 1 b- medicina veterinária; 1c- animais em decomposição; 2- hospitais; 3a- esgoto doméstico; 3b- efluente ETE; 4- agricultura: lodo de ETE usado como fertilizante, agropecuária; 5- lavagem, banhos, natação; 6- efluentes de indústrias farmacêuticas (legais e ilegais); 7- aterros e cemitérios; 8- aquicultura; 9- drogas para controle de pragas; 10- reações que ocorrem no ambiente: fototransformação, alterações físico-químicas, volatilização etc. Fonte: USEPA (http://www.epa.gov/ppcp). 
Os fármacos residuais são continuamente lançados no ambiente e uma das principais rotas de aporte é o esgoto doméstico devido ao intensivo uso de medicamentos pela medicina humana. Após serem ingeridos pelos organismos, muitos fármacos são modificados estruturalmente por vários mecanismos, como por exemplo, pelo processo enzimático ou por microorganismos no intestino, porém alguns medicamentos são excretados na forma inalterada (MULROY, 2001; CALAMARI et al., 2003). Entretanto, mesmo não sendo liberados na forma original, esses medicamentos podem ser excretados na forma conjugada com glicuronídeos, que são facilmente clivados durante a passagem pela ETE disponibilizando assim o composto original no ambiente (HEBERER, 2002). Após a excreção, os resíduos de fármacos, seguem diretamente para o ambiente ou para as ETE, no caso de cidades que possuam essas estações. No entanto, no Brasil, essa é a realidade da minoria dos municípios visto que, um estudo feito pela organização não-governamental Trata Brasil, em parceria com o Ministério das Cidades, demonstrou que dos 8,5 bilhões de litros de esgoto gerados por dia no Brasil, 5,4 bilhões são despejados no ambiente todos os dias sem tratamento algum, ou seja, apenas $36 \%$ do esgoto gerado recebe algum tipo de tratamento. $\mathrm{O}$ estudo demonstrou também que entre os anos de 2003 e 2007 houve um avanço de $14 \%$ no atendimento de esgoto nas cidades observadas e de $5 \%$ no tratamento (TRATA BRASIL, 2010).

Entretanto, o monitoramento de efluente de ETE revelou a ineficiência desses sistemas de tratamento em promover a degradação de resíduos de fármacos, uma vez que a grande maioria das substâncias detectada nos afluentes é ainda encontrada nos efluentes (HERNANDO et al., 2006; FENT et al., 2006; GÓMEZ et al., 2007). 
As ETE são planejadas para tratar águas residuais urbanas e industriais e a eficiência dessas estações é normalmente medida por parâmetros como remoção de nitrogênio, fosfato, patógenos, demanda bioquímica de oxigênio, material particulado e íons metálicos. No entanto, elas não são planejadas para remover quantitativamente outros poluentes, como é o caso de resíduos de fármacos. A maioria das ETE possui apenas processos de tratamento físicos e biológicos que normalmente são ineficazes na remoção destes resíduos (ZORITA et al., 2009).

Devido à ineficiência das ETE em remover fármacos resistentes a processos, ocorridos nas ETE ou não, como biodegradação, fotólise e hidrólise, é contínuo o aporte destes contaminantes em ecossistemas aquáticos, conferindo-lhes assim característica de pseudopersistência, embora possuam tempo de meia-vida relativamente curto. Além disso, a alta polaridade e baixa volatilidade da maioria dessas substâncias contribui para a permanência destas no meio (HERNANDO et al., 2006).

Além disso, existem outras fontes também importantes de contaminação do ambiente por fármacos residuais, como por exemplo, efluentes de indústrias farmacêuticas tratados de forma ineficiente (LARSSON et al., 2007; LARSSON et al., 2009) e uso de lodo de ETE na agricultura. A disposição inadequada de medicamentos vencidos ou não também é uma fonte de contaminação do ambiente por fármacos a ser considerada, pois normalmente esses medicamentos são descartados no lixo comum e vão parar em aterros sanitários (KÜMMERER, 2009).

A medicina veterinária também utiliza uma grande gama de medicamentos como antibióticos, antiparasitas, antifúngicos e hormônios para promover crescimento. Os resíduos de fármacos excretados pelos animais vão diretamente para o ambiente e 
dessa forma, constituem-se uma fonte importante de contaminação (BOXALL et al., 2003).

\subsubsection{Efeitos de resíduos de fármacos nos organismos}

Os efeitos provocados por esses resíduos em humanos não estão bem elucidados, no entanto, cânceres de mama, testicular e de próstata e a redução da fertilidade masculina são doenças que estão relacionadas a esses contaminantes (CASTRO, 2002).

Existem vários estudos sobre a resistência de bactérias a antibióticos (KÜMMERER, 2004; HIRSCH et al., 1999). Os antibióticos também podem inibir o crescimento de algas, como por exemplo, a alga Microcystis aeruginosa teve seu crescimento inibido em presença de concentrações menores do que $0,1 \mathrm{mg} \mathrm{L}^{-1}$ de antibiótico (HALLING-SORENSEN, 2000). Considerando que as algas são a base da cadeia alimentar, mesmo um pequeno declínio na população pode resultar em um desequilíbrio nos ambientes aquáticos (KÜMMERER, 2009).

Os estrogênios sintéticos, como os contraceptivos, podem interferir no funcionamento natural do sistema endócrino de espécies animais, incluindo os seres humanos. Esses fármacos induzem vários efeitos adversos em organismos aquáticos. Folmar e colaboradores (2000) observaram que concentrações a partir $100 \mathrm{ng} \mathrm{L}^{-1}$ de 17 a-etinilestradiol (estrogênio sintético) induziram à síntese da proteína vitelogenina em peixes machos da espécie Cyprinodon variegatus, proteína essa que só é encontrada em fêmeas. 
No estudo de Rodgers-Gray e colaboradores (2001) peixes jovens da espécie Rutilus rutilus foram expostos a concentrações gradativas de efluente de ETE por 150 dias contendo além de outros perturbadores endócrinos, estrogênios sintéticos. Os resultados mostraram que a exposição induziu à feminização de peixes machos. Subseqüentemente, os peixes foram gradativamente expostos a águas naturais por mais 150 dias, resultando na redução de vitelogenina no plasma, porém, não se observou alteração no sistema sexual feminizado dos peixes, indicando que o desenvolvimento da anomalia no sistema reprodutivo não foi revertida.

Outra questão relevante a ser considerada no que diz respeito aos efeitos causados por esses micropoluentes é a questão da exposição simultânea a diversos compostos e possíveis efeitos sinérgicos. Pomati e colaboradores (2006) observaram que uma mistura de fármacos (atenolol, bezafibrato, carbamazepina, ibuprofeno e lincomicina, dentre outros) em concentrações de nanogramas por litro inibiram o crescimento de células embrionárias humanas. Efeitos adversos de mistura de fármacos em organismos aquáticos também foram observados (POMATI et al., 2008).

Os efeitos provocados em seres humanos pela ingestão de resíduos de fármacos parece ser negligenciável uma vez que a dosagem que o indivíduo pode receber tomando 2 litros de água por dia ao longo de 70 anos por exemplo, é mais baixa que as dosagens terapêuticas receitadas pelos profissionais da saúde. Entretanto, ainda não se sabe se os efeitos causados por uma dosagem terapêutica em um curto intervalo de tempo são os mesmos que pequenas dosagens ao longo da vida do indivíduo. Além disso, também são desconhecidos os efeitos da ingestão desses micropoluentes a fetos, crianças e pessoas doentes (KÜMMERER, 2009). 
Como pode ser observado, existem na literatura alguns dados sobre efeitos agudos de resíduos de fármacos em microorganismos aquáticos como problemas de reprodução e crescimento (FENT, 2006). No entanto, efeitos crônicos são mais prováveis, pois os microorganismos são expostos a baixas concentrações de forma contínua. Entretanto, efeitos crônicos são menos avaliados, pois requerem um longo período para constatação (MADDEN et al., 2009).

Como os efeitos provocados por esses resíduos não são ainda muito conhecidos é difícil estimar qual concentração será prejudicial e para que tipo de organismos. Dessa forma, não existe legislação estabelecida quanto aos limites permitidos dessas substâncias no ambiente.

Diante dessa conjuntura, a diminuição da utilização de medicamentos parece ser uma estratégia impraticável diante do aumento populacional gradativo e principalmente aumento da expectativa de vida, que consequentemente demanda maior quantidade de medicamentos. Entretanto, algumas medidas como investimentos em educação (no sentido de diminuir a automedicação), restrição na prescrição de medicamentos, políticas de disposição adequada de medicamentos vencidos, tratamentos de efluentes de ETE mais eficientes na eliminação desses resíduos, além do desenvolvimento de novos fármacos biodegradáveis e/ou menos persistentes no ambiente, podem a médio e longo prazo diminuir a contaminação do ambiente por esses micropoluentes (KÜMMERER, 2009).

Neste contexto, além de medidas que possam minimizar a contaminação do ambiente por esses resíduos, o estudo de processos que promovam a degradação de fármacos residuais se mostra atual e relevante. 


\subsection{Processos Oxidativos Avançados (POA)}

\subsubsection{Histórico}

O ozônio foi utilizado para a desinfecção de águas em 1886 por De Meritens. Isso mostra que a utilização de oxidantes no tratamento de águas é bem antiga. Entretanto, a terminologia "Tecnologias de Oxidação Avançada" foi utilizada pela primeira vez em 1973 durante o Simpósio Internacional em ozônio para o tratamento de águas e efluentes. Vários trabalhos foram então publicados na literatura sobre essas tecnologias, destacando-se quatro períodos cronológicos distintos: entre 1976 e 1985 foram poucos trabalhos científicos publicados e praticamente nenhuma aplicação concreta; entre 1985 e 1990 devido ao aumento da preocupação com temas relacionados à contaminação ambiental houve um aumento no número de trabalhos publicados referentes à degradação de contaminantes; até o final da década de 90 houve muitas discussões sobre as vantagens e desvantagens dos processos pois o aumento do número de trabalhos levou a uma disseminação de resultados contraditórios; atualmente nota-se uma visão mais realista e conservadora das possibilidades dessas tecnologias, bem como a aplicação desses processos de forma viável e competitiva comparado aos processos convencionais de tratamentos de águas e efluentes (GÁLVEZ et al., 2001; TEIXEIRA; JARDIM, 2004).

Os chamados Processos Oxidativos Avançados (POA) estão sendo cada vez mais reconhecidos como alternativa para a degradação de contaminantes, visto que em 1998 a USEPA lançou um Handbook dos POA destacando trabalhos importantes feitos na área. Além disso, congressos internacionais como o "15th International Conference 
on Advanced Oxidation Technologies for Treatment of water, air and soil" (AOTs-15) realizado nos EUA em 2009, o qual acontece anualmente, e o "International Conference on Oxidation Technologies for Water and Wastewater Treatment" (AOP5) realizado na Alemanha em 2009 o qual é trienal, tem reunido renomados pesquisadores de várias regiões do mundo que trabalham com esse tema. No Brasil o Encontro sobre aplicações ambientais de Processos Oxidativos Avançados realizou sua quinta edição bianual em 2009.

$\mathrm{Na}$ literatura existem vários artigos de revisão sobre a degradação de diferentes tipos de contaminantes como pesticidas, corantes e também de efluentes industriais e domésticos por POA (PIGNATELLO; OLIVEROS; MacKAY, 2006; GOGATE; PANDIT, 2004; NOGUEIRA et al., 2007), inclusive sobre a degradação de resíduos de fármacos (MELO et al., 2009; KLAVARIOTI; MANTZAVINOS; KASSINOS, 2008).

\subsubsection{Fundamentos dos Processos Oxidativos Avançados}

Os POA são processos que baseiam-se na geração do radical hidroxila $\left({ }^{\circ} \mathrm{OH}\right)$, um agente extremamente oxidante, capaz de oxidar uma vasta gama de compostos orgânicos e inorgânicos. $O$ radical hidroxila apresenta um alto potencial padrão de redução $\left(E^{\circ}=+2,73 \vee\right.$ versus eletrodo normal de hidrogênio $\left.(E N H)\right)$, comparado à maioria dos oxidantes comuns (Tabela 2) e dessa forma é capaz de promover a oxidação de compostos a $\mathrm{CO}_{2}, \mathrm{H}_{2} \mathrm{O}$ e ácidos inorgânicos provenientes dos heteroátomos da molécula, apresentando constantes de velocidade da ordem de $10^{6}$ $10^{9} \mathrm{~L} \mathrm{~mol} \mathrm{~s}^{-1}$ (HAAG; YAO, 1992; BUXTON et al., 1988). 
Tabela 2. Potencial padrão de redução ( $\left.\mathrm{E}^{\circ}\right)$ de alguns oxidantes versus eletrodo normal de hidrogênio $(\mathrm{ENH})$.

Espécie

\begin{tabular}{cc}
\hline $\mathrm{F}_{2(\mathrm{~g})}+2 \mathrm{H}^{+}+2 \mathrm{e}^{-} \rightarrow 2 \mathrm{HF}$ & 3,08 \\
$\mathrm{HO}^{-}+\mathrm{H}^{+}+\mathrm{e}^{-} \rightarrow \mathrm{H}_{2} \mathrm{O}$ & 2,73 \\
$\mathrm{O}_{(\mathrm{g})}+2 \mathrm{H}^{+}+2 \mathrm{e}^{-} \rightarrow 2 \mathrm{H}_{2} \mathrm{O}$ & 2,43 \\
$\mathrm{O}_{3}(\mathrm{~g})+2 \mathrm{H}^{+}+2 \mathrm{e}^{-} \rightarrow \mathrm{O}_{2}(\mathrm{~g})+\mathrm{H}_{2} \mathrm{O}$ & 2,08 \\
$\mathrm{H}_{2} \mathrm{O}_{2}+2 \mathrm{H}^{+}+2 \mathrm{e}^{-} \rightarrow 2 \mathrm{H}_{2} \mathrm{O}$ & 1,76 \\
$\mathrm{MnO}_{4}^{-}+8 \mathrm{H}^{+}+5 \mathrm{e}^{-} \rightarrow \mathrm{Mn}^{2+}+4 \mathrm{H}_{2} \mathrm{O}$ & 1,51 \\
$\mathrm{HClO}^{+} \mathrm{H}^{+}+\mathrm{e}^{-} \rightarrow 1 / 2 \mathrm{Cl}_{2(\mathrm{~g})}+\mathrm{H}_{2} \mathrm{O}$ & 1,63 \\
$\mathrm{Cl}_{2}(\mathrm{~g})+2 \mathrm{e}^{-} \rightarrow 2 \mathrm{Cl}^{-}$ & 1,36 \\
$\mathrm{ClO}_{2}^{-}+\mathrm{H}^{+}+\mathrm{e}^{-} \rightarrow \mathrm{HClO}_{2}$ & 1,28 \\
$1 / 2 \mathrm{O}_{2(\mathrm{~g})}+2 \mathrm{H}^{+}+2 \mathrm{e}^{-} \rightarrow \mathrm{H}_{2} \mathrm{O}$ & 1,23 \\
\hline BRATSH, 1989; WARDMAN, 1989. &
\end{tabular}

BRATSH, 1989; WARDMAN, 1989.
Eo (V)

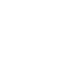

A geração de radical hidroxila se dá pela combinação de oxidantes como peróxido de hidrogênio ou ozônio com irradiação ultravioleta (UV) ou visível (Vis) na presença de catalisadores como íons metálicos ou semicondutores. O Esquema 1 apresenta os principais processos oxidativos avançados existentes (GOGATE; PANDIT, 2004). 


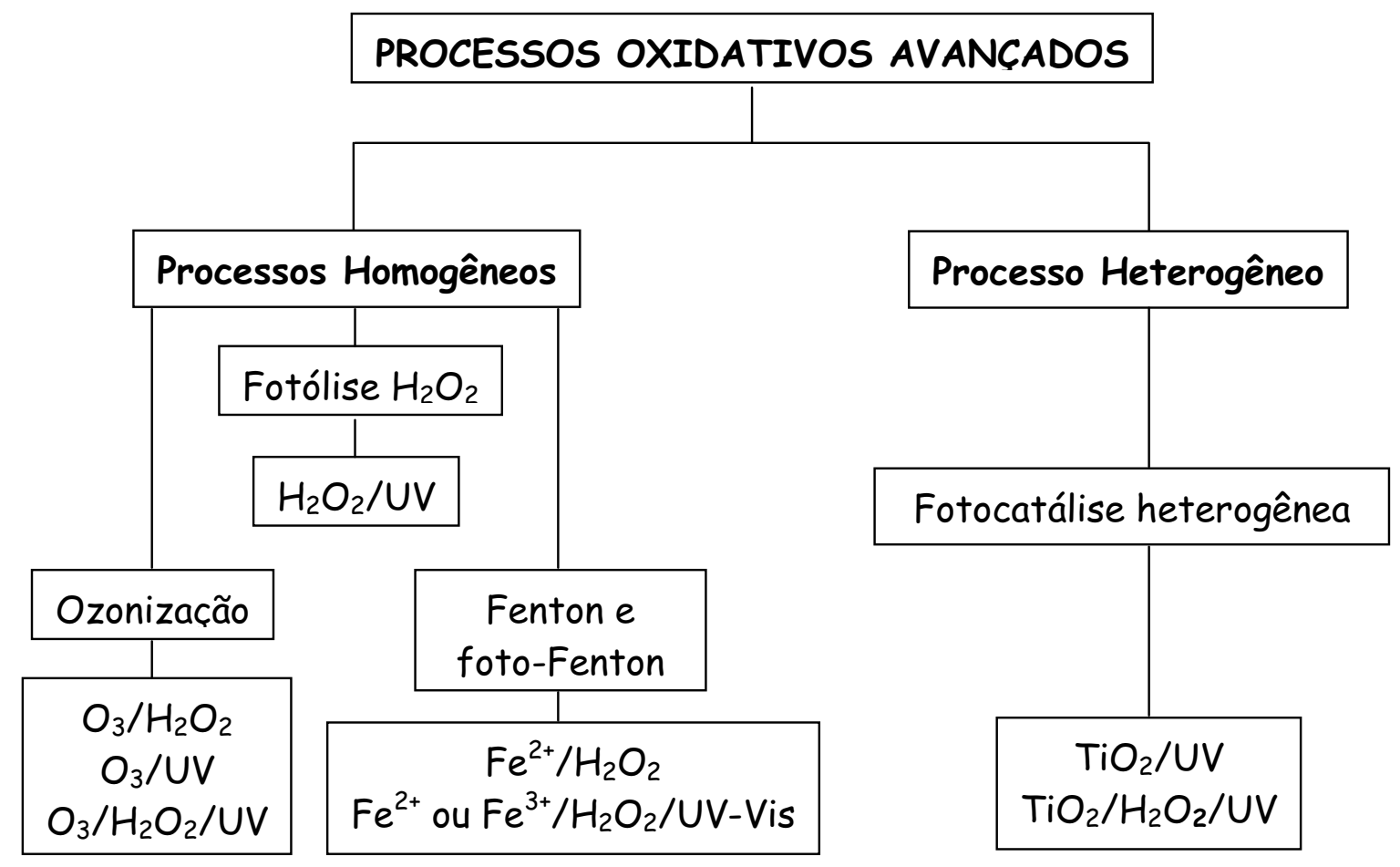

Esquema 1. Principais Processos Oxidativos Avançados.

A oxidação dos compostos orgânicos pelo radical hidroxila é promovida basicamente por três mecanismos (LEGRINI; OLIVEROS; BRAUN, 1993):

- Abstração de átomo de hidrogênio: ocorre geralmente com hidrocarbonetos alifáticos e promove a formação de radicais orgânicos (Eq. 1).

$\mathrm{RH}+{ }^{\bullet} \mathrm{OH} \rightarrow{ }^{\bullet} \mathrm{R}+\mathrm{H}_{2} \mathrm{O}$

- Adição eletrofílica: adição de ${ }^{\bullet} \mathrm{OH}$ a ligações $\pi$ formando radicais orgânicos, ocorre geralmente com hidrocarbonetos insaturados ou aromáticos (Eq. 2).

$\mathrm{PhX}+{ }^{\circ} \mathrm{OH} \rightarrow \mathrm{HOPhX}^{\bullet}$

- Transferência eletrônica: ocorre normalmente com hidrocarbonetos halogenados (Eq. 3).

$\mathrm{RX}+{ }^{\circ} \mathrm{OH} \rightarrow \mathrm{RX}^{\bullet+}+\mathrm{OH}^{-}$ 
Reações radicalares, como por exemplo, a recombinação de radicais hidroxila regenerando $\circ \mathrm{H}_{2} \mathrm{O}_{2}$, também podem ocorrer, porém essas são indesejáveis pois diminuem a eficiência do processo de degradação. Além disso, a eficiência do processo de degradação de contaminantes pode ser diminuída também pelo consumo de radicais •OH pelo próprio $\mathrm{H}_{2} \mathrm{O}_{2}$ (PIGNATELLO; OLIVEROS; MacKAY, 2006).

\subsubsection{Processo Fenton e foto-Fenton}

A reação de Fenton é conhecida desde 1894 quando Henry J. Fenton observou a oxidação do ácido tartárico na presença de $\mathrm{H}_{2} \mathrm{O}_{2}$ e íons ferrosos (FENTON, 1894). Entretanto, somente 40 anos mais tarde foi proposto o mecanismo de geração de radical hidroxila que ocorre por meio da decomposição catalítica do peróxido de hidrogênio em meio ácido, como mostra a Equação 4 (HABER; WEISS, 1934):

$\mathrm{Fe}^{2+}+\mathrm{H}_{2} \mathrm{O}_{2} \rightarrow \mathrm{Fe}^{3+}+\mathrm{OH}^{-}+{ }^{\circ} \mathrm{OH} \quad \mathrm{k}=76 \mathrm{~L} \mathrm{~mol}^{-1} \mathrm{~s}^{-1}$

Em soluções aquosas com pH menor que 3, na ausência de ligantes, o Fe(II) existe predominantemente como o aquo-complexo $\mathrm{Fe}\left(\mathrm{H}_{2} \mathrm{O}\right)_{6}{ }^{2+}$. Isso pode ser observado na Figura 2 que apresenta a especiação do $\mathrm{Fe}$ (II) em função do pH. Acima de pH 3 a espécie predominante é a $\mathrm{Fe}\left(\mathrm{H}_{2} \mathrm{O}\right)_{5}(\mathrm{OH})^{+}$e entre $\mathrm{pH} 2$ e 4 a espécie $\mathrm{Fe}\left(\mathrm{H}_{2} \mathrm{O}\right)_{4}(\mathrm{OH})_{2}$ também ocorre e é cerca de 10 vezes mais reativa que o complexo $\mathrm{Fe}\left(\mathrm{H}_{2} \mathrm{O}\right)_{6}{ }^{2+}$. 


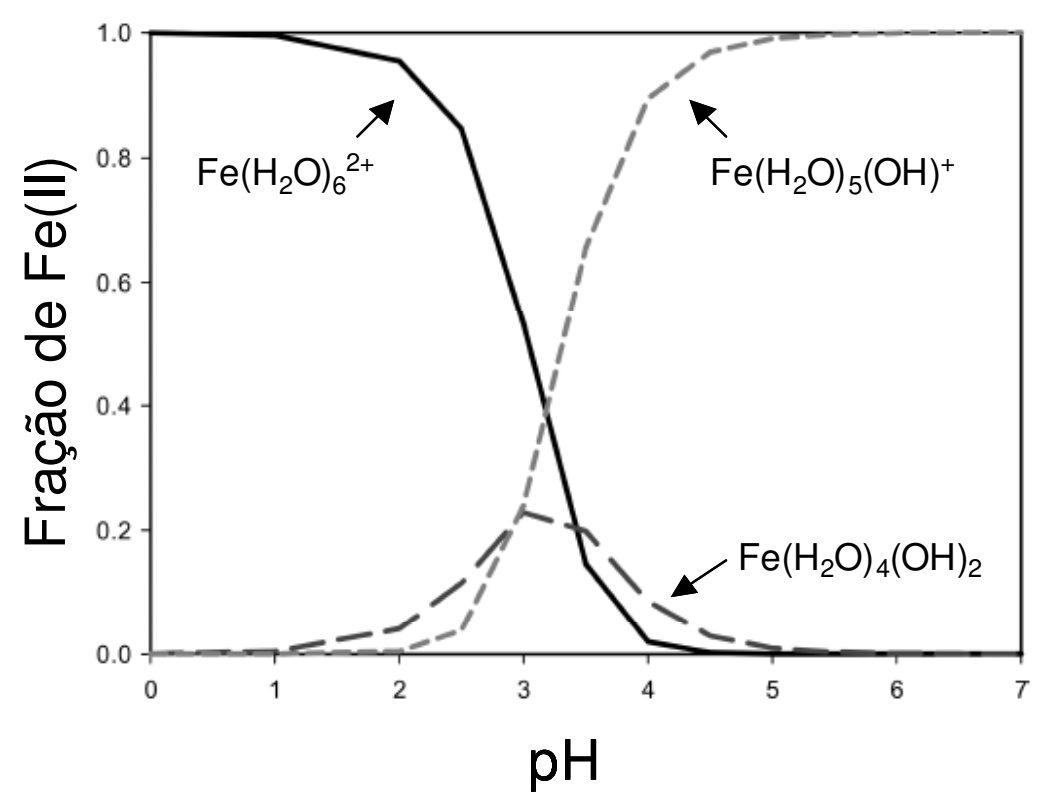

Figura 2. Especiação de $\mathrm{Fe}(\mathrm{II})$ em água em função do pH. (Adaptado de Pignatello et al., 2006).

Os íons férricos também reagem com $\mathrm{H}_{2} \mathrm{O}_{2}$, entretanto com uma velocidade muito menor comparada aos íons ferrosos, formando $\mathrm{Fe}^{2+}$ além de outros radicais (Eq. 5,6) (WALLING; GOOSEN, 1973).

$\mathrm{Fe}^{3+}+\mathrm{H}_{2} \mathrm{O}_{2} \stackrel{\hookrightarrow}{\rightarrow} \mathrm{Fe}-\mathrm{OOH}^{2+}+\mathrm{H}^{+} \quad \mathrm{k}=0,001-0,01 \mathrm{~L} \mathrm{~mol}^{-1} \mathrm{~s}^{-1}$

$\mathrm{Fe}-\mathrm{OOH}^{2+} \rightarrow \mathrm{HO}_{2}{ }^{\cdot}+\mathrm{Fe}^{2+}$

No processo foto-Fenton a velocidade das reações de oxidação pode ser aumentada com a incidência de radiação na amostra. Tanto os íons ferrosos, conforme já mencionado, quanto os íons férricos estão na forma de espécies hidroxiladas em solução aquosa, cuja proporção depende do pH. A irradiação das espécies hidroxiladas de $\mathrm{Fe}(\mathrm{III})$ promove a transferência de um elétron do ligante para o metal, conhecida como transferência de carga ligante-metal, proporcionando assim, a formação do radical hidroxila e a regeneração de Fe(II) (Eq. 7) (FAUST; HOIGNÉ, 1990): 
$\mathrm{Fe}(\mathrm{OH})^{2+}+\mathrm{hv} \rightarrow \mathrm{Fe}^{2+}+{ }^{\circ} \mathrm{OH}$

Em pH menor que 2,5 a espécie de $\mathrm{Fe}(\mathrm{III})$ predominante é $\mathrm{Fe}\left(\mathrm{H}_{2} \mathrm{O}\right)_{6}{ }^{3+}$ (Fig. 3A), sendo neste $\mathrm{pH}$ a espécie responsável pela geração de ${ }^{\circ} \mathrm{OH}$, proveniente da fotólise dos aquocomplexos de Fe(III) (FENG; NANSHENG, 2000).
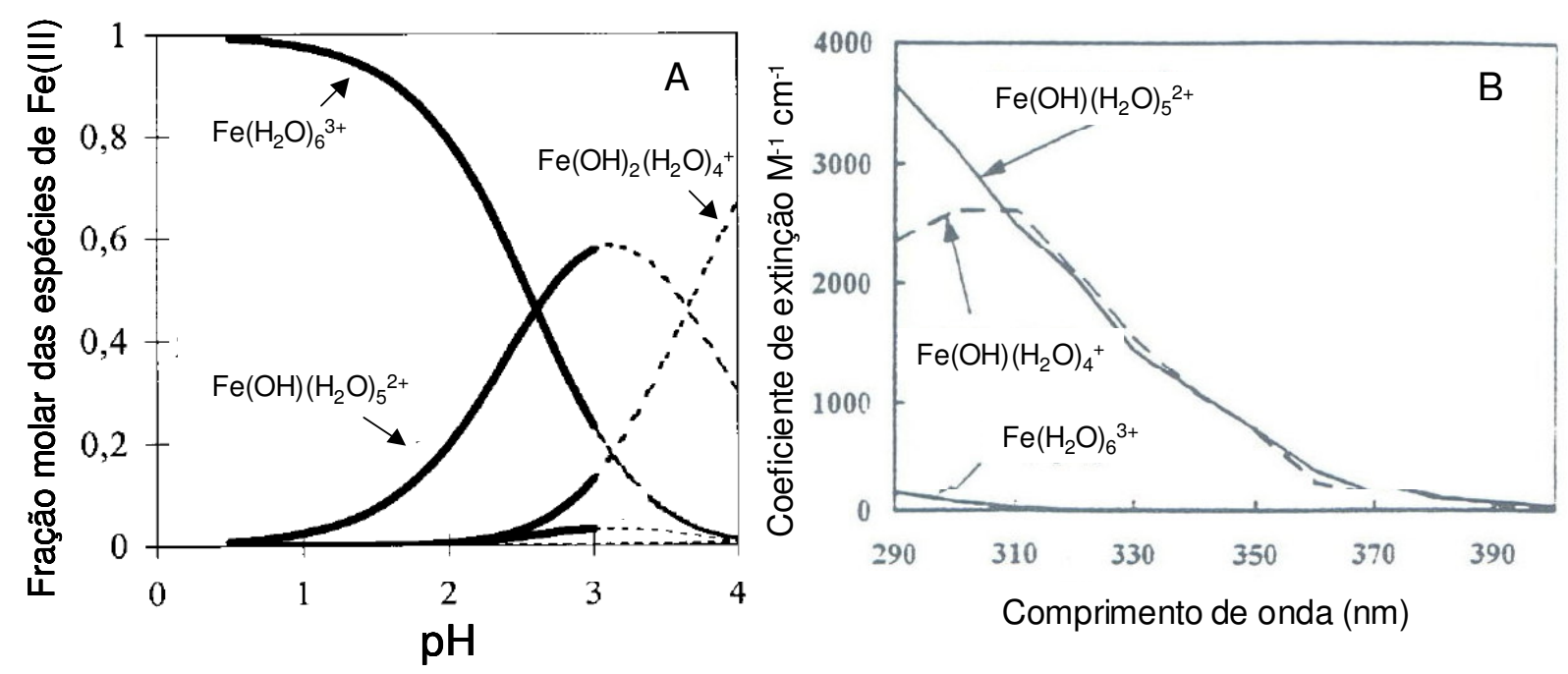

Figura 3. (A) Especiação das espécies de Fe(III) em água (Fe(III) $=1 \times 10^{-3} \mathrm{~mol} \mathrm{~L}^{-1}$; Força iônica $0,1 \mathrm{~mol} \mathrm{~L}^{-1} ; 25^{\circ} \mathrm{C}$ ). As linhas tracejadas referem-se as regiões supersaturadas com $\mathrm{Fe}(\mathrm{III})(\mathrm{OH})_{3}$. (adaptado de GALLARD; LAAT; LEGUBE, 1999). (B) Espectro de absorção de $\mathrm{Fe}$ (III) monomérico e das espécies de hidroxo-complexos de $\mathrm{Fe}$ (III) (adaptado de SAFARZADEH-AMIRI; BOLTON; CARTER, 1996b).

A espécie dominante em pH 3,0 é a $\mathrm{Fe}(\mathrm{OH})\left(\mathrm{H}_{2} \mathrm{O}\right)_{5}{ }^{2+}$ (Fig.3A) a qual é a principal responsável pela geração de ${ }^{\circ} \mathrm{OH}$, pois apresenta rendimento quântico (medida da eficiência fotônica de uma reação fotoquímica definido como o número de mols de um produto formado ou reagente consumido por número de mols de fótons absorvidos) de geração de $\mathrm{Fe}(\mathrm{II})$ de 0,14 em 313 nm (FAUST; HOIGNÉ, 1990) muito maior quando comparado à espécie $\mathrm{Fe}\left(\mathrm{H}_{2} \mathrm{O}\right)_{6}{ }^{3+}$ que apresenta rendimento de 0,065 em $254 \mathrm{~nm}$ (LANGFORD; CAREY, 1975). Além disso, esta espécie apresenta uma absorção em 
comprimentos de onda de $290-400 \mathrm{~nm}$ muito maior comparada as outras espécies de $\mathrm{Fe}$ (III) (Fig. 3B). A geração de ${ }^{\bullet} \mathrm{OH}$ por meio da fotólise das outras espécies hidroxiladas de ferro pode ser ignorada (FAUST; HOIGNÉ, 1990).

Dessa forma, a irradiação promove, além da formação de ${ }^{\circ} \mathrm{OH}$, a fotorredução do $\mathrm{Fe}^{3+}$ regenerando $\mathrm{Fe}^{2+}$ para continuar o ciclo (Eq. 4), aumenta a decomposição de $\mathrm{H}_{2} \mathrm{O}_{2}$ pela absorção de irradiação ultravioleta e também proporciona a fotólise de complexos orgânicos de $\mathrm{Fe}($ III) gerados durante a degradação (PIGNATELLO, 1992).

$\mathrm{O}$ pH considerado ótimo para as reações de Fenton e foto-Fenton é por volta de 3 (NOGUEIRA; GUIMARÃES, 2000), pois as espécies mais reativas tanto de $\mathrm{Fe}(\mathrm{II})$ quanto de $\mathrm{Fe}$ (III) estão presentes neste valor de $\mathrm{pH}$. Além disso, é também neste $\mathrm{pH}$ que a espécie de $\mathrm{Fe}$ (III) mais fotorreativa apresenta maior absorção, conforme já mencionado (Fig. 3B), e dessa forma, por meio de sua fotólise promove maior geração de radical ${ }^{\circ} \mathrm{OH}$ e consequentemente maior degradação do contaminante.

A degradação é prejudicada em $\mathrm{pH}$ maior que 3 pois ocorre a precipitação do ferro dependendo de sua concentração e temperatura. A co-precipitação dos íons ferrosos diminui também a eficiência do processo Fenton. Já em pH menor que 2,5 altas concentrações de $\mathrm{H}^{+}$podem seqüestrar o radical hidroxila (Eq. 8) e consequentemente também diminuir a eficiência do sistema (SPINKS; WOODS, 1990). $\mathrm{HO}^{\bullet}+\mathrm{H}^{+}+\mathrm{e}^{-} \rightarrow \mathrm{H}_{2} \mathrm{O} \quad \mathrm{k}=7 \times 10^{9} \mathrm{~L} \mathrm{~mol}^{-1} \mathrm{~s}^{-1}$

A complexação do ferro com ligantes orgânicos é considerada vantajosa para o processo foto-Fenton pois permite a extensão da banda de absorção de luz para o visível aumentando assim a eficiência do sistema. Além disso, a utilização de 
complexos orgânicos permite que as reações ocorram numa faixa mais ampla de $\mathrm{pH}$ (ZUO; HOIGNÉ, 1992; SAFARZADEH-AMIRI; BOLTON; CATER, 1996a).

O ferrioxalato de potássio ( $\mathrm{FeOx}$ ) é um complexo de ferro bastante utilizado em reações foto-Fenton pois, além das vantagens anteriormente citadas, a irradiação de FeOx apresenta rendimento quântico de geração de $\mathrm{Fe}(\mathrm{II})$ 1,24 em 300 nm. Isso significa que a fotorredução de $\mathrm{Fe}(\mathrm{III})$ a $\mathrm{Fe}(\mathrm{II})$ é mais favorecida quando $\mathrm{FeOx}$ é irradiado, disponibilizando assim, Fe(II) para a continuação do ciclo e a conseqüente geração de ${ }^{\circ} \mathrm{OH}$.

Além disso, a fotólise de $\mathrm{FeOx}$ (Eq. 9-11) que ocorre durante o processo de degradação, gera outros radicais orgânicos também capazes de oxidar o compostoalvo. Dessa forma, além de aumentar a eficiência do sistema, a fotólise propicia também o consumo da matéria orgânica adicional proveniente do oxalato (SAFARZADEH-AMIRI; BOLTON; CATER, 1996a).

$\left[\mathrm{Fe}\left(\mathrm{C}_{2} \mathrm{O}_{4}\right)_{3}\right]^{3-}+\mathrm{hv} \rightarrow\left[\mathrm{Fe}\left(\mathrm{C}_{2} \mathrm{O}_{4}\right)_{2}\right]^{2-}+\mathrm{C}_{2} \mathrm{O}_{4}^{-\bullet}$

$\mathrm{C}_{2} \mathrm{O}_{4}^{-\bullet}+\left[\mathrm{Fe}\left(\mathrm{C}_{2} \mathrm{O}_{4}\right)_{3}\right]^{3-} \rightarrow\left[\mathrm{Fe}\left(\mathrm{C}_{2} \mathrm{O}_{4}\right)_{2}\right]^{2-}+\mathrm{C}_{2} \mathrm{O}_{4}{ }^{2-}+2 \mathrm{CO}_{2}$

$\mathrm{C}_{2} \mathrm{O}_{4}^{-\bullet}+\mathrm{O}_{2} \rightarrow \mathrm{O}_{2}^{-\bullet}+2 \mathrm{CO}_{2}$

Vários trabalhos na literatura constataram a maior eficiência do $\mathrm{FeOx}$ na degradação de contaminantes orgânicos quando comparados aos aquo-complexos de ferro (NOGUEIRA; SILVA; TROVÓ, 2005; BAUTITZ; NOGUEIRA, 2007).

Os complexos de ferro são utilizados no processo foto-Fenton pois são capazes de absorver radiação visível, como por exemplo, pode-se citar o FeOx que apresenta absortividade máxima da ordem de $10^{3}-10^{4} \mathrm{~L} \mathrm{~mol}^{-1} \mathrm{~cm}^{-1}$ no intervalo de 200 a $480 \mathrm{~nm}$. Nesse contexto, a radiação solar pode ser uma alternativa economicamente viável, pois 
permite diminuir os custos com energia durante a degradação de contaminantes orgânicos por processo foto-Fenton.

O processo foto-Fenton apresenta várias vantagens como, por exemplo, simplicidade, abundância e não toxicidade do ferro utilizado como catalisador. $\mathrm{O}$ peróxido de hidrogênio é consumido durante o processo e não ocasiona problemas ambientais. Além disso, dentre os POA, é o processo que apresenta o menor custo operacional (BAUER; FALLMANN, 1997; AZBAR; YONAR; KESTIOGLU, 2004). Entretanto, conforme já mencionado, o pH influencia diretamente na eficiência do processo foto-Fenton sendo assim a principal limitação, pois é necessário o ajuste de $\mathrm{pH}$ para o tratamento e a posterior neutralização para descarte do efluente (PIGNATELLO, 1992).

\subsubsection{Degradação de fármacos por Processos Oxidativos Avançados}

Na literatura existem vários trabalhos sobre a degradação de fármacos por POA (MELO et al., 2009; KLAVARIOTI; MANTZAVINOS; KASSINOS, 2009; ESPLUGAS et al., 2007). A Tabela 3 lista alguns desses trabalhos. 
Tabela 3. Degradação de fármacos por Processos Oxidativos Avançados

Fármaco POA Referências

\begin{tabular}{|c|c|c|}
\hline Fármaco & POA & Referências \\
\hline \multirow{3}{*}{ Amoxicilina } & $\mathrm{Fe}^{2+} / \mathrm{H}_{2} \mathrm{O}_{2} / \mathrm{UV}$ & Elmolla et al., 2009 \\
\hline & $\mathrm{O}_{3}$ & Andreozzi et al., 2005 \\
\hline & $\mathrm{Fe}^{3+} / \mathrm{FeOx} / \mathrm{H}_{2} \mathrm{O}_{2} / \mathrm{UV}$, solar & Trovó et al., 2008 \\
\hline \multirow{4}{*}{ Bezafibrato } & $\mathrm{O}_{3}$ & Dantas et al., 2007 \\
\hline & $\mathrm{O}_{3}, \mathrm{O}_{3} / \mathrm{H}_{2} \mathrm{O}_{2}$ & Huber et al., 2003 \\
\hline & $\mathrm{TiO}_{2} / \mathrm{UV}$ & Lambropoulou, 2008 \\
\hline & $\mathrm{Fe}^{3+} / \mathrm{FeOx} / \mathrm{H}_{2} \mathrm{O}_{2} / \mathrm{UV}$, solar & Trovó et al., 2008 \\
\hline \multirow{3}{*}{ Carbamazepina } & $\mathrm{O}_{3}, \mathrm{O}_{3} / \mathrm{UV}, \mathrm{H}_{2} \mathrm{O}_{2} / \mathrm{UV}$ & Gerbhardt et al., 2007 \\
\hline & $\mathrm{O}_{3} / \mathrm{H}_{2} \mathrm{O}_{2}$ & Huber et al., 2003 \\
\hline & $\mathrm{H}_{2} \mathrm{O}_{2} / \mathrm{UV}$ & Vogna et al., 2004 \\
\hline \multirow{2}{*}{ Diazepam } & $\mathrm{O}_{3}, \mathrm{O}_{3} / \mathrm{UV}, \mathrm{H}_{2} \mathrm{O}_{2} / \mathrm{UV}$ & Gerbhardt et al., 2007 \\
\hline & $\mathrm{O}_{3} / \mathrm{H}_{2} \mathrm{O}_{2}$ & Huber et al., 2003 \\
\hline \multirow{6}{*}{ Diclofenaco } & $\mathrm{H}_{2} \mathrm{O}_{2} / \mathrm{UV}$ & Kim et al., 2009 \\
\hline & $\mathrm{TiO}_{2} / \mathrm{UV}$ & Calza et al., 2006 \\
\hline & $\mathrm{Fe}^{2+} / \mathrm{H}_{2} \mathrm{O}_{2} /$ solar & Pérez-Estrada et al., 2005 \\
\hline & $\mathrm{Fe}^{3+} / \mathrm{H}_{2} \mathrm{O}_{2} / \mathrm{UV}$ & Ravina et al., 2002 \\
\hline & $\mathrm{Fe}^{2+} / \mathrm{H}_{2} \mathrm{O}_{2}$ & Packer et al., 2003 \\
\hline & $\mathrm{O}_{3}, \mathrm{O}_{3} / \mathrm{UV}, \mathrm{H}_{2} \mathrm{O}_{2} / \mathrm{UV}$ & Gerbhardt et al., 2007 \\
\hline \multirow{2}{*}{ Dipirona } & $\mathrm{Fe}^{2+} \mathrm{H}_{2} \mathrm{O}_{2} /$ solar & \\
\hline & $\mathrm{TiO}_{2} /$ solar & Perez-tstrada et al., zou \\
\hline \multirow{2}{*}{$17 \propto-$ Etinilestradiol } & $\mathrm{TiO}_{2} / \mathrm{UV}$ & Coleman et al., 2004 \\
\hline & $\mathrm{O}_{3} / \mathrm{H}_{2} \mathrm{O}_{2}$ & Huber et al., 2003 \\
\hline \multirow{2}{*}{ Ibuprofeno } & $\mathrm{O}_{3} / \mathrm{H}_{2} \mathrm{O}_{2}$ & Zwiener et al., 2000 \\
\hline & $\mathrm{Fe}^{2+/} \mathrm{H}_{2} \mathrm{O}_{2}$ & Packer et al., 2003 \\
\hline \multirow{2}{*}{ lopromida } & $\mathrm{O}_{3}$ & Huber et al., 2005 \\
\hline & $\mathrm{O}_{3} / \mathrm{H}_{2} \mathrm{O}_{2}, \mathrm{O}_{3} / \mathrm{UV}$ & Ternes et al., 2003 \\
\hline \multirow{3}{*}{ Metronidazol } & $\mathrm{H}_{2} \mathrm{O}_{2} / \mathrm{UV}$ & \\
\hline & $\mathrm{Fe}^{2+/} \mathrm{H}_{2} \mathrm{O}_{2}$ & Shemer et al., 2006 \\
\hline & $\mathrm{Fe}^{2+/} \mathrm{H}_{2} \mathrm{O}_{2} / \mathrm{UV}$ & \\
\hline
\end{tabular}




\begin{tabular}{ccc}
\hline & $\mathrm{H}_{2} \mathrm{O}_{2} / \mathrm{UV}$ & Kim et al., 2009 \\
Naproxeno & $\mathrm{O}_{3}$ & Huber et al., 2005 \\
& $\mathrm{H}_{2} \mathrm{O}_{2} / \mathrm{UV}$ & Pereira et al., 2007 \\
& $\mathrm{Fe}^{2+/} \mathrm{H}_{2} \mathrm{O}_{2}$ & Packer et al., 2003 \\
\hline Paracetamol & $\mathrm{O}_{3}, \mathrm{H}_{2} \mathrm{O}_{2} / \mathrm{UV}$ & Andreozzi et al., 2003 \\
& $\mathrm{Fe}^{3+} / \mathrm{FeOx} / \mathrm{H}_{2} \mathrm{O}_{2} / \mathrm{UV}$, solar & Trovó et al., 2008 \\
\hline Ranitidina & $\mathrm{TiO}_{2} / \mathrm{UV}$ & Addamo et al., 2005 \\
& $\mathrm{Fe}^{2+} / \mathrm{H}_{2} \mathrm{O}_{2}$ & Abellán et al., 2007 \\
\hline Sulfametoxazol & $\mathrm{Fe}^{2+} / \mathrm{H}_{2} \mathrm{O}_{2} / \mathrm{solar}$ & Trovó et al., 2009 \\
& $\mathrm{O}_{3}, \mathrm{O}_{3} / \mathrm{H}_{2} \mathrm{O}_{2}$ & Lin et al., 2009 \\
\hline Tetraciclina & $\mathrm{H}_{2} \mathrm{O}_{2} / \mathrm{UV}$ & Kim et al., 2009 \\
& $\mathrm{TiO}_{2} / \mathrm{UV}$ & Reyes et al., 2006 \\
& $\mathrm{Fe}^{3+} / \mathrm{FeOx}_{\mathrm{H}} \mathrm{O}_{2} / \mathrm{UV}$, solar & Bautitz et al., 2007 \\
\hline
\end{tabular}

Conforme já mencionado, as ETE não são eficientes na eliminação de resíduos de fármacos e além disso muitos fármacos residuais são lançados diretamente no ambiente. Nesse contexto, a degradação desses resíduos pode ser feita por meio de um tratamento complementar com os POA. Sob o ponto de vista operacional, os POA podem ser aplicados tanto na saída das ETE, evitando assim a contaminação dos corpos d'água, bem como em etapas finais do processo de tratamento de água, pois dessa forma, garantiria que esses resíduos fossem eliminados da água potável.

A aplicação de POA na saída da ETE parece ser a opção mais adequada uma vez que evitando que esses resíduos cheguem às águas superficiais os efeitos para os organismos aquáticos seriam minimizados, bem como a água captada para abastecimento público também estaria menos contaminada. 


\subsection{Sistema de degradação de contaminantes baseado em Ferro Metálico ( $\mathrm{Fe}^{\circ}$ )}

A utilização de ferro metálico na degradação de contaminantes orgânicos e remoção de espécies inorgânicas ganhou destaque principalmente após o trabalho de Gilham e colaboradores (1996) que desenvolveram uma técnica in situ para o tratamento de águas subterrâneas contaminadas com compostos orgânicos clorados (ZHANG, 2003). O processo foi baseado na passagem da água contaminada por uma barreira reativa permeável (Fig. 4) que continha camadas finas de areia entre as quais foi adicionado $\mathrm{Fe}^{0}$ na forma de pequenos grânulos.

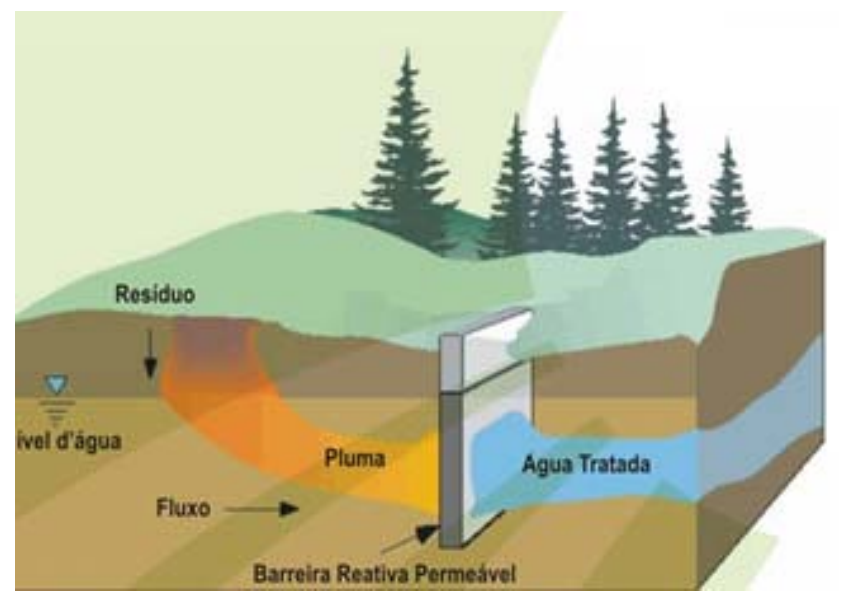

Figura 4. Representação de uma barreira reativa permeável. Fonte: USEPA.

Os bons resultados obtidos no tratamento de águas subterrâneas fizeram com que o sistema ferro metálico fosse estudado para promover a degradação/remoção de muitas outras substâncias, como por exemplo DDT, nitrato, corantes têxteis, (SAYLES et al., 1997; SOHN et al, 2006; NAM et al., 2000; EPOLITO et al., 2008).

A redução de contaminantes é possível, pois o ferro metálico possui poder redutor devido ao potencial padrão de redução de $-0,44 \mathrm{~V}$ do par redox $\mathrm{Fe}^{2+/} \mathrm{Fe}^{\circ}$. $\mathrm{A}$ desalogenação de organoclorados mediada por ferro metálico pode ocorrer por três 
rotas: por meio da transferência direta de elétrons do $\mathrm{Fe}^{\circ}$ para o composto orgânico adsorvido na superfície metálica; redução do composto-alvo pelo $\mathrm{Fe}^{2+}$ proveniente da oxidação do Feo-; e também pelo agente redutor $\mathrm{H}_{2}$ proveniente da corrosão do $\mathrm{Fe}$ o pela água.

Entretanto, o ferro metálico limita-se normalmente à redução de grupos funcionais de compostos orgânicos e não à sua mineralização (PEREIRA; FREIRE, 2005), o que pode significar uma desvantagem desse processo uma vez que subprodutos formados podem apresentar toxicidade maior do que o composto original. Existem trabalhos que relatam a utilização de ferro metálico como gerador de $\mathrm{Fe}^{2+}$ para a reação de Fenton, promovendo assim a mineralização de compostos por meio de reações oxidativas (LIAO et al., 2003). O acoplamento de reações redutivas com ferro metálico e oxidativas com reações tipo Fenton também propicia a mineralização de poluentes uma vez que o $\mathrm{Fe}^{\circ}$ promove a redução destes compostos tornando-os mais susceptíveis à degradação por processos oxidativos (OH et al., 2003).

$\mathrm{Na}$ presença de $\mathrm{Fe}^{\circ}$ o oxigênio pode ser reduzido, por meio da transferência de dois elétrons, ao ânion radical superóxido $\left(\mathrm{O}_{2}{ }^{\circ-}\right)$ e consequentemente gerar $\mathrm{H}_{2} \mathrm{O}_{2}$ no meio (Eq. 12) (JOO; FEITZ; WAITE, 2004). A reação entre $\mathrm{Fe}^{2+}$ e $\mathrm{H}_{2} \mathrm{O}_{2}$ gera o radical hidroxila, conforme já mencionado, e consequentemente a degradação do contaminante.

$\mathrm{Fe}^{\circ}+\mathrm{O}_{2}+2 \mathrm{H}^{+} \rightarrow \mathrm{Fe}^{2+}+\mathrm{H}_{2} \mathrm{O}_{2}$

Uma outra abordagem proposta que utiliza ferro metálico é a mineralização promovida por reações oxidativas baseadas na utilização de $\mathrm{Fe}^{\underline{0}}$, ácido etilenodiaminotetracético (EDTA) e oxigênio (Sistema $\mathrm{Fe} / \mathrm{EDTA} / \mathrm{O}_{2}$ ). A reação de $\mathrm{Fe}$ o 
com $\mathrm{O}_{2}$ produz espécies oxidantes capazes de degradar compostos orgânicos (JOO; FEITZ; WAITE, 2004). Além disso, a adição de um ligante como por exemplo o EDTA pode melhorar significativamente a eficiência do processo (KEENAN; SEDLAK, 2008a). O mecanismo proposto para o sistema $\mathrm{Fe} / \mathrm{EDTA} / \mathrm{O}_{2}$ é representado por meio das equações 13-18 (LAINE et al., 2008).

$\mathrm{Fe}^{\mathrm{o}} \rightarrow \mathrm{Fe}^{2+}+2 \mathrm{e}^{-}$

$\mathrm{Fe}^{2+}+\mathrm{EDTA} \rightarrow \mathrm{Fe}{ }^{\|} \mathrm{EDTA}$

$\mathrm{Fe}{ }^{\| E D T A}+\mathrm{O}_{2} \rightarrow \mathrm{Fe}^{\|} \mathrm{EDTA}-\mathrm{O}_{2}$

$\mathrm{Fe}^{\prime \prime} \mathrm{EDTA}-\mathrm{O}_{2} \rightarrow \mathrm{Fe} \mathrm{e}^{\mathrm{II}} \mathrm{EDTA}+\mathrm{O}_{2}^{\bullet-}$

$\mathrm{Fe}$ "EDTA $+\mathrm{O}_{2}^{\bullet-}+2 \mathrm{H}^{+} \rightarrow \mathrm{Fe}^{\prime \prime \prime} \mathrm{EDTA}+\mathrm{H}_{2} \mathrm{O}_{2}$

$\mathrm{Fe}$ "IEDTA $+\mathrm{H}_{2} \mathrm{O}_{2} \rightarrow \mathrm{Fe}^{\prime \prime \prime} \mathrm{EDTA}+\mathrm{HO}^{-}+\mathrm{HO}^{\bullet}$

O complexo Fe"EDTA (Eq. 13) formado por meio da oxidação do ferro (Eq. 13) reduz o oxigênio (Eq.15-16) que por sua vez, promove a formação de $\mathrm{H}_{2} \mathrm{O}_{2}$ (Eq. 17). A geração de radical hidroxila ocorre por meio de reações do tipo Fenton, entre $\mathrm{O}_{2} \mathrm{O}_{2}$ formado in situ com o complexo Fe"EDTA (Eq. 18).

A adição de um ligante ao sistema pode alterar a produção das espécies oxidantes de diferentes maneiras (KEENAN; SEDLAK, 2008a):

1- O complexo Fe"EDTA pode acelerar a reação de Fenton uma vez que esse reage mais rapidamente com $\circ \mathrm{H}_{2} \mathrm{O}_{2}$ comparado com o íon ferroso;

2- O EDTA também pode evitar a precipitação do Fe(III) que consequentemente pode levar à coprecipitação do $\mathrm{Fe}(\mathrm{II})$ ou à passivação da superfície do $\mathrm{Fe}$-o ocasionando a diminuição da eficiência do processo; 
3- A oxidação do $\mathrm{Fe}(\mathrm{II})$ pelo $\mathrm{O}_{2}$, para formar as espécies de $\mathrm{O}_{2}\left(\mathrm{O}_{2}{ }^{\bullet-}\right.$ e $\left.\mathrm{HO}_{2}{ }^{\circ}\right)$ que darão origem ao $\mathrm{H}_{2} \mathrm{O}_{2}$, é fortemente dependente do $\mathrm{pH}$ e praticamente insignificante em valores de $\mathrm{pH}$ menores que 5 na ausência de ligante (KEENAN; SEDLAK, 2008b); o ligante pode acelerar a reação do $\mathrm{Fe}(\mathrm{II}) \operatorname{com} \circ \mathrm{O}_{2}$ e consequentemente a formação de $\mathrm{H}_{2} \mathrm{O}_{2}$.

No entanto, segundo os autores anteriormente mencionados, esses mecanismos não estão totalmente elucidados, nem as espécies responsáveis pela oxidação são identificadas.

Existem poucos trabalhos na literatura sobre a degradação de contaminantes pelo sistema $\mathrm{Fe} / \mathrm{EDTA} / \mathrm{O}_{2}$ por se tratar de um processo relativamente novo.

A degradação de um efluente têxtil pelo sistema $\mathrm{Fe} / \mathrm{EDTA} / \mathrm{O}_{2}$ foi estudada e os resultados alcançados foram muito promissores. Após 180 minutos de reação foi obtido $68,6 \%$ de remoção de carbono orgânico total (COT) e 92,2\% de diminuição da demanda química de oxigênio (DQO) (ZHOU et al., 2009). Outros corantes têxteis e o 2,4-diclorofenol também foram degradados pelo sistema $\mathrm{Fe} / \mathrm{EDTA} / \mathrm{O}_{2}$ com bons resultados de remoção de COT e de degradação do composto-alvo (CHANG et al., 2009a; CHANG et al., 2009b; ZHOU et al., 2008). Até o momento, não foi encontrado nenhum trabalho sobre a degradação de fármacos residuais pelo sistema $\mathrm{Fe}$ o/EDTA $/ \mathrm{O}_{2}$.

\subsection{Fármacos estudados}

Os fármacos diazepam, propranolol e lincomicina foram escolhidos para o desenvolvimento desse trabalho devido à ocorrência dessas substâncias em ambientes 
aquáticos, pois há um intenso consumo pela população em geral de ansiolíticos, medicamentos para o tratamento da hipertensão arterial e antibióticos. A solubilidade em água dessas substâncias também influenciou na escolha uma vez que esse fator viabiliza o tratamento pelos processos propostos.

\subsubsection{Diazepam (DZP)}

Diazepam é da família das benzodiazepinas que são psicofármacos com propriedades anticonvulsivante, ansiolítico, sedativo, e relaxante muscular. É usado no tratamento de transtornos de ansiedade severos, como hipnótico no tratamento da insônia e como sedativo (ANVISA - Agência Nacional de Vigilância Sanitária, 2009). Resíduos de DZP foram detectados na concentração de $1 \mu \mathrm{g} \mathrm{L}^{-1}$ em efluente de ETE e $10 \mathrm{ng} \mathrm{L^{-1 }}$ em águas superficiais (HALLING-SORENSEN, 1998). Em estudo de ecotoxicidade crônica, a concentração de $10 \mu \mathrm{g} \mathrm{L}^{-1}$ de DZP inibiu a regeneração dos pólipos do cnidário Hydra vulgaris (PASCOE; KARNTANUT; MULLER, 2003). A Figura 5 apresenta a fórmula estrutural de DZP.

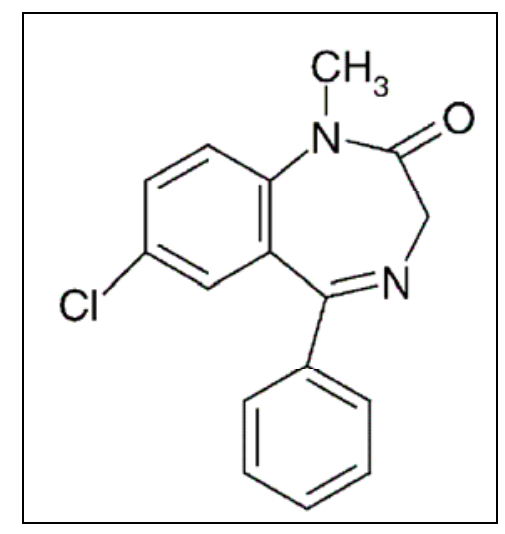

Figura 5. Estrutura molecular do fármaco diazepam (massa molar $284,7 \mathrm{~g} \mathrm{~mol}^{-1}$ ). 


\subsubsection{Cloridrato de propranolol (PPN)}

Propranolol é um beta-adrenérgico não-cardiosseletivo amplamente utilizado no tratamento ou prevenção de muitos transtornos, incluindo o infarto do miocárdio, arritmias, angina pectoris, hipertensão, emergências hipertensivas, hipertireoidismo (ANVISA, 2009). Esse fármaco (Fig. 6) foi detectado em águas superficiais em concentração máxima de $107 \mathrm{ng} \mathrm{L}^{-1}$ e em efluentes de ETE em concentrações médias de $304 \mu \mathrm{g} \mathrm{L}^{-1}$ (ROBERTS; THOMAS, 2006), pois o processo convencional de ETE não se mostrou eficiente na sua remoção (MAURER et al., 2007). Em estudo de ecotoxicidade aguda realizado com Daphnia magna o PPN apresentou efeito negativo mensurável $\left(\mathrm{EC}_{50}\right)$ de $7,5 \mathrm{mg} \mathrm{L}^{-1}$ e para a alga Desmodesmus subscapicatus $\mathrm{EC}_{50}$ de $5,8 \mathrm{mg} \mathrm{L}^{-1}$ (CLEUVERS, 2003).

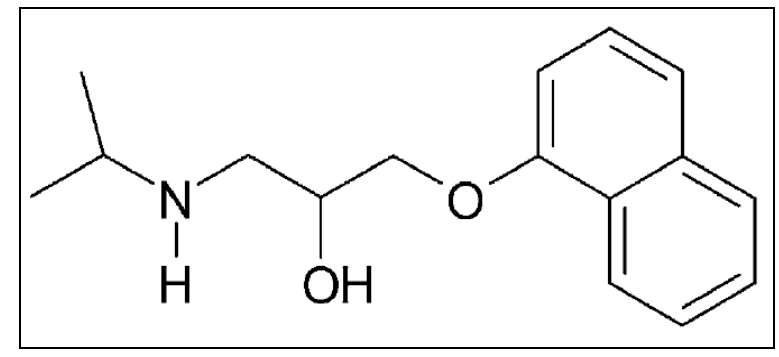

Figura 6. Estrutura molecular do fármaco cloridrato de propranolol (massa molar 259,3 $\mathrm{g} \mathrm{mol}^{-1}$ ).

\subsubsection{Cloridrato de lincomicina (LCM)}

O fármaco lincomicina (LCM) é um antibiótico lincosânido obtido do Streptomices lincolnensis que possui efeito antimicrobiano sobre os microorganismos Gram-positivos como estreptococo, pneumococo e estafilococo. É utilizado no tratamento de 
pneumopatias, infecções estafilocócicas, infecções pélvicas, obstétricas e ginecológicas (ANVISA, 2009). Esse antibiótico (Fig. 7) foi detectado em efluente tratado de hospital em concentrações que variaram de 300 a $2000 \mathrm{ng} \mathrm{L}^{-1}$ (BROWN et al., 2006). A lincomicina apresentou $\mathrm{EC}_{50}$ de 195, 1510 e $1630 \mu \mathrm{g} \mathrm{L}^{-1}$ para as algas Synechococcus leopoliensis, Pseudokirchneriella subcapitata, Cyclotella meneghiniana, respectivamente (ANDREOZZI et al., 2006).

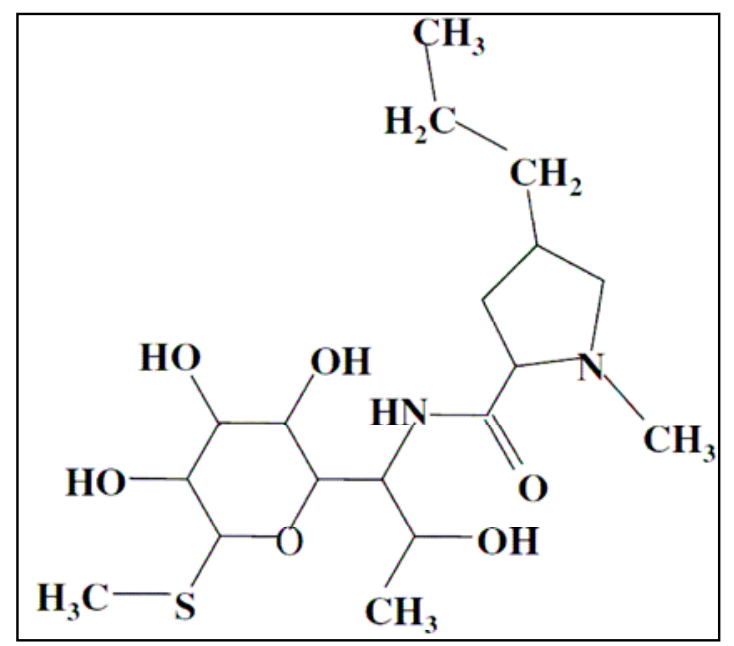

Figura 7. Estrutura molecular do fármaco cloridrato de lincomicina (massa molar $443,0 \mathrm{~g} \mathrm{~mol}^{-1}$ ). 


\section{OBJETIVOS}

Estudar a degradação dos fármacos diazepam, propranolol e lincomicina por processo foto-Fenton e identificar os primeiros intermediários de degradação, bem como avaliar a degradação do fármaco diazepam pelo processo $\mathrm{Fe}$-/EDTA/O $/$. 


\section{MATERIAIS E MÉTODOS}

\subsection{Reagentes}

Os reagentes utilizados nesse trabalho foram: peróxido de hidrogênio $\left(\mathrm{H}_{2} \mathrm{O}_{2}\right)$ 29\% (m/m) (Synth); sulfato ferroso $\left(\mathrm{FeSO}_{4} .7 \mathrm{H}_{2} \mathrm{O}\right)$ (Carlo Erba); borohidreto de sódio $\left(\mathrm{NaBH}_{4}\right)$ (Vetec); ácido etilenodiaminotetracético (EDTA) (Mallinckrodt); ácido sulfúrico $\left(\mathrm{H}_{2} \mathrm{SO}_{4}\right)$ (Synth); fosfato de potássio monobásico $\left(\mathrm{KH}_{2} \mathrm{PO}_{4}\right)$ (Baker); metanol (HPLC) (Tedia); nitrato férrico $\left[\mathrm{Fe}\left(\mathrm{NO}_{3}\right)_{3} .9 \mathrm{H}_{2} \mathrm{O}\right]$ (Merck); hidróxido de sódio ( $\mathrm{NaOH}$ ) (Synth); acetonitrila (Baker); metavanadato de amônio $\left(\mathrm{NH}_{4} \mathrm{VO}_{3}\right)$ (Vetec); oxalato de potássio $\left(\mathrm{K}_{2} \mathrm{C}_{2} \mathrm{O}_{4} \cdot \mathrm{H}_{2} \mathrm{O}\right)$ (Nuclear); ácido trifluoracético $\left(\mathrm{CF}_{3} \mathrm{CO}_{2} \mathrm{H}\right)$ (Ackos); catalase bovina (2.300

unidades $\mathrm{mg}^{-1}$ ) (Sigma-Aldrich); ferro metálico microparticulado, 20 mesh (800 $\mu \mathrm{m}$ ) (Alfa Aesar); palha de aço; padrão de cloridrato de propranolol $\left(\mathrm{C}_{16} \mathrm{H}_{12} \mathrm{NO}_{2} \cdot \mathrm{HCl}\right)$ (SigmaAldrich); padrão de cloridrato de lincomicina $\left(\mathrm{C}_{18} \mathrm{H}_{34} \mathrm{~N}_{2} \mathrm{O}_{6} \mathrm{~S}\right.$. $\left.\mathrm{HCl}\right)$; príncipio ativo de diazepam $\left(\mathrm{C}_{16} \mathrm{H}_{13} \mathrm{~N}_{2} \mathrm{ClO}\right)$ adquirido de fonte comercial.

\subsection{Preparo das soluções}

Todas as soluções foram preparadas utilizando água Milipore Mili-Q dissolvendo quantidades apropriadas do sólido em determinada quantidade de água, inclusive as soluções dos fármacos, com exceção do fármaco diazepam que ficou sob agitação por 12 horas para total solubilização do mesmo. 
A solução de metavanadato de amônio $0,0600 \mathrm{~mol} \mathrm{~L}^{-1} \mathrm{em} \mathrm{H}_{2} \mathrm{SO}_{4}$ 0,560 $\mathrm{mol} \mathrm{L}^{-1}$ foi preparada sob agitação e aquecimento.

O ferrioxalato de potássio $(\mathrm{FeOx})$ foi sintetizado pela reação entre oxalato de potássio e nitrato férrico (Eq. 19) (CALVERT; PITTS, 1966). Para a síntese do complexo foram adicionados com agitação $17,0 \mathrm{~mL}$ da solução de nitrato de ferro $1,76 \mathrm{~mol} \mathrm{~L}^{-1} \mathrm{a}$ $50,0 \mathrm{~mL}$ da solução de oxalato $1,80 \mathrm{~mol} \mathrm{~L}^{-1}$. Houve o aparecimento de coloração verde característica do complexo ferrioxalato de potássio. Nesta solução foi adicionado um pequeno cristal de $\mathrm{FeOx}$ como primeiro núcleo para cristalização. O complexo foi recristalizado três vezes em água e um rendimento médio de $78 \%$ foi obtido.

$3 \mathrm{~K}_{2} \mathrm{C}_{2} \mathrm{O}_{4} \cdot \mathrm{H}_{2} \mathrm{O}+\mathrm{Fe}\left(\mathrm{NO}_{3}\right)_{3} \cdot 9 \mathrm{H}_{2} \mathrm{O} \rightarrow \mathrm{K}_{3} \mathrm{Fe}\left(\mathrm{C}_{2} \mathrm{O}_{4}\right)_{3} \cdot 3 \mathrm{H}_{2} \mathrm{O}+3 \mathrm{KNO}_{3}+9 \mathrm{H}_{2} \mathrm{O}$

\subsection{Síntese das nanopartículas de ferro metálico $\left(\mathrm{Fe}^{\circ}\right)$}

Os experimentos de degradação de diazepam baseados em ferro metálico foram feitos com dois tamanhos de partículas de ferro: nanoparticulado e microparticulado.

A síntese das nanopartículas de ferro foi feita de acordo com procedimento descrito por Ponder e colaboradores (2000). Normalmente a síntese do $\mathrm{Fe}^{0}$ é feita a partir de cloreto férrico, no entanto, como nesse trabalho foram utilizadas reações oxidativas, o cloreto foi evitado uma vez que pode atuar como sequestrador de radical hidroxila.

Uma solução de borohidreto de sódio $\left(180 \mathrm{mmol} \mathrm{L}^{-1}\right)$ foi adicionada em excesso a uma vazão de $37 \mathrm{~mL} \mathrm{~min}{ }^{-1}$ com o auxílio de uma bomba peristáltica, a uma solução de sulfato ferroso $\left(90 \mathrm{mmol} \mathrm{L}^{-1}\right) \mathrm{com} \mathrm{pH}$ ajustado para 6,8 sob agitação mecânica 
(Quimis), em temperatura ambiente, para formar as nanopartículas de acordo com a Equação. 20:

$2 \mathrm{Fe}^{2+}+\mathrm{BH}_{4}^{-}+2 \mathrm{H}_{2} \mathrm{O} \rightarrow 2 \mathrm{Fe}_{(\mathrm{s})}^{\mathrm{o}}+\mathrm{BO}_{2}^{-}+4 \mathrm{H}^{+}+2 \mathrm{H}_{2(\mathrm{~g})}$

Após a adição de borohidreto, a suspensão resultante ficou sob agitação por 20 minutos e foi lavada com água deionizada por três vezes e mantida congelada até a realização dos experimentos. A água utilizada nas lavagens e para o armazenamento das nanopartículas foi previamente mantida sob borbulhamento de nitrogênio por 20 minutos para a retirada do $\mathrm{O}_{2}$, para evitar a oxidação do ferro.

O ferro nanoparticulado (solução estoque armazenada na concentração de $5 \mathrm{~g}$ $\mathrm{L}^{-1}$ ) foi adicionado aos experimentos após descongelamento e sonicação por alguns segundos para homogeneização da suspensão.

\subsection{Degradação dos fármacos}

3.4.1 Processo foto-Fenton com radiação artificial (lâmpada de luz negra)

Os experimentos de fotodegradação com radiação artificial foram feitos em um reator anteriormente descrito por Nogueira e Guimarães (2000). O reator consiste de um cilindro de vidro de $3,80 \mathrm{~cm}$ de diâmetro interno, $42,0 \mathrm{~cm}$ de altura e possui volume total de $280 \mathrm{~mL}$. Foi utilizada uma lâmpada de luz negra de $15 \mathrm{~W}$ de potência com emissão máxima em $365 \mathrm{~nm}$ e $410 \mathrm{~nm}$ e $19 \mathrm{~W} \mathrm{~cm}^{2}$ de irradiância média. A solução foi bombeada para a base do reator por meio de uma bomba peristáltica (Masterflex L/S 7518-12) a uma vazão de $80 \mathrm{~mL} \mathrm{~min}^{-1}$ e recirculada no sistema (Fig. 8). 


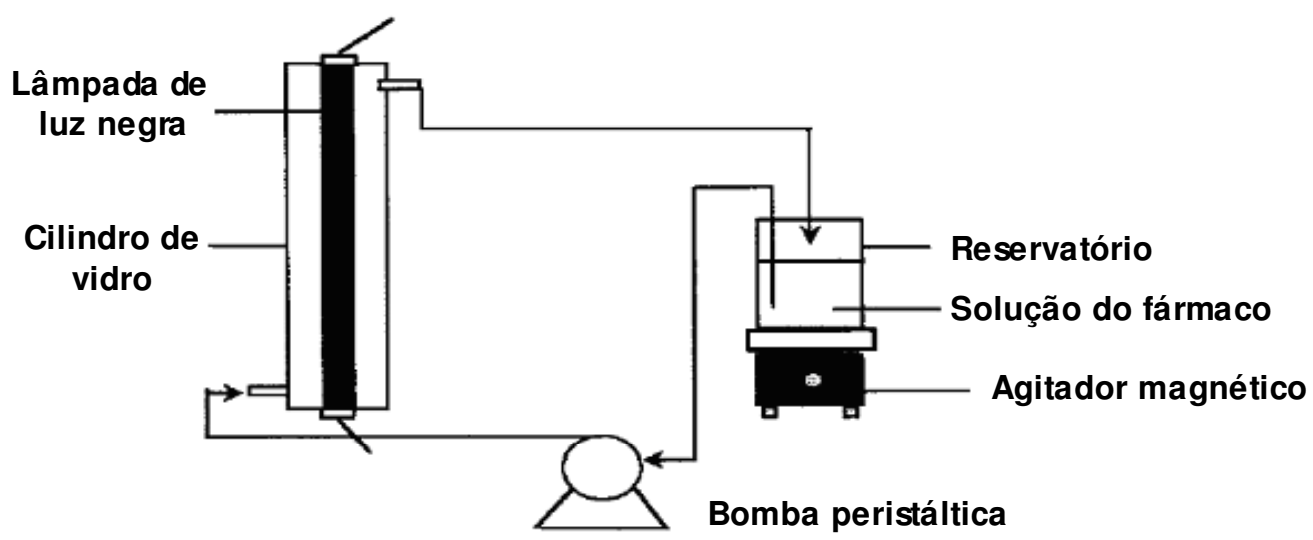

Figura 8. Representação esquemática do reator utilizado nos experimentos de fotodegradação.

Todos os experimentos de degradação foram feitos com soluções dos fármacos nas concentrações apresentadas na Tabela 4. Após a adição de ferro o pH foi ajustado para 2,50 com $\mathrm{H}_{2} \mathrm{SO}_{4}$ tendo em vista que o processo foto-Fenton apresenta maior eficiência nesse valor de pH (NOGUEIRA; GUIMARÃES, 2000; PIGNATELLO, 1992). Por último foi acrescentado o $\mathrm{H}_{2} \mathrm{O}_{2}$ e iniciada a agitação e a recirculação da solução e após o completo preenchimento do reator a lâmpada foi ligada.

Tabela 4. Concentração inicial dos fármacos nos experimentos de degradação.

\begin{tabular}{cccc}
\hline Fármaco & $\begin{array}{c}\text { Concentração } \\
\left(\mathbf{m o l ~ L}^{-1}\right)\end{array}$ & $\begin{array}{c}\text { Concentração } \\
\left(\mathbf{m g ~ L}^{-1}\right)\end{array}$ & $\begin{array}{c}\text { Concentração } \\
\left(\mathbf{m g ~ L}^{-1} \text { de carbono) }\right.\end{array}$ \\
\hline Diazepam & $8,78 \times 10^{-5}$ & 25 & 16,8 \\
Propranolol & $8,45 \times 10^{-5}$ & 25 & 16,2 \\
Lincomicina & $5,64 \times 10^{-5}$ & 25 & 11,6 \\
\hline
\end{tabular}

3.4.2 Processo foto-Fenton com radiação solar

Os experimentos sob radiação solar foram feitos em um reator composto por um tubo de vidro com 3,6 cm de diâmetro e 49,5 cm de comprimento e volume de $510 \mathrm{~mL}$. Esse tubo foi sobreposto a uma superfície refletora inclinada $22^{\circ}$, ângulo que 
corresponde à latitude de Araraquara. A sequência de procedimentos para iniciar os experimentos e as concentrações iniciais de fármacos foi a mesma que a utilizada nos experimentos sob luz negra, com exceção do volume da solução de fármaco $(750 \mathrm{~mL})$. A intensidade luminosa e a dose UV foram medidas com um radiômetro PMA 2100 (Solar Light Co) na região UVA (320-400 nm). Os experimentos foram realizados entre os meses de junho a agosto das 10 às 14 horas na cidade de Araraquara - Brasil (22ㅇ S $48^{\circ} \mathrm{W}$ ). A irradiância solar nesses experimentos variou entre 1,5 e $2,0 \mathrm{~mW} \mathrm{~cm}^{-2}$. A medida da dose de radiação UV que atinge o sistema por um determinado tempo permite a comparação dos resultados. A Figura 9 mostra a configuração do reator.

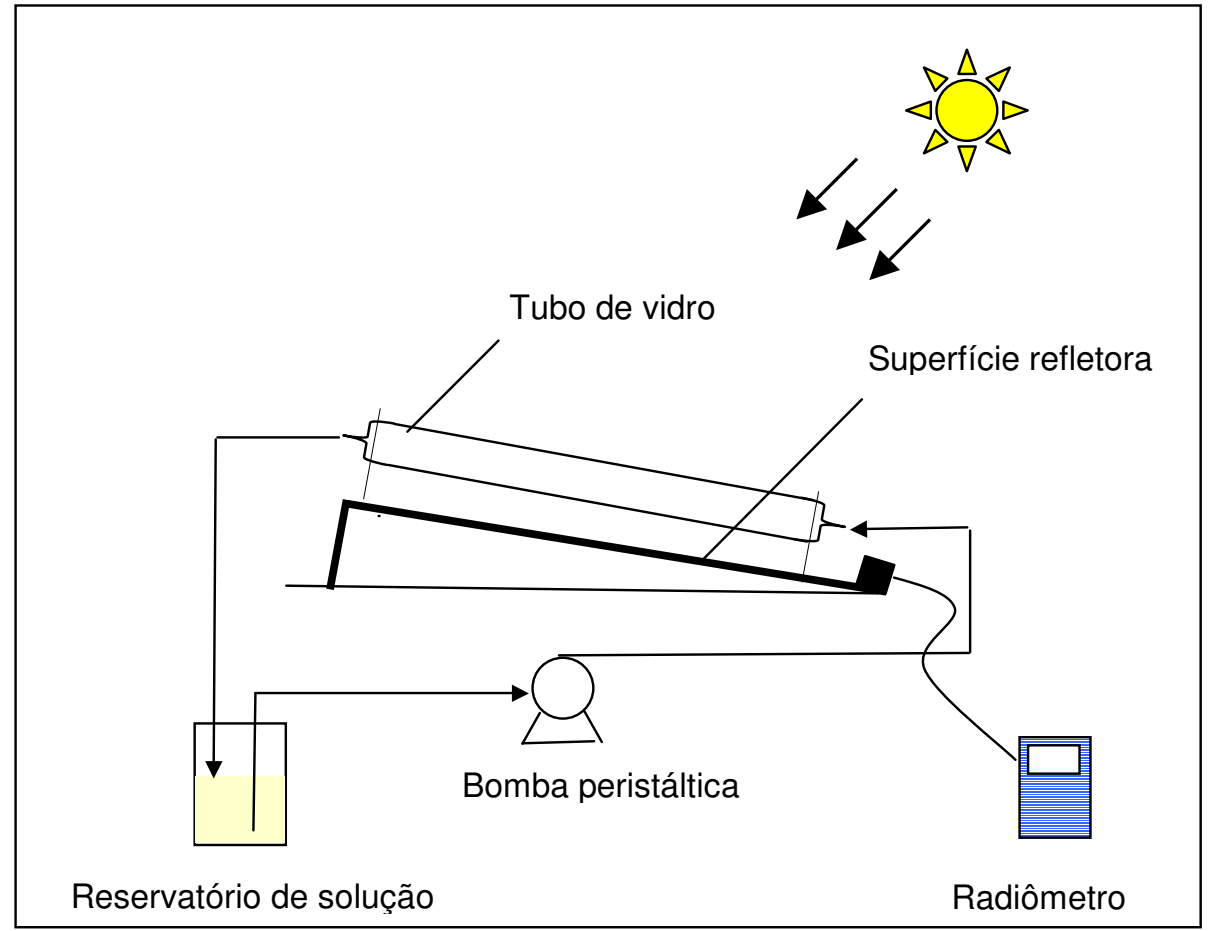

Figura 9. Reator utilizado para fotodegradação dos fármacos sob radiação solar. 
3.4.3 Sistema de degradação do fármaco diazepam baseado em ferro metálico $\left(\mathrm{Fe}^{\circ}\right)$

Os experimentos com as nanopartículas de ferro foram feitos em um béquer de $250 \mathrm{~mL}$. O experimento era iniciado imediatamente após a adição de suspensão de $\mathrm{Fe}^{\circ}$ e de EDTA à solução de diazepam $\left(25 \mathrm{mg} \mathrm{L}^{-1}\right)(150 \mathrm{~mL})$, seguida do borbulhamento de ar e agitação magnética (Agitador Fisatom). $\mathrm{O}$ borbulhamento de ar para fornecimento de $\mathrm{O}_{2}$ foi feito com uma bomba de aquário. Os experimentos na ausência de $\mathrm{O}_{2}$ foram feitos sob borbulhamento de gás nitrogênio. $\mathrm{O}$ pH inicial dos experimentos foi ajustado e mantido com $\mathrm{H}_{2} \mathrm{SO}_{4}$. A manutenção do $\mathrm{pH}$ em alguns experimentos foi feita por meio da adição de ácido ao sistema. As amostras retiradas durante o experimento foram centrifugadas a 2000 rpm (centrífuga Centribio) por 5 minutos, filtradas em membranas de celulose regenerada (Pró-análise) $(0,45 \mu \mathrm{m}$ de poro, $17 \mathrm{~mm}$ de diamêtro) e imediatamente analisadas.

Os experimentos com as micropartículas de ferro de 20 mesh $(800 \mu \mathrm{m})$ (Alfa Aesar) foram feitos em um béquer de $400 \mathrm{~mL}$. O ferro microparticulado foi lavado com ácido $\left(\mathrm{HCl}\right.$ ou $\mathrm{H}_{2} \mathrm{SO}_{4}$ ) na concentração $1 \mathrm{~mol} \mathrm{~L}^{-1}$ (3 $\mathrm{mL}$ de ácido, ultra-som por 15 segundos, seguida da retirada do excesso do ácido) para a solubilização das camadas de óxidos superficiais antes dos experimentos. A lavagem das micropartículas de ferro com ácido e adição deste no sistema implicava em uma diminuição do pH da solução de diazepam de 5 para 3 . No entanto, o pH rapidamente aumentava e mantinha-se entre 5-6 e por isso nenhum ajuste foi feito. $O$ início do experimento se dava pela adição de $\mathrm{Fe}^{\circ}$ à solução do fármaco e EDTA que estavam sob borbulhamento de ar e 
agitação mecânica. A Tabela 5 apresenta as concentrações dos reagentes que foram utilizadas nos experimentos.

Tabela 5. Concentração inicial dos reagentes utilizados no sistema de degradação com $\mathrm{Fe}^{\underline{0}}$

\begin{tabular}{cccc}
\hline Reagente & $\begin{array}{c}\text { Concentração } \\
\left(\mathbf{m o l ~ L}^{-1}\right)\end{array}$ & $\begin{array}{c}\text { Concentração } \\
\left(\mathbf{m g ~ L}^{-1}\right)\end{array}$ & $\begin{array}{c}\text { Concentração } \\
\left(\mathbf{m g ~ L}^{-1} \text { de carbono) }\right.\end{array}$ \\
\hline \multirow{3}{*}{ EDTA } & $80 \times 10^{-6}$ & 29,8 & 9,57 \\
& $200 \times 10^{-6}$ & 74,4 & 24,0 \\
& $300 \times 10^{-6}$ & 112 & 36,0 \\
$320 \times 10^{-6}$ & 119 & 38,4 \\
& $600 \times 10^{-6}$ & 223 & 72,0 \\
\hline & & $\left(\mathbf{g ~ L}^{-1}\right)$ & - \\
$\mathrm{Fe}^{-0}$ & $200 \times 10^{-6}$ & 0,0112 & - \\
& $54,0 \times 10^{-3}$ & 3,02 & - \\
& $89,2 \times 10^{-3}$ & 5,00 & - \\
& $95,0 \times 10^{-3}$ & 5,32 & - \\
& $110 \times 10^{-3}$ & 6,16 & \\
& 0,446 & 25,0 & \\
\hline
\end{tabular}

As amostras retiradas durante o experimento foram filtradas em membranas, conforme já mencionado anteriormente, e o carbono orgânico dissolvido (COD) foi imediatamente determinado. A Figura 10 apresenta uma fotografia do sistema de degradação do fármaco diazepam baseado em ferro metálico.

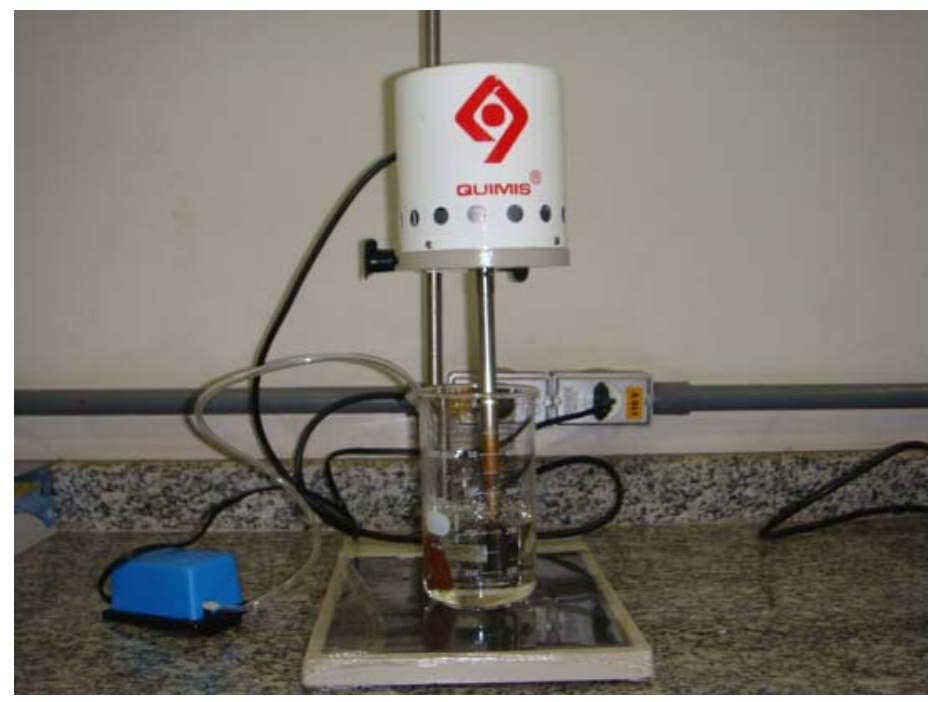

Figura 10. Sistema de degradação baseado em ferro metálico do fármaco diazepam. 


\subsection{Efluente de estação de tratamento de esgoto (ETE)}

Considerando que os processos de degradação de fármacos são estudados com o intuito de uma futura aplicação, neste trabalho foi avaliada a influência da matriz onde normalmente os fármacos residuais são encontrados: efluente de ETE.

O efluente foi coletado na ETE de Araraquara-SP que é de responsabilidade do Departamento Autônomo de Água e Esgotos (DAAE). A ETE é localizada na Rodovia SP 255 às margens do Ribeirão das Cruzes e possui dois módulos com capacidade total de tratamento de 800 litros de esgotos por segundo. Cada módulo é composto de lagoa aerada, onde o esgoto é submetido à agitação mecânica com o intuito de promover a oxigenação e facilitar assim a decomposição da matéria orgânica; lagoa de sedimentação, para decantação das partículas sólidas e lagoa de lodo, onde as partículas sólidas decantadas transformam-se no lodo que será posteriormente descartado em aterro sanitário ou utilizado para adubação agrícola.

A amostra do efluente foi coletada e cedida pelo DAAE no dia 12/06/08, a qual foi mantida sob refrigeração por no máximo 10 dias, até a realização dos experimentos. Segundo os parâmetros avaliados pelo DAAE (Anexo 1), esse efluente atende as normas da resolução 357 do Conselho nacional de meio ambiente (CONAMA) (Brasil, 2005) de lançamento de efluentes de ETE.

O efluente foi fortificado com o analito na mesma concentração utilizada nos experimentos feitos em água deionizada $\left(25,0 \mathrm{mg} \mathrm{L}^{-1}\right)$. As amostras retiradas durante os experimentos de fotodegradação foram filtradas em membranas Millipore $(0,45 \mu \mathrm{m}$ de poro, $13 \mathrm{~mm}$ de diâmetro) antes das análises. 


\subsection{Análises Químicas}

\subsubsection{Determinação de Carbono Orgânico Total (COT)}

A mineralização dos fármacos, conversão a dióxido de carbono e água, foi monitorada por determinações de carbono orgânico total em um analisador de carbono TOC 5000A - Shimadzu. Para a determinação de carbono total, a amostra injetada é carregada para um tubo de combustão a $680^{\circ} \mathrm{C}$ e sofre oxidação catalítica a $\mathrm{CO}_{2}$. Para a determinação de carbono inorgânico a amostra injetada reage com ácido fosfórico $25 \%$, sendo que todo carbono inorgânico é convertido a $\mathrm{CO}_{2}$ e detectado por absorção no infravermelho não dispersivo. O COT é dado pela subtração de carbono total (CT) e carbono inorgânico (Cl). Padrões de $\mathrm{Cl}$ e CT foram preparados e armazenados conforme instruções do manual do equipamento.

A concentração de COT refere-se ao carbono proveniente dos fármacos, produtos orgânicos da degradação e também do oxalato quando da utilização do complexo FeOx. As amostras foram analisadas imediatamente antes dos experimentos e após a retirada de alíquotas de $4,00 \mathrm{~mL}$, sem qualquer tratamento prévio, a menos que seja mencionado. 
3.6.2 Determinação de peróxido de hidrogênio $\left(\mathrm{H}_{2} \mathrm{O}_{2}\right)$

3.6.2.1 Determinação de $\mathrm{H}_{2} \mathrm{O}_{2}$ residual nos experimentos foto-Fenton - método do metavanadato de amônio

A medida de peróxido de hidrogênio residual foi feita com o intuito de verificar o consumo deste oxidante durante os experimentos de fotodegradação dos fármacos pelo processo foto-Fenton e desta forma avaliar a eficiência do processo e/ou a necessidade de sua reposição. Essa medida é feita por meio do monitoramento espectrofotométrico (Espectrofotômetro UV mini-1240/Shimadzu) do íon peroxovanádio, formado pela reação do peróxido de hidrogênio com metavanadato de amônio (Eq. 21), o qual possui máximo de absorção em 450 nm (NOGUEIRA; OLIVEIRA; PATERLINI, 2005). Para esta análise, foram adicionados de 4,00 a $6,00 \mathrm{~mL}$ de amostra em 1,00 mL de metavanadato de amônio e completado o volume com água deionizada para 10,00 $\mathrm{mL}$.

$\mathrm{VO}_{3}{ }^{-}+4 \mathrm{H}^{+}+\mathrm{H}_{2} \mathrm{O}_{2} \rightarrow \mathrm{VO}_{2}{ }^{3+}+3 \mathrm{H}_{2} \mathrm{O}$

3.6.2.2 Determinação de $\mathrm{H}_{2} \mathrm{O}_{2}$ gerado no sistema de degradação baseado em ferro metálico - método da $D P D$

Uma vez que o mecanismo proposto para as reações de oxidação no sistema Fe을TA $/ \mathrm{O}_{2}$ envolvem a formação de $\mathrm{H}_{2} \mathrm{O}_{2}$, foi feito o estudo de sua determinação. Com esse objetivo, buscou-se um método de quantificação com sensibilidade suficiente 
para determinar $\mathrm{H}_{2} \mathrm{O}_{2}$ em baixas concentrações. Dos métodos relatados na literatura o desenvolvido por Bader e colaboradores (1988) foi o que apresentou limite de quantificação compatível com a faixa que esperava-se encontrar nesse estudo ( $\mu \mathrm{mol}$ $\left.\mathrm{L}^{-1}\right)$. Este método baseia-se na oxidação da enzima peroxidase de raiz forte (horseradish peroxidase) (POD) pelo $\mathrm{H}_{2} \mathrm{O}_{2}$ para um estado de alta valência o qual por sua vez promove a oxidação de duas moléculas de N,N-dietil-p-fenilenediamina (DPD) para o radical cátion $\mathrm{DPD}^{\circ+}$ o qual é estabilizado por ressonância (Esquema 2) e apresenta absorção máxima em 551 nm.
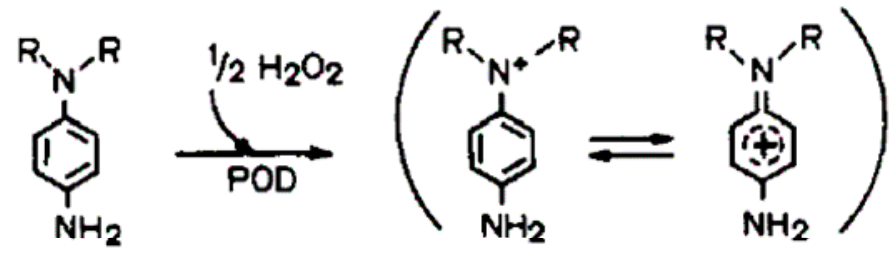

DPD

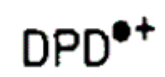

Esquema 2. Reação base do método de determinação de $\mathrm{H}_{2} \mathrm{O}_{2}$ desenvolvido por Bader e colaboradores, 1988.

O procedimento de análise consistiu em misturar na cubeta de $1 \mathrm{~cm}$ de caminho ótico, $0,4 \mathrm{~mL}$ de tampão fostato $\mathrm{pH} 6\left(0,5 \mathrm{~mol} \mathrm{~L}^{-1}\right), 0,1 \mathrm{~mL}$ de bipiridina $\left(0,01 \mathrm{~mol} \mathrm{~L}^{-1}\right), 2$ $\mathrm{mL}$ de amostra; $20 \mu \mathrm{L}$ de EDTA $\left(0,1 \mathrm{~mol} \mathrm{~L}^{-1}\right), 30 \mu \mathrm{L}$ de DPD $\left(1 \%\right.$ em $\left.0,1 \mathrm{~mol} \mathrm{~L}^{-1} \mathrm{H}_{2} \mathrm{SO}_{4}\right)$ e $25 \mu \mathrm{L}$ de HRP (50 $\left.\mathrm{g} \mathrm{mL}^{-1}\right)$, nesta ordem (volume total 2,58 $\mathrm{mL}$ ) e com subsequente medida de absorbância em 551 nm. 
3.6.3 Cromatografia Líquida de Alta eficiência acoplada ao detector de arranjo de diodos (CLAE-UV)

A oxidação dos fármacos durante os processos de degradação foi verificada por meio do decaimento de sua concentração a qual foi monitorada pela técnica de Cromatografia Líquida de Alta Eficiência (CLAE-UV) em fase reversa com detecção por absorção no ultravioleta. O equipamento utilizado foi um cromatógrafo Varian ProStar 230 com detector UV-Vis ProStar 310, coluna Luna $5 \mu$ C-18 fase reversa $(250 \times 4,60$ $\mathrm{mm}$ ) (Phenomex) mantida em forno a $40^{\circ} \mathrm{C}$.

As condições cromatográficas utilizadas foram:

$\checkmark$ Diazepam: fase móvel metanol:acetonitrila:água (45:25:30) vazão 0,8 mL $\min ^{-1}$, comprimento de onda de detecção $230 \mathrm{~nm}$.

$\checkmark$ Propranolol: fase móvel $0,02 \mathrm{~mol} \mathrm{~L}^{-1} \mathrm{KH}_{2} \mathrm{PO}_{4}$ :acetonitrila (72:28) vazão 1,2 $\mathrm{mL} \mathrm{min}{ }^{-1}$, comprimento de onda de detecção $215 \mathrm{~nm}$.

$\checkmark$ Lincomicina: fase móvel 0,02 mol L-1 $\mathrm{KH}_{2} \mathrm{PO}_{4}$ :acetonitrila:MeOH (70:15:15) vazão $0,8 \mathrm{~mL} \mathrm{~min}{ }^{-1}$, comprimento de onda de detecção $206 \mathrm{~nm}$.

3.6.4 Cromatografia Líquida de Alta Eficiência acoplada à espectrometria de massas (CLAE-EM)

A cromatografia líquida acoplada à espectrometria de massas é uma técnica útil para identificar intermediários de degradação. A identificação destes intermediários permite propor a rota de degradação do contaminante.

Para a identificação dos intermediários formados durante a degradação dos fármacos foram feitos experimentos de degradação em uma condição não otimizada 
(menores concentrações de $\mathrm{Fe}$ e $\mathrm{H}_{2} \mathrm{O}_{2}$ ), pois na melhor condição os intermediários são formados e rapidamente degradados impossibilitando sua detecção.

O primeiro equipamento utilizado na identificação dos intermediários de degradação do DZP foi o UltroTOFQ - ESI TOF (Bruker Daltonics) com interface electrospray operando em modo positivo de ionização e detector de massas de tempo de vôo (Time of Flight - TOF). A separação cromatográfica desses intermediários foi feita por cromatografia líquida de alta eficiência com fase móvel composta por metanol:água 60:40 a uma vazão de 0,8 $\mathrm{mL} \mathrm{min}^{-1}$ e volume de injeção $20 \mu \mathrm{L}$ em uma coluna de fase reversa C-18 $5 \mu$ de tamanho de partícula $(4,6$ × $250 \mathrm{~mm})$ (Luna Phenomex).

O segundo equipamento utilizado para a identificação dos intermediários de degradação de DZP e também dos intermediários do PPN e LCM foi o cromatógrafo Nano Acquity Ultra Performance (Waters), disponibilizado pelo Laboratório Nacional de Luz Síncrotron (LNLS). A fase móvel utilizada para os três fármacos foi solução aquosa de ácido fórmico $0,1 \%$ e solução de metanol com $0,1 \%$ ácido fórmico em diferentes proporções: DZP 45:55; PPN 68:32 e LCM 83:13 a uma vazão de 0,6 $\mu \mathrm{L} \mathrm{min}{ }^{-1}$ e volume de injeção $6 \mu \mathrm{L}$ em uma coluna capilar de fase reversa $C_{18}(75 \mu \mathrm{m} \times 100 \mathrm{~mm})$ (NanoAcquity UPLC, Waters). O espectrômetro de massas foi o Micromass Q-TOF (Waters) com interface electrospray operando no modo positivo, com energia de colisão de $10 \mathrm{eV}$ e voltagem do cone $100 \mathrm{~V}$. O monitoramento da relação massa/carga $(\mathrm{m} / \mathrm{z})$ foi feito de 30 até 500 para o DZP e PPN e de 30 até 700 para a LCM e o processamento dos dados foi feito no programa Masslynx versão 4.0. 


\section{RESULTADOS E DISCUSSÃo}

\subsection{Avaliação da confiabilidade analítica do método de determinação dos fármacos}

Para monitorar a concentração dos fármacos durante os experimentos de fotodegradação foi utilizada a técnica de CLAE. A condição cromatográfica testada para DZP, PPN e LCM foi baseada no trabalho de Prado e colaboradores (2005), El-saharty e colaboradores (2003) e Augugliaro e colaboradores (2005), respectivamente.

Para o DZP a fase móvel metanol:acetonitrila:água na proporção 45:25:30 com vazão de $0,8 \mathrm{~mL} \mathrm{~min}^{-1}$ foi testada e mantida. $O$ tempo de retenção $\left(\mathrm{t}_{\mathrm{r}}\right)$ para o referido fármaco se manteve em aproximadamente 8,5 minutos, com monitoramento no comprimento de onda máximo de absorção de $230 \mathrm{~nm}$.

Para o fármaco PPN a fase móvel utilizada foi $0,02 \mathrm{~mol} \mathrm{~L}^{-1} \mathrm{KH}_{2} \mathrm{PO}_{4}$ :acetonitrila na proporção (80:20) e vazão de $3 \mathrm{~mL} \mathrm{~min}^{-1}$. Com o objetivo de diminuir o consumo de solventes utilizou-se vazão de $1 \mathrm{~mL} \mathrm{~min}^{-1}$, no entanto o tempo de retenção do analito foi de 25 minutos e o pico apresentava encaudamento. $O$ encaudamento do pico pode ser provocado por silanóis residuais da coluna que interagem com o analito dificultando a eluição. Dessa forma foi utilizada uma concentração maior de tampão $\mathrm{KH}_{2} \mathrm{PO}_{4}(0,03 \mathrm{e}$ $\left.0,04 \mathrm{~mol} \mathrm{~L}^{-1}\right)$ em outras proporções com acetonitrila, na tentativa de diminuir a interação desses grupos livres com o PPN. No entanto, não foi observada melhora significativa na simetria do pico, e levando em consideração que altas concentrações de tampão podem danificar a coluna, a concentração inicial $\left(0,02 \mathrm{~mol} \mathrm{~L}^{-1}\right)$ foi mantida. A mudança da vazão de $1 \mathrm{~mL} \min ^{-1}$ para $1,2 \mathrm{~mL} \min ^{-1}$ foi o que promoveu a diminuição do 
encaudamento de maneira mais significativa. Portanto, a condição cromatográfica para a determinação de PPN ficou assim definida: $0,02 \mathrm{~mol} \mathrm{~L}^{-1} \mathrm{KH}_{2} \mathrm{PO}_{4}$ :acetonitrila na proporção 72:28 e comprimento de onda de deteç̧ão $215 \mathrm{~nm}$, com tempo de retenção de 7,7 minutos.

Para o antibiótico LCM a condição cromatográfica avaliada foi fase móvel 0,02 mol L-1 $\mathrm{KH}_{2} \mathrm{PO}_{4}$ :acetonitrila:metanol (80:10:10), comprimento de onda de deteç̧ão 206 $\mathrm{nm}$ e vazão de $0,5 \mathrm{~mL} \mathrm{~min}^{-1}$. No entanto, nessa condição a linha base apresentou-se muito instável, pois o tampão utilizado também absorve nesse comprimento de onda. Dessa forma, diminuiu-se a proporção de tampão para $60 \%$, mas devido à maior força de eluição resultante, o tempo de retenção diminuiu muito (de 10 para 6 minutos). Assim foi testada uma condição intermediária: fase móvel $0,02 \mathrm{~mol} \mathrm{~L}^{-1}$ $\mathrm{KH}_{2} \mathrm{PO}_{4}$ :acetonitrila:metanol (70:15:15), comprimento de onda $206 \mathrm{~nm}$ e vazão de 0,8 $\mathrm{mL} \min ^{-1}$. Essa condição resultou em um pico simétrico e com tempo de retenção de 9 minutos e portanto, foi mantida para as análises.

A Figura 11 apresenta os espectros de absorção no UV-vis dos fármacos estudados. 

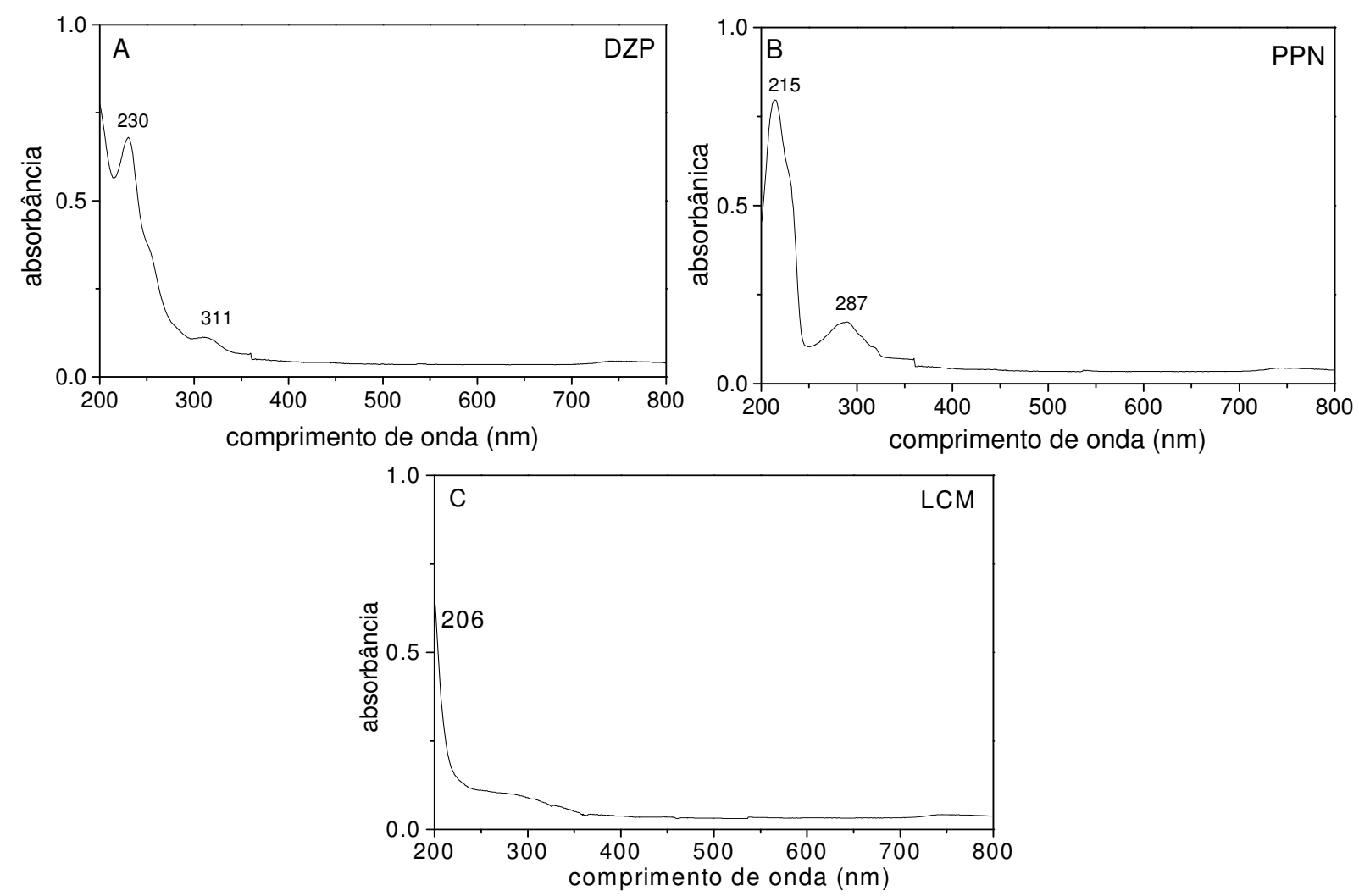

Figura 11. Espectro de absorção no UV-vis de diazepam (A), propranolol (B) e lincomicina (C) em água deionizada. Concentração dos fármacos $[\mathrm{DZP}]=[\mathrm{PPN}]=5,0 \mathrm{mg} \mathrm{L}^{-1} ;[\mathrm{LCM}]$ $=25,0 \mathrm{mg} \mathrm{L}^{-1}$.

Para avaliar a confiabilidade dos métodos propostos foi feito o estudo de linearidade. A linearidade permite verificar se os resultados obtidos são diretamente proporcionais à concentração do fármaco, dentro de uma faixa de concentração de trabalho. Para tanto, curvas analíticas foram feitas com soluções-padrão dos fármacos estudados (Fig. 12) e como pode-se verificar por meio dos coeficientes de correlação (R) existe linearidade nas faixas de concentrações testadas. 


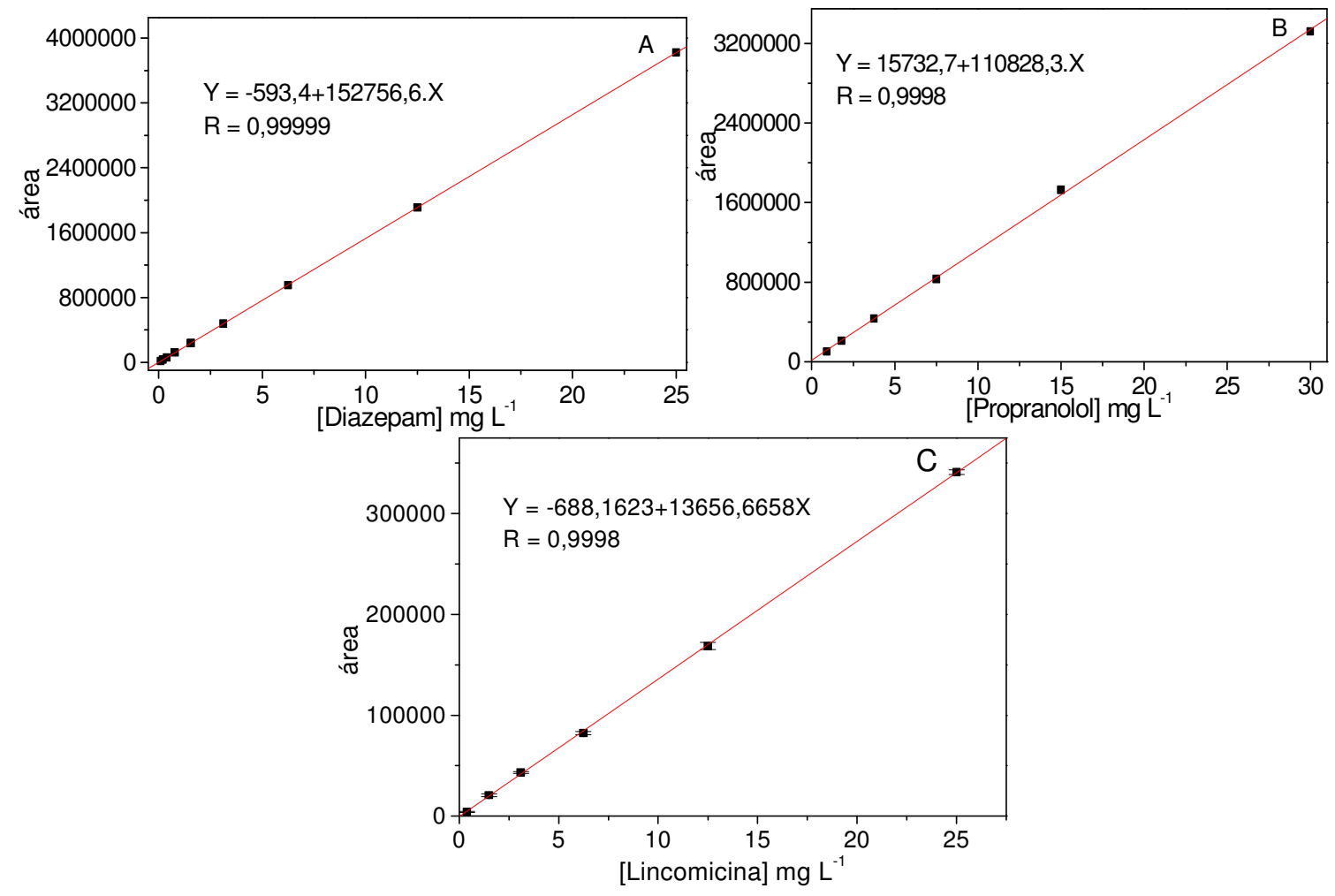

Figura 12. Curvas analíticas preparadas com soluções-padrão com concentrações de 0,0976 a $25,0 \mathrm{mg} \mathrm{L}^{-1}$ para o fármaco DZP $(\mathrm{A})$ concentrações de 0,937 a $30,0 \mathrm{mg} \mathrm{L}^{-1}$ para o PPN (B) e de 0,390 a $25,0 \mathrm{mg} \mathrm{L}^{-1}$ para a LCM.

Para a confirmação deste resultado foi feita também uma relação entre o sinal analítico/concentração do fármaco versus log de sua concentração (Fig. 13) e todos os pontos testados, com exceção do primeiro ponto para o fármaco LCM, encontram-se dentro de um limite aceitável entre 95 e 105\%, conforme sugerido na literatura (RIBANI et al., 2004). 

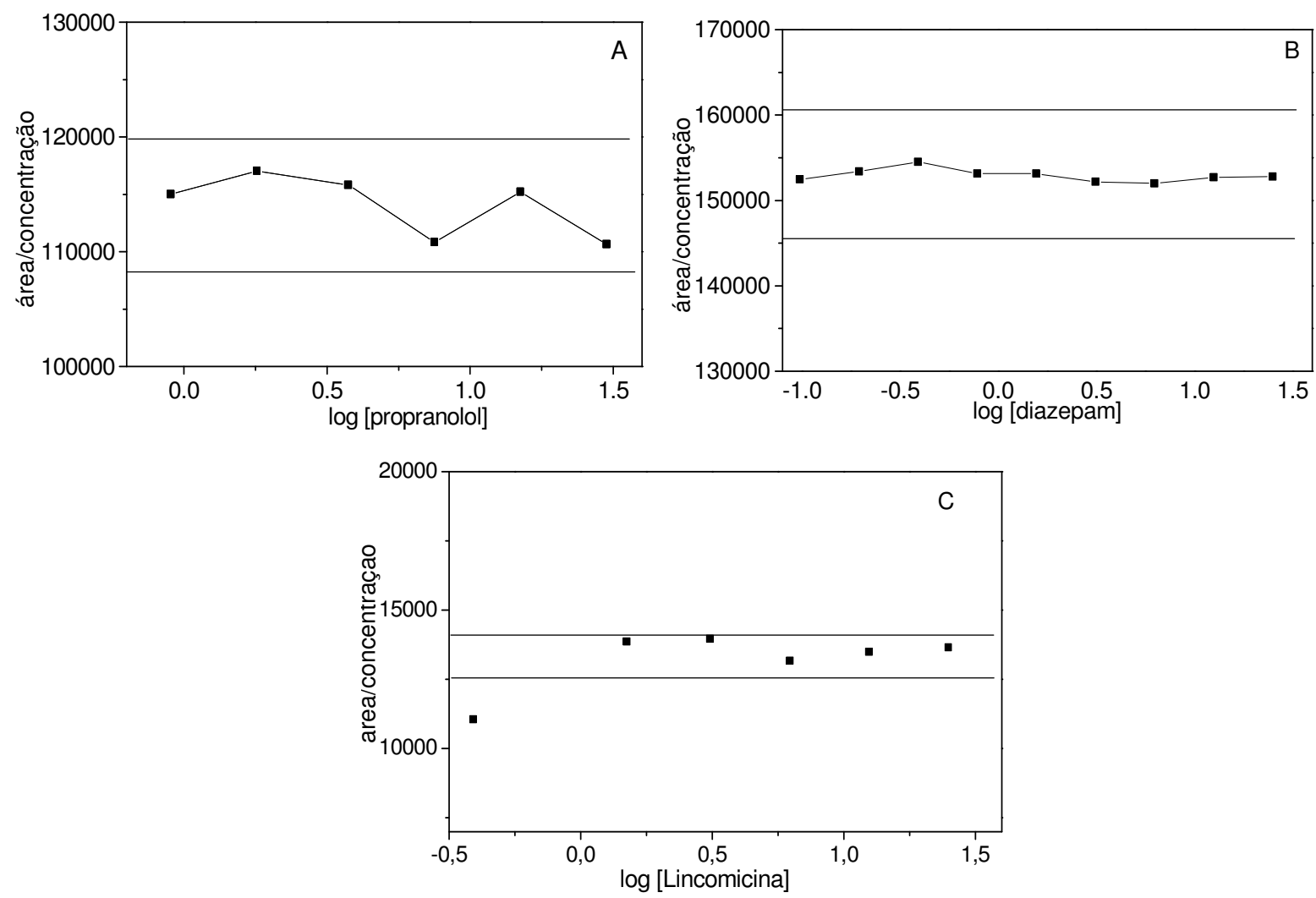

Figura 13. Gráfico da razão sinal/concentração versus concentração em escala logarítmica para o fármaco DZP (A), PPN (B), e LCM (C).

Outro parâmetro que permite avaliar a confiabilidade dos dados a serem obtidos, além da linearidade, é o limite de detecção (LD) e de quantificação (LQ). O LD representa a menor concentração do fármaco detectada enquanto o LQ é a menor concentração que pode ser quantificada. Para esses cálculos utilizou-se os dados da curva analítica, conforme recomendado pela IUPAC (CURRIE, 1999), LD = 3 x s/S e LQ = 10 x s/S, onde s é a estimativa do desvio padrão da curva analítica e S é a inclinação ou coeficiente angular da curva analítica. A tabela 6 apresenta os LD e LQ dos fármacos estudados. 
Tabela 6. Equações das curvas analíticas, intervalo de linearidade, coeficientes de correlação (R), limite de detecção (LD) e de quantificação (LQ) para os fármacos estudados.

\begin{tabular}{cccccc}
\hline Fármaco & Curva analítica & $\begin{array}{c}\text { Intervalo de } \\
\text { linearidade }\left(\mathbf{m g ~ L}^{-1}\right)\end{array}$ & $\mathbf{R}(\mathbf{n}=6)$ & $\begin{array}{c}\text { LD } \\
\left(\mathbf{~ m ~ L ~ L}^{-1}\right)\end{array}$ & $\begin{array}{c}\text { LQ } \\
\left(\mathbf{m g ~ L}^{-1}\right)\end{array}$ \\
\hline Diazepam & $\mathrm{Y}=-593,4+1,52 \times 10^{5} . \mathrm{X}$ & $25,0-0,097$ & 0,9999 & 0,036 & 0,120 \\
Propranolol & $\mathrm{Y}=15732,6+1,10 \times 10^{5} . \mathrm{X}$ & $30,0-0,94$ & 0,9997 & 0,786 & 2,594 \\
Lincomicina & $\mathrm{Y}=-688,2+1,36 \times 10^{5} . \mathrm{X}$ & $25,0-1,50$ & 0,9998 & 0,285 & 0,940 \\
\hline
\end{tabular}

\subsection{Degradação dos fármacos mediada pelo processo foto-Fenton}

4.2.1 Procedimentos testados para interromper a reação de Fenton

4.2.1.1 Extração em fase sólida (EFS)

O monitoramento da eficiência do processo de degradação é feito por meio de análise das amostras retiradas dos experimentos em tempos previamente estabelecidos. Como a reação de Fenton necessita ser interrompida para preservar o analito até o momento da análise, faz-se necessária a utilização de procedimentos que possibilitem sua interrupção. A extração em fase sólida é uma técnica de separação líquido-sólido que permite o isolamento do analito de interesse para posterior análise.

A técnica EFS foi avaliada para o fármaco propranolol, utilizando cartuchos Sep Pack C18 (Waters). O condicionamento foi feito com 5,0 mL de metanol e em seguida $3,00 \mathrm{~mL}$ de água, após esse procedimento $5,0 \mathrm{~mL}$ de solução de PPN foram percolados pelo cartucho e a eluição foi feita com $5,0 \mathrm{~mL}$ de metanol. A Tabela 7 mostra os 
resultados de recuperação do fármaco, os quais não apresentaram repetibilidade indicando que não há precisão para os níveis de concentração testados.

Tabela 7. Recuperação de PPN em água com cartuchos Sep-Pack C18

\begin{tabular}{cccc}
\hline PPN (mg L-1 $)$ & $\begin{array}{c}\text { Recuperação } \\
(\%)\end{array}$ & $\begin{array}{c}\text { Média } \pm \text { desvio } \\
\text { padrão }\end{array}$ & $\begin{array}{c}\text { Coeficiente de } \\
\text { variação (\%) }\end{array}$ \\
\hline & 102,5 & & \\
25,00 & 57,19 & $90,56 \pm 16,91$ & 19 \\
& 112,0 & & \\
\hline & 44,09 & & \\
10,00 & 109,6 & $67,94 \pm 36,19$ & 53 \\
& 50,15 & & \\
\hline
\end{tabular}

Com base na literatura, outro procedimento de EFS foi testado. A modificação foi feita na etapa da eluição onde foi adicionado $1 \%$ de ácido trifluoracético (TFA) ao metanol (MARTIN et al., 2004). Como pode-se observar nos dados da Tabela 8 houve repetibilidade dos resultados e consequentemente precisão dos dados obtidos utilizando esse nova forma de eluição.

Tabela 8. Recuperação de PPN em água, eluição com metanol - 1\%TFA.

\begin{tabular}{|c|c|c|c|}
\hline PPN $\left(\mathrm{mg} \mathrm{L}^{-1}\right)$ & $\begin{array}{c}\text { Recuperação } \\
(\%)\end{array}$ & $\begin{array}{l}\text { Média } \pm \text { desvio } \\
\text { padrão }\end{array}$ & $\begin{array}{l}\text { Coeficiente de } \\
\text { variação(\%) }\end{array}$ \\
\hline 24,00 & $\begin{array}{l}100,4 \\
97,77 \\
103,8\end{array}$ & $100,6 \pm 3,0$ & 3 \\
\hline 9,40 & $\begin{array}{l}98,71 \\
110,4 \\
109,8\end{array}$ & $106,3 \pm 6,6$ & 6 \\
\hline 5,00 & $\begin{array}{l}102,0 \\
100,4 \\
102,6\end{array}$ & $101,6 \pm 1,1$ & 1 \\
\hline
\end{tabular}

A utilização da técnica de EFS para a interrupção da reação de Fenton é bem estabelecida na literatura (MELO; BAUTITZ; NOGUEIRA, 2008), entretanto o custo dos 
cartuchos é elevado. Dessa forma, considerando os custos dos cartuchos e também com o intuito de avaliar a eficiência da enzima catalase em promover a decomposição de $\mathrm{H}_{2} \mathrm{O}_{2}$ para interromper a reação de Fenton foram feitos estudos para verificar a possibilidade de utilização dessa enzima.

\subsubsection{Enzima catalase}

A catalase é uma enzima que promove a decomposição de $\mathrm{H}_{2} \mathrm{O}_{2}$ e por isso vem sendo utilizada para interromper a reação de Fenton (ARSLAN-ALATON, 2007). Malato e colaboradores (2002) utilizaram catalase para decompor $\mathrm{H}_{2} \mathrm{O}_{2}$ residual de amostras de experimento de degradação de pesticidas por processo foto-Fenton. A concentração de catalase utilizada foi $2 \mathrm{mg} \mathrm{L}^{-1}$ e segundo os autores essa concentração é suficiente para decompor até $20 \mathrm{mmol} \mathrm{\textrm {L } ^ { - 1 }}$ de $\mathrm{H}_{2} \mathrm{O}_{2}$. $\mathrm{O}$ procedimento consiste em retirar as amostras do experimento, fazer o ajuste do $\mathrm{pH}$ entre 6-7 com $\mathrm{NaOH}$ para a precipitação dos íons ferro e em seguida adicionar catalase na concentração descrita e manter a amostra sob agitação por 10 minutos.

Alguns testes preliminares foram feitos com o intuito de verificar a velocidade e a eficácia da catalase na decomposição de $\mathrm{H}_{2} \mathrm{O}_{2}$. Em uma solução de $\mathrm{H}_{2} \mathrm{O}_{2} 20,0$ mmol L-1 foram adicionadas diferentes concentrações de catalase que variaram entre $2,0 \mathrm{mg} \mathrm{L}^{-1}$ e $16 \mathrm{mg} \mathrm{L}^{-1}$. A concentração de $\mathrm{H}_{2} \mathrm{O}_{2}$ foi monitorada pelo método espectrofotométrico pela reação com metavanadato, conforme descrito anteriormente.

No entanto verificou-se que mesmo utilizando a maior concentração de catalase (16 $\mathrm{mg} \mathrm{L}^{-1}$ ) somente após 5 minutos de reação a concentração de $\mathrm{H}_{2} \mathrm{O}_{2}$ encontrava-se abaixo do limite de detecção do método $\left(\mathrm{LD}=0,143 \mathrm{mmol} \mathrm{L}^{-1}\right)$. Portanto não houve 
aumento na velocidade de decomposição de $\mathrm{H}_{2} \mathrm{O}_{2}$ proporcional à concentração de catalase.

Para avaliar a eficiência desse procedimento em um experimento de fotodegradação foi utilizado o fármaco diazepam $\left(25 \mathrm{mg} \mathrm{L}^{-1}\right)$, com os reagentes de Fenton, $\mathrm{Fe}\left(\mathrm{NO}_{3}\right)_{3} \quad 0,200 \mathrm{mmol} \mathrm{L}^{-1} \mathrm{e} \mathrm{H}_{2} \mathrm{O}_{2} 20,0 \mathrm{mmol} \mathrm{L}^{-1}$. Foram retiradas duas amostras desse experimento, no tempo 2 e 16 minutos, sendo que essas amostras foram divididas em duas alíquotas, uma seguiu imediatamente para a análise cromatográfica. Após o ajuste de $\mathrm{pH}$ e adição da catalase em excesso $\left(3 \mathrm{mg} \mathrm{L}^{-1}\right)$, para garantir a total decomposição de $\mathrm{H}_{2} \mathrm{O}_{2}$, e agitação magnética por 10 minutos a outra alíquota foi armazenada sob refrigeração. A Tabela 9 apresenta os resultados das amostras mantidas sob refrigeração por um determinado período e posteriormente analisadas. A concentração de DZP foi mantida praticamente inalterada, mesmo após 40 dias de armazenamento. Nas amostras controle armazenadas sob refrigeração, mas sem ajuste de pH e sem a adição de catalase, a concentração de DZP diminuiu 60\% após 1 hora de armazenagem. Nas amostras controle onde não foi adicionada catalase mas foi feito o ajuste de pH a concentração de DZP não se alterou significativamente após 1 hora de armazenagem. 
Tabela 9. Monitoramento da concentração de DZP após adição de catalase.

\begin{tabular}{|c|c|c|}
\hline $\begin{array}{c}\text { Tempo } \\
\text { experimento (min.) }\end{array}$ & $\begin{array}{c}\text { Tempo armazenagem } \\
\text { (hora) }\end{array}$ & {$[D Z P] \mathrm{mg} \mathrm{L}^{-1}$} \\
\hline \multirow[t]{7}{*}{2} & 0 & 22,1 \\
\hline & 0,5 & 21,4 \\
\hline & 5 & 22,5 \\
\hline & 22 & 22,0 \\
\hline & 240 & 22,1 \\
\hline & 360 & 22,2 \\
\hline & 960 & 22,1 \\
\hline \multirow[t]{7}{*}{16} & 0 & 9,59 \\
\hline & 0,5 & 9,70 \\
\hline & 5 & 9,43 \\
\hline & 22 & 9,52 \\
\hline & 240 & 9,69 \\
\hline & 360 & 9,31 \\
\hline & 960 & 8,99 \\
\hline
\end{tabular}

$\mathrm{O}$ procedimento que utiliza catalase para promover a decomposição de $\mathrm{H}_{2} \mathrm{O}_{2}$ e consequentemente interromper a reação de Fenton se mostrou eficaz e apresenta vantagens em relação aos cartuchos EFS, como rapidez, eliminação do fator recuperação e boa relação custo/benefício, além de promover a preservação da amostra como um todo. Portanto esse procedimento foi escolhido para preservação das amostras dos fármacos estudados até o momento da análise por CLAE-UV. Vale 
ressaltar que a enzima catalase foi adicionada somente nas amostras analisadas por cromatografia e não nas amostras de COT, visto que a adição da catalase implica em adição de matéria orgânica na amostra.

4.2.2 Fotodegradação de diazepam por processo foto-Fenton sob radiação artificial (lâmpada de luz negra)

A espécie de ferro utilizada nos experimentos é um parâmetro importante do processo de fotodegradação, pois cada composto-alvo pode apresentar diferentes interações com o ferro e com isso favorecer ou não o tratamento (NOGUEIRA; SILVA; TROVÓ, 2005).

Nesse trabalho foram testados ferro livre, $\left.\mathrm{FeNO}_{3}\right)_{3}$, e ferro complexado, $\mathrm{FeOx}$, na concentração $0,20 \mathrm{mmol} \mathrm{L}^{-1}$. Concentrações maiores de ferro não foram testadas pois segundo a resolução do CONAMA no 357 de 17 de março de 2005 (BRASIL, 2005), o limite de ferro para descarte de efluentes é $15 \mathrm{mg} \mathrm{L}^{-1}$ o que corresponde a $0,267 \mathrm{mmol}$ $\mathrm{L}^{-1}$. Assim uma concentração superior à citada ultrapassaria o limite permitido no Brasil. Evidentemente o ferro pode ser separado do efluente pela basificação do meio e consequente precipitação na forma de seus hidróxidos, entretanto isso requer custos adicionais o que contraria os propósitos desse trabalho. Concentrações menores normalmente resultam em menor velocidade de reação com consequente aumento no tempo de tratamento (GOGATE; PANDIT, 2004).

Os resultados apresentados na Figura 14A indicaram que $\mathrm{FeOx}$ mostrou-se mais eficiente no processo de degradação pois em 8 minutos de tratamento ocorreu praticamente total oxidação do fármaco, enquanto que com $\mathrm{Fe}\left(\mathrm{NO}_{3}\right)_{3}$ isso só ocorreu 
em 20 minutos de tratamento. Conforme já mencionado, o $\mathrm{FeOx}$ possui rendimento quântico de geração de $\mathrm{Fe}^{2+}(1,24$ a 300 nm) (HATCHARD; PARKER, 1956) muito maior do que espécies hidroxiladas de ferro e consequentemente, proporciona maior degradação. Além disso, o ferro livre pode ser complexado por substâncias nitrogenadas, como é o caso do DZP, ficando dessa forma indisponível para reagir com $\mathrm{H}_{2} \mathrm{O}_{2}$, diminuindo assim a formação de radical hidroxila e consequentemente a degradação do composto-alvo (NOGUEIRA; SILVA; TROVÓ, 2005).

O estudo cinético das reações de fotodegradação demonstrou que na presença de $\mathrm{FeOx}$ a reação seguiu cinética de pseudo-primeira ordem, pois apresentou relação linear no gráfico do logaritmo natural da concentração do fármaco versus o tempo de degradação. Dessa forma, foi possível obter a constante de velocidade inicial da reação (k), a qual foi $0,39 \mathrm{~min}^{-1}(\mathrm{R}=0,990)$. Na presença de $\mathrm{Fe}\left(\mathrm{NO}_{3}\right)_{3}$.a reação seguiu cinética de ordem zero, na qual a velocidade é independente da concentração dos reagentes, e a constante de velocidade inicial obtida foi de $1,3 \mathrm{mg} \mathrm{L}^{-1} \mathrm{~min}^{-1}(R=0,999)$.

Em relação à remoção de COT (Fig. 14B), $\mathrm{Fe}\left(\mathrm{NO}_{3}\right)_{3}$ removeu cerca de $80 \%$, enquanto que com $\mathrm{FeOx}$ a remoção ultrapassou $90 \%$ após 60 minutos de tratamento. Nos experimentos controle feitos para avaliar a fotólise do fármaco e a influência de $\mathrm{H}_{2} \mathrm{O}_{2}$ na ausência de ferro no processo de degradação, observou-se que não houve diminuição significativa da concentração de DZP e nem da concentração de COT (Figura 14). Pode-se observar também que embora a reação de Fenton tenha promovido oxidação de DZP comparável à obtida em presença de radiação, no processo foto-Fenton, a remoção de COT promovida pela reação Fenton foi muito inferior à obtida em presença de radiação. 

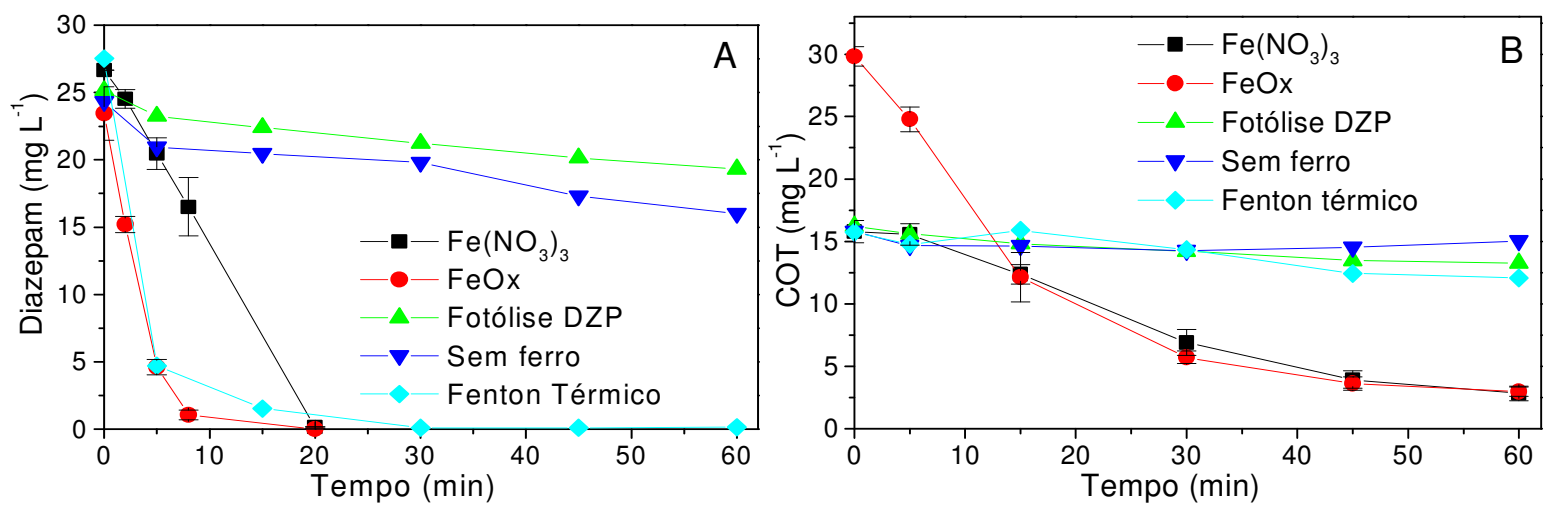

Figura 14. Influência da utilização de ferro livre ou complexado na oxidação de DZP (A), e na remoção de COT $(B)$, sob radiação de lâmpada de luz negra. Condições iniciais: $[D Z P]=25,0 \mathrm{mg} \mathrm{L}^{-1} ;[\mathrm{FeOx}]=\left[\mathrm{Fe}\left(\mathrm{NO}_{3}\right)_{3}\right]=0,20 \mathrm{mmol} \mathrm{L}^{-1} ;\left[\mathrm{H}_{2} \mathrm{O}_{2}\right]=5,0 \mathrm{mmol} \mathrm{L}^{-1}$. Fenton térmico $=\left[\mathrm{FeSO}_{4}\right]=0,20 \mathrm{mmol} \mathrm{L}^{-1} ;\left[\mathrm{H}_{2} \mathrm{O}_{2}\right]=5,0 \mathrm{mmol} \mathrm{L}^{-1}$; sem irradiação.

A concentração de $\mathrm{H}_{2} \mathrm{O}_{2}$ é um fator extremamente importante para o processo de fotodegradação, pois tanto a falta como o excesso desse reagente pode diminuir a eficiência do tratamento. Na degradação de dietil ftalato por processo foto-Fenton foi observado que na concentração $5,00 \times 10^{-4} \mathrm{~mol} \mathrm{~L}^{-1}$ de $\mathrm{H}_{2} \mathrm{O}_{2}$ a degradação do composto-alvo ultrapassava $75 \%$ e que ao dobrar a concentração de $\mathrm{H}_{2} \mathrm{O}_{2}$ a porcentagem de degradação diminuía para 58\% (YANG et al., 2005), demonstrando que há uma concentração ótima de $\mathrm{H}_{2} \mathrm{O}_{2}$ que precisa ser estudada para cada composto-alvo.

Para avaliar a influência da concentração de $\mathrm{H}_{2} \mathrm{O}_{2}$ na degradação de DZP foram testadas três concentrações 1,$00 ; 5,00$ e $10,0 \mathrm{mmol}^{-1}$, sendo a razão molar $\mathrm{Fe}: \mathrm{H}_{2} \mathrm{O}_{2}$ $1: 5,1: 25,1: 50$ respectivamente. Os resultados demonstraram que não houve diferenças significativas entre as três concentrações estudadas e que praticamente total oxidação foi promovida em 10 minutos de tratamento (Figura 15A). 
Com relação à remoção de COT, a concentração $1,00 \mathrm{mmol} \mathrm{L}^{-1}$ apresentou a menor porcentagem de mineralização (73\%) em 60 minutos, enquanto que nas maiores concentrações de $\mathrm{H}_{2} \mathrm{O}_{2}$, a porcentagem de mineralização ultrapassou $90 \%$ no mesmo tempo de tratamento (Figura 15B).

No experimento feito com $\mathrm{FeOx}$, na ausência de $\mathrm{H}_{2} \mathrm{O}_{2}$ ocorreu praticamente a total oxidação do fármaco e $50 \%$ de remoção de COT em 60 minutos. No entanto, vale ressaltar que a remoção de COT mencionada corresponde à fotólise de $\mathrm{FeOx}$, que ocorre em 30 minutos de irradiação (dado não mostrado). A oxidação de DZP com FeOx pode estar sendo promovida pelos radicais formados durante a fotólise do $\mathrm{FeOx}$ (Eq. 9-11).

A oxidação de DZP com $\mathrm{Fe}\left(\mathrm{NO}_{3}\right)_{3}$ na ausência de $\mathrm{H}_{2} \mathrm{O}_{2}$ foi aproximadamente $50 \%$ e sem remoção de COT em 60 minutos de tratamento. Neste caso a oxidação pode estar sendo promovida por radicais hidroxila formados durante a irradiação de espécies hidroxiladas de ferro, conforme já mencionado (Eq. 7) (FAUST; HOIGNÉ, 1990). 

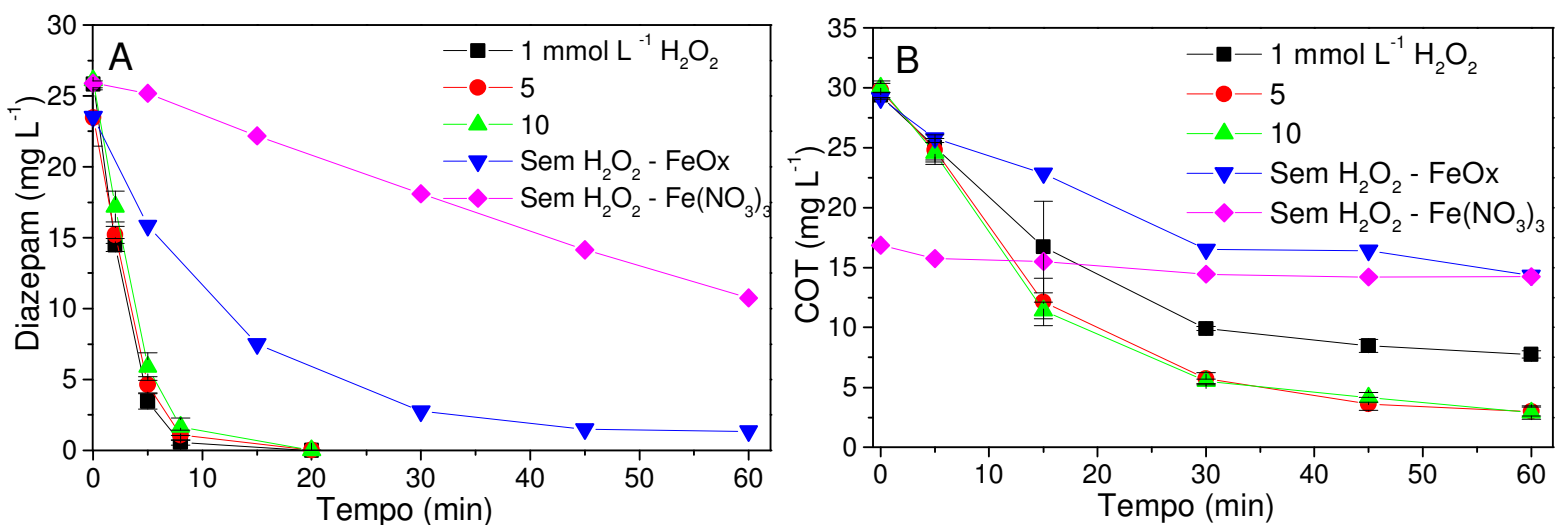

Figura 15. Influência da concentração de $\mathrm{H}_{2} \mathrm{O}_{2}$ na oxidação de DZP (A), e na remoção de COT (B) sob radiação de lâmpada de luz negra. Condições iniciais: [DZP] $=25,0 \mathrm{mg} \mathrm{L}^{-1}$; $[\mathrm{FeOx}]=\left[\mathrm{Fe}\left(\mathrm{NO}_{3}\right)_{3}\right]=0,20 \mathrm{mmol} \mathrm{L}{ }^{-1}$.

O consumo de $\mathrm{H}_{2} \mathrm{O}_{2}$ é uma medida indireta da eficiência do processo de degradação, pois quanto maior for o consumo, maior será a formação de radical hidroxila e consequentemente, a degradação do composto-alvo. O monitoramento da concentração de $\mathrm{H}_{2} \mathrm{O}_{2}$ foi feito durante os experimentos em que foi avaliada a influência das espécies de ferro presentes no meio e como pode-se verificar na Figura 16A, FeOx consumiu maior quantidade de $\mathrm{H}_{2} \mathrm{O}_{2}$. No experimento feito na ausência de ferro não houve consumo de $\mathrm{H}_{2} \mathrm{O}_{2}$.

Nos experimentos em que foi avaliada a influência da concentração de $\mathrm{H}_{2} \mathrm{O}_{2}$ na degradação de DZP verificamos que a menor concentração testada $1,00 \mathrm{mmol} \mathrm{L}^{-1}$ foi totalmente consumida após 15 minutos de tratamento (Figura 16B). Esse fato pode explicar a menor remoção de COT que essa concentração proporcionou. Entretanto ao utilizar a concentração $10,0 \mathrm{mmol} \mathrm{L}^{-1}$ não se observou melhora significativa na remoção de COT, mesmo havendo $\mathrm{H}_{2} \mathrm{O}_{2}$ residual no final do tratamento. Altas concentrações de $\mathrm{H}_{2} \mathrm{O}_{2}$ podem ocasionar competição pelo radical hidroxila (PIGNATELLO, 1992) diminuindo a eficiência do processo, como mostra a Equação 22: 
$\mathrm{H}_{2} \mathrm{O}_{2}+{ }^{\circ} \mathrm{OH} \rightarrow \mathrm{H}_{2} \mathrm{O}+\mathrm{HO}_{2}^{\cdot}$
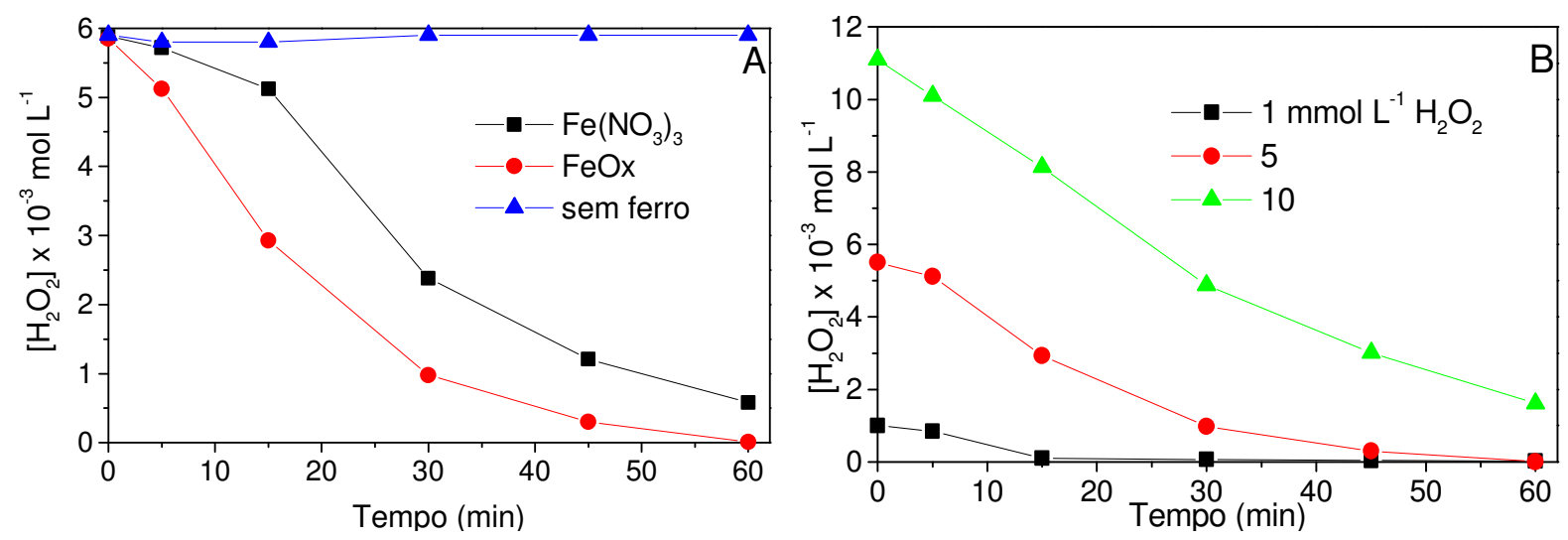

Figura 16. Consumo de $\mathrm{H}_{2} \mathrm{O}_{2}$ durante fotodegradação de DZP. Influência das espécies de ferro (A), e da concentração de $\mathrm{H}_{2} \mathrm{O}_{2}(B)$. Condições iniciais: [DZP] $=25,0 \mathrm{mg} \mathrm{L}^{-1}$; [FeOx] $=0,20 \mathrm{mmol} \mathrm{L}^{-1} ;\left[\mathrm{H}_{2} \mathrm{O}_{2}\right]=5,0 \mathrm{mmol} \mathrm{L} \mathrm{L}^{-1}$ (para o gráfico $\mathrm{A}$ ).

A degradação do fármaco DZP foi avaliada por outros POA, entretanto, não foram encontrados na literatura trabalhos com os processos Fenton e foto-Fenton para este fármaco. Huber e colaboradores (2003), relataram a vagarosa remoção de DZP por ozônio molecular com uma reação de segunda ordem de $0,75 \mathrm{~mol} \mathrm{~L}^{-1} \mathrm{~s}^{-1}$ a $20 \stackrel{\circ}{\circ} \mathrm{C}$. A ozonização de $142 \mathrm{mg} \mathrm{L}^{-1}$ de DZP resultou em 65\% de remoção do fármaco com uma dose de ozônio de $2 \mathrm{mg} \mathrm{L}^{-1}$ em 10 minutos. A concentração de $1 \mathrm{mg} \mathrm{L}^{-1}$ de DZP adicionada em um efluente de ETE foi 53,77 e $61 \%$ removida pelos processos $\mathrm{O}_{3}$, $\mathrm{O}_{3} / \mathrm{UV}$ e $\mathrm{H}_{2} \mathrm{O}_{2} / \mathrm{UV}$, respectivamente (GEBHARDT; SCHRODER, 2007). Em outro trabalho de ozonização de um efluente de ETE, mais de $90 \%$ de DZP foi removido utilizando uma relação de $\mathrm{O}_{3}$ :COT de 1,0 (WERT; ROSARIO-ORTIZ; SNYDER, 2009).

Portanto, o processo foto-Fenton pode ser utilizado para a degradação de resíduos de DZP uma vez que promoveu a oxidação do fármaco em minutos de tratamento e removeu mais de $90 \%$ de COT em 60 minutos. Esse alto índice de 
remoção de COT é uma vantagem desse processo, pois intermediários formados durante a degradação podem ser mais tóxicos que o composto original. Mesmo assim, antes da aplicação desse processo, seria aconselhável um estudo de ecotoxicidade para verificar se a concentração residual de carbono orgânico não se refere a compostos mais tóxicos que o DZP.

4.2.3 Fotodegradação de propranolol por processo foto-Fenton sob radiação artificial (lâmpada de luz negra)

A influência do ferro livre ou complexado foi avaliada no processo de degradação de PPN (Figura 17). O ferro complexado (FeOx) promoveu a degradação do fármaco rapidamente (8 $\mathrm{min}$ ), com uma constante de velocidade inicial de pseudo-primeira ordem de $0,60 \mathrm{~min}^{-1}(\mathrm{R}=0,986)$ enquanto que com ferro livre, $\left(\mathrm{Fe}\left(\mathrm{NO}_{3}\right)_{3}\right.$, a total oxidação só ocorreu em 20 minutos de tratamento, com constante de velocidade inicial de ordem zero de $1,2 \mathrm{mg} \mathrm{L}^{-1} \mathrm{~min}^{-1}(R=0,997)$.

Com relação à remoção de COT (Fig. 17B), os resultados entre as fontes de ferro avaliadas foram semelhantes, resultando em um COT residual médio de $4 \mathrm{mg} \mathrm{L}^{-1}$, mesmo existindo a contribuição do carbono do complexo oxalato. Na ausência de ferro não houve degradação de PPN e a fotólise do fármaco pode ser desconsiderada. Já a reação de Fenton, na ausência de irradiação, oxidou o composto-alvo em 60 minutos, porém sem remoção significativa de COT (Fig. 17B). 

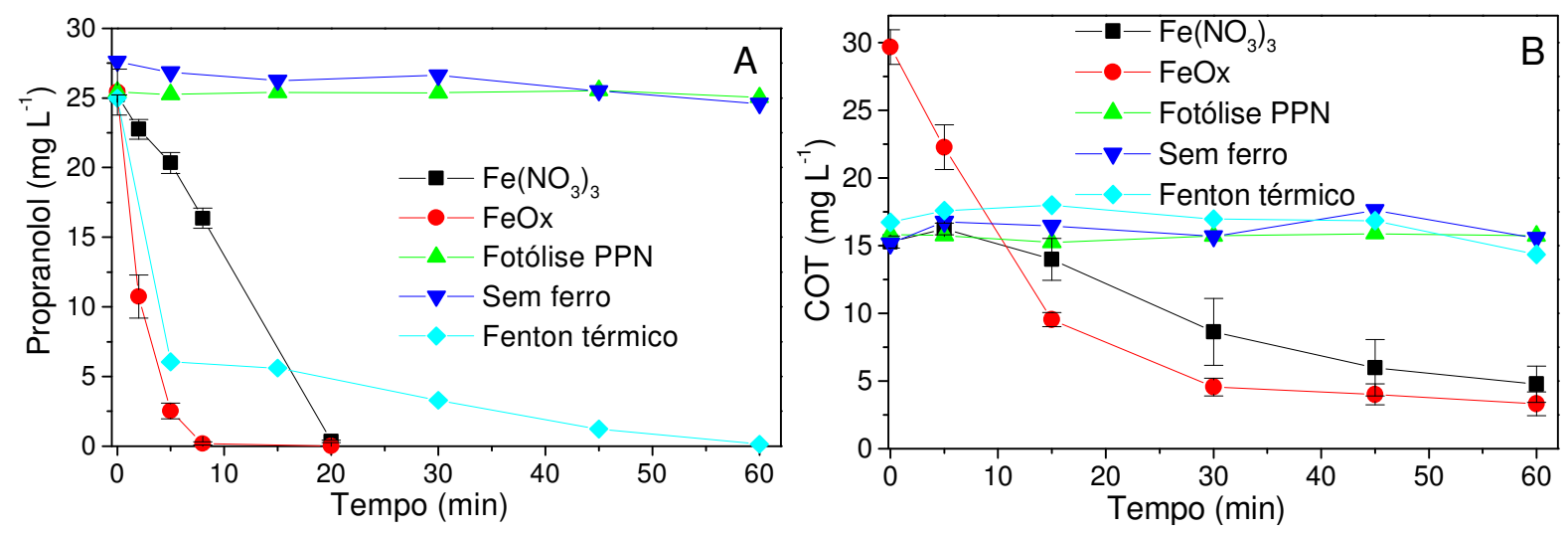

Figura 17. Influência da utilização de ferro livre ou complexado na oxidação de PPN (A), e na remoção de COT $(B)$, sob radiação de lâmpada de luz negra. Condições iniciais: $[P P N]=25,0 \mathrm{mg} \mathrm{L}^{-1} ;[\mathrm{FeOx}]=\left[\mathrm{Fe}\left(\mathrm{NO}_{3}\right)_{3}\right]=0,20 \mathrm{mmol} \mathrm{L}^{-1} ;\left[\mathrm{H}_{2} \mathrm{O}_{2}\right]=5,0 \mathrm{mmol} \mathrm{L}^{-1}$. Fenton térmico $=\left[\mathrm{FeSO}_{4}\right]=0,20 \mathrm{mmol} \mathrm{L}^{-1} ;\left[\mathrm{H}_{2} \mathrm{O}_{2}\right]=5,0 \mathrm{mmol} \mathrm{L}^{-1}$; sem irradiação.

O monitoramento da concentração de PPN durante os experimentos de degradação em que foi avaliada a influência da concentração de $\mathrm{H}_{2} \mathrm{O}_{2}$ demonstrou que as três concentrações testadas 1,$00 ; 5,00$ e 10,0 mmol L-1 promoveram a degradação de PPN em 8 minutos de tratamento (Fig. 18A).

Como já mencionado anteriormente, radicais formados durante a fotólise do complexo FeOx podem promover a oxidação do composto-alvo na ausência de $\mathrm{H}_{2} \mathrm{O}_{2}$, uma vez que utilizando $\mathrm{Fe}\left(\mathrm{NO}_{3}\right)_{3}$ essa oxidação foi muito menos significativa $(<40 \%)$ (Fig. 18A).

Uma diferença de $10 \%$ a menos no percentual de remoção de COT, utilizando a menor concentração de $\mathrm{H}_{2} \mathrm{O}_{2}\left(1,00 \mathrm{mmol} \mathrm{L}^{-1}\right)$, foi observada em relação às demais concentrações testadas $\left(5,00\right.$ e $\left.10,0 \mathrm{mmol} \mathrm{L}^{-1}\right)$ que propiciaram $90 \%$ de mineralização (Figura 18B). 

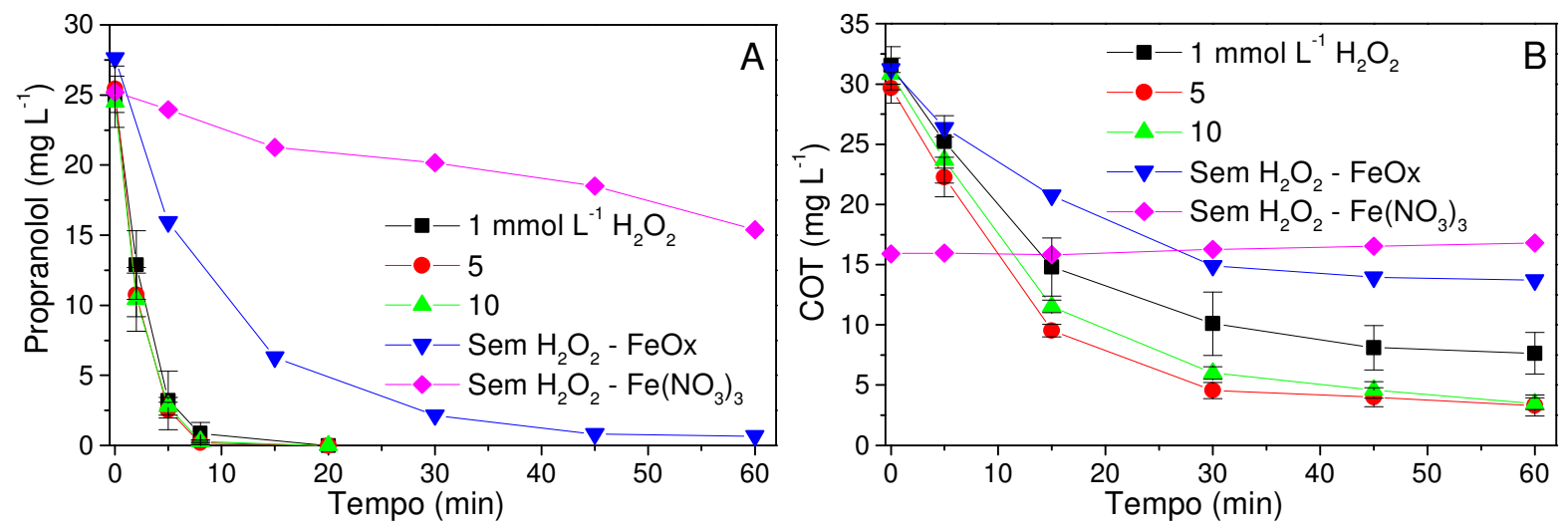

Figura 18. Influência da concentração de $\mathrm{H}_{2} \mathrm{O}_{2}$ na oxidação de PPN (A), e na remoção de COT (B), sob radiação de lâmpada de luz negra. Condições iniciais: $[P P N]=25,0 \mathrm{mg} \mathrm{L}^{-1}$; $[\mathrm{FeOx}]=\left[\mathrm{Fe}\left(\mathrm{NO}_{3}\right)_{3}\right]=0,20 \mathrm{mmol} \mathrm{L}^{-1}$.

$\mathrm{O}$ monitoramento da concentração de $\mathrm{H}_{2} \mathrm{O}_{2}$ residual durante os experimentos de fotodegradação de PPN mostrou que $\mathrm{FeOx}$ consumiu $\mathrm{H}_{2} \mathrm{O}_{2}$ mais rapidamente que $\mathrm{Fe}\left(\mathrm{NO}_{3}\right)_{3}$, mas ao final do tratamento o consumo pelas duas espécies de ferro foi praticamente o mesmo (Figura 19A). Na Figura 19B pode-se verificar que ao utilizar a

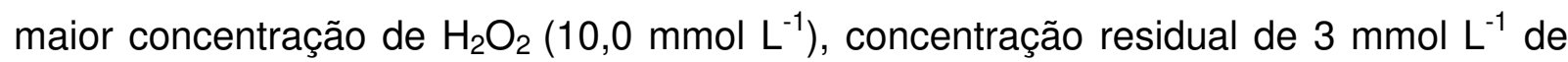
$\mathrm{H}_{2} \mathrm{O}_{2}$ foi determinada no final do tratamento, mas que isso não implicou em maiores porcentagens de degradação de PPN. $\mathrm{Na}$ concentração intermediária, $\quad \mathrm{H}_{2} \mathrm{O}_{2}$ foi totalmente consumido em 60 minutos e na menor concentração $\left(1,00 \mathrm{mmol} \mathrm{L}{ }^{-1}\right)$ em 15 minutos. 

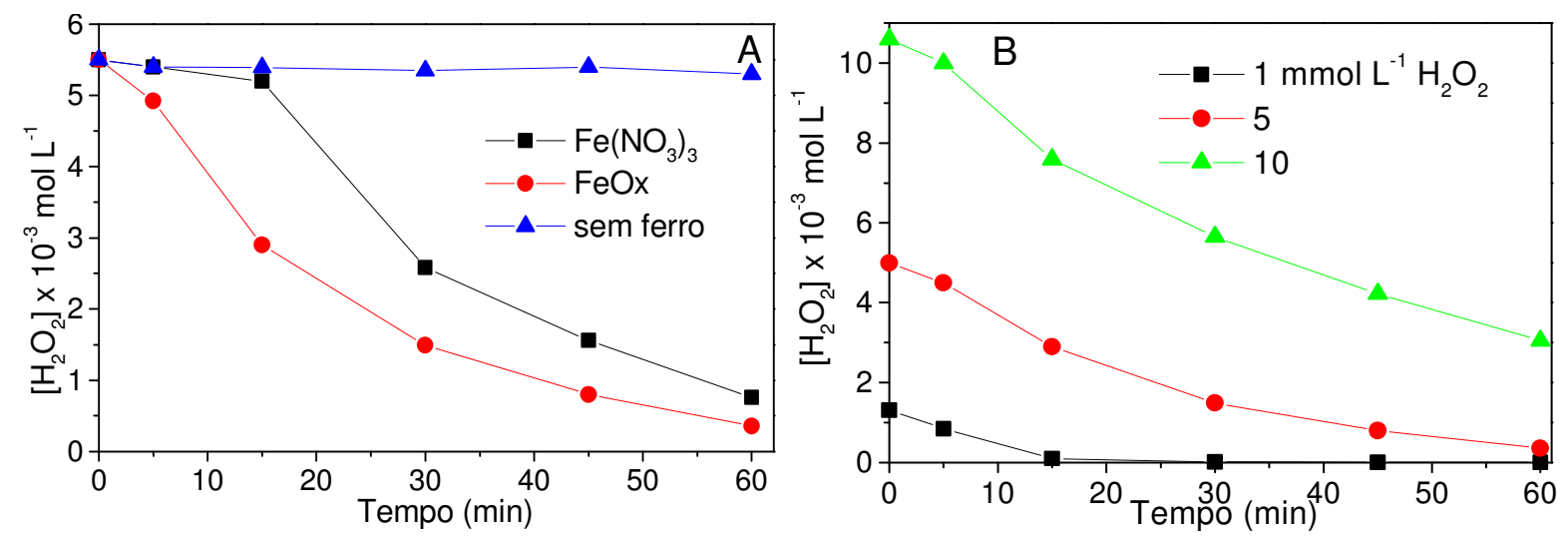

Figura 19. Consumo de $\mathrm{H}_{2} \mathrm{O}_{2}$ durante fotodegradação de PPN. Influência das espécies de ferro (A), e da concentração de $\mathrm{H}_{2} \mathrm{O}_{2}(\mathrm{~B})$. Condições iniciais: [PPN] $=25,0 \mathrm{mg} \mathrm{L}^{-1}$; [FeOx] $=0,20 \mathrm{mmol} \mathrm{L}^{-1} ;\left[\mathrm{H}_{2} \mathrm{O}_{2}\right]=5,0 \mathrm{mmol} \mathrm{L}^{-1}$ (para o gráfico $\mathrm{A}$ ).

A ozonização também foi o POA mais estudado para a degradação de PPN. Ternes e colaboradores (2003) demonstraram que a concentração de $0,18 \mu \mathrm{g} \mathrm{L}^{-1}$ de PPN encontrada em efluente de ETE foi eficientemente removida por ozônio em uma dose de $5 \mathrm{mg} \mathrm{L}^{-1}$. A remoção de $325,5 \mu \mathrm{g} \mathrm{L}^{-1}$ de PPN também foi alcançada após ozonização com uma dose de $4,75 \mathrm{mg} \mathrm{L}^{-1}$ de $\mathrm{O}_{3}$ em uma mistura de seis fármacos (ANDREOZZl et al., 2004).

O processo foto-Fenton, estudado nesse trabalho, foi muito eficiente também na degradação de PPN. Os resultados de oxidação e de remoção de COT de PPN indicam que esse processo poderia ser aplicado para a degradação desses resíduos, pois o tempo utilizado para o tratamento é relativamente curto e os custos com reagentes não são elevados. 
4.2.4 Fotodegradação de lincomicina por processo foto-Fenton sob radiação artificial (lâmpada de luz negra)

Resultados semelhantes aos dos fármacos DZP e PPN foram obtidos para o antibiótico LCM, pois em 8 minutos de tratamento a concentração de LCM já estava abaixo do limite de detecção $\left(0,285 \mathrm{mg} \mathrm{L}^{-1}\right)$, na presença de FeOx. A oxidação na ausência de radiação, Fenton térmico, foi promovida em 60 minutos (Fig. 20A). Entretanto, uma menor remoção de COT, comparada aos outros fármacos estudados, foi observada. Utilizando $\mathrm{Fe}\left(\mathrm{NO}_{3}\right)_{3}$ pouco mais de $20 \%$ de degradação foi observada, já a degradação promovida pelo $\mathrm{FeOx}$ foi de $80 \%$. Os experimentos controle, na ausência de ferro e fotólise de LCM não apresentaram resultados significativos de oxidação e mineralização (Fig. 20B).
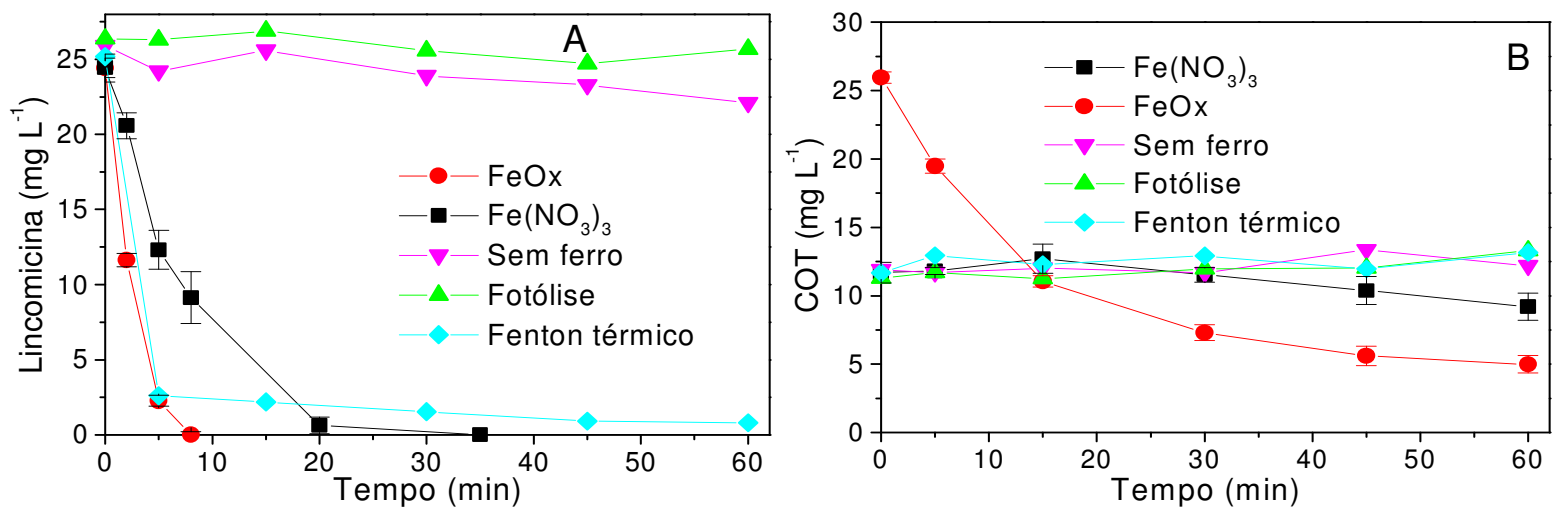

Figura 20. Influência da utilização de ferro livre ou complexado na oxidação de LCM (A), e na remoção de COT $(B)$, sob radiação de lâmpada de luz negra. Condições iniciais: $[\mathrm{LCM}]=25,0 \mathrm{mg} \mathrm{L}^{-1} ;[\mathrm{FeOx}]=\left[\mathrm{Fe}\left(\mathrm{NO}_{3}\right)_{3}\right]=0,20 \mathrm{mmol} \mathrm{L}^{-1} ;\left[\mathrm{H}_{2} \mathrm{O}_{2}\right]=5,0 \mathrm{mmol} \mathrm{L}^{-1}$. Fenton térmico $=\left[\mathrm{FeSO}_{4}\right]=0,20 \mathrm{mmol} \mathrm{L}^{-1} ;\left[\mathrm{H}_{2} \mathrm{O}_{2}\right]=5,0 \mathrm{mmol} \mathrm{L}^{-1}$; sem irradiação.

A Figura $21 \mathrm{~A}$ mostra que as concentrações de $\mathrm{H}_{2} \mathrm{O}_{2}$ avaliadas promoveram a oxidação de LCM em poucos minutos de tratamento, o que prova a eficiência do 
processo. Além disso, cerca de $80 \%$ de remoção de COT foi alcançada com as três concentrações de $\mathrm{H}_{2} \mathrm{O}_{2}$ testadas. Esse resultado é importante, pois permite a utilização de concentrações mais baixas de reagentes, sem diminuir a eficiência do processo, diminuindo custos do tratamento.

$\mathrm{O}$ ferro complexado promoveu maior degradação na ausência de $\mathrm{H}_{2} \mathrm{O}_{2}$ comparado ao ferro livre (Fig. 21).
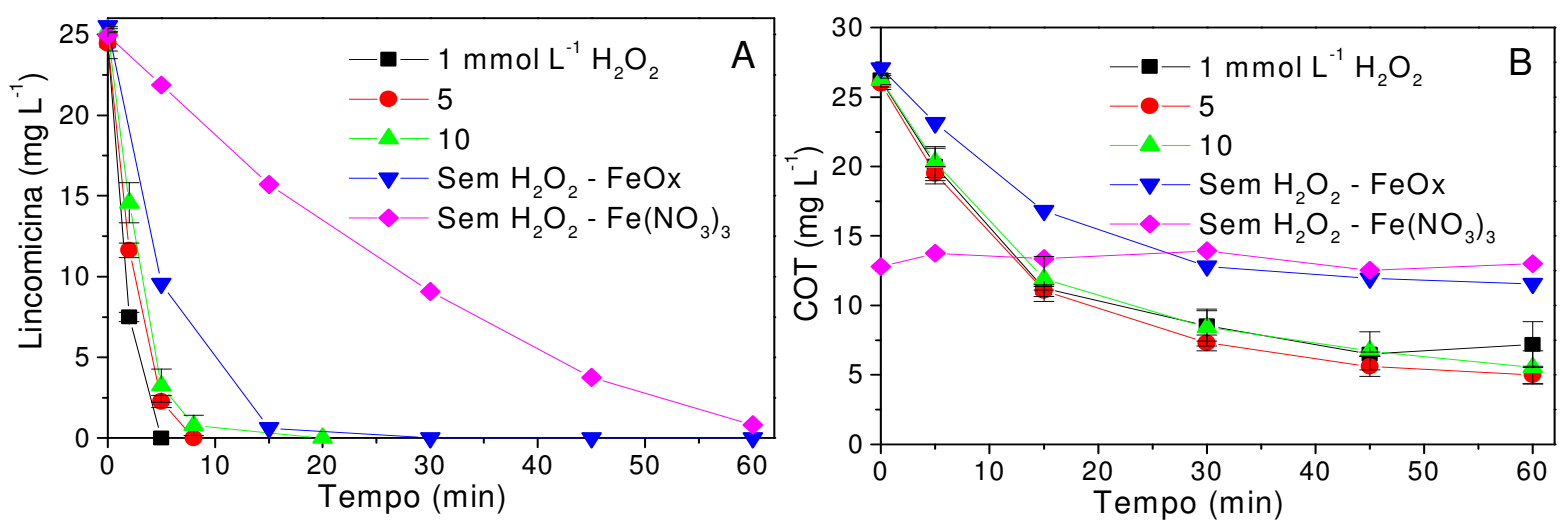

Figura 21. Influência da concentração de $\mathrm{H}_{2} \mathrm{O}_{2}$ na oxidação de LCM (A), e na remoção de COT (B), sob radiação de lâmpada de luz negra. Condições iniciais: $[\mathrm{LCM}]=25,0 \mathrm{mg} \mathrm{L}^{-1}$; $[\mathrm{FeOx}]=\left[\mathrm{Fe}\left(\mathrm{NO}_{3}\right)_{3}\right]=0,20 \mathrm{mmol} \mathrm{L}^{-1}$.

O monitoramento da concentração de $\mathrm{H}_{2} \mathrm{O}_{2}$ foi feito durante os experimentos em que foi avaliada a influência das espécies de ferro presentes no meio durante a degradação de LCM e como pode-se verificar na Figura 22A, FeOx consumiu maior quantidade de $\mathrm{H}_{2} \mathrm{O}_{2}$ o que foi condizente com a maior degradação promovida. Nos experimentos feitos na ausência de ferro e na ausência de radiação não foi observado consumo de $\mathrm{H}_{2} \mathrm{O}_{2}$ (Figura 22A).

Nos experimentos em que foi avaliada a influência da concentração de $\mathrm{H}_{2} \mathrm{O}_{2}$ na degradação de LCM foi verificado que a menor concentração testada, $1,00 \mathrm{mmol}^{-1}$, já estava abaixo do limite de detecção do método após 15 minutos de tratamento (Figura 
22B). Ao utilizar a concentração $10,0 \mathrm{mmol} \mathrm{L}^{-1}$ não se observou melhora significativa na remoção de COT, mesmo havendo $\mathrm{H}_{2} \mathrm{O}_{2}$ residual no final do tratamento.
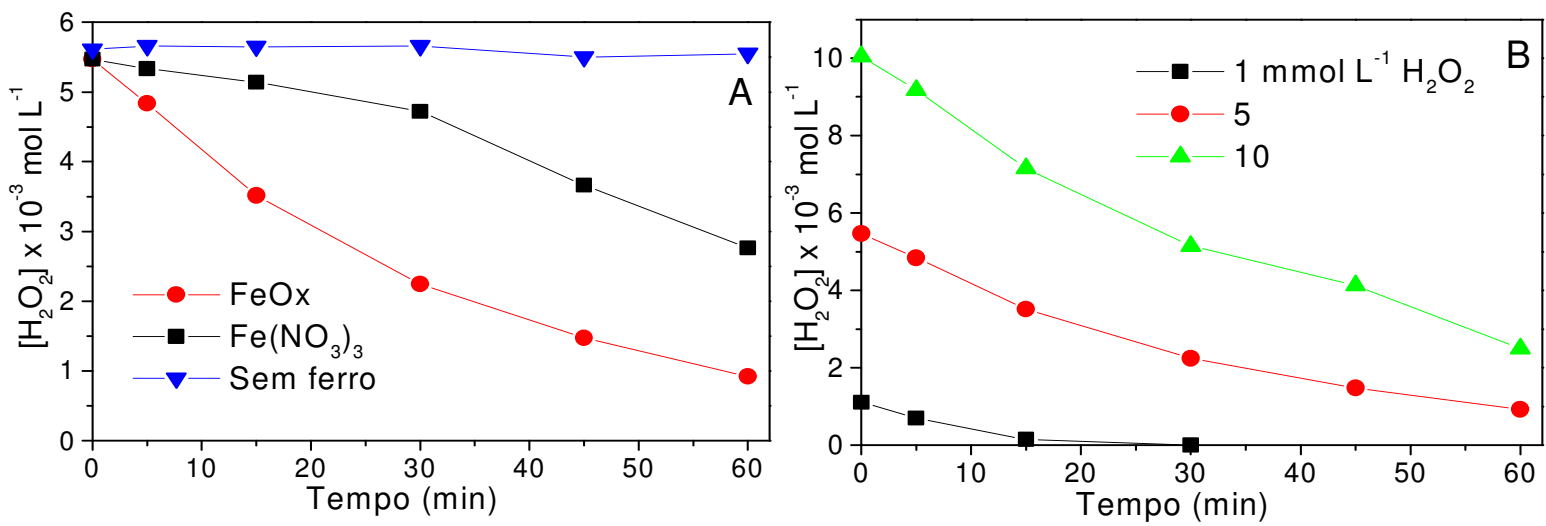

Figura 22. Consumo de $\mathrm{H}_{2} \mathrm{O}_{2}$ durante fotodegradação de LCM. Influência das espécies de ferro (A), e da concentração de $\mathrm{H}_{2} \mathrm{O}_{2}(\mathrm{~B})$. Condições iniciais: [LCM] $=25,0 \mathrm{mg} \mathrm{L}^{-1}$; [FeOx] $=0,20 \mathrm{mmol} \mathrm{L}^{-1} ;\left[\mathrm{H}_{2} \mathrm{O}_{2}\right]=5,0 \mathrm{mmol} \mathrm{L}^{-1}$ (para o gráfico $\mathrm{A}$ ).

O processo foto-Fenton nas condições estudadas foi muito mais eficiente em promover a degradação do antibiótico LCM do que trabalhos relatados na literatura. Addamo e colaboradores (2005), estudaram a degradação desse antibiótico utilizando fotocatálise heterogênea e a total oxidação do composto só foi obtida após 1 hora e meia de irradiação. Embora a concentração utilizada $\left(50 \mathrm{mg} \mathrm{L}^{-1}\right)$ tenha sido maior do que a estudada neste trabalho, a mineralização obtida pelos pesquisadores foi de aproximadamente $60 \%$ após 5 horas de tratamento. Em outro trabalho, a ozonização de LCM $\left(0,5 \mathrm{mmol} \mathrm{L}^{-1}\right)$ a pH 5,5 promoveu sua completa remoção após 2 minutos de tratamento $\left(\mathrm{O}_{3}=0,4 \mathrm{mmol} \mathrm{L}^{-1}\right)$, entretanto, a mineralização obtida após 180 minutos de reação foi menor que 10\% (ANDREOZZI et al., 2006).

A comparação das constantes de velocidade inicial das reações de degradação dos fármacos estudados demonstrou que em presença de $\mathrm{FeOx}$ a velocidade de degradação do PPN $\left(k=0,60 \mathrm{~min}^{-1}\right)$ foi maior que a do DZP $\left(k=0,39 \mathrm{~min}^{-1}\right)$, embora o 
valor das constantes seja muito próximo. Entretanto, a maior velocidade de reação inicial do DZP poderia ser explicado por meio dos efeitos promovidos pelos grupos substituintes do anel aromático das moléculas. O PPN apresenta um grupo ativador ligado ao anel naftaleno (-O-) o que proporciona uma densidade eletrônica maior ao anel deixando-o mais suscetível ao eletrófilo $\left({ }^{\circ} \mathrm{OH}\right)$. Já o DZP apresenta além de um átomo de cloro o qual desativa o anel benzênico clorado por atrair os elétrons, um grupamento imino $(-\mathrm{C}=\mathrm{N}-)$ que desativa também o anel fenílico, diminuindo assim a velocidade de ataque do radical hidroxila a molécula.

O fármaco lincomicina embora não apresente anel aromático e nem ligações insaturadas que são sítios muito suscetíveis ao ataque do radical hidroxila, possui centros nucleofílicos como o $\mathrm{S}-\mathrm{CH}_{3}$ e os átomos de nitrogênio, que explicam a rápida degradação a qual foi confirmada pela constante de velocidade inicial $\left(k=0,48 \mathrm{~min}^{-1}\right)$.

\subsubsection{Fotodegradação dos fármacos sob radiação solar}

A utilização da radiação solar em processos de tratamento de efluentes é uma alternativa viável, especialmente no Brasil. A grande vantagem em relação à utilização de radiação artificial é a diminuição de custos com energia elétrica.

O complexo ferrioxalato de potássio apresenta grande potencial para ser aplicado em tratamentos que utilizem radiação solar (SAFARZADEH-AMIRI; BOLTON; CARTER, 1996a), pois absorve mais no visível comparado a espécies hidroxiladas de ferro.

A comparação de resultados de fotodegradação sob radiação solar é dificultada devido às variações das condições climáticas durante o dia e o ano. Desse modo, 
esses experimentos foram feitos considerando a dose UV acumulada durante a exposição, pois possibilita a comparação dos resultados.

A utilização de ferro livre e complexado foi avaliada sob radiação solar. $\mathrm{FeOx}$ normalmente apresenta maior eficiência sob radiação solar, porém foi avaliada também a utilização de ferro livre uma vez que, conforme descrito na literatura, isso depende também da estrutura do composto-alvo e não somente da espécie de ferro utilizada (NOGUEIRA; SILVA; TROVÓ, 2005).

A fotodegradação dos fármacos sob radiação solar apresentou resultados semelhantes e muito satisfatórios para os três fármacos estudados. Na Figura 23A,C,E pode-se observar que a oxidação dos fármacos foi rapidamente promovida pelas duas espécies de ferro estudadas, sendo ainda maior para as reações com FeOx. A total oxidação para os três fármacos foi alcançada com $0,562 \mathrm{~J} \mathrm{~cm}^{-2}$ de energia, que corresponde a aproximadamente 5 minutos de tratamento.

Considerando que a intensidade média da lâmpada é de $19 \mathrm{~W} \mathrm{~cm}^{-2}, 5$ minutos de irradiação artificial correspondem a uma dose de energia de $0,57 \mathrm{~J} \mathrm{~cm}^{-2}$. Dessa forma é possível comparar os resultados obtidos pelas duas fontes de irradiação e estimar que a remoção de COT obtida sob radiação solar foi maior que os índices obtidos sob radiação artificial. A remoção promovida por $\mathrm{FeOx}$, sob radiação solar, ultrapassou $92 \%$ para os três fármacos ao final do tratamento (Fig. 23B,D,F). A diferença mais significativa foi para o antibiótico LCM que teve a remoção aumentada de 20 (Fig. 20B) para $68 \%$ (Fig. 23F) em aproximadamente 60 minutos de irradiação solar $\left(7,080 \mathrm{~J} \mathrm{~cm}^{-2}\right)$ com $\mathrm{Fe}\left(\mathrm{NO}_{3}\right)_{3}$ e de 80 (Fig. 20B) para 92\% (Fig. 23F) com FeOx com o mesmo tempo de tratamento (aproximadamente 60 minutos). Provavelmente, por a radiação solar apresentar uma maior faixa de emissão da radiação, maior número de fótons pode ser 
aproveitado na geração de radical hidroxila e consequentemente maior degradação ocorreu do que quando comparada à lâmpada que emite em 365 nm e 410 nm (ZHENG et al., 2007).
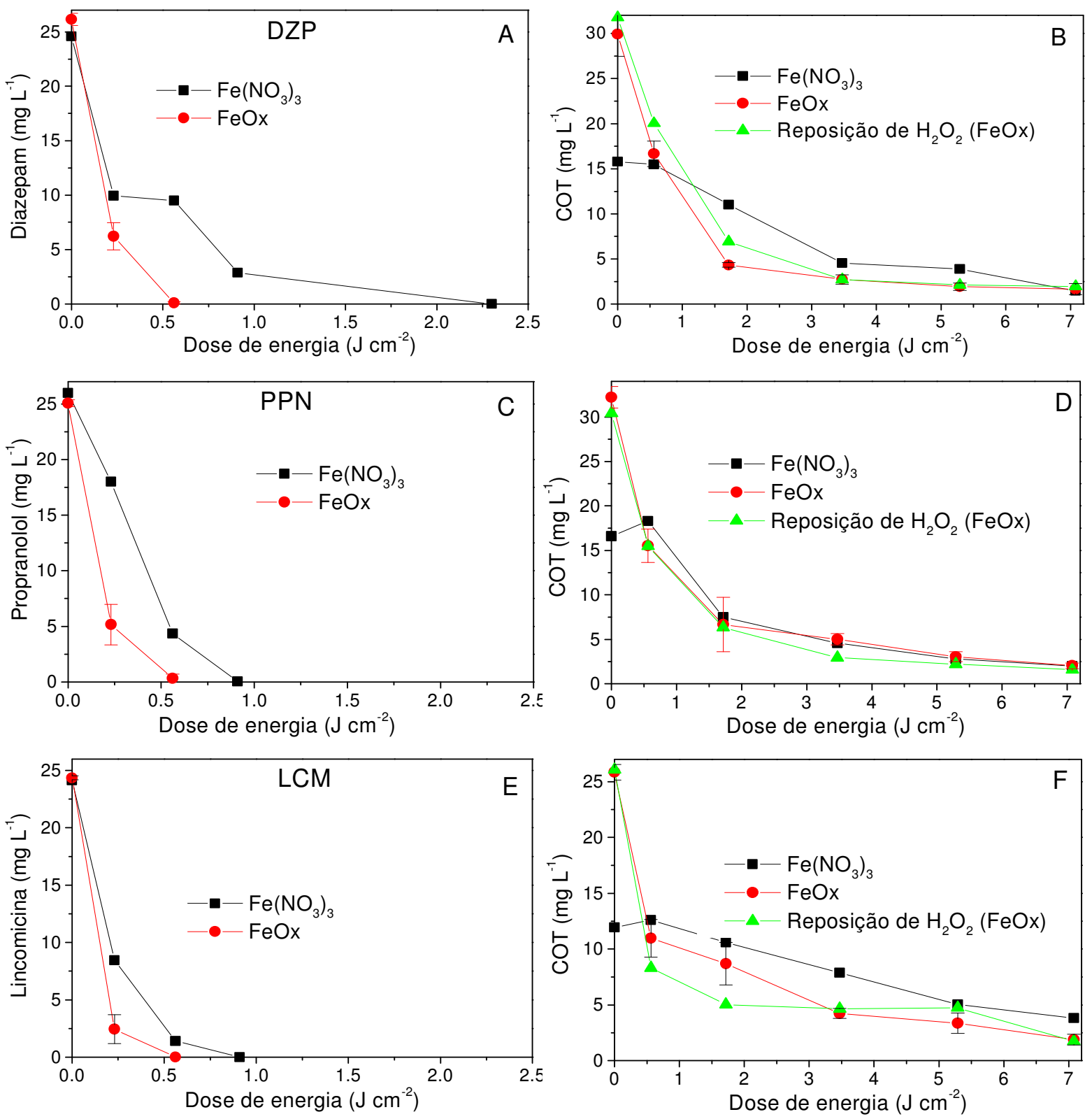

Figura 23. Influência da utilização de ferro livre ou complexado na oxidação de DZP (A), PPN (C) e LCM (E), e na remoção de COT de DZP (B), PPN (D) e LCM (F) sob radiação solar. Condições iniciais: $[\mathrm{DZP}]=[\mathrm{PPN}]=[\mathrm{LCM}]=25,0 \mathrm{mg} \mathrm{L}^{-1} ;[\mathrm{FeOx}]=\left[\mathrm{Fe}\left(\mathrm{NO}_{3}\right)_{3}\right]$ $=0,20 \mathrm{mmol} \mathrm{L}^{-1} ;\left[\mathrm{H}_{2} \mathrm{O}_{2}\right]=5,0 \mathrm{mmol} \mathrm{L}^{-1}$. 
$\mathrm{O}$ monitoramento da concentração de $\mathrm{H}_{2} \mathrm{O}_{2}$ durante os experimentos de fotodegradação dos fármacos sob irradiação solar mostrou que ao atingir uma dose de energia de aproximadamente $3,5 \mathrm{~J} \mathrm{~cm}^{-2}$, que corresponde a aproximadamente 30 minutos de tratamento, a concentração inicial de $\mathrm{H}_{2} \mathrm{O}_{2}\left(5,00 \mathrm{mmol} \mathrm{L}^{-1}\right)$ já havia sido praticamente totalmente consumida, nos experimentos com ferro complexado (Fig. 24). Com o intuito de verificar se uma maior remoção de matéria orgânica no final do tratamento poderia ser obtida foi feito um experimento com reposição de $\mathrm{H}_{2} \mathrm{O}_{2}$. Em aproximadamente 30 minutos de tratamento, $1,36 \times 10^{-3}$ mol de $\mathrm{H}_{2} \mathrm{O}_{2}$ foram adicionados ao experimento, totalizando $5,11 \times 10^{-3} \mathrm{~mol}$ de $\mathrm{H}_{2} \mathrm{O}_{2}$. Entretanto como pode-se observar na Figura 23B,D,F nenhuma melhora significativa no índice de remoção de matéria orgânica foi observada, o que demonstra que a concentração desse oxidante não foi o limitante da reação, mas provavelmente houve a formação de subprodutos recalcitrantes, não passíveis de degradação pelo processo foto-Fenton. 

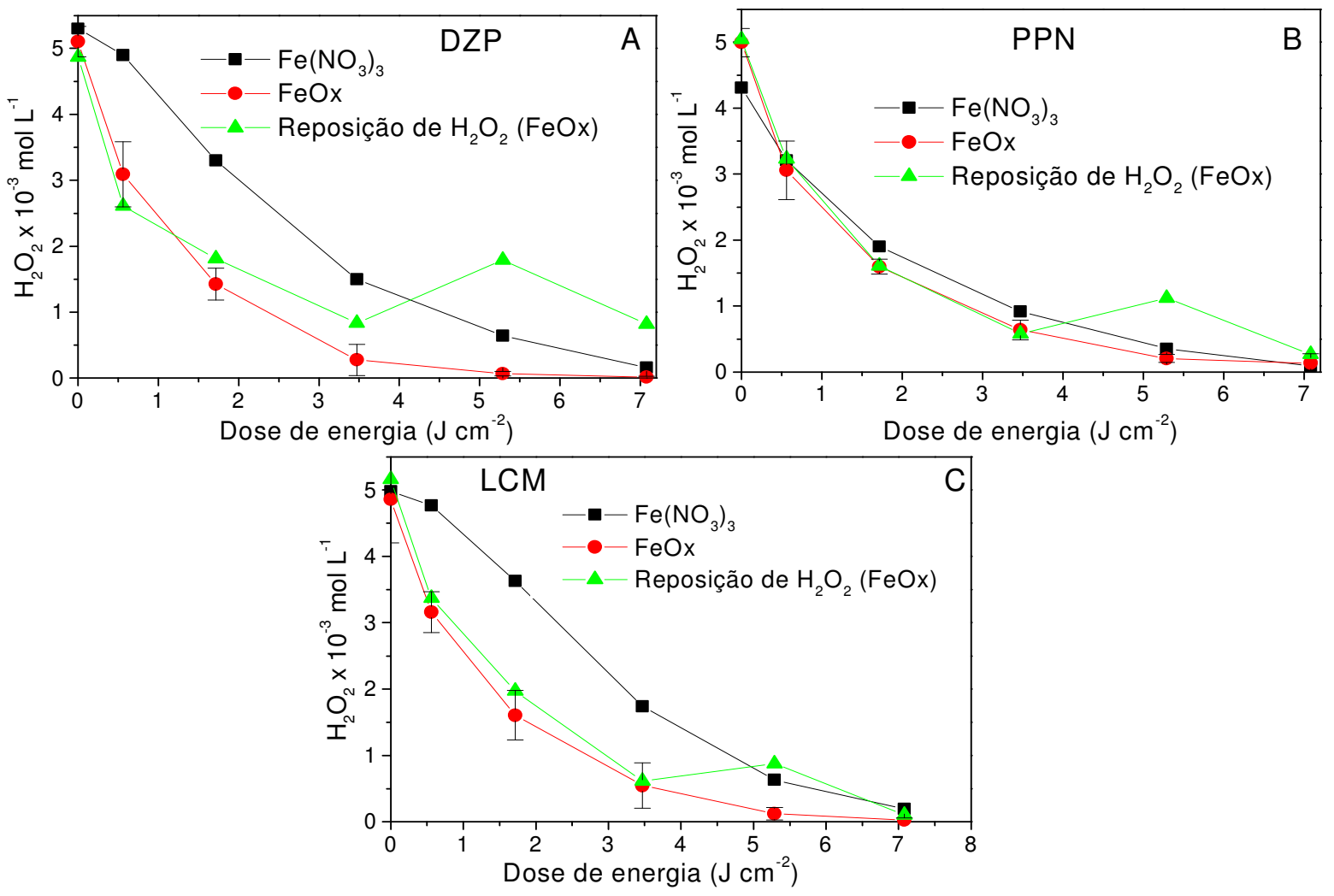

Figura 24. Consumo de $\mathrm{H}_{2} \mathrm{O}_{2}$ durante fotodegradação de DZP (A), PPN (B) e LCM (C) sob radiação solar. Influência das espécies de ferro e da reposição de $\mathrm{H}_{2} \mathrm{O}_{2}$. Condições iniciais: $[\mathrm{DZP}]=[\mathrm{PPN}]=[\mathrm{LCM}]=25,0 \mathrm{mg} \mathrm{L}^{-1} ;[\mathrm{FeOx}]=\left[\mathrm{Fe}\left(\mathrm{NO}_{3}\right)_{3}\right]=0,20 \mathrm{mmol} \mathrm{L}^{-1}$; $\left[\mathrm{H}_{2} \mathrm{O}_{2}\right]=5,0 \mathrm{mmol} \mathrm{L} \mathrm{L}^{-1}$; com reposição de mais $1,36 \times 10^{-3} \mathrm{~mol} \mathrm{H}_{2} \mathrm{O}_{2}$ aos 30 minutos.

4.2.6 Fotodegradação dos fármacos em efluente de estação de tratamento de esgoto (ETE)

Considerando que o estudo de um processo de remediação visa sempre uma possível aplicação, neste trabalho foi avaliada a influência da matriz efluente de ETE, onde normalmente os fármacos residuais são encontrados. Conforme já mencionado, o processo foto-Fenton poderia ser utilizado, como complemento aos processos convencionais, na saída das ETE, uma vez que vários trabalhos na literatura descrevem 
a ocorrência de fármacos nesses efluentes (GÓMEZ et al., 2007), ou posterior aos processos convencionais de tratamento de água.

A influência da matriz é um parâmetro muito importante a ser estudado pois a matéria orgânica presente pode influenciar no processo de fotodegradação além de espécies inorgânicas como por exemplo carbonato e cloreto (ZEPP et al., 1985; LEGRINI et al., 1993).

Para verificar essa influência foram feitos experimentos com o fármaco DZP dissolvido diretamente no efluente após agitação por 12 horas. $\mathrm{O}$ efluente coletado apresentou pH 6,90, 44,12 $\mathrm{mg} \mathrm{L}^{-1}$ de carbono orgânico dissolvido (COD) e 55,5 $\mathrm{mg} \mathrm{L}^{-1}$ de carbono inorgânico.

Nestes experimentos foi utilizada a melhor condição obtida para a degradação de DZP em água deionizada: $\mathrm{pH}$ 2,50, [FeOx] 0,20 mmol L-1 e $\left[\mathrm{H}_{2} \mathrm{O}_{2}\right] 5,0 \mathrm{mmol} \mathrm{L}{ }^{-1}$, primeiramente com radiação artificial. A Figura 25A mostra que a oxidação de DZP não foi prejudicada na presença de efluente de ETE, pois resultado similar ao obtido com água deionizada foi alcançado. Entretanto, a remoção de COD foi influenciada pela matriz, pois utilizando água deionizada o carbono remanescente foi de aproximadamente $3 \mathrm{mg} \mathrm{L}^{-1}$, enquanto que em efluente de ETE o carbono remanescente foi $10 \mathrm{mg} \mathrm{L}^{-1}$ (Fig. 25B). No entanto vale ressaltar que a concentração inicial de matéria orgânica era de $44,12 \mathrm{mg} \mathrm{L}^{-1}$ de carbono proveniente do efluente e aproximadamente $30 \mathrm{mg} \mathrm{L}^{-1}$ do DZP e FeOx resultando em aproximadamente $75 \mathrm{mg} \mathrm{L}^{-1}$ e destes apenas $10 \mathrm{mg} \mathrm{L}^{-1}$ não foram mineralizados.

Com o intuito de remover a matéria orgânica remanescente, outro experimento foi feito com uma concentração inicial menor de $\mathrm{H}_{2} \mathrm{O}_{2}$ e com reposições deste oxidante ao longo do tempo, pois observou-se por meio das análises de $\mathrm{H}_{2} \mathrm{O}_{2}$ residual, que aos 
45 minutos de tratamento a concentração de $\mathrm{H}_{2} \mathrm{O}_{2}$ já havia sido praticamente totalmente consumida (dado não mostrado), uma vez que a matéria orgânica e carbonatos presentes na matriz também consomem radical hidroxila (GAO; ZEPP, 1998; LEGRINI et al., 1993). Mesmo com reposição de $\mathrm{H}_{2} \mathrm{O}_{2}$ (3 mmol L-1 inicial; adição de $1,23 \times 10^{-3} \mathrm{~mol}$ em 30 minutos e mais $0,0035 \times 10^{-3} \mathrm{~mol}$ em $105 \mathrm{~min}$ ) não se observou uma maior remoção de matéria orgânica (Figura 25B). Provavelmente a remoção total não esteja sendo alcançada não pela falta de $\mathrm{H}_{2} \mathrm{O}_{2}$, mas sim devido a compostos recalcitrantes presentes no efluente de ETE e/ou subprodutos da degradação de DZP.
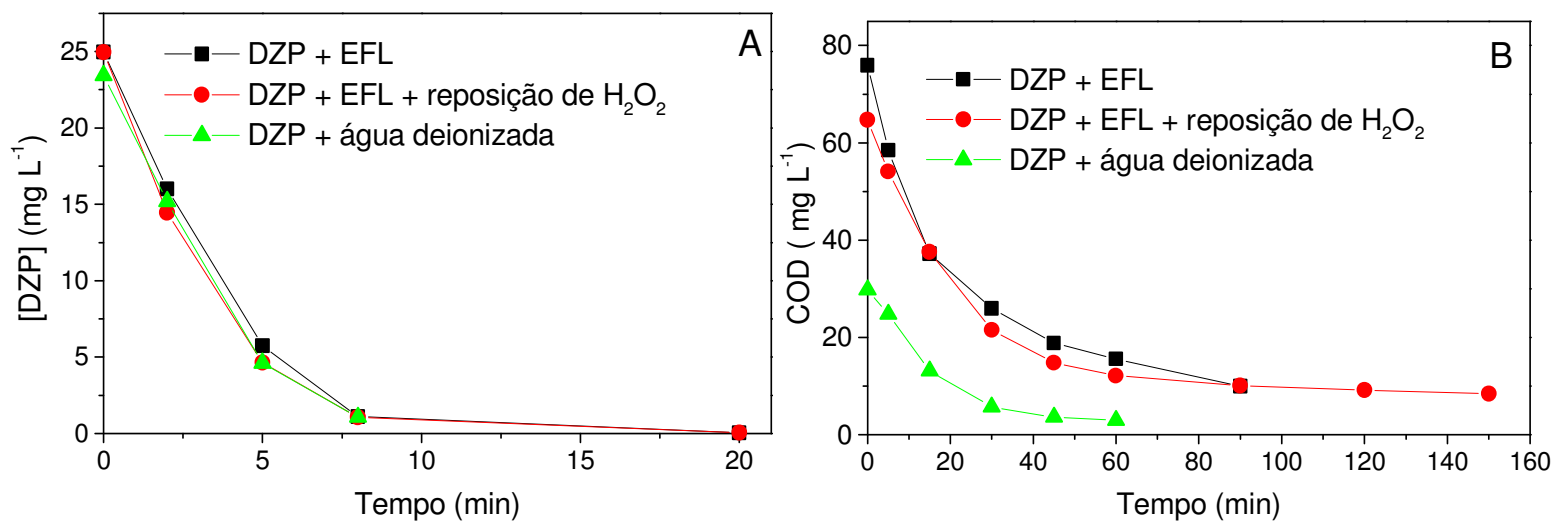

Figura 25. Influência da matriz na oxidação de DZP (A), e na remoção de COD (B) sob lâmpada de luz negra. Condições iniciais: $[D Z P]=25,0 \mathrm{mg} \mathrm{L}^{-1}$; $[\mathrm{FeOx}]=0,20 \mathrm{mmol}$ $\mathrm{L}^{-1} ;\left[\mathrm{H}_{2} \mathrm{O}_{2}\right]=5,0$ mmol L-1 - reposicão $\mathrm{H}_{2} \mathrm{O}_{2}$ (adição de $1,23 \times 10^{-3} \mathrm{~mol}$ em 30 minutos e mais $0,0035 \times 10^{-3} \mathrm{~mol}$ em $\left.105 \mathrm{~min}\right)$. EFL - efluente.

Para verificar a influência de compostos ou subprodutos recalcitrantes na remoção da matéria orgânica pelo processo foto-Fenton foi feito um experimento de fotodegradação só do efluente, com as condições [FeOx] 0,2 $\mathrm{mmol} \mathrm{L}^{-1}$ e $\left[\mathrm{H}_{2} \mathrm{O}_{2}\right] 5 \mathrm{mmol}$ $\mathrm{L}^{-1}$ em adição única. Como pode-se observar na Figura 26 somente $50 \%$ de COD foi removido, restando ainda $23,6 \mathrm{mg} \mathrm{L}^{-1}$ de carbono, o que demonstra que sob essas condições experimentais, existem mesmo compostos recalcitrantes ao processo. 


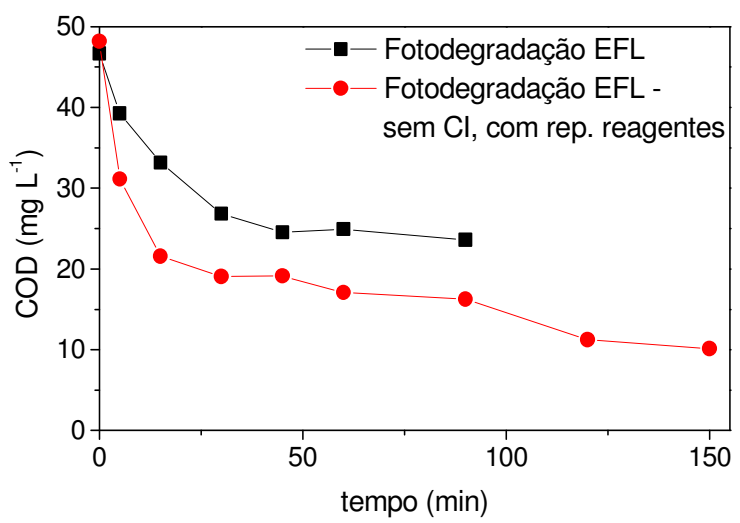

Figura 26. Fotodegradação do efluente (EFL) sob radiação de lâmpada de luz negraCondições iniciais: $[\mathrm{FeOx}]=0,20 \mathrm{mmol} \mathrm{L}^{-1} ;\left[\mathrm{H}_{2} \mathrm{O}_{2}\right]=5,0 \mathrm{mmol} \mathrm{L}^{-1}$. Fotodegradação do efluente (EFL) - sem carbono inorgânico $(\mathrm{Cl})$ e com reposição de reagentes. Condições iniciais: $[\mathrm{FeOx}]=0,20 \mathrm{mmol} \mathrm{L}^{-1} ;\left[\mathrm{H}_{2} \mathrm{O}_{2}\right]=5,0 \mathrm{mmol} \mathrm{L}^{-1}$ com reposicões (FeOx - 8,18 x 10 $0^{-5} \mathrm{~mol}$ aos 90 min.; $\mathrm{H}_{2} \mathrm{O}_{2}-1,19 \times 10^{-3}$ mol em 120 minutos).

Na tentativa de aumentar a mineralização, foi removido o carbono inorgânico do efluente antes do início do experimento por meio da diminuição do pH para 2,5 e agitação por 2 horas pois embora $0 \mathrm{pH}$ fosse ajustado para 2,5 no início dos experimentos, a solução não ficava sob agitação tempo suficiente para a eliminação de todo carbono inorgânico (residual $\cong 30 \mathrm{mg} \mathrm{L}^{-1}$ ). Como mencionado anteriormente, o carbono inorgânico é um sequestrante de radical hidroxila (Eq 23-24), podendo ocasionar, assim, uma diminuição da eficiência do processo (LEGRINI et al., 1993).

$\mathrm{HO}^{\circ}+\mathrm{HCO}_{3}^{-} \rightarrow \mathrm{H}_{2} \mathrm{O}+\mathrm{CO}_{3}^{*}$

$\mathrm{HO}^{\circ}+\mathrm{CO}_{3}^{2-} \rightarrow \mathrm{HO}^{-}+\mathrm{CO}_{3}{ }^{-}$

A Figura 26 mostra que no experimento de fotodegradação do efluente feito na ausência de carbono inorgânico (residual $0,5 \mathrm{mg} \mathrm{L}^{-1}$ ), a mineralização foi cerca de $16 \%$ maior (aos 90 min.) comparada ao experimento feito na presença de aproximadamente $30 \mathrm{mg} \mathrm{L}^{-1}$ de carbono inorgânico. Entretanto esse resultado ainda não foi satisfatório, 
pois restavam cerca de $16 \mathrm{mg} \mathrm{L}^{-1}$ de COD aos 90 minutos de tratamento. Para certificar-se de que a eficiência do processo não estava sendo comprometida pela falta de reagentes aos 90 minutos de tratamento foi adicionado ao sistema mais $8,18 \times 10^{-5}$ mol de FeOx para garantir que houvesse ferro disponível para a reação de Fenton, uma vez que o mesmo poderia estar sendo complexado pela matéria orgânica presente na amostra de efluente de ETE. Aos 120 minutos foi adicionado $1,19 \times 10^{-3} \mathrm{~mol}^{\mathrm{de} \mathrm{H}_{2} \mathrm{O}_{2}}$ pois por meio das análises de $\mathrm{H}_{2} \mathrm{O}_{2}$ residual (dado não mostrado) foi observado que este oxidante havia sido consumido. Entretanto a remoção de COD, mesmo com a reposição dos reagentes não foi maior do que a obtida no primeiro experimento feito, onde restavam aproximadamente $10 \mathrm{mg} \mathrm{L}^{-1}$ de COD. Isso comprovou que existiam substâncias e/ou subprodutos recalcitrantes ao processo foto-Fenton independente da condição utilizada.

Para verificar a influência do carbono inorgânico na fotodegradação de DZP foi feito um experimento em sua ausência. Entretanto os resultados obtidos $\left(13 \mathrm{mg} \mathrm{L}^{-1}\right.$ de COD remanescente) não demonstraram maior eficiência de remoção de COD do que a obtida na presença de carbono inorgânico.

Bautitz e Nogueira (2007) observaram que na degradação do antibiótico tetraciclina por processo foto-Fenton, essa mesma matriz influenciou a remoção de COD sob radiação artificial, porém sob radiação solar esse efeito não foi observado. Dessa forma um experimento de fotodegradação de DZP foi feito utilizando radiação solar nas seguintes condições: $[\mathrm{FeOx}] 0,2 \mathrm{mmol} \mathrm{L}^{-1}$ e $\left[\mathrm{H}_{2} \mathrm{O}_{2}\right] 5 \mathrm{mmol} \mathrm{L}^{-1}$. No entanto, ao final de 90 minutos de tratamento o resultado obtido foi similar ao alcançado utilizando radiação artificial, aproximadamente $13 \mathrm{mg} \mathrm{L}^{-1}$ de COD remanescente (dado não 
mostrado), o que confirma a hipótese de que independente da condição experimental espécies recalcitrantes foram formadas.

A influência da matriz sob radiação artificial foi avaliada também para o fármaco LCM e como pode-se observar na Figura 27A a oxidação de LCM também não foi influenciada pela matriz. Em contrapartida, a remoção de COD (Figura 27B) foi influenciada pela matriz uma vez que houve cerca de $70 \%$ de mineralização, mesmo com reposição de reagentes, contra $80 \%$ obtido em água deionizada. Esses resultados reforçam a hipótese de que existiam espécies recalcitrantes no efluente, uma vez que o efluente utilizado nos experimentos do fármaco LCM foi o mesmo utilizado para o DZP.
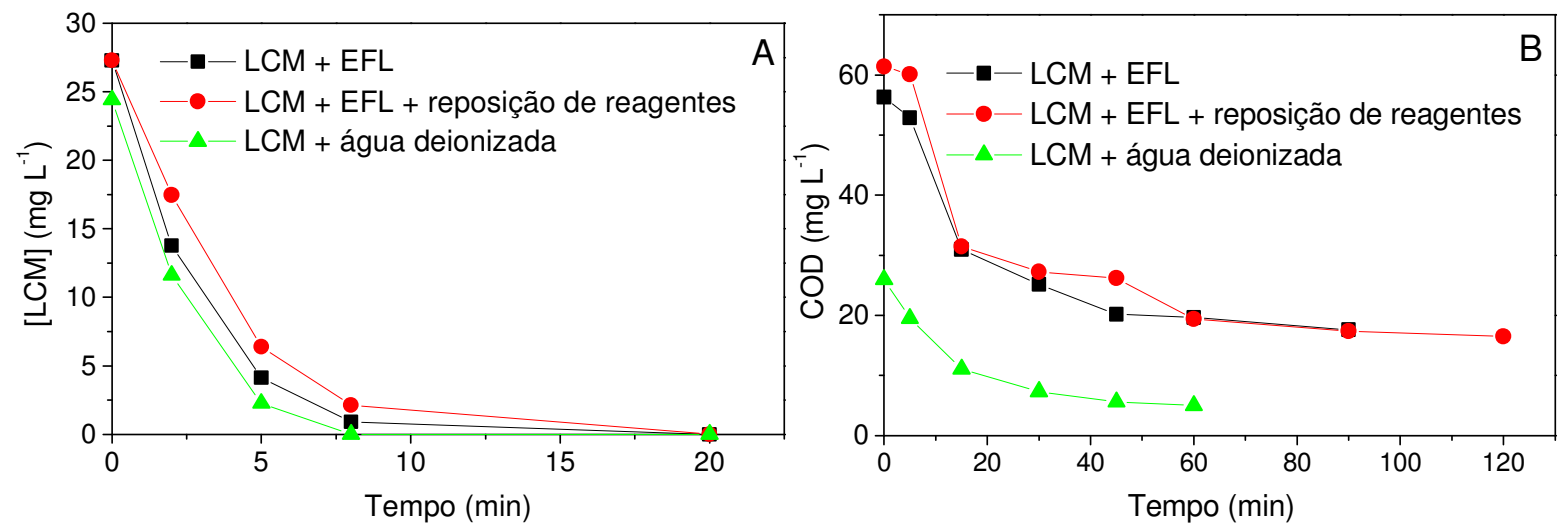

Figura 27. Influência da matriz na oxidação de LCM (A), e na remoção de COD (B) sob radiação artificial. Carbono inorgânico retirado antes dos experimentos. Condições iniciais: $[\mathrm{LCM}]=25,0 \mathrm{mg} \mathrm{L}^{-1} ;[\mathrm{FeOx}]=0,20 \mathrm{mmol} \mathrm{L}^{-1} ;\left[\mathrm{H}_{2} \mathrm{O}_{2}\right]=5,0 \mathrm{mmol} \mathrm{L}^{-1}-$ Experimento com reposição de reagentes (adição de $8,18 \times 10^{-5} \mathrm{~mol} \mathrm{FeOx}$ aos 90 min.; $1,19 \times 10^{-3}$ mol de $\mathrm{H}_{2} \mathrm{O}_{2}$ aos 120 minutos de tratamento). $\mathrm{EFL}$ - efluente.

Embora constatada a influência do efluente de ETE na remoção de COD durante a fotodegradação dos fármacos, os resultados obtidos são satisfatórios uma vez que essa matriz é composta por uma enorme variedade de compostos, dentre os quais 
devem estar substâncias que podem diminuir a eficiência do processo, como citado no inicio deste item.

4.2.7 Identificação dos intermediários formados durante a degradação dos fármacos por processo foto-Fenton pela técnica de Cromatografia Líquida de Alta Eficiência acoplada à espectrometria de massas (CLAE-EM)

\subsubsection{Intermediários de degradação do fármaco diazepam}

A detecção e identificação de fármacos e seus metabólitos no ambiente, bem como os intermediários de processos de degradação, tem sido feita pela técnica de CLAE-EM (PÉREZ; BARCELÓ, 2007; RADJENOVIC; PETROVIC; BARCELÓ, 2007). Essa técnica apresenta algumas vantagens em relação à Cromatografia Gasosa acoplada à Espectrometria de Massas (CG-EM) por exemplo, pois, tanto os fármacos como seus metabólitos ou intermediários, são moléculas polares que apresentam pouca volatilidade e necessitam de derivatização para serem analisadas por CG-MS. A derivatização representa uma desvantagem pois a análise de fármacos normalmente é feita de forma simultânea com fármacos de grupos funcionais muito diferentes (PÉREZ; BARCELÓ, 2007). Além disso, a técnica de CG-EM também não é indicada para análise de compostos termicamente instáveis (RADJENOVIC; PETROVIC; BARCELÓ, 2009).

Os intermediários de degradação do fármaco DZP foram analisados primeiramente, conforme já mencionado, por meio do equipamento UltroTOF $F_{Q}-E S I$ TOF. As amostras para essas análises foram retiradas de um experimento de 
degradação feito nas seguintes condições: DZP $=25 \mathrm{mg} \mathrm{L}^{-1} ; \mathrm{FeOx}=0,1 \mathrm{mmol} \mathrm{L}^{-1} ; \mathrm{H}_{2} \mathrm{O}_{2}$ $=10 \mathrm{mmol} \mathrm{L}^{-1} ; \mathrm{pH}$ 2,5. Vale ressaltar que essa não era a melhor condição de degradação, mas foi usada para diminuir a velocidade da reação, o que foi confirmado pois aos 40 minutos de tratamento a amostra ainda continha $9,65 \mathrm{mg} \mathrm{L}^{-1}$ de COT.

No entanto, como pode ser visto na Figura 28 , os intermediários não foram detectados (foram analisadas amostras retiradas do experimento de 5 em 5 minutos por 40 minutos), sendo possível visualizar apenas o pico do DZP aos 27,1 minutos.

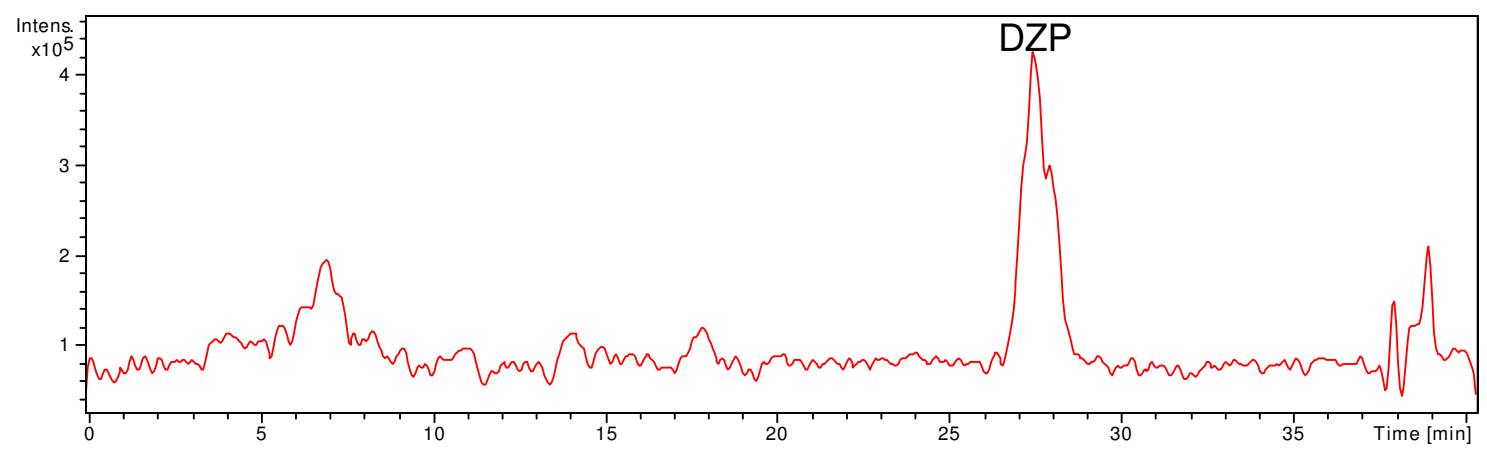

Figura 28. Cromatograma de íons totais (TIC) da amostra retirada do experimento de degradação de DZP por processo foto-Fenton aos 5 minutos de tratamento. Condições iniciais: DZP $=25 \mathrm{mg} \mathrm{L}^{-1} ; \mathrm{FeOx}=0,1 \mathrm{mmol} \mathrm{L}^{-1} ; \mathrm{H}_{2} \mathrm{O}_{2}=10 \mathrm{mmol} \mathrm{L}^{-1}$.

Entretanto, por meio do cromatograma obtido por CLAE-UV (Fig. 29) pode-se observar alguns possíveis intermediários de degradação de DZP formados durante o tratamento. $\mathrm{O}$ cromatograma refere-se à mesma amostra citada anteriormente, que foi retirada do experimento de fotodegradação aos 5 minutos de tratamento. 


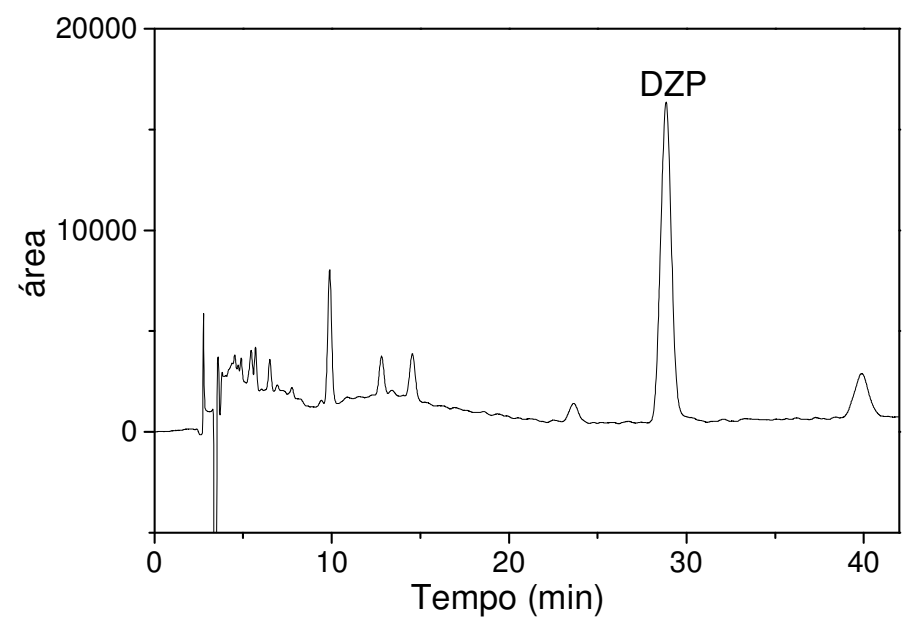

Figura 29. Cromatograma obtido por CLAE-UV da amostra retirada do experimento de degradação de DZP por processo foto-Fenton aos 5 minutos de tratamento. Condições iniciais: DZP $=25 \mathrm{mg} \mathrm{L}^{-1} ; \mathrm{FeOx}=0,1 \mathrm{mmol} \mathrm{L}^{-1} ; \mathrm{H}_{2} \mathrm{O}_{2}=10 \mathrm{mmol} \mathrm{L}^{-1}$.

Dessa forma, como a sensibilidade do equipamento não estava adequada à concentração dos intermediários na amostra, foi feito um procedimento onde a fração da amostra que continha os intermediários (picos cromatográficos - Fig 29) era coletada após passar pelo detector e essa fração era analisada por injeção direta no espectrômetro, no intuito de aumentar a sensibilidade. No entanto, não se obteve êxito nesse procedimento, pois não foi possível detectar os intermediários, pelo menos não no modo que o procedimento foi executado, demandando talvez a coleta de um número maior de frações (foram feitas coletas de apenas duas corridas cromatográficas).

Outro equipamento de CLAE-EM foi utilizado devido a uma proposta aprovada pelo Laboratório Nacional de Luz Síncrontron (LNLS) que disponibiliza a usuários um equipamento que utiliza coluna cromatográfica capilar e detector de tempo de vôo.

Várias tentativas foram feitas modificando as condições do experimento de fotodegradação no intuito de promover uma oxidação mais branda e dessa forma 
detectar um número maior de intermediários. Foram feitos experimentos em concentrações mais baixas de ferro e de $\mathrm{H}_{2} \mathrm{O}_{2}$ e as amostras foram preservadas de duas maneiras. Primeiramente foi utilizada a enzima catalase para consumir $\mathrm{H}_{2} \mathrm{O}_{2}$ e interromper a reação de Fenton. No entanto, na condição cromatográfica que estava sendo utilizada foi possível verificar a eluição da enzima durante a análise, fato que não era percebido nos cromatogramas obtidos por CLAE-UV. A eluição da enzima foi comprovada por meio do branco do experimento, no qual todo o procedimento experimental foi feito, porém na ausência de DZP e pode-se verificar na Figura 30 que a eluição da enzima ocorria entre 4 e 17 minutos da corrida cromatográfica, podendo, dessa forma, dificultar a detecção de intermediários de DZP que poderiam eluir nesse tempo.

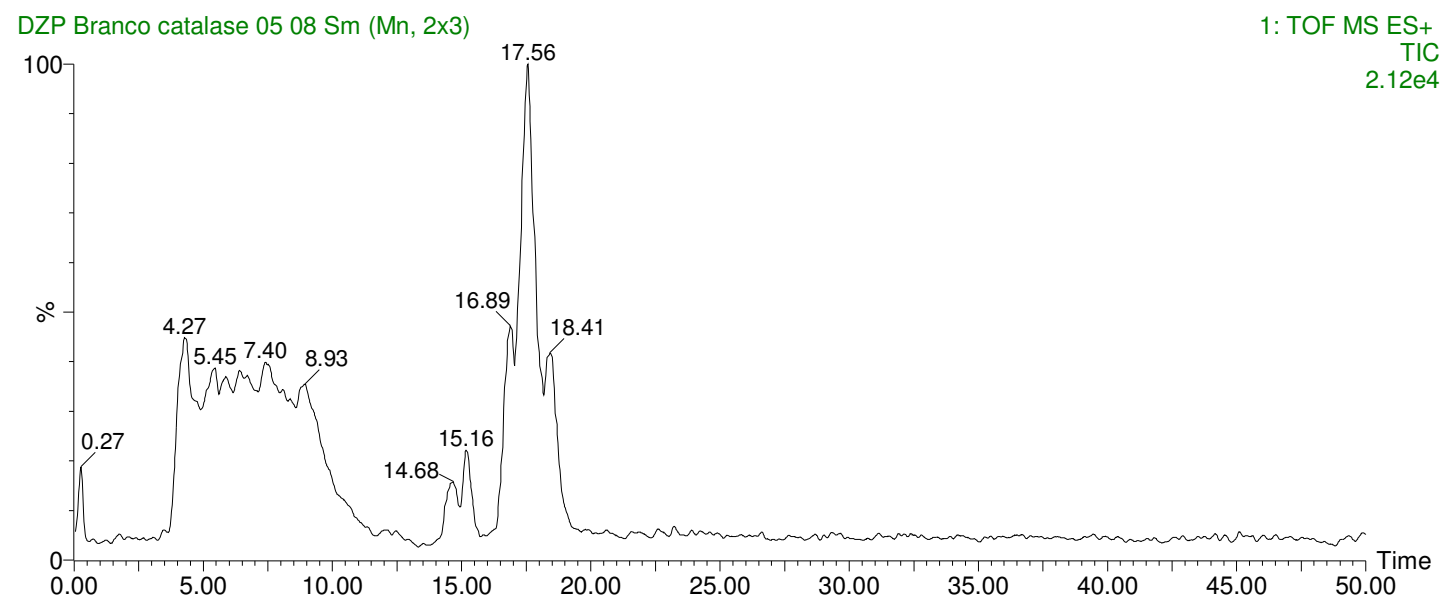

Figura 30. Cromatograma de íons totais (TIC) do branco experimental com adição de catalase para interrupção da reação de Fenton. Condições iniciais: FeOx $=0,1 \mathrm{mmol} \mathrm{L}^{-1}$; $\mathrm{H}_{2} \mathrm{O}_{2}=10 \mathrm{mmol} \mathrm{L}^{-1}$; amostra retirada do experimento aos 5 minutos de tratamento.

Considerando a interferência da enzima catalase, por meio de sua eluição durante a corrida cromatográfica, cartuchos de extração em fase sólida foram utilizados 
para extrair o DZP e os intermediários. Os níveis de recuperação conseguidos para o DZP nestes cartuchos foram bastante variáveis, não apresentando, portanto, repetibilidade. Porém, considerando-se que as análises eram qualitativas e não quantitativas esses cartuchos foram utilizados mesmo sem níveis aceitáveis de repetibilidade.

A Figura 31A mostra o espectro de massas referente ao padrão de DZP que apresentou íon molecular protonado $[\mathrm{M}+\mathrm{H}]^{+}$de relação massa/carga $(\mathrm{m} / \mathrm{z}) 285,0718$. A fragmentação deste íon é mostrada na Figura 31B.

O fragmento de relação $\mathrm{m} / \mathrm{z} 257,0900$ refere-se à perda da carbonila, e esse mesmo fragmento porém com a perda de cloro dá origem ao fragmento de relação $\mathrm{m} / \mathrm{z}$ 222,1249. O fragmento de relação $\mathrm{m} / \mathrm{z} 154,0468$ pode ser atribuído à cisão das ligações entre C-N. Esse padrão de fragmentação foi observado também por outros autores (VAN DER VEN et al., 2004; ZHU; LUO, 2005). O padrão de fragmentação foi estudado com o intuito de propor a estrutura dos intermediários pois, uma vez que se conhece onde ocorreu a quebra das ligações da molécula do DZP, com sua respectiva relação $\mathrm{m} / \mathrm{z}$, pode-se deduzir onde ocorreu a entrada de um grupo $\mathrm{OH}$, por exemplo. 


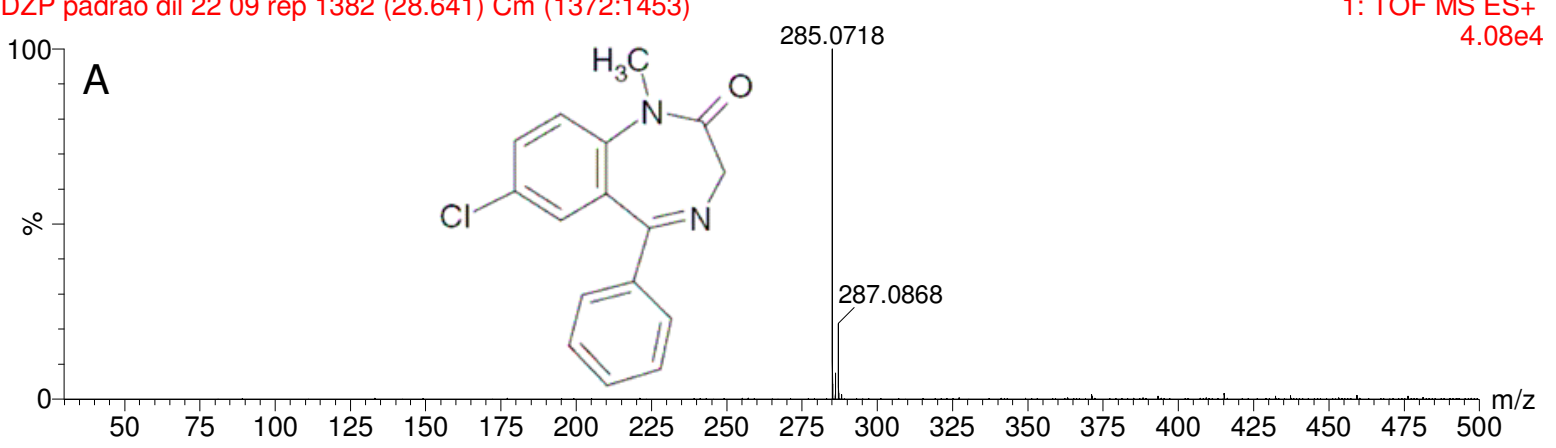

DZP padrao 170955498 (30.485)

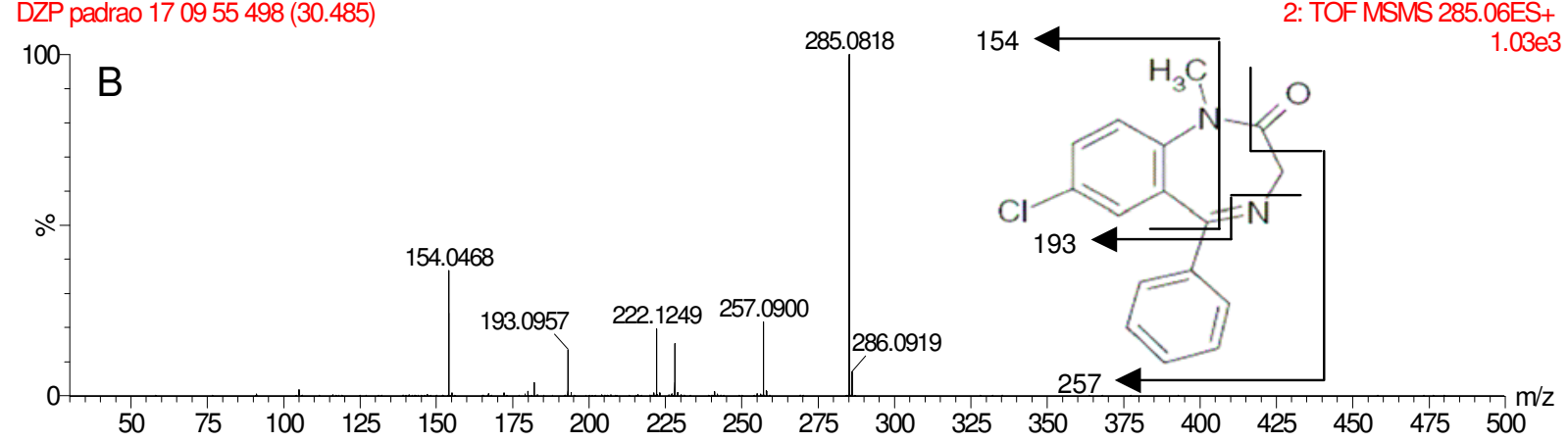

Figura 31. Espectro de massas do padrão de DZP (A) e sua respectiva fragmentação (MSMS) (B).

Foi possível identificar apenas intermediários hidroxilados de degradação de DZP por processo foto-Fenton, sendo estes três isômeros estruturais com a entrada de uma hidroxila e três isômeros estruturais com a entrada de duas hidroxilas. A Figura 32 apresenta o cromatograma pelo pico base (BPI - Base peak intensity - Pico base refere-se ao pico mais intenso do espectro que tem arbitrariamente a intensidade de $100 \%$ ) de uma amostra retirada de um experimento de fotodegradação aos 5 minutos de tratamento, com a indicação de 6 compostos que puderam ser identificados (denominados $D_{n}$ ). 


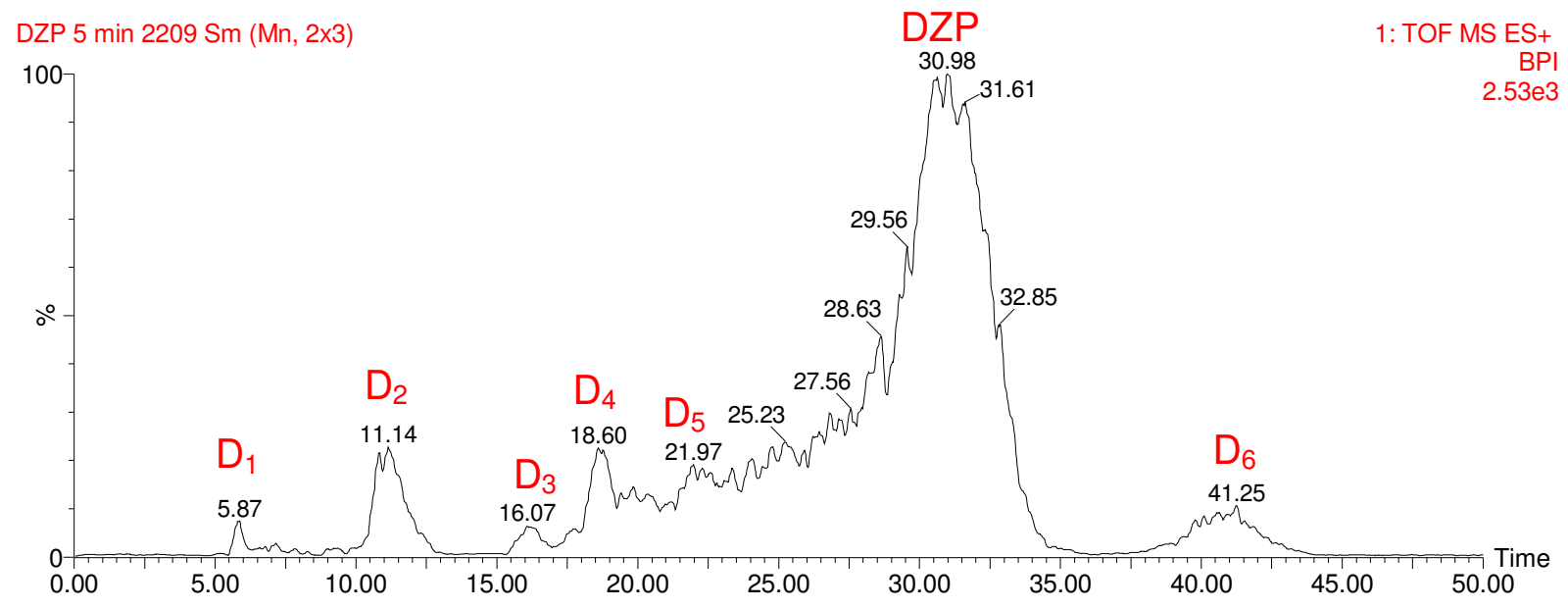

Figura 32. Cromatograma pelo pico base (BPI) da amostra retirada do experimento de fotodegradação de DZP aos 5 minutos de tratamento por processo foto-Fenton. Condições experimentais: $\mathrm{FeOx}=0,10 \mathrm{mmol} \mathrm{L}^{-1} ; \mathrm{H}_{2} \mathrm{O}_{2}=1,0 \mathrm{mmol} \mathrm{L}^{-1} ; \mathrm{pH} 2,5$.

Os compostos $D_{1}, D_{5}$ e $D_{6}$ são isômeros pois apresentam íon molecular de relação m/z 301, ou seja, a entrada de uma hidroxila na molécula do DZP. A Figura 33 A, B e C apresenta os espectros de massas referentes a esses intermediários com seus respectivos tempos de retenção, 5,87; 21,9 e 41,2 minutos. 


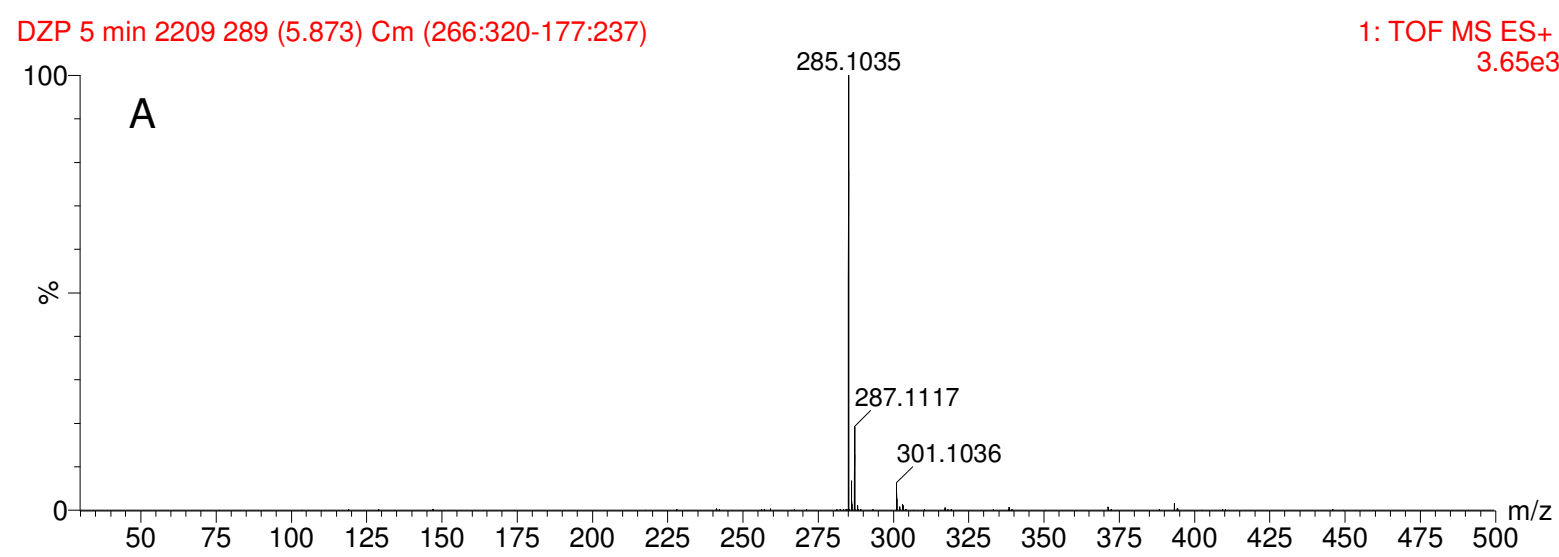

DZP 5 min 2209958 (21.864) Cm (953:974)

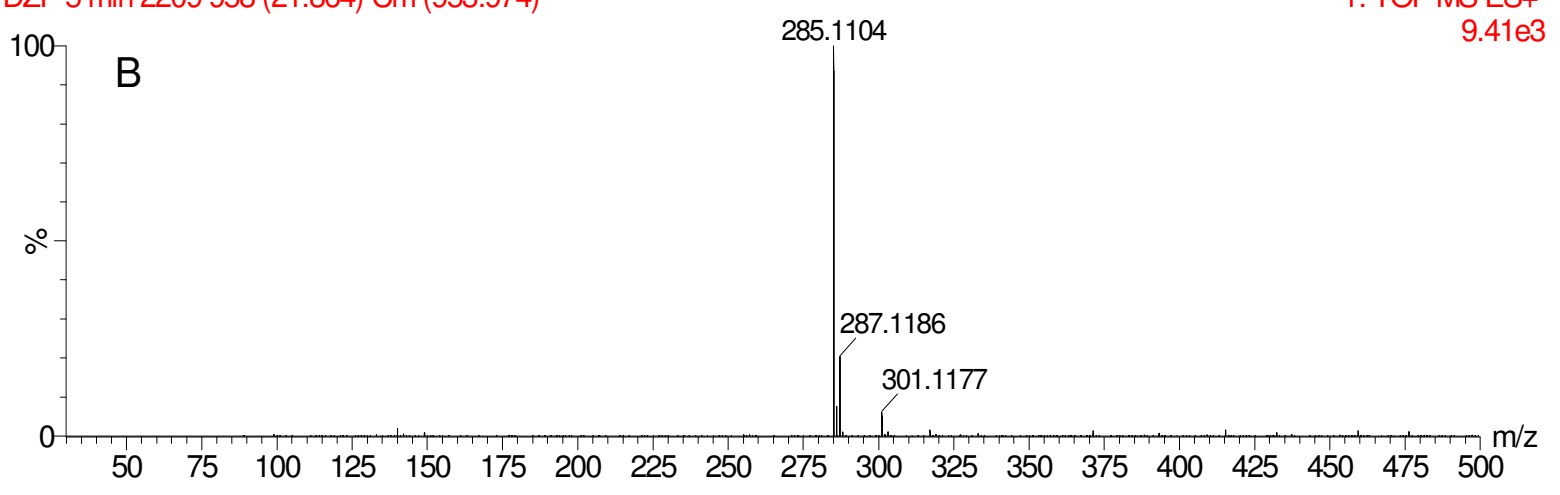

DZP 5 min 22091766 (40.617) Cm (1724:1810-1894:1940)

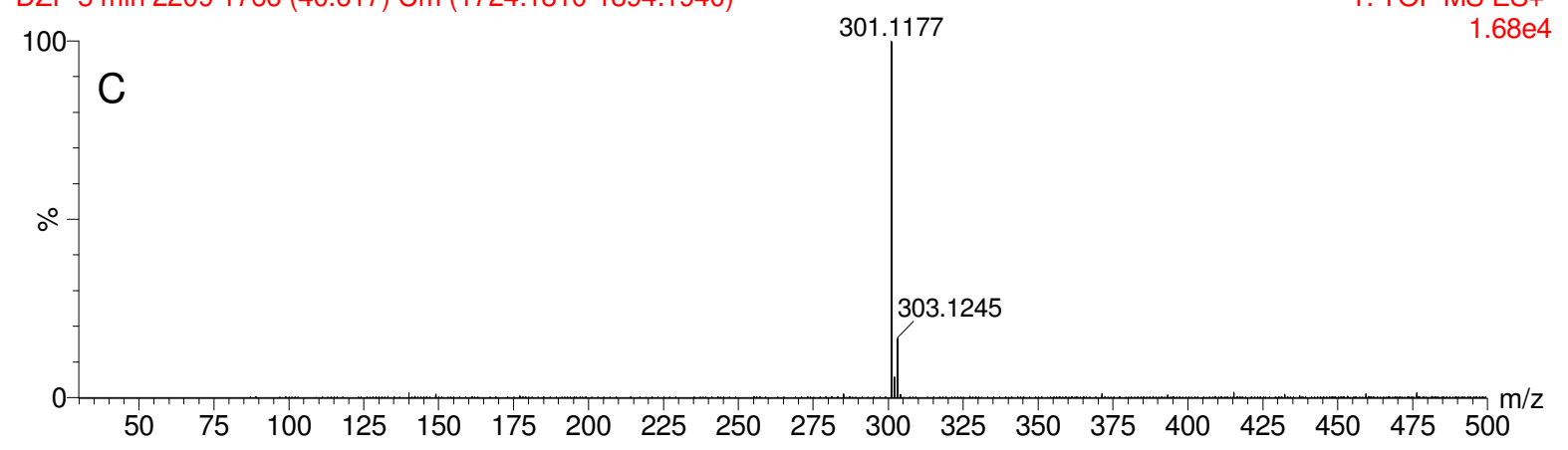

Figura 33. Espectro de massas dos compostos $D_{1}(A) ; D_{5}(B)$ e $D_{6}(C)(\mathrm{m} / \mathrm{z} 301)$, formados durante a degradação de DZP por processo foto-Fenton.

O padrão de fragmentação do íon molecular de relação massa/carga 301 permitiu propor a localização da hidroxila na molécula (Fig. 34). Os fragmentos 170 e 209 foram encontrados no espectro de fragmentação de um dos isômeros $\left(D_{5} ; t_{r}=21,9\right.$ 
min.) (Fig. 34A). O fragmento 170 indica a entrada da hidroxila no anel benzênico que tem o cloro. Já o fragmento 209 indica uma estrutura com a entrada de uma hidroxila no anel diazepínico (que contém os átomos de $\mathrm{N}$ ), no entanto, com perda do radical fenílico e de um átomo de nitrogênio.

Os outros dois isômeros ( $D_{1}$ e $D_{6} ; t_{r}=5,87$ e 41,2 min.) possuem fragmentos 209 e 154 (Fig. 34B). O fragmento 154 indica que a hidroxila não deve ter entrado no anel benzênico que contém o cloro, pois esse fragmento é observado também na fragmentação do DZP, e sim no anel diazepínico. Já o fragmento 209, como já mencionado, indica uma estrutura com a entrada de uma hidroxila, com perda do radical fenílico e de um átomo de nitrogênio. Entretanto, considerando os fragmentos encontrados para os intermediários $D_{1}$ e $D_{6}$ conclui-se que só existe uma posição em que a hidroxila poderia entrar no anel diazepínico (Fig. 34B) e dessa forma provavelmente esses dois compostos são estereoisômeros, uma vez que o carbono onde ocorre a entrada da hidroxila apresenta quiralidade. 
DZP 5 min 220984 (20.501)

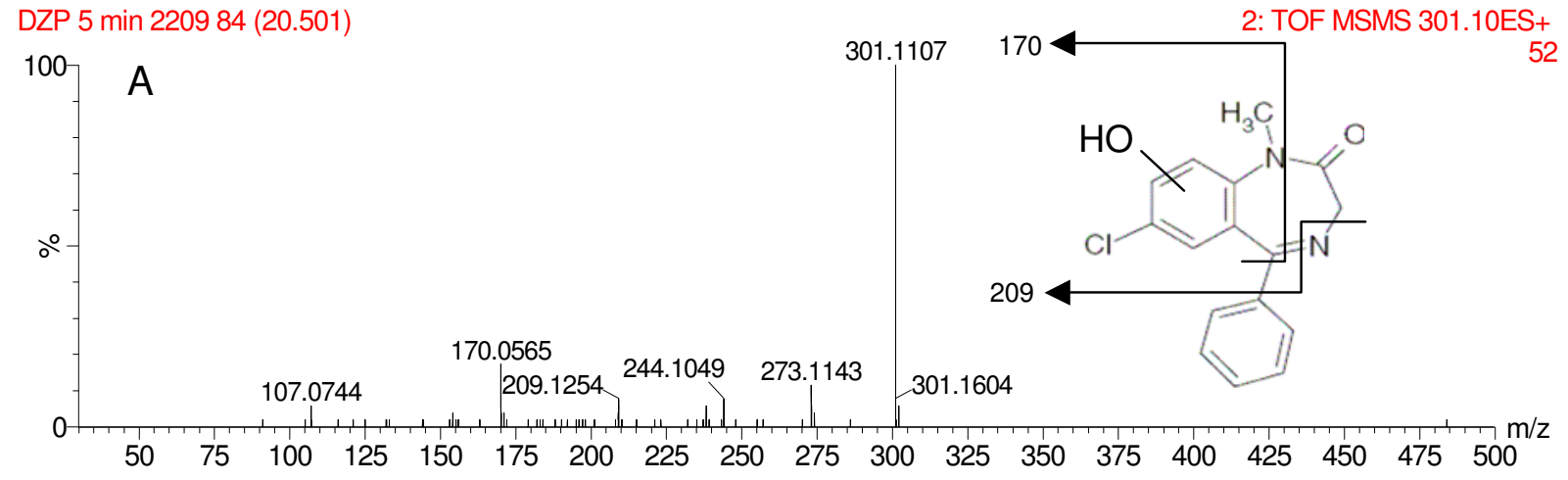

DZP 5 min 2209209 (40.943)

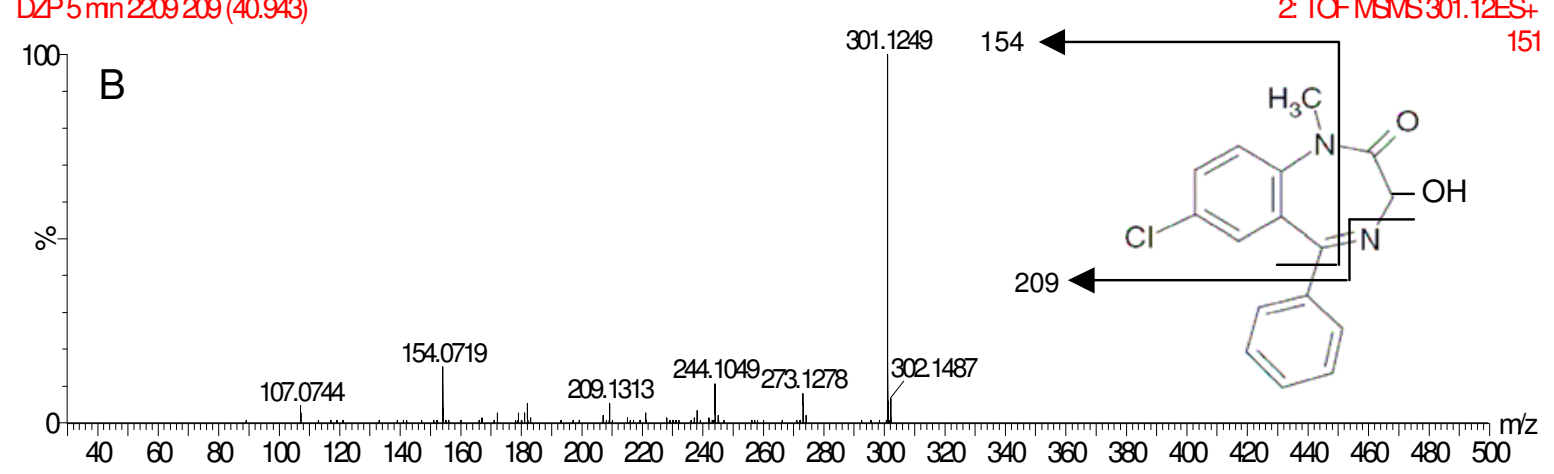

Figura 34. Fragmentação (MSMS) dos isômeros que apresentaram relação massa/carga 301, formados durante a degradação de DZP por processo foto-Fenton. A- Isômero $D_{5}$, B- Isômero $D_{1}$ e $D_{6}$ (formados pela entrada de uma hidroxila).

Os outros três isômeros apresentaram relação m/z $317\left(D_{2}, D_{3}\right.$ e $\left.D_{4}\right)$, o que corresponde a compostos formados com a entrada de duas hidroxilas. Estes compostos apresentaram tempos de retenção de 11,$1 ; 16,0$ e 18,6 minutos, respectivamente, e os espectros de massas correspondentes são mostrados na Figura 35 A,B,C. 

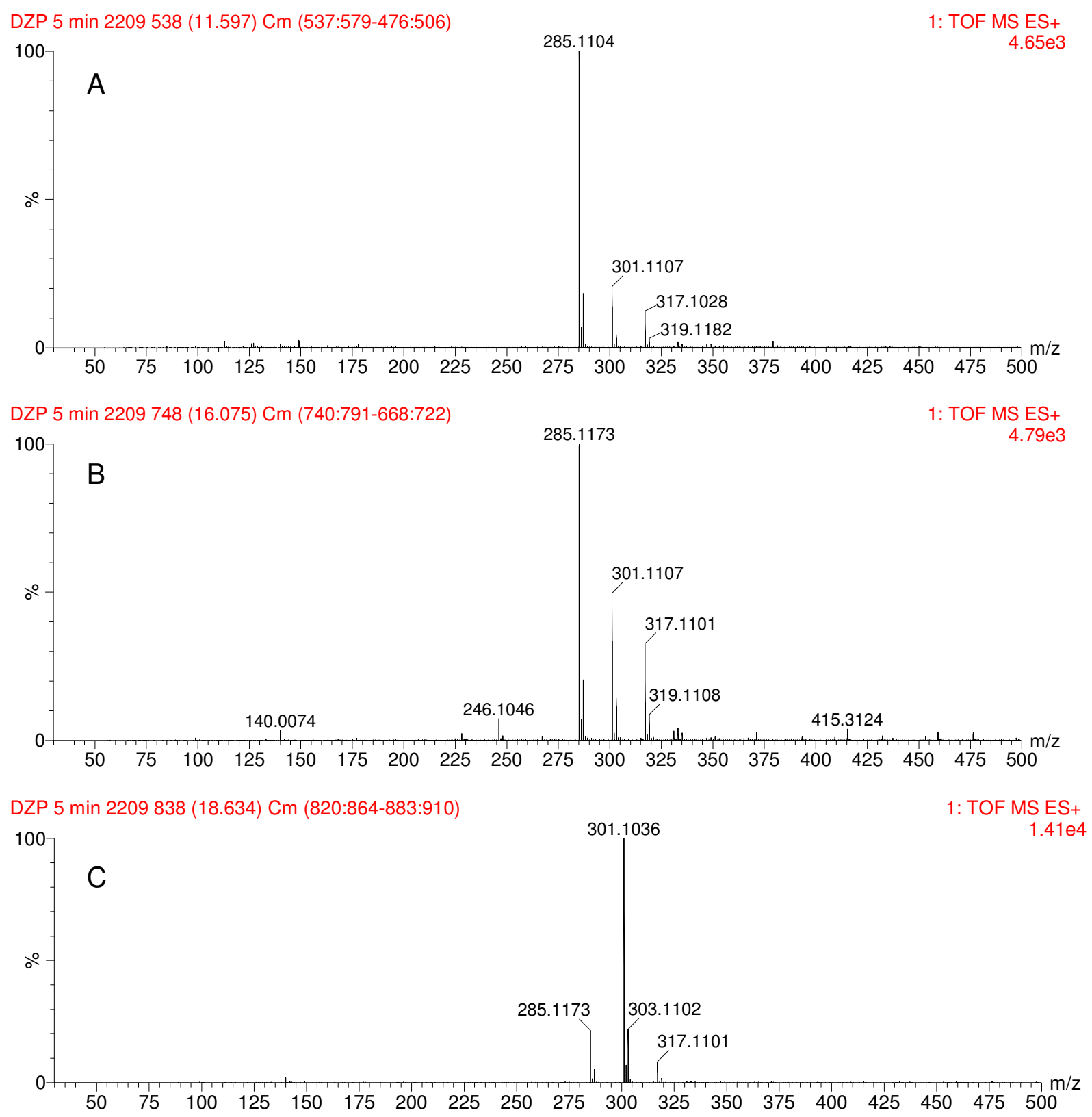

Figura 35. Espectro de massas dos compostos $D_{2}(A)$; $D_{3}(B)$ e $D_{4}(C)$ (m/z 317), formados durante a degradação de DZP por processo foto-Fenton.

O padrão de fragmentação do íon molecular de relação m/z 317 permitiu propor a localização das duas hidroxilas na molécula (Fig. 36). Foi obtido o espectro de fragmentação para os três isômeros de relação massa/carga 317 com fragmentos 225 e 
170. O fragmento 225 refere-se à entrada de duas hidroxilas na molécula, uma no anel clorado e outra no anel diazepínico, no entanto, com a perda do radical fenílico e um átomo de nitrogênio. Já o fragmento 170 indica a entrada de uma hidroxila no anel benzênico que tem o cloro.

DZP 5 min 1709152 (15.348)
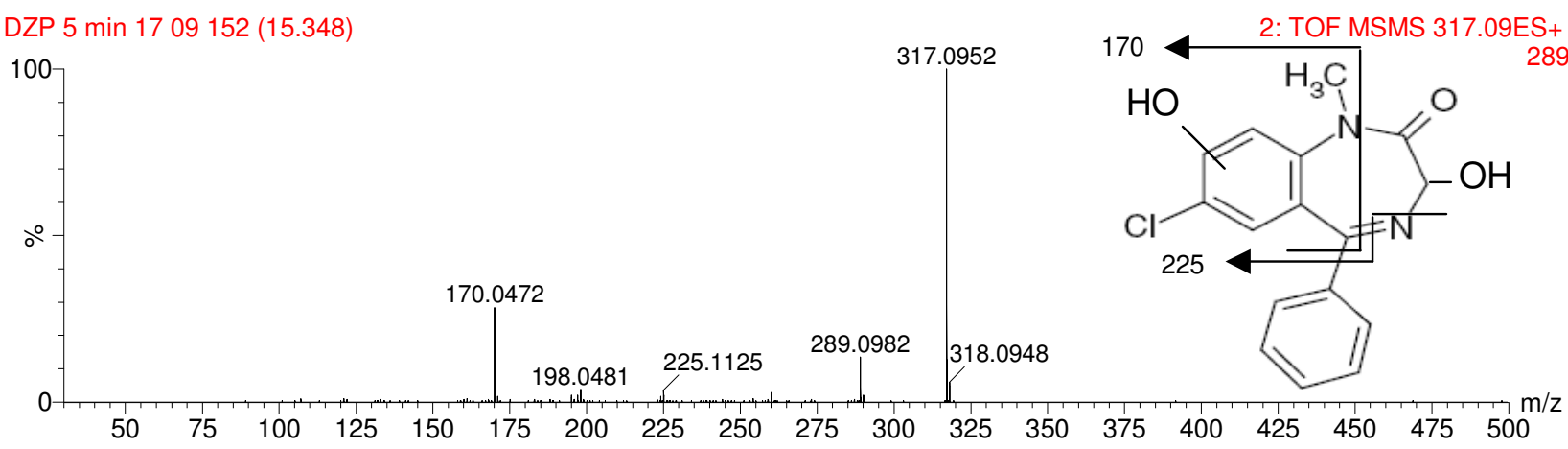

Figura 36. Fragmentação (MSMS) dos isômeros $D_{2}, D_{3}, D_{4}$, que apresentaram relação $\mathrm{m} / z 317$, formados durante a degradação de DZP por processo foto-Fenton.

A Tabela 10 apresenta um resumo dos intermediários formados durante a degradação de DZP por processo foto-Fenton.

Tabela 10. Intermediários de degradação de DZP formados por processo foto-Fenton

\begin{tabular}{c|c|c|c|c|c}
\hline $\begin{array}{c}\text { Interme- } \\
\text { diários }\end{array}$ & $\begin{array}{c}\text { Tempo } \\
\text { retenção } \\
(\min )\end{array}$ & {$[\mathrm{M+H}]^{+}$} & $\begin{array}{c}\text { Fórmula } \\
\text { molecular }\end{array}$ & $\begin{array}{c}\text { Fórmula estrutural } \\
\text { proposta }\end{array}$ & $\begin{array}{c}\text { Fragmentos } \\
\text { (MSMS) }\end{array}$ \\
\hline $\mathrm{D}_{1}$ & 5,87 & 301,1036 & $\mathrm{C}_{16} \mathrm{H}_{13} \mathrm{~N}_{2} \mathrm{ClO}_{2}$ &
\end{tabular}




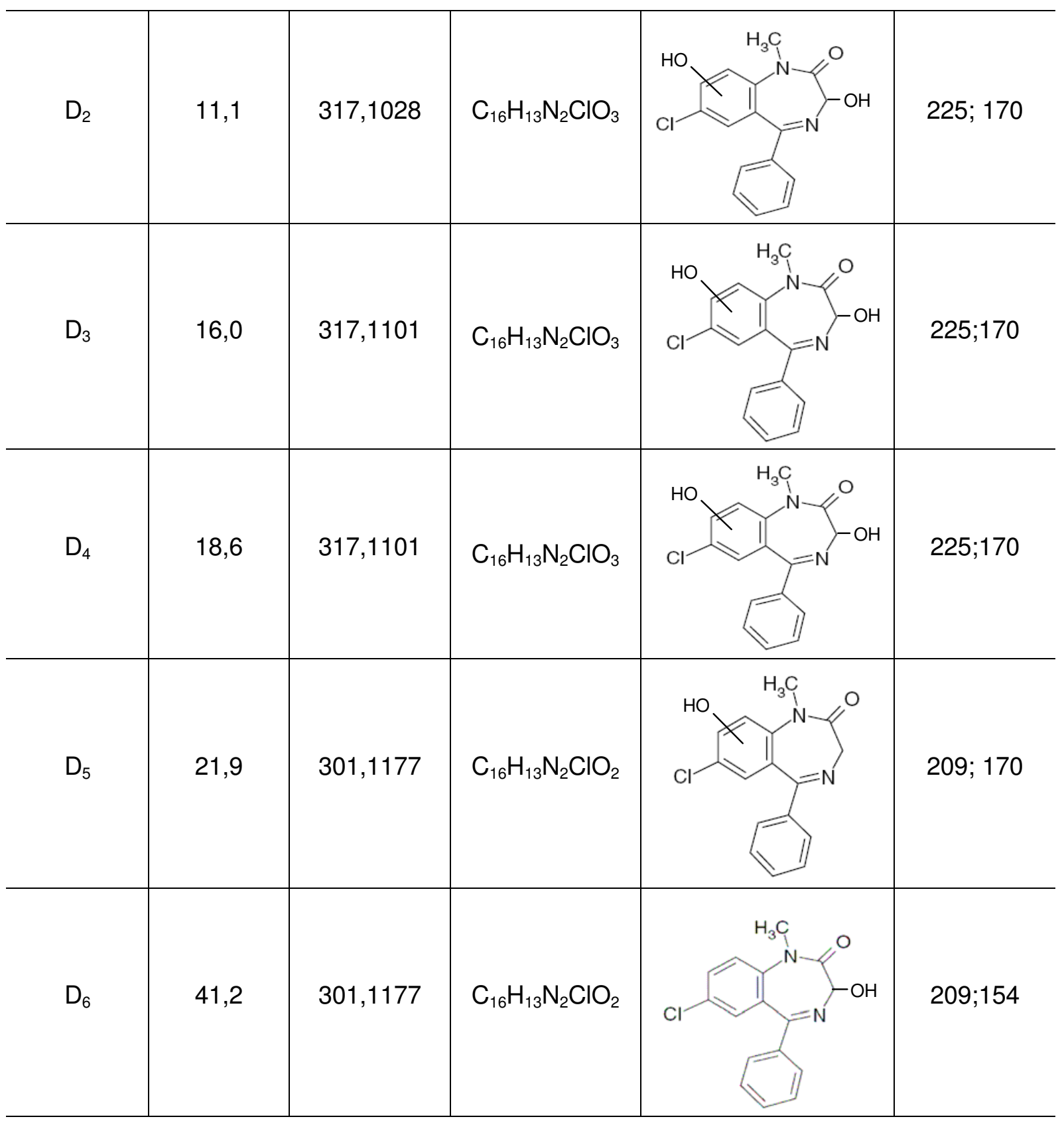

A fragmentação do íon molecular dos intermediários propostos foi determinante para a elucidação da localização das hidroxilas. Esses intermediários apresentaram hidroxilação no anel diazepínico e no anel benzênico que contém o cloro. Isso pode ser explicado pelo fato de que o ataque eletrofílico do radical hidroxila no anel fenílico não é favorecido devido ao grupamento $-\mathrm{C}=\mathrm{N}$ retirar elétrons do anel desativando-o. 
A técnica de CLAE-EM é utilizada na detecção de DZP em ambientes aquáticos (VAN DER VEN et al., 2004), entretanto, como mencionado anteriormente, poucos trabalhos relatam a degradação de DZP por POA e dessa forma não foi encontrado na literatura nenhum estudo de identificação de intermediários de degradação.

\subsubsection{Intermediários de degradação do fármaco propranolol}

O estudo da identificação dos intermediários formados durante a degradação do fármaco PPN também foi feito e como pode-se verificar na Figura 37A, o íon molecular do padrão apresentou relação m/z 260,1096. O espectro de fragmentação (MSMS) (Fig. 37B) mostrou que o fragmento mais intenso (m/z 116) refere-se à quebra da ligação CO com consequente perda da ramificação do anel naftaleno. Esse padrão de fragmentação já foi relatado na literatura (PATEL et. al, 2009).

PPN padrao 22091143 (22.568) Cm (1142:1214) 100

A

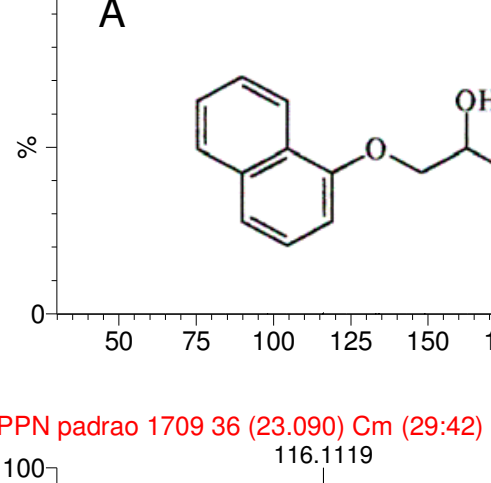

100
116.1119

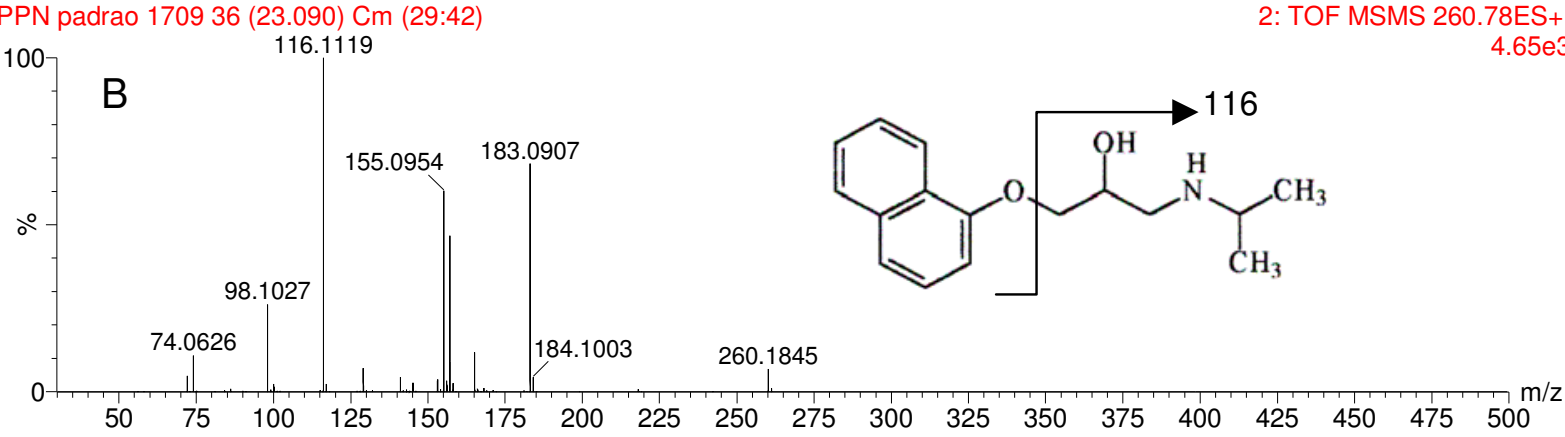

Figura 37. Espectro de massas do padrão de PPN (A) e sua respectiva fragmentação (MSMS) (B). 
Primeiramente foi utilizada a condição experimental PPN $=25 \mathrm{mg} \mathrm{L}^{-1} ; \mathrm{FeOx}=0,1$ mmol L-1; $\mathrm{H}_{2} \mathrm{O}_{2}=10 \mathrm{mmol} \mathrm{L}^{-1} ; \mathrm{pH} 2,5$, com o intuito de promover uma degradação mais branda o que pode ser comprovada pelas análises de COT pois aos 45 minutos de tratamentos a amostra ainda continha $6,85 \mathrm{mg} \mathrm{L}^{-1}$ de COT. Em um primeiro momento, a interrupção da reação de Fenton foi feita por meio da enzima catalase. No entanto, como pode-se verificar na Figura 38 tanto no tempo 2 minutos (Fig. 38A) como no tempo 8 minutos de tratamento (Fig 38B), não foi possível identificar nenhum intermediário de degradação do PPN (foram retiradas amostras aos 2, 5, 8, 15 e 45 minutos de tratamento), sendo possível apenas a visualização da eluição da enzima catalase durante a análise.

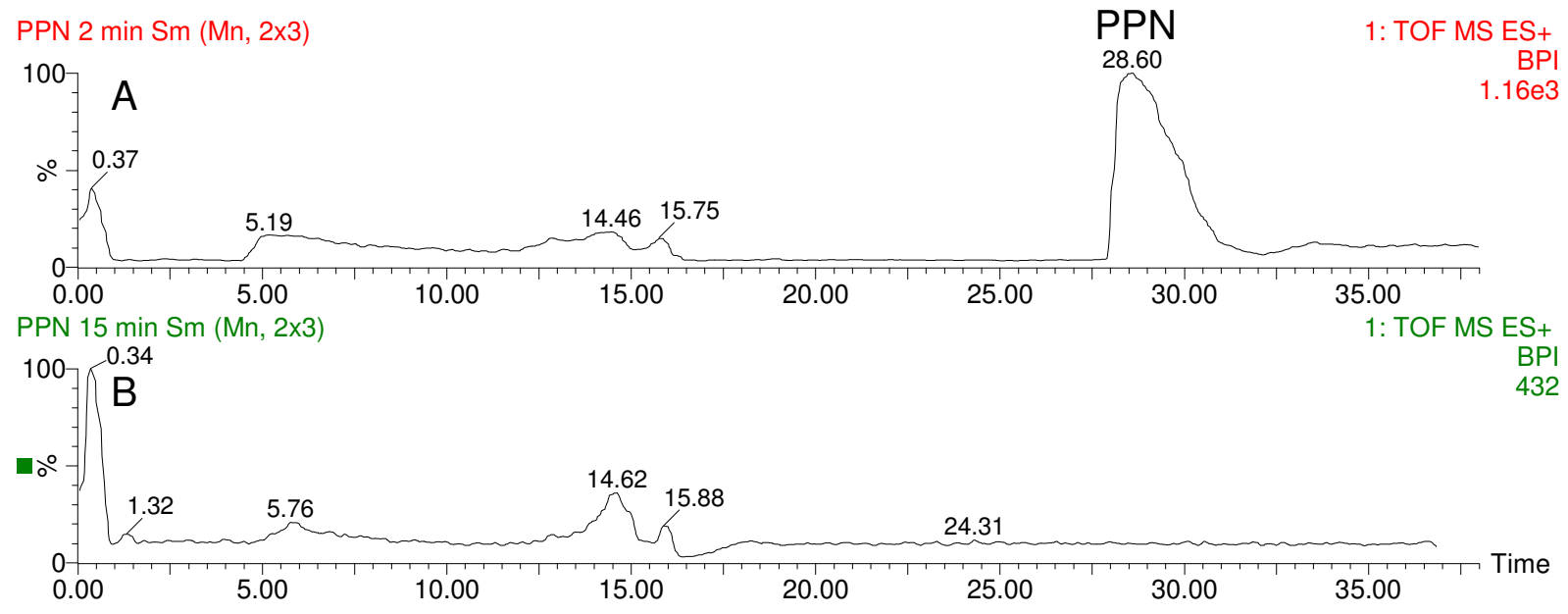

Figura 38. Cromatograma pelo pico base (BPI) da amostra retirada do experimento de fotodegradação de PPN aos 2 minutos (A) e aos 15 minutos (B).

Dessa forma, outro experimento foi feito variando a concentração de $\mathrm{FeOx}(0,10$ para $\left.0,20 \mathrm{mmol} \mathrm{L}^{-1}\right)$ e de $\mathrm{H}_{2} \mathrm{O}_{2}\left(10,0\right.$ para $\left.5,0 \mathrm{mmol} \mathrm{L}^{-1}\right)$, no entanto, novamente nenhum intermediário foi identificado. 
Para verificar a possibilidade de não preservação da amostra durante o procedimento de interrupção da reação de Fenton com a catalase e como no início do trabalho tinha sido feito um estudo de recuperação do PPN em cartuchos de extração em fase sólida, estes cartuchos foram então utilizados para a recuperação do PPN e seus intermediários.

Dessa forma, outro experimento de fotodegradação foi feito em outra condição experimental $\left(\mathrm{FeOx}=0,1 \mathrm{mmol} \mathrm{L}^{-1}\right.$ e $\mathrm{H}_{2} \mathrm{O}_{2}=5 \mathrm{mmol} \mathrm{L}^{-1}$ ) e com a utilização dos cartuchos de EFS para a extração do PPN e dos intermediários de degradação. O estudo de recuperação de PPN nos cartuchos demonstrou que o eluente que apresentou maior eficiência foi metanol com TFA (1\%). Entretanto, para fazer a injeção das amostras na coluna foi necessário fazer uma diluição de 10 vezes, porque esse era o limite suportado pela coluna cromatográfica com relação ao TFA utilizado na eluição das amostras, e assim mais uma vez não foi possível visualizar nenhum intermediário.

Em uma nova tentativa, foi feito um outro experimento de fotodegradação nas seguintes condições experimentais ( $\mathrm{FeOx}=0,1 \mathrm{mmol} \mathrm{L}^{-1}$ e $\mathrm{H}_{2} \mathrm{O}_{2}=1 \mathrm{mmol} \mathrm{L}{ }^{-1}$ ) e foi utilizada novamente a enzima catalase. Como pode ser visto na Figura 39A, embora tenha ocorrido a eluição da enzima durante a análise (branco Fig. 39B) foi possível identificar dois intermediários de degradação do PPN com tempos de retenção 14,38 e 14,82 minutos. 


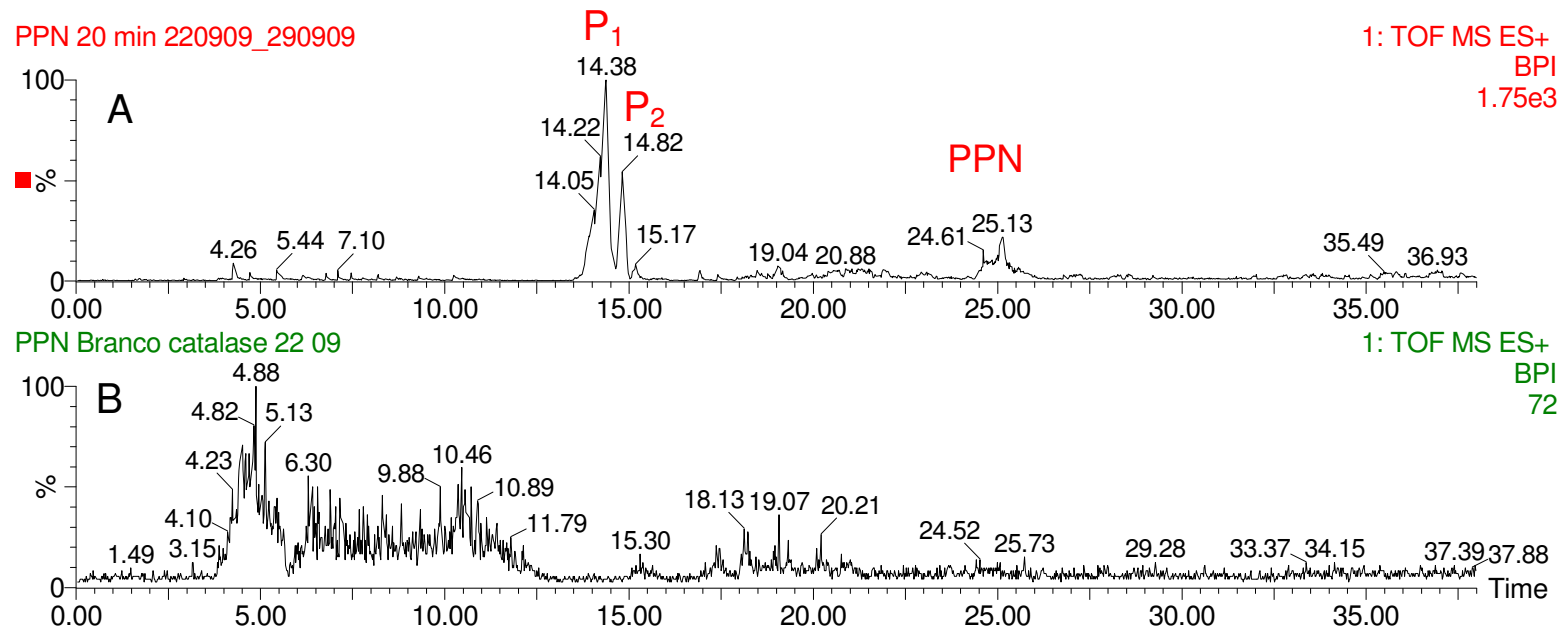

Figura 39. Cromatograma pelo pico base (BPI) referente à amostra retirada do experimento de fotodegradação de PPN aos 20 minutos (A) e branco do experimento (B).

O composto $1\left(\mathrm{P}_{1}\right)$ apresentou o espectro de massas mostrado na Figura 40A, com íon molecular protonado $[\mathrm{M}+\mathrm{H}]^{+}$de relação $\mathrm{m} / \mathrm{z} 372,1368$, que possivelmente é a estrutura que apresenta a entrada de sete hidroxilas na molécula do PPN. O composto $2\left(P_{2}\right)$ (Fig. 40B) apresentou o íon molecular de relação m/z 340,1565 e provavelmente é produto da entrada de cinco hidroxilas na molécula de PPN. A elucidação da estrutura dos intermediários não foi possível, pois para esse fármaco não se obteve com êxito a fragmentação (MSMS) do íon molecular. 


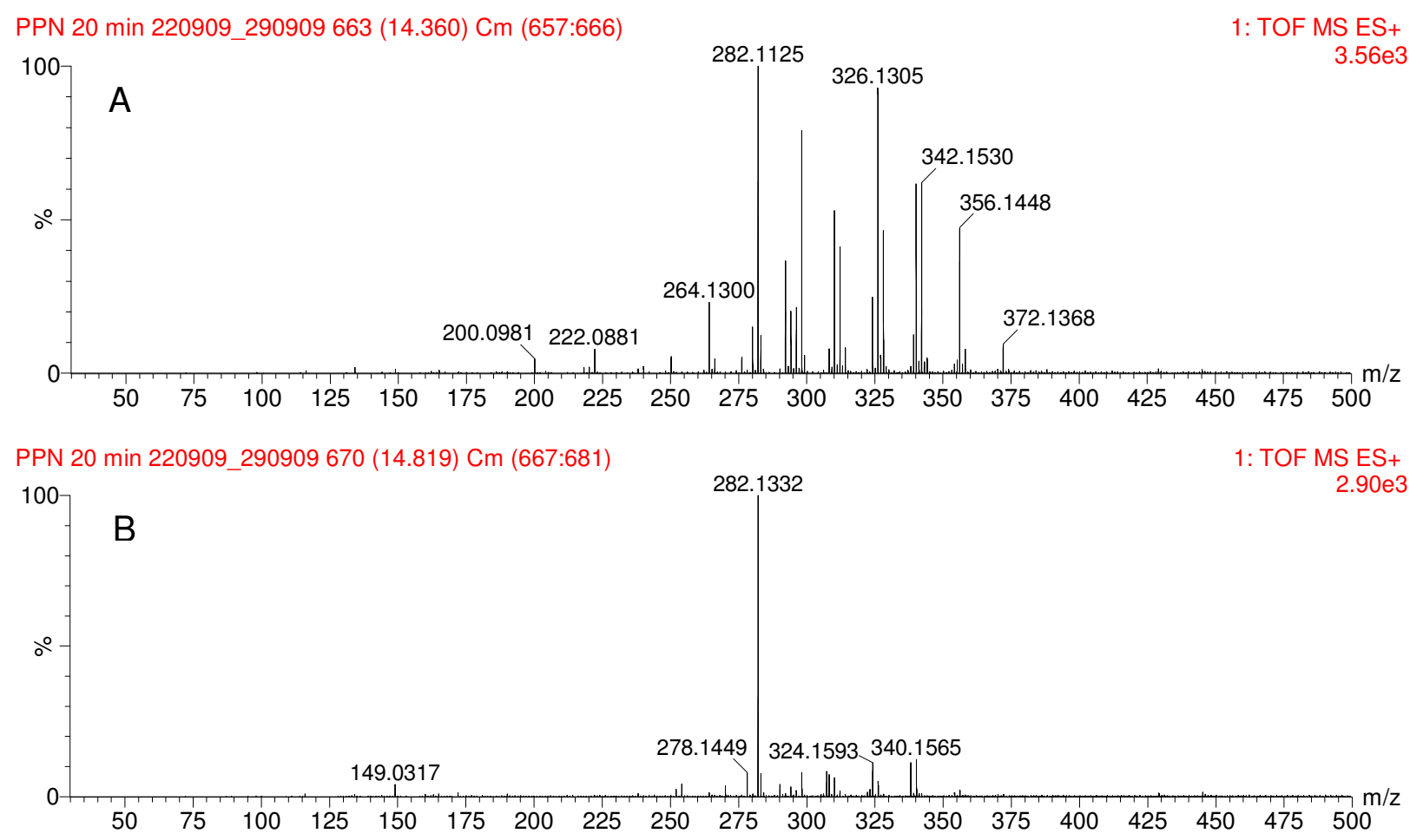

Figura 40. Espectros de massas referentes aos intermediários de degradação do $P P N P_{1}(A)$ e $\mathrm{P}_{2}(\mathrm{~B})$.

Os intermediários de degradação de PPN por ozonização foram estudados por Benner e Ternes (2009). A ozonização de PPN levou à formação de 5 intermediários os quais apresentaram vários isômeros estruturais. A maioria dos intermediários foi formada pelo ataque do $\mathrm{O}_{3}$ ao anel naftaleno o que resultou na abertura do anel com consequente formação de aldeídos. Embora a reação tenha sido feita também em pH 8, onde normalmente há a formação de radical $\mathrm{OH}$, nenhum intermediário encontrado durante a ozonização corresponde aos encontrados neste estudo, provavelmente pelas condições experimentais serem muito diferentes. 


\subsubsection{Intermediários de degradação do fármaco lincomicina}

Para a identificação dos intermediários de degradação do fármaco lincomicina por processo foto-Fenton foi feito um experimento nas seguintes condições experimentais: $\mathrm{FeOx}=0,10 \mathrm{mmol} \mathrm{L}^{-1}$ e $\mathrm{H}_{2} \mathrm{O}_{2}=10,0 \mathrm{mmol} \mathrm{L}^{-1}, \mathrm{pH} 2,5$. A enzima catalase foi utilizada para consumir $\mathrm{H}_{2} \mathrm{O}_{2}$ e consequentemente interromper a reação de degradação de LCM, pois nos testes feitos com cartuchos de EFS não se obteve nenhuma recuperação, tanto para cartuchos C18 (Waters) como para os cartuchos Oasis (HLB). No entanto, nenhum intermediário foi identificado, conforme mostra a Figura 41, em amostras retiradas aos 2 e 8 minutos de tratamento, podendo ser identificado apenas o pico da lincomicina com tempo de retenção de 15,5 minutos.

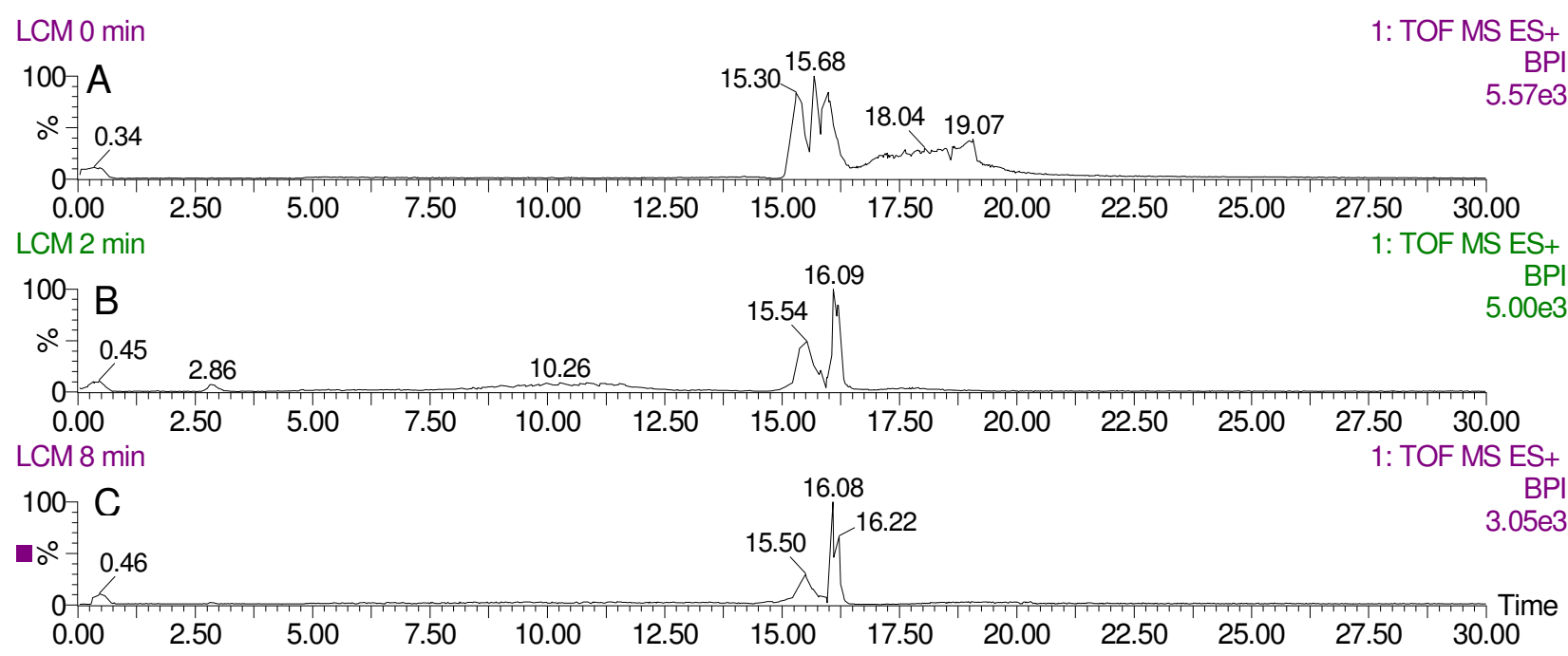

Figura 41. Cromatograma pelo pico base (BPI) obtido para as amostras $0(A), 2$ (B) e $8(C)$ minutos de degradação de LCM por processo foto-Fenton. 
O espectro de massas do padrão de LCM apresentou íon molecular de relação m/z 407,2100 (Fig. 42A). O espectro de fragmentação (Fig. 42B) apresentou o fragmento mais intenso de relação m/z 126,1336 que corresponde ao 3-propil-N-metil-1pirrolidina. Já o fragmento 359 refere-se à perda do grupamento $\mathrm{SCH}_{3}$ da molécula da LCM. Esses fragmentos foram observados também por Wang e colaboradores (2009).

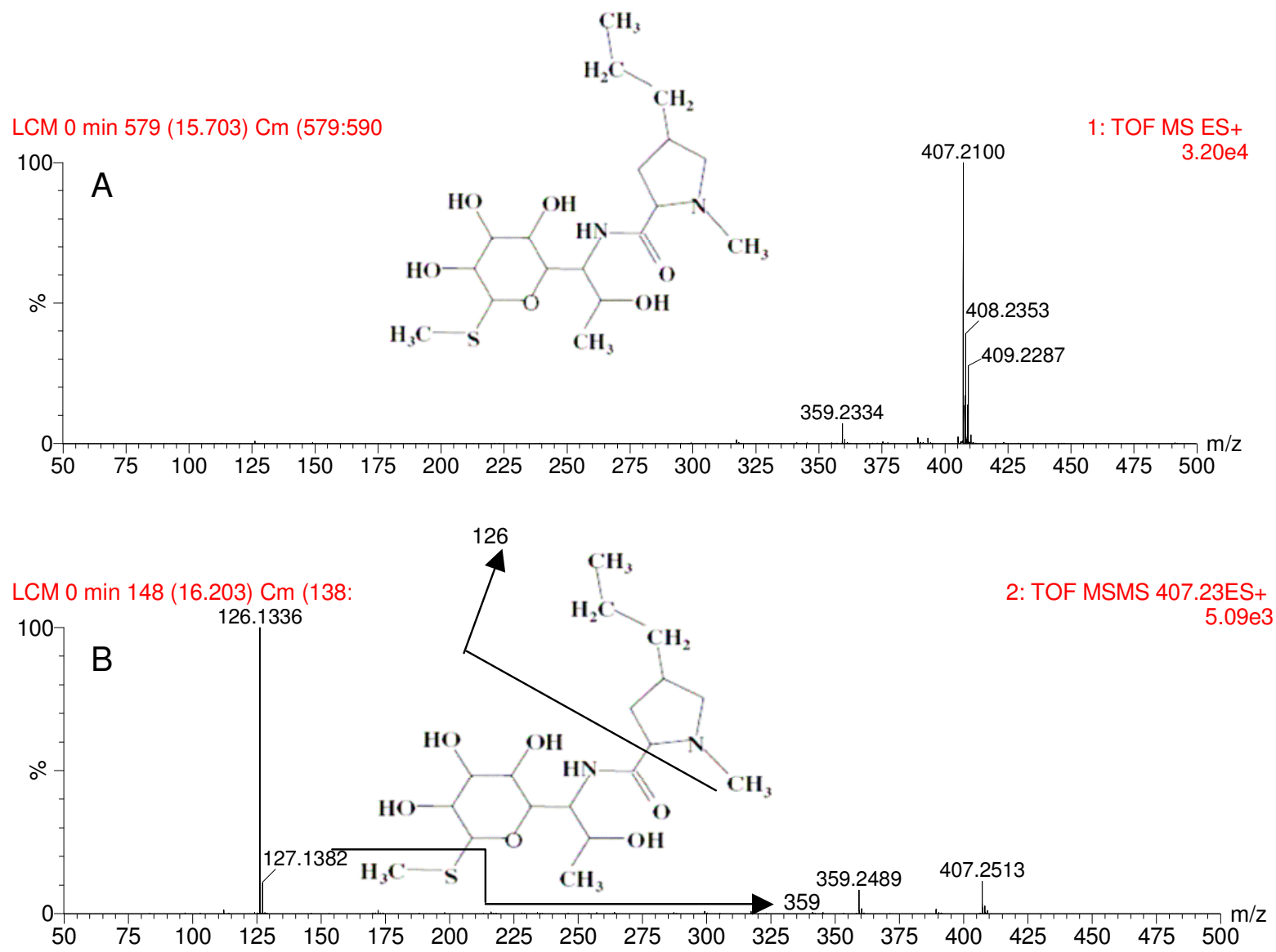

Figura 42. Espectro de massas do padrão de LCM (A) e sua respectiva fragmentação (MSMS) (B).

Em uma nova tentativa de identificar intermediários de degradação de LCM, as condições experimentais foram modificadas para: $\mathrm{FeOx}=0,20 \mathrm{mmol} \mathrm{L}{ }^{-1}$ e $\mathrm{H}_{2} \mathrm{O}_{2}=5,0$ $\mathrm{mmol} \mathrm{L}^{-1}, \mathrm{pH} 2,5$, e conforme pode-se verificar na Figura 43A foi possível identificar um 
composto hidroxilado com tempo de retenção 17,07 minutos e de relação m/z 423,2183 (Fig. 43B) que se refere possivelmente à entrada de uma hidroxila na molécula de LCM.
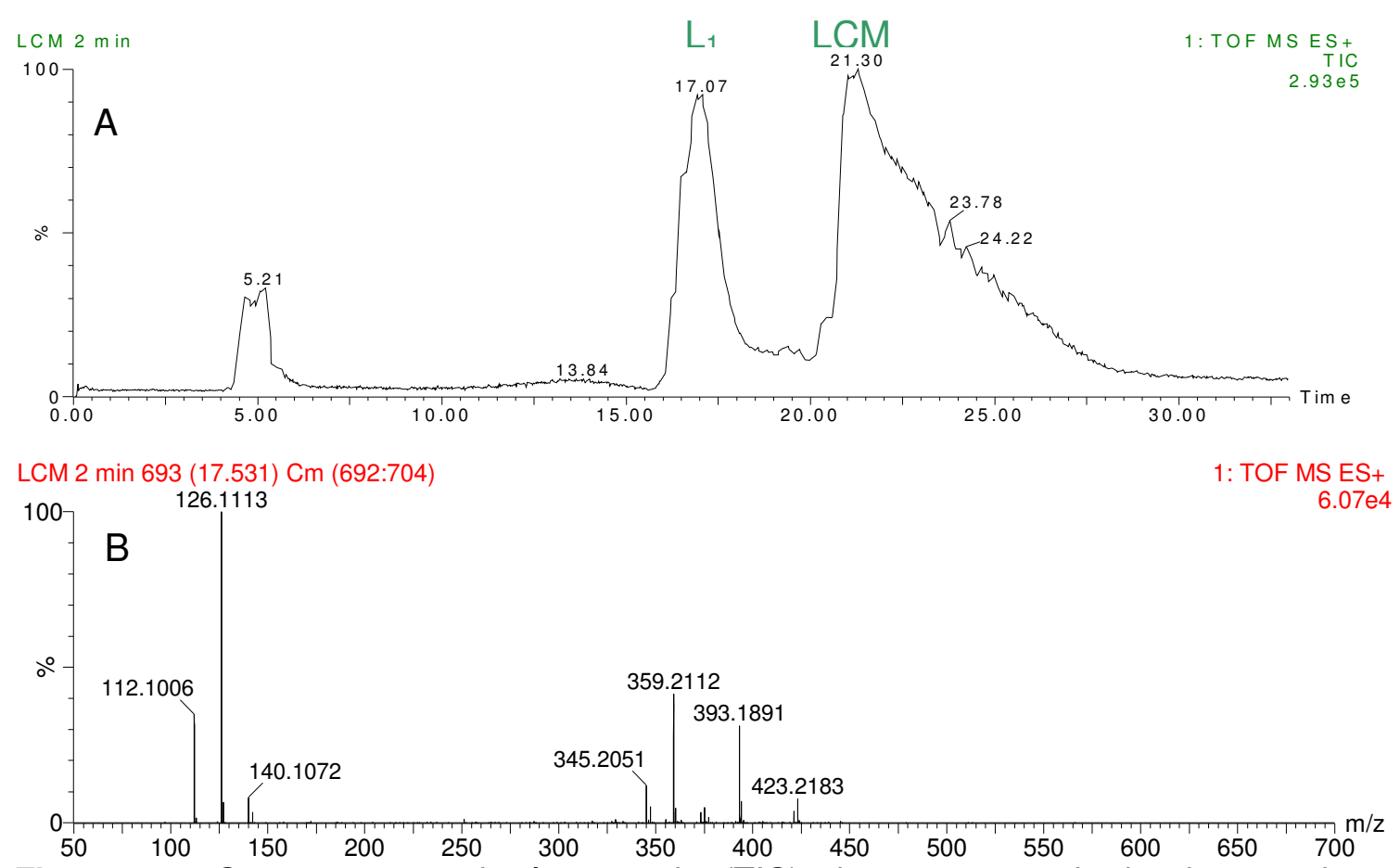

Figura 43. Cromatograma de íons totais (TIC) da amostra retirada do experimento de fotodegradação de LCM aos 2 minutos de tratamento $(A)$ e espectro de massas do $\mathrm{C}_{1}(\mathrm{~B})$.

No cromatograma dos íons totais (TIC - Total ĺon Current) por volta de 5 minutos e 13 minutos foi possível verificar picos referentes à enzima catalase, pois o cromatograma foi comparado com o cromatograma do branco (dado não mostrado). Mesmo analisando amostras retiradas do experimento de fotodegradação de LCM nos tempos $2,5,20$, 40, e 90 minutos de tratamento apenas o intermediário $L_{1}$ pôde ser detectado e identificado. Devido à ausência de fragmentação do íon molecular (MSMS) e à complexidade da molécula de LCM não foi possível determinar em que posição ocorreu a entrada da hidroxila. No entanto, pela análise dos fragmentos da Figura 43B, é possível detectar o fragmento 126 correspondente a 3-propil-N-metil-1-pirrolidina (Fig. 
42 B), e dessa forma pode-se concluir que a entrada da hidroxila não deve ter ocorrido nesta parte da molécula.

O estudo dos intermediários de degradação dos três fármacos revelou que apenas compostos hidroxilados, formados provavelmente na primeira etapa da oxidação, puderam ser detectados e identificados. Entretanto, por meio das análises de COT fica claro que a oxidação atingiu estágios superiores à hidroxilação, pois grande parte da matéria orgânica foi removida. As hipóteses levantadas para a não detecção de outros intermediários foram: a não preservação dos intermediários durante o armazenamento, embora as amostras após adição de catalase tenham sido mantidas congeladas até momentos anteriores à análise e formação de baixas concentrações dos intermediários mais oxidados, impedindo assim, a detecção.

O estudo da identificação dos intermediários formados no processo de degradação dos fármacos foi prejudicado principalmente pela indisponibilidade de equipamento, pois a proposta aprovada pelo LNLS apresentava número limitado de dias de análise (5 dias).

\subsection{Degradação do fármaco diazepam por reações baseadas em ferro metálico} $\left(\mathrm{Fe}^{\circ}\right)$

4.3.1 Degradação de DZP com ferro nanoparticulado

Inicialmente o objetivo do estudo do sistema $\mathrm{Fe}^{-}$era promover a redução do fármaco diazepam e por isso ferro nanoparticulado foi usado devido à maior área superficial das nanopartículas, uma vez que as reações redutivas ocorrem na superfície 
do metal. Entretanto, reações de oxidação foram também estudadas pois, segundo a literatura, são mais promissoras uma vez que podem promover também a mineralização do composto-alvo.

A Figura 44 apresenta uma série de experimentos preliminares que foram feitos com ferro nanoparticulado, sintetizado conforme anteriormente mencionado, para testar o grande número de variáveis do processo $\mathrm{Fe}^{\mathrm{o}}$. $\mathrm{O}$ ensaio 1 foi feito somente na presença de $\mathrm{Fe}^{\circ} \mathrm{com} \mathrm{pH}$ inicial ajustado para $3 \mathrm{com}_{2} \mathrm{SO}_{4}$. O ajuste de $\mathrm{pH}$ inicial foi feito e mantido em alguns experimentos para tentar evitar a formação de hidróxidos de ferro pois, após adição de $\mathrm{Fe}^{\circ} \mathrm{o} \mathrm{pH}$ da solução subia imediatamente para 8-9 devido à oxidação do ferro e consequente formação de íons hidroxila (Eq. 25):

$2 \mathrm{Fe}^{\circ}+\mathrm{O}_{2}+2 \mathrm{H}_{2} \mathrm{O} \rightarrow 2 \mathrm{Fe}^{2+}+4 \mathrm{OH}^{-}$

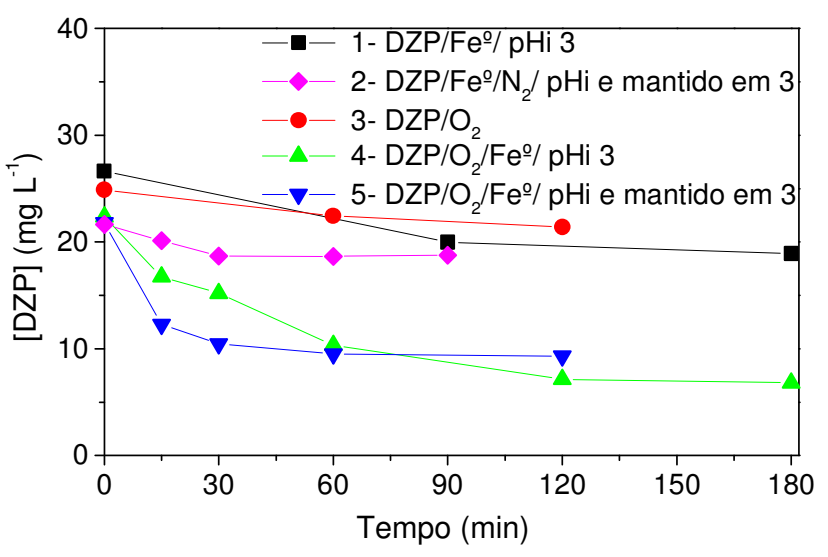

Figura 44. Remoção de DZP por meio do sistema ferro metálico nanoparticulado. Condição inicial: $[\mathrm{DZP}]=21-26 \mathrm{mg} \mathrm{L}^{-1} ;\left[\mathrm{Fe}^{0}\right]=3 \mathrm{~g} \mathrm{~L}^{-1}$. Agitação magnética.

Uma vez que em condição anóxica (ensaio 2) também não foi obtida remoção significativa do fármaco, o borbulhamento de ar foi feito para fornecer $\mathrm{O}_{2}$ ao sistema e assim facilitar as reações 1, 3, 4 e 5 conforme esquematizado na Figura 45. 


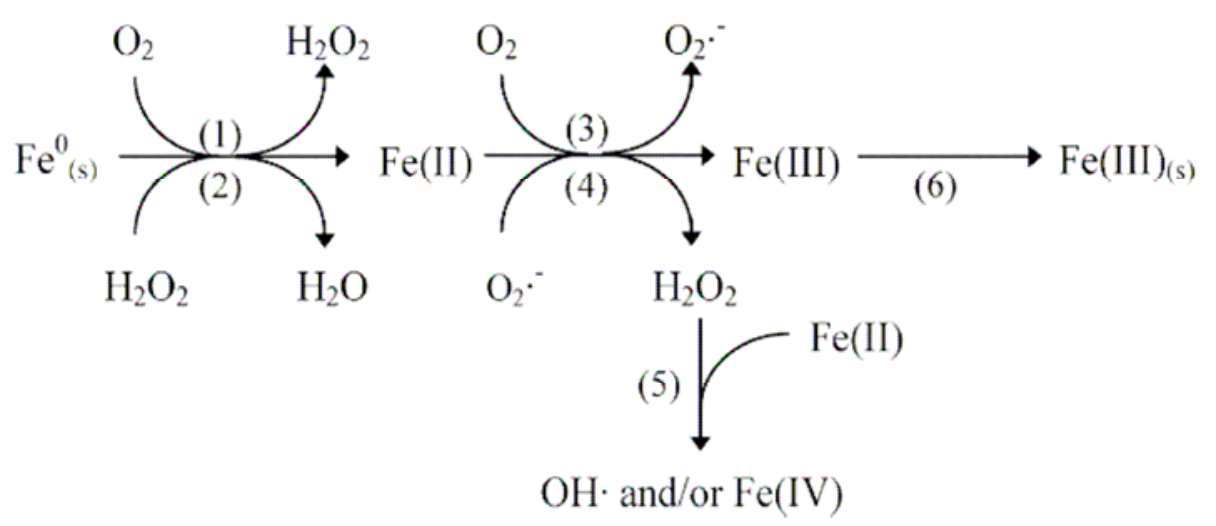

Figura 45. Reações possíveis no sistema $\mathrm{Fe} \% \mathrm{O}_{2}$ (KEENAN; SEDLAK, 2008a).

O experimento controle feito para verificar se ocorria a volatilização de DZP (ensaio 3), uma vez que os experimentos seriam feitos sob fluxo de ar, mostrou que em 2 horas de borbulhamento de ar houve perda de cerca de $14 \%$ de DZP. Os experimentos feitos na presença de ar e $\mathrm{Fe}^{\circ}$ (ensaio 4-5) mostraram que com $\mathrm{pH}$ mantido em 3 a velocidade de remoção foi maior, embora o percentual de remoção de DZP após 120 minutos tenha sido semelhante nos dois ensaios.

Os resultados obtidos no monitoramento da remoção de COD (dado não mostrado) mostraram que não houve remoção em nenhum dos experimentos cujos resultados são apresentados na Figura 44. Como mencionado anteriormente, o sistema $\mathrm{Fe}^{\mathrm{o}} / \mathrm{O}_{2}$ pode promover a degradação de compostos orgânicos, entretanto para o fármaco testado e nas condições experimentais utilizadas os resultados não foram satisfatórios, uma vez que foi obtida apenas a remoção do fármaco (aproximadamente $60 \%$ ), mas não a mineralização do mesmo. Dessa forma, na tentativa de melhorar a oxidação e promover a mineralização do fármaco foi testada a adição do ligante EDTA ao sistema (sistema $\mathrm{Fe}^{\circ} / \mathrm{EDTA} / \mathrm{O}_{2}$ ). 
Neste trabalho várias concentrações de $\mathrm{Fe}^{\mathrm{o}}$ e EDTA foram testadas, pois a literatura relata que a razão molar de $\mathrm{Fe}^{\circ}$ :EDTA maior do que 1:1 pode prejudicar a formação do complexo Fe"EDTA-O $\mathrm{O}_{2}$ o qual é indispensável para a geração de $\mathrm{H}_{2} \mathrm{O}_{2}$ (NORADOUN; CHENG, 2005).

As maiores concentrações de ferro testadas apresentaram os melhores resultados (Fig. 46 - ensaios a, d, e). Entretanto, a razão molar Feํ:EDTA não pode ser 1:1 porque para utilizar por exemplo, $110 \mathrm{mmol} \mathrm{L}^{-1}$ de EDTA (concentração de Fe ${ }^{\circ}$ utilizada nos ensaios a e b, Fig. 46) isso significaria adicionar ao sistema mais de 13000 $\mathrm{mg} \mathrm{L}^{-1}$ de carbono, o que é totalmente inviável. A maior concentração de EDTA testada foi $3,0 \times 10^{-4} \mathrm{~mol} \mathrm{~L}^{-1}$, o que corresponde a cerca de $36 \mathrm{mg} \mathrm{L}^{-1}$ de carbono, contra $16 \mathrm{mg}$ $\mathrm{L}^{-1}$ do composto-alvo. Entretanto, pode-se observar na Figura 46A que a adição de EDTA favoreceu significativamente a oxidação, embora a remoção de COD em todos os experimentos aparentemente foi correspondente somente ao carbono do próprio ligante (Fig. 46B). O experimento feito em razão molar 1:1 apresentou o pior resultado (Fig. 46 ensaio c) provavelmente devido à menor concentração de Fe ${ }^{\circ}$ utilizada. 


$$
\begin{aligned}
& \text { a- }[\mathrm{Fe}] 110 \times 10^{-3} \text { [EDTA] } 80 \times 10^{-6} \mathrm{~mol} \mathrm{~L}^{-1} \\
& \text { b- }[\mathrm{Fe}] 110 \times 10^{-3} \mathrm{~mol} \mathrm{~L}^{-1} \mathrm{sem} \text { EDTA } \\
& \text { c- }[\mathrm{Fe}] 200 \times 10^{-6} \text { [EDTA] } 200 \times 10^{-6} \mathrm{~mol} \mathrm{~L}^{-1} \\
& \text { d- }[\mathrm{Fe}] 54 \times 10^{-3} \text { [EDTA] } 300 \times 10^{-6} \mathrm{~mol} \mathrm{~L}^{-1} \\
& \text { e- }[\mathrm{Fe}] 95 \times 10^{-3} \text { [EDTA] } 300 \times 10^{-6} \mathrm{~mol} \mathrm{~L}^{-1}
\end{aligned}
$$
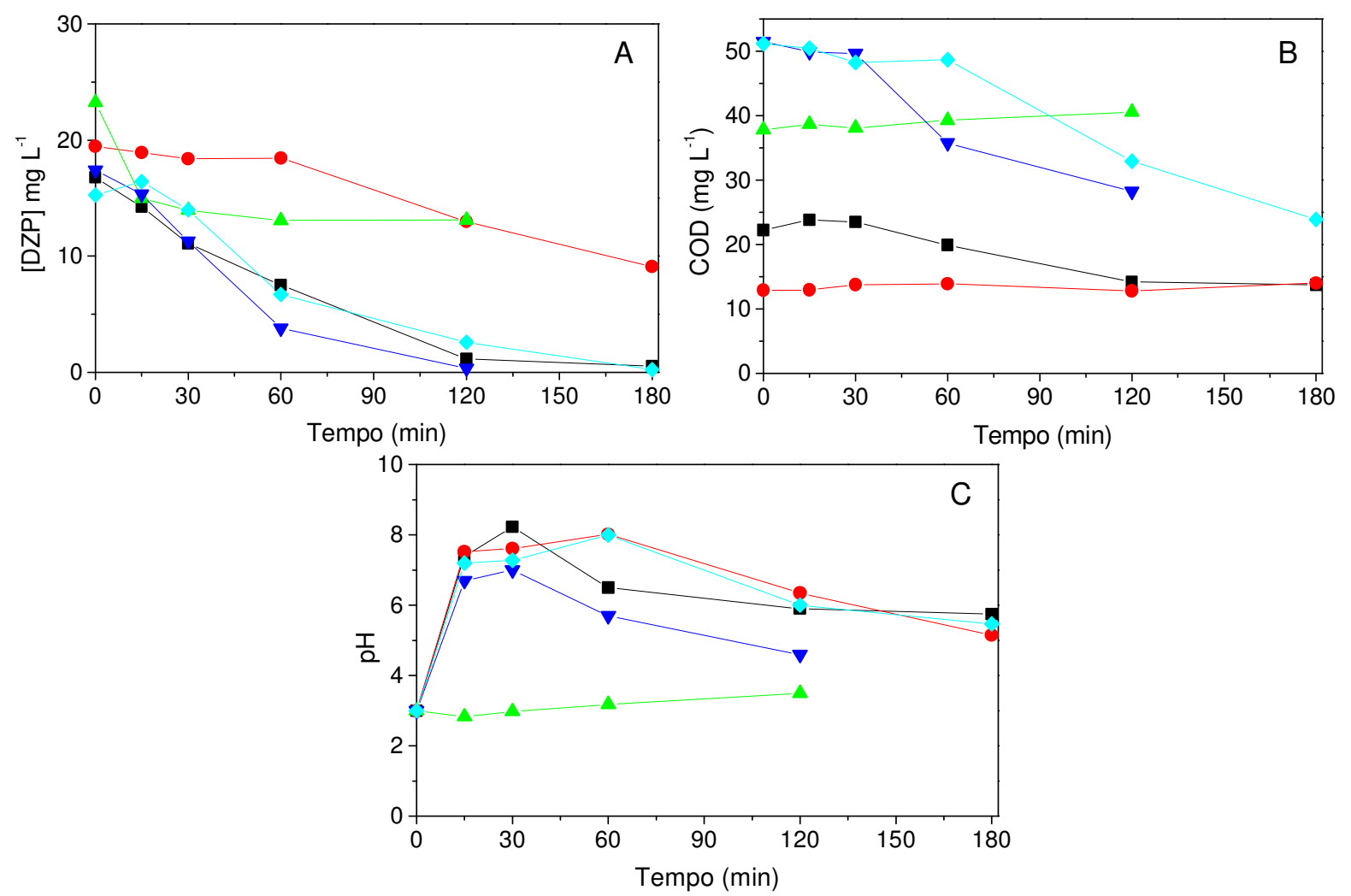

Figura 46. Remoção de DZP pelo sistema $\mathrm{Fe} / / E D T A / O_{2}$. (A) remoção de $\operatorname{COD}(\mathrm{B})$, monitoramento do $\mathrm{pH}(\mathrm{C})$. Condição inicial: $[\mathrm{DZP}]=15-23 \mathrm{mg} \mathrm{L}^{-1}$; Com borbulhamento de ar e agitação magnética. ( $\mathrm{Fe}^{\mathrm{o}}$ nanoparticulado).

O monitoramento do $\mathrm{pH}$ revelou que embora o $\mathrm{pH}$ fosse ajustado para 3 no início dos experimentos, este subia rapidamente como já mencionado anteriormente (Fig. 46 C). Uma das vantagens do ligante é não ser necessário o uso de meio ácido, pois permite tratar efluentes com valores de $\mathrm{pH}$ perto da neutralidade. 
Um dos primeiros trabalhos que relatam a utilização do sistema $\mathrm{Fe} / \mathrm{EDTA} / \mathrm{O}_{2}$ foi de Noradoun e colaboradores (2003) para a degradação de 4-clorofenol e pentaclorofenol obtida em 4 e 70 horas, respectivamente. Visto que esses autores relatam a utilização de ferro microparticulado em altas concentrações $\left(50 \mathrm{~g} \mathrm{~L}^{-1}\right)$ a próxima etapa desse trabalho foi verificar essa possibilidade.

\subsubsection{Degradação de DZP com ferro microparticulado}

Conforme já mencionado, alguns trabalhos da literatura relatam a utilização de ferro microparticulado no sistema que utiliza EDTA e $\mathrm{O}_{2}$ para a degradação de contaminantes (NORADOUN; CHENG, 2005; ZHOU et al., 2009). Dessa forma, os experimentos a seguir relatados foram feitos com ferro microparticulado (20 mesh - 800 $\mu \mathrm{m})$.

4.3.2.1 Influência do pré-tratamento das micropartículas de $\mathrm{Fe}^{\circ}$ e das concentrações de $F e^{o}$ e EDTA

Em processos heterogêneos como $\mathrm{Fe}^{\circ}$, a adsorção do contaminante na superfície das partículas do $\mathrm{Fe}^{\mathrm{o}}$ é uma preocupação relatada por vários autores (NORADOUN et al., 2003; ZHOU et al., 2009). Entretanto, após testes para verificar a extensão da adsorção, os valores encontrados por esses autores foram negligenciáveis. Nesse trabalho, também foram feitos alguns ensaios para verificar a adsorção do fármaco DZP na superfície do $\mathrm{Fe}^{\circ}$. Após 30 minutos de tratamento, uma 
amostra foi retirada de um experimento de degradação e dividida em duas alíquotas: a primeira foi filtrada e o sobrenadante injetado no cromatógrafo; na segunda foi adicionado metanol, com o intuito de dissolver moléculas de DZP adsorvidas na superfície do $\mathrm{Fe}^{\circ}$ e posteriormente também injetada no cromatógrafo. Entretanto, os resultados de concentração de DZP foram semelhantes, o que indica que não havia ocorrido adsorção. Outro ensaio foi feito adicionando ácido $(\mathrm{HCl})$ para dissolver as camadas superficiais do precipitado de óxidos e hidróxidos de ferro de uma amostra, porém a concentração de DZP encontrada nesta solução também indicou que não houve adsorção. Por fim, foi feito um experimento de degradação com o intuito de parar a reação em 30 minutos, medir a concentração de DZP em todo o sobrenadante e dissolver com $\mathrm{HCl}$ todo o material sólido, formado por precipitado de óxidos e hidróxidos de ferro. Entretanto, devido provavelmente ao grande tamanho das micropartículas, não foi possível dissolver todo o precipitado, nem em condições drásticas $\left(\mathrm{HCl}, \mathrm{H}_{2} \mathrm{SO}_{4}\right.$ concentrado). O resultado da análise da concentração de DZP na solução resultante, também não demonstrou adsorção. Portanto, conclui-se que não ocorreu adsorção de DZP nas partículas de $\mathrm{Fe}^{\mathrm{o}}$ nas condições utilizadas neste trabalho.

Como esses experimentos foram feitos sob fluxo de ar e com uma vigorosa agitação mecânica por tratar-se de um processo heterogêneo, um experimento controle foi feito para avaliar a volatilização de DZP e verificou-se que $24 \%$ de remoção de COD e de DZP aconteceu devido à volatilização após 120 minutos de tratamento. Nos resultados apresentados a seguir, não foi descontado o percentual relativo à volatilização.

As partículas de $\mathrm{Fe}^{\circ}$ podem apresentar óxidos em sua superfície, que por sua vez passivam a superfície do metal dificultando as reações que ali ocorrem. Dessa 
forma, as partículas de $\mathrm{Fe}^{-}$passaram por um pré-tratamento, no qual foram lavadas com ácido $\left(\mathrm{HCl}\right.$ ou $\left.\mathrm{H}_{2} \mathrm{SO}_{4}\right)$ na concentração $1,0 \mathrm{~mol} \mathrm{~L}^{-1}$ para a ativação da superfície. $\mathrm{A}$ princípio foi testado o ácido clorídrico, uma vez que este ácido é mais eficiente na remoção de óxidos de ferro (ATKINS ; JONES, 2001).

Para avaliar o efeito do pré-tratamento das partículas de $\mathrm{Fe}^{\circ}$ foram feitos dois experimentos (dado não mostrado) em condições semelhantes ([Feo $]=5 \mathrm{~g} \mathrm{~L}^{-1}$; [EDTA] $=112 \mathrm{mg} \mathrm{L}^{-1}$ ), diferindo apenas na lavagem ou não das micropartículas. Ao final de 60 minutos de experimento, a oxidação de DZP foi de aproximadamente $50 \%$ em ambos os casos, mas a remoção de COD foi favorecida no experimento onde houve a lavagem do ferro. Embora tenha sido alcançado somente $10 \%$ de remoção de COD, esse resultado é um indicativo de que a ativação do metal provavelmente proporciona uma maior produção de oxidante e consequentemente uma maior remoção de COD. Na tentativa de aumentar a degradação do composto-alvo bem como a remoção de carbono orgânico, a concentração de EDTA no sistema foi dobrada (223 mg L $\left.\mathrm{L}^{-1}\right)$ e ao final de 90 minutos de tratamento a oxidação de DZP aumentou para 77\%. No entanto, a remoção de COD não ultrapassou $9 \%$.

$\mathrm{Na}$ busca pela otimização das concentrações dos reagentes a próxima etapa foi aumentar a concentração de Feํo. Nos experimentos da Figura 47 em que a concentração de $\mathrm{Fe}^{-}$foi aumentada de $5 \mathrm{~g} \mathrm{~L}^{-1}$ para 25 e $40 \mathrm{~g} \mathrm{~L}^{-1}$, pôde-se verificar um significativo aumento na remoção de COD. Quanto à oxidação de DZP, níveis de 67 e $75 \%$ foram alcançados respectivamente nas concentrações 25 e $40 \mathrm{~g} \mathrm{~L}^{-1}$ de $\mathrm{Fe}^{\circ}$. Ao final de 60 minutos de tratamento a remoção de COD foi de $60 \%$ em ambos os casos, sendo que aparentemente a maior concentração de $\mathrm{Fe}^{-}$utilizada $\left(40 \mathrm{~g} \mathrm{~L}^{-1}\right)$ só influenciou na velocidade da reação. 
Para verificar o efeito do pré-tratamento das micropartículas utilizando essas maiores concentrações de $\mathrm{Fe}^{-}$, outro experimento sem a lavagem do $\mathrm{Fe}^{\circ}$ foi feito. No entanto, o resultado do experimento sem lavagem anterior foi confirmado pois, embora haja oxidação de DZP de aproximadamente $60 \%$, nenhuma remoção de COD é observada.
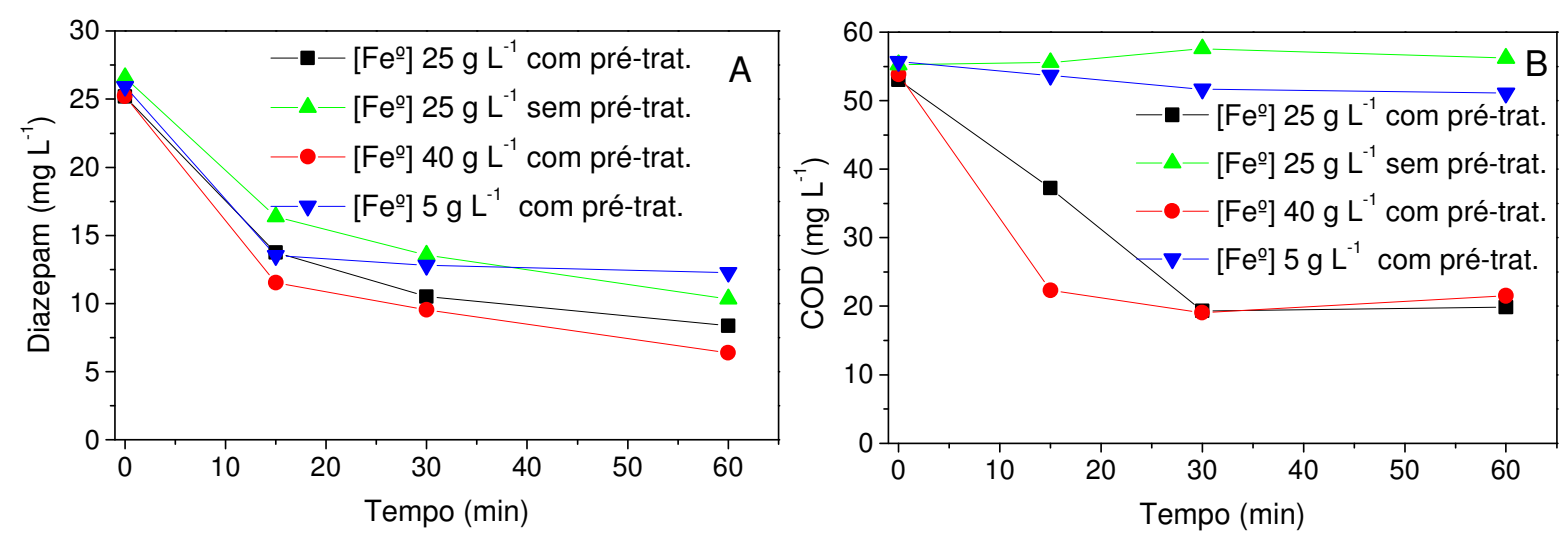

Figura 47. Influência da concentração e pré-tratamento de $\mathrm{Fe}^{\circ}$ microparticulado na oxidação de DZP (A) e remoção de COD (B). Condições experimentais: [DZP] $=25 \mathrm{mg} \mathrm{L}^{-1}$; [EDTA] $=119 \mathrm{mg} \mathrm{L}^{-1}$; borbulhamento de ar; agitação mecânica; lavagem de $\mathrm{Fe}$ o $\mathrm{HCl}$ $1,0 \mathrm{~mol} \mathrm{~L}^{-1}$.

O pré-tratamento das micropartículas nestes experimentos foi feito com ácido clorídrico, pois esse é mais eficiente na dissolução de óxidos de ferro. No entanto, o cloreto residual pode diminuir a eficiência do tratamento uma vez que pode sequestrar radicais hidroxila, conforme mostra a Equação 26 (PIGNATELLO; OLIVEROS; MacKAY, 2006).

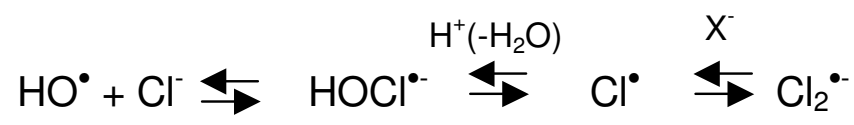

Dessa forma, foram feitos experimentos com o intuito de verificar a interferência dos íons cloretos na eficiência do processo de degradação. A Figura 48 mostra que a 
oxidação de DZP é favorecida quando o pré-tratamento é feito com ácido sulfúrico e embora a velocidade de remoção de COD tenha sido maior quando ácido clorídrico foi utilizado, para evitar colocar um interferente no sistema, a lavagem do $\mathrm{Fe}^{0}$ passou a ser feita com ácido sulfúrico.
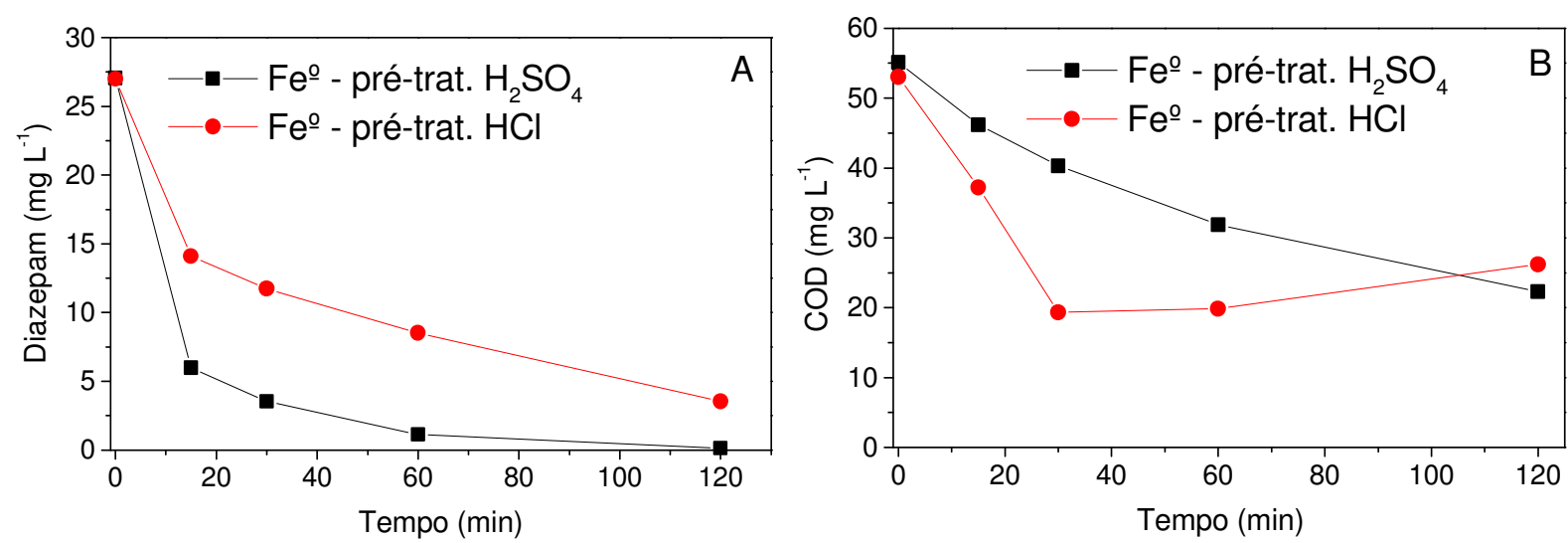

Figura 48. Influência do ácido usado no pré-tratamento das micropartículas de $\mathrm{Fe}^{\circ}$ na oxidação de DZP (A) e remoção de COD (B). Condições experimentais:[DZP] $=25 \mathrm{mg} \mathrm{L}^{-1}$; $\left[\mathrm{Fe}^{\circ}\right]=25 \mathrm{~g} \mathrm{~L}^{-1} ;[\mathrm{EDTA}]=119 \mathrm{mg} \mathrm{L}^{-1}$, borbulhamento de ar; agitação mecânica.

Para verificar a influência do EDTA no sistema foram feitos experimentos variando a concentração deste ligante. A Figura 49 mostra que a oxidação de DZP foi similar para as duas concentrações de EDTA testadas, pois encontravam-se abaixo do limite de detecção em aproximadamente 60 minutos, mas foi prejudicada na ausência de EDTA uma vez que a oxidação não ultrapassou $80 \%$ em 120 minutos de tratamento. Com relação à remoção de COD, percentuais semelhantes foram obtidos, aproximadamente $60 \%$ para as duas concentrações testadas. No entanto, a maior concentração testada não foi utilizada pois a eficiência alcançada com essa maior concentração não justifica a maior adição de matéria orgânica proveniente do ligante ao sistema. Na ausência de EDTA, porém foi obtido somente 16\% de remoção de COD. Entretanto vale ressaltar que essa remoção refere-se ao carbono correspondente ao 
composto-alvo, e no caso da adição de EDTA há uma maior remoção de COD mas que é também correspondente ao próprio ligante pois há adição de $38 \mathrm{mg} \mathrm{L}^{-1}$ de carbono quando a concentração $119 \mathrm{mg} \mathrm{L}^{-1}$ de EDTA é utilizada e $72 \mathrm{mg} \mathrm{L}^{-1}$ quando a concentração de EDTA é $223 \mathrm{mg} \mathrm{L}^{-1}$.

Na Figura 49 pode-se observar também que a velocidade inicial de oxidação de DZP é muito maior nos primeiros 15 minutos de tratamento e praticamente a mesma para as duas concentrações de EDTA testadas. Essa maior velocidade inicial de reação pode ser atribuída ao fato de que no início dos experimentos a superfície do metal ainda não está passivada e, dessa forma, as reações acontecem mais rapidamente. Com o passar do tempo, a superfície vai sendo coberta por possíveis óxidos e hidróxidos formados, dificultando as reações.
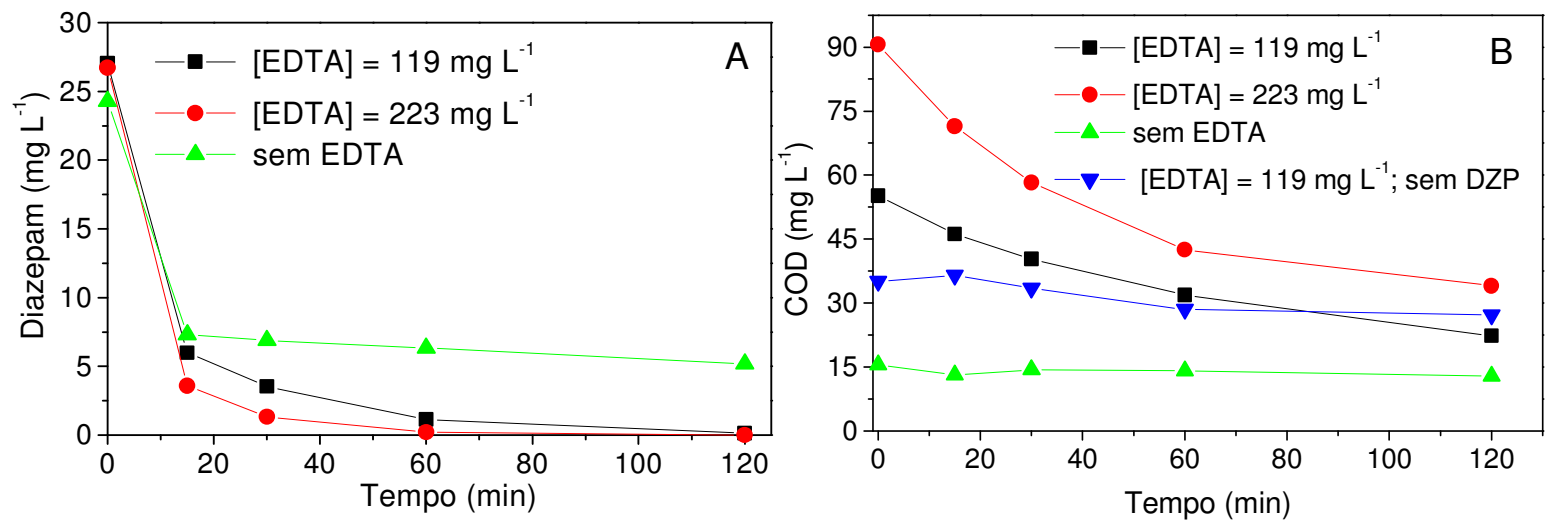

Figura 49. Influência da concentração de EDTA na oxidação de DZP (A) e remoção de COD (B). Condições experimentais: [DZP] $=25 \mathrm{mg} \mathrm{L}^{-1} ;\left[\mathrm{Fe}^{\circ}\right.$ microparticulado] $=25 \mathrm{~g} \mathrm{~L}^{-1}$, borbulhamento de ar; agitação mecânica; lavagem de $\mathrm{Fe}^{\circ}: \mathrm{H}_{2} \mathrm{SO}_{4} 1,0$ mol L-11.

No experimento controle feito na ausência de DZP (Fig. 49B) verifica-se que a remoção de COD referente apenas ao EDTA não ultrapassou $23 \%$ o que significa que a maior parte da remoção de COD obtida nos outros experimentos é do carbono proveniente do composto-alvo. 
Embora por meio destes experimentos não tenha ficado muito evidente a importância do EDTA neste sistema, a literatura relata que para a formação do $\mathrm{H}_{2} \mathrm{O}_{2}$ esse complexante é imprescindível, uma vez que o complexo formado com $\mathrm{Fe}^{2+}$ combina-se com moléculas de água e $\mathrm{O}_{2}$, como mostram as Equações 27-31, para a subsequente formação de $\mathrm{H}_{2} \mathrm{O}_{2}$ (SEIBIG; VAN ELDIK, 1997, ZHOU et al., 2009).

$$
\begin{aligned}
& \mathrm{Fe}^{2+}+\mathrm{EDTA}+\mathrm{H}_{2} \mathrm{O} \rightarrow\left[\mathrm{Fe}^{\prime \prime}(\mathrm{EDTA})\right] \rightarrow\left[\mathrm{Fe}^{\prime \prime}(\mathrm{EDTA})\left(\mathrm{H}_{2} \mathrm{O}\right)\right]^{2-} \\
& {\left[\mathrm{Fe}^{\prime \prime}(\operatorname{EDTA})\left(\mathrm{H}_{2} \mathrm{O}\right)\right]^{2-}+\mathrm{O}_{2} \leftarrow \rightarrow\left[\mathrm{Fe}^{\prime \prime}(\operatorname{EDTA})\left(\mathrm{O}_{2}\right)\right]^{2-}+\mathrm{H}_{2} \mathrm{O}} \\
& {\left[\mathrm{Fe}^{\prime \prime}(\mathrm{EDTA})\left(\mathrm{O}_{2}\right)\right]^{2-} \rightarrow\left[\mathrm{Fe}^{\prime \prime \prime}(\mathrm{EDTA})\left(\mathrm{O}_{2}^{-}\right)\right]^{2-}} \\
& \left.\mathrm{Fe}^{\prime \prime \prime}(\text { EDTA })\left(\mathrm{H}_{2} \mathrm{O}\right)\right]^{2-}+\left[\mathrm{Fe}^{\prime \prime \prime}(\text { EDTA })\left(\mathrm{O}_{2}{ }^{-}\right)\right]^{2-} \rightarrow\left[(\text { EDTA }) \mathrm{Fe}^{\prime \prime \prime}\left(\mathrm{O}_{2}{ }^{2-}\right) \mathrm{Fe}^{\prime \prime \prime \prime}(\text { EDTA })\right]^{4-}+\mathrm{H}_{2} \mathrm{O} \\
& {\left[(E D T A) \mathrm{Fe}^{\prime \prime \prime}\left(\mathrm{O}_{2}{ }^{2-}\right) \mathrm{Fe}^{\prime \prime \prime}(\text { EDTA })\right]^{4-} \rightarrow\left[\mathrm{Fe}^{\prime \prime \prime}(\text { EDTA }) \mathrm{H}_{2} \mathrm{O}\right]^{-}+\mathrm{H}_{2} \mathrm{O}_{2}}
\end{aligned}
$$

Uma concentração de EDTA próxima à deste trabalho $\left(119 \mathrm{mg} \mathrm{L}^{-1}\right)$ foi utilizada por Sanchez e colaboradores (2007) para a degradação de fenol em sistema que utiliza ferro metálico e EDTA. A concentração de EDTA de $100 \mathrm{mg} \mathrm{L}^{-1}$ promoveu $85 \%$ de conversão de fenol a outros compostos aromáticos em 360 minutos de tratamento. Nesse mesmo tempo de tratamento, $70 \%$ de remoção foi obtida para o composto 0 cresol e $68 \%$ para a anilina. O composto mais refratário estudado por esses autores foi o p-nitrofenol que apresentou apenas $28 \%$ de remoção em 360 minutos.

\subsubsection{2 $\mathrm{Fe}^{\underline{0}}$ versus $\mathrm{Fe}^{2+}$}

Para verificar o papel do $\mathrm{Fe}^{\mathrm{o}}$ neste sistema foi feito um experimento utilizando $\mathrm{Fe}^{2+}\left(\mathrm{FeSO}_{4}\right)$ ao invés de $\mathrm{Fe}^{\circ}$. A Figura 50 mostra que somente $23 \%$ de oxidação de 
DZP foi alcançada no experimento feito com $\mathrm{Fe}^{2+}$ contra $100 \%$ no experimento feito com $\mathrm{Fe}^{\circ}$ em 120 minutos de tratamento. Além disso, praticamente nenhuma remoção de COD foi obtida partindo de $\mathrm{Fe}^{2+}$ sendo que no mesmo tempo $60 \%$ de remoção foi obtida partindo de $\mathrm{Fe}^{\circ}$.
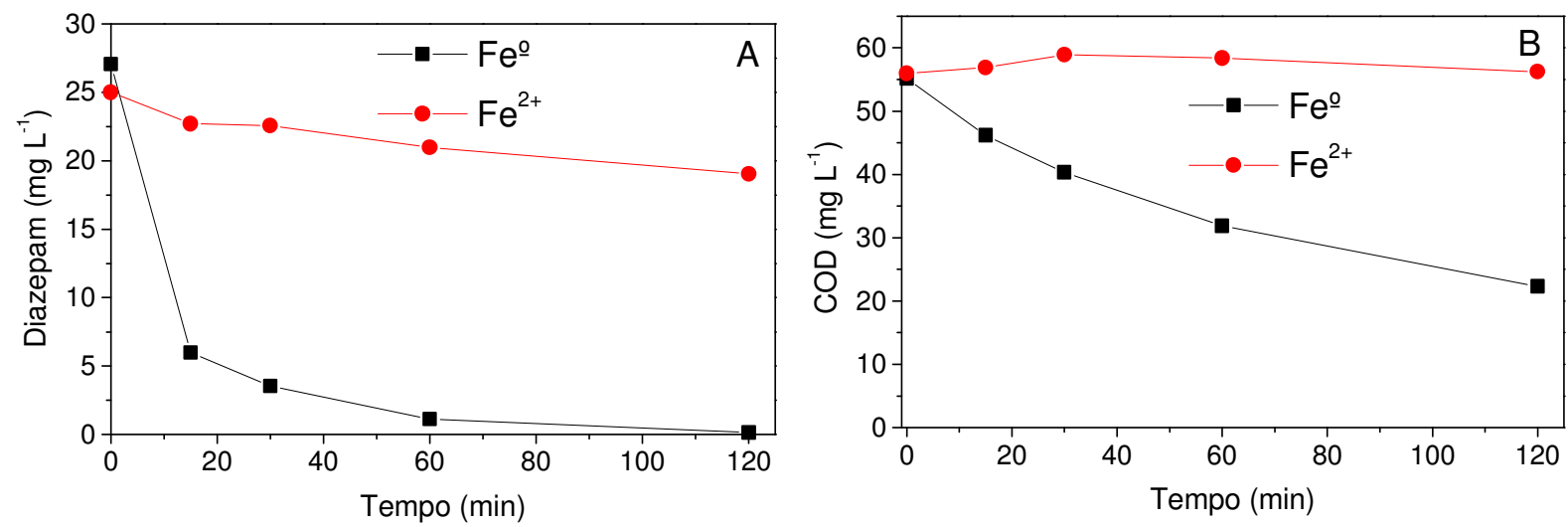

Figura 50. Influência do $\mathrm{Fe}^{\circ}$ na oxidação de $\operatorname{DZP}(\mathrm{A})$ e remoção de $\mathrm{COD}$ (B). Condições experimentais: $[\mathrm{DZP}]=25 \mathrm{mg} \mathrm{L}^{-1} ;\left[\mathrm{Fe}^{\circ}\right.$ microparticulado $]=25 \mathrm{~g} \mathrm{~L}^{-1} ;\left[\mathrm{Fe}^{2+}\right]=5 \mathrm{~g} \mathrm{~L}^{-1}$; $[E D T A]=119 \mathrm{mg} \mathrm{L}^{-1}$; borbulhamento de ar; agitação mecânica; lavagem de $\mathrm{Fe}^{\mathrm{o}}$ : $\mathrm{H}_{2} \mathrm{SO}_{4} 1,0 \mathrm{~mol} \mathrm{~L}^{-1}$.

Esse resultado demonstra a importância do $\mathrm{Fe}^{-}$neste sistema, uma vez que a transferência de elétrons do $\mathrm{Fe}^{\circ}$ para o $\mathrm{O}_{2}$ também pode possibilitar a geração de $\mathrm{H}_{2} \mathrm{O}_{2}$ e consequentemente de oxidantes. Esse mecanismo ainda não está bem estabelecido, no entanto, acredita-se que os elétrons provenientes da oxidação do ferro promovam a redução do $\mathrm{O}_{2}$ adsorvido na superfície ao ânion-radical superóxido ou ao radical hidroperoxila, e este por sua vez pode gerar $\mathrm{H}_{2} \mathrm{O}_{2}$ no meio rapidamente, por meio de desprotonação, conforme as Equações 32-34 (JOO; FEITZ; WAITE, 2004).

$$
\begin{aligned}
& \mathrm{Fe}^{\circ} \rightarrow \mathrm{Fe}^{2+}+2 \mathrm{e}^{-} \\
& \left(\mathrm{O}_{2}\right)_{\text {ads }}+\mathrm{e}^{-} \rightarrow \mathrm{O}_{2}^{-\bullet} \text { ou } \mathrm{HO}_{2}{ }^{-} \\
& \mathrm{HO}_{2}+\mathrm{HO}_{2}^{\cdot} \rightarrow \mathrm{H}_{2} \mathrm{O}_{2}+\mathrm{O}_{2}
\end{aligned}
$$


Para verificar a possibilidade da utilização de $\mathrm{Fe}^{-0}$ proveniente de outra fonte foram feitos alguns testes com palha de aço comercial. A palha de aço foi cortada (menores pedaços possíveis) e foi adicionada sem nenhum tratamento prévio a uma solução de DZP sob borbulhamento de ar. A concentração de $3 \mathrm{~g} \mathrm{~L}^{-1}$ de palha de aço promoveu a oxidação de $91 \%$ da concentração de DZP $\left(25 \mathrm{mg} \mathrm{L}^{-1}\right)$ em 6 horas de tratamento, entretanto sem nenhuma remoção de COD. Em outro experimento feito com a mesma concentração de palha de aço mas em presença de EDTA (119 mg L $\left.\mathrm{L}^{-1}\right)$ e borbulhamento de ar a total oxidação de DZP $\left(25 \mathrm{mg} \mathrm{L}^{-1}\right)$ foi obtida em 120 minutos de tratamento, porém ainda sem remoção de COD. Em uma nova tentativa, foram adicionados $25 \mathrm{~g} \mathrm{~L}^{-1}$ de palha, sendo que desta vez não foi cortada e sim acomodada nas paredes interiores do béquer e lavada com ácido, mesmo procedimento feito com o $\mathrm{Fe}^{\circ}$ microparticulado, na presença de EDTA $\left(119 \mathrm{mg} \mathrm{L}^{-1}\right)$ e borbulhamento de ar. Em 2 horas de tratamento observou-se $77 \%$ de oxidação de DZP e $40 \%$ de remoção de COD, e provavelmente o resultado só não foi melhor devido à dificuldade de agitação efetiva encontrada pois o $\mathrm{Fe}^{\circ}$ estava imóvel em volta do béquer e somente a solução estava sob agitação, dificultando dessa forma, as reações que acontecem na superfície do $\mathrm{Fe}^{\mathrm{o}}$.

A utilização de $\mathrm{Fe}^{\circ}$ proveniente de outras fontes demonstrou uma potencialidade do sistema $\mathrm{Fe}$ o/EDTA $/ \mathrm{O}_{2}$, entretanto, por tratar-se de um processo heterogêneo a grande dificuldade encontrada com a palha de aço foi à ineficiência da agitação, uma vez que ocorria aglomeração do material. 


\subsubsection{Influência do $\mathrm{pH}$ e $\mathrm{O}_{2}$ no sistema $\mathrm{Fe}^{\circ} / \mathrm{EDTA}$}

O processo $\mathrm{Fe}$ - $/ E D T A / \mathrm{O}_{2}$ tem uma capacidade tamponante que mantém o $\mathrm{pH}$ do meio entre 5-6, atribuída por muitos autores à formação de ácidos orgânicos provenientes da degradação do composto-alvo e do EDTA (NORADOUN et al., 2003; ZHOU; WONG; LU, 2008). No entanto, nos experimentos feitos com monitoramento de pH (Fig. 51), na ausência de compostos orgânicos também pôde-se verificar a ação tamponante, evidenciando que a formação de ácidos orgânicos provenientes de produtos de degradação não é a razão da estabilidade do pH.

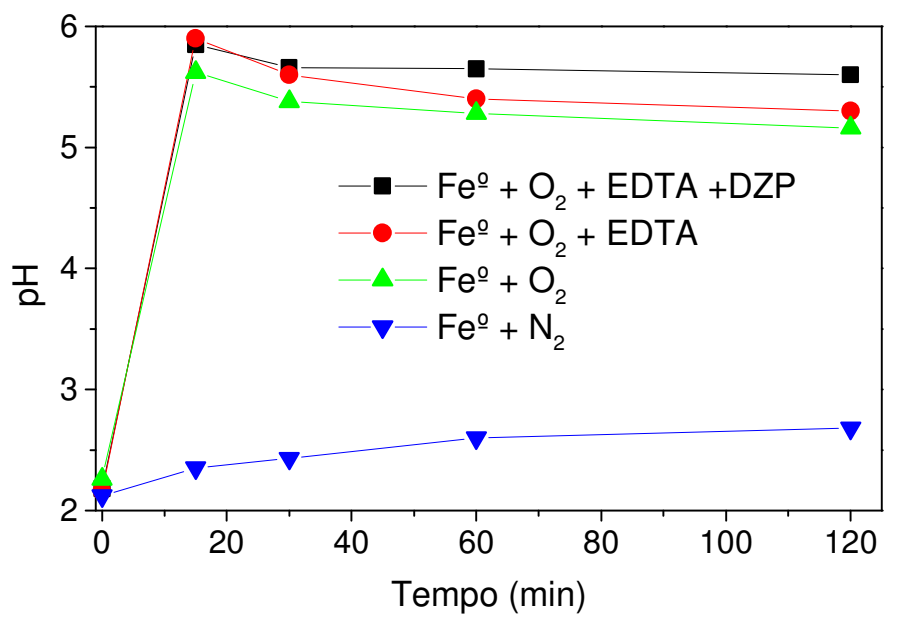

Figura 51. Monitoramento de $\mathrm{pH}$ durante degradação de DZP no sistema Feํo. Condições experimentais:[DZP] $=25 \mathrm{mg} \mathrm{L}^{-1} ;$ [Fe $\mathrm{e}^{-}$microparticulado] $=25 \mathrm{~g} \mathrm{~L}^{-1}$, [EDTA] $=119$ $\mathrm{mg} \mathrm{L}^{-1}$.

$\mathrm{Na}$ oxidação do $\mathrm{Fe}^{-}$na ausência de $\mathrm{O}_{2}$ íons $\mathrm{OH}^{-}$são produzidos, pois os elétrons provenientes da oxidação do $\mathrm{Fe}^{-}$são transferidos para $\mathrm{H}^{+}$e $\mathrm{H}_{2} \mathrm{O}$ reduzindo-os a $\mathrm{H}_{2}$ e $\mathrm{OH}^{-}$respectivamente, conforme as equações 35 e 36 :

$$
\begin{aligned}
& \mathrm{Fe}^{\circ}+2 \mathrm{H}^{+} \rightarrow \mathrm{Fe}^{2+}+\mathrm{H}_{2} \\
& \mathrm{Fe}^{\circ}+2 \mathrm{H}_{2} \mathrm{O} \rightarrow \mathrm{Fe}^{2+}+\mathrm{H}_{2}+2 \mathrm{OH}^{-}
\end{aligned}
$$


Já em meio aeróbio o $\mathrm{O}_{2}$ é o receptor de elétrons produzindo apenas $\mathrm{Fe}^{2+}$ e íons $\mathrm{OH}^{\prime}$, conforme já demonstrado na Equação 25:

$2 \mathrm{Fe}^{\circ}+\mathrm{O}_{2}+2 \mathrm{H}_{2} \mathrm{O} \rightarrow 2 \mathrm{Fe}^{2+}+4 \mathrm{OH}^{-}$

A estequiometria das reações 35 e 36 mostra que na ausência de $\mathrm{O}_{2} \circ \mathrm{pH}$ do meio mantém-se mais ácido, o que também foi constatado nos experimentos feitos com e sem $\mathrm{O}_{2}$ (Fig. 51).

A hidrólise dos íons ferrosos e férricos formados na oxidação do $\mathrm{Fe}^{0}$ gera íons $\mathrm{H}^{+}$ que mantém o meio ácido (entre 1,5 até 3), dependendo da concentração de ferro presente.

Dessa forma, neste trabalho a ação tamponante foi atribuída ao equilíbrio entre os íons $\mathrm{H}^{+}$provenientes da hidrólise dos íons ferrosos, continuamente introduzidos no sistema pela oxidação do $\mathrm{Fe}^{\circ}$, e os íons $\mathrm{OH}^{-}$produzidos na oxidação contínua do $\mathrm{Fe}^{\circ}$.

Com o intuito de verificar a influência do $\mathrm{pH}$ no sistema $\mathrm{Fe} / \mathrm{EDTA} / \mathrm{O}_{2}$, um experimento foi feito com o $\mathrm{pH}$ mantido em $3 \mathrm{com} \mathrm{H}_{2} \mathrm{SO}_{4}$ (dado não mostrado). Ao final de 60 minutos de tratamento, 93\% de oxidação de DZP foi alcançado e apenas 3\% de $\mathrm{COD}$ foi removido. Em $\mathrm{pH} 3$, íons $\mathrm{H}^{+}$podem combinar-se com o complexo $\mathrm{Fe}(\mathrm{II})$-EDTA formando a espécie diprotonada [Fe(II)-EDTAH $\left.\mathrm{E}_{2}\left(\mathrm{H}_{2} \mathrm{O}\right)\right]$ que devido à sua geometria reage menos com $\mathrm{O}_{2}$ comparada as outras espécies do complexo e consequentemente produz menos $\mathrm{H}_{2} \mathrm{O}_{2}$ (SEIBIG; VAN ELDIK, 1997). Provavelmente por esse motivo a remoção de $\mathrm{COD}$ foi prejudicada. No entanto, $\mathrm{O}_{2} \mathrm{O}_{2}$ formado a partir do $\mathrm{Fe}^{-}$, como já mencionado, provavelmente foi suficiente para promover a oxidação de DZP. Resultado semelhante foi observado por Zhou e colaboradores (2009) na degradação de corantes 
têxteis com pH mantido em 2, pois praticamente 100\% de oxidação do corante RB5 foi alcançada em 180 minutos de tratamento, mas somente $2,2 \%$ de COT foi removido.

Para verificar a influência do oxigênio no sistema foram feitos experimentos sob fluxo de nitrogênio. A Figura 52 mostra que mesmo sob condições anaeróbias ocorreu $67 \%$ de remoção de DZP. Esse resultado sugere que podem ocorrer reações na superfície do metal por meio de transferência de elétrons do ferro para o composto-alvo. A degradação de DZP na ausência de EDTA reforça esta hipótese uma vez que apenas ferro e DZP estavam presentes no sistema. A ausência de remoção de COD em condições anaeróbias já era esperada uma vez que sem $\mathrm{O}_{2}$ a formação de $\mathrm{H}_{2} \mathrm{O}_{2}$ é improvável e consequentemente, sem a formação de espécies oxidantes não há remoção de COD.

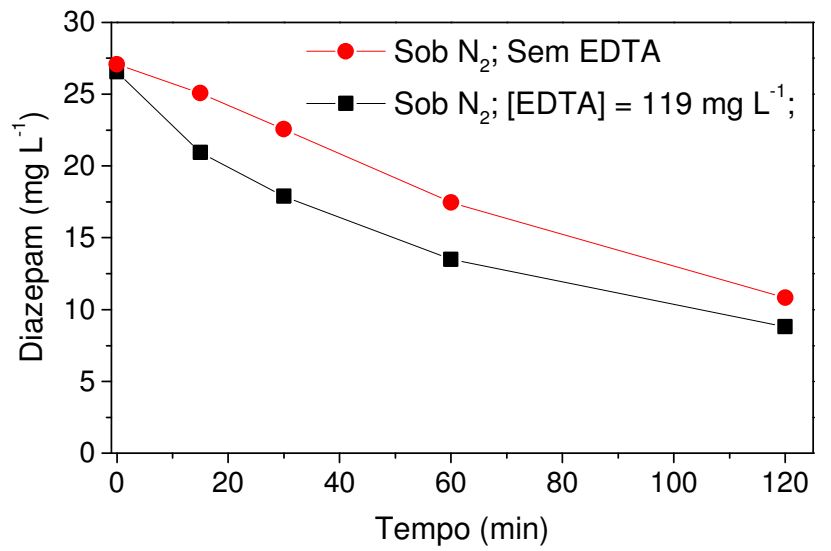

Figura 52. Influência de $\mathrm{O}_{2}$ na remoção de DZP. Condições experimentais: [DZP] $=25 \mathrm{mg} \mathrm{L}^{-1}$; $\left[\mathrm{Fe}^{\mathrm{o}}\right.$ microparticulado] $=25 \mathrm{~g} \mathrm{~L}^{-1}$, [EDTA] $=119 \mathrm{mg} \mathrm{L}^{-1}$; borbulhamento de $\mathrm{N}_{2}$.

\subsubsection{Determinação de $\mathrm{H}_{2} \mathrm{O}_{2}$ no sistema $\mathrm{Fe}$-/EDTA/O $\mathrm{O}_{2}$}

Com o objetivo de confirmar a geração de $\mathrm{H}_{2} \mathrm{O}_{2}$ in situ no sistema $\mathrm{Fe}$-/EDTA/O 2 foi aplicado o método de determinação que baseia-se na oxidação da enzima 
peroxidase de raiz forte pelo $\mathrm{H}_{2} \mathrm{O}_{2}$. O método original proposto para determinação de $\mathrm{H}_{2} \mathrm{O}_{2}$ foi modificado por Balmer e Sulzberger (1999), para minimizar a interferência dos íns ferrosos e férricos por meio da complexação com bipiridina e EDTA respectivamente. Essa modificação, adição de bipiridina e EDTA para complexar íons ferrosos e férricos, foi mantida neste trabalho na tentativa de minimizar essa interferência. No entanto, a concentração de ferro utilizada por Balmer e Sulzberger foi $6 \times 10^{-6} \mathrm{~mol} \mathrm{~L}^{-1}$, ao passo que neste trabalho a concentração de $\mathrm{Fe}^{\circ}$ utilizada foi de 0,45 $\mathrm{mol} \mathrm{L}^{-1}\left(25 \mathrm{~g} \mathrm{~L}^{-1}\right)$, dessa forma testes foram feitos para avaliar essa interferência.

Nos testes feitos para verificar a exatidão do método com concentrações conhecidas de $\mathrm{H}_{2} \mathrm{O}_{2}$ resultados satisfatórios foram obtidos. No entanto, quando foram adicionadas soluções de $\mathrm{Fe}^{2+}$ em concentração equivalente à que haveria no sistema $\mathrm{Fe} / \mathrm{EDTA} / \mathrm{O}_{2}$, algumas interferências foram encontradas.

Foram feitos testes com concentrações de $\mathrm{Fe}^{3+}$ ou $\mathrm{Fe}^{2+}$ de $90 \times 10^{-3} \mathrm{~mol} \mathrm{~L}^{-1}$ (que corresponde à gerada por $5 \mathrm{~g} \mathrm{~L}^{-1}$ de $\mathrm{Fe}^{\circ}$ ). Entretanto a hidrólise produzida por esses íns impedia a manutenção do pH em 6, pH ideal para a formação do radical cátion DPD ${ }^{*+}$. Outra dificuldade encontrada foi a coloração do complexo de $\mathrm{Fe}^{2+}$ formado com a bipiridina, pois devido à grande concentração de $\mathrm{Fe}^{2+}$ e consequentemente do complexo formado, este apresentava absorbância na mesma faixa de comprimento de onda do radical cátion $\mathrm{DPD}^{\circ+}$. Vários testes foram feitos na tentativa de minimizar essas interferências como variar a concentração de ferro e complexantes, entretanto, nenhuma com sucesso. A literatura relata que concentrações de $F e^{\circ}$ de $150 \mathrm{mg} \mathrm{L}^{-1}$ já são desafiantes no sentido de determinar $\mathrm{H}_{2} \mathrm{O}_{2}$ por esse método devido à interferência dos íons férricos e ferrosos formados, pois estes podem promover a oxidação da DPD e 
dessa forma levar a valores superestimados da concentração de $\mathrm{H}_{2} \mathrm{O}_{2}$ (KATSOYIANNIS; RUETTIMANN; HUG, 2008).

Dessa forma, infelizmente não foi possível quantificar a concentração de $\mathrm{H}_{2} \mathrm{O}_{2}$ gerada in situ no sistema $\mathrm{Fe}$ o/EDTA/O $\mathrm{O}_{2}$.

4.3.3 Comparação da degradação do fármaco diazepam obtida pelo processo fotoFenton e pelo sistema $\mathrm{Fe}$ \%/EDTA $/ \mathrm{O}_{2}$ e dos intermediários formados durante os dois processos

Comparando a degradação do fármaco DZP obtida pelo processo foto-Fenton e pelo sistema $\mathrm{Fe} / \mathrm{EDTA} / \mathrm{O}_{2}$, fica evidente que o processo foto-Fenton foi mais eficiente, pois promoveu total oxidação do fármaco em 8 minutos de tratamento e remoção de COT de mais de $90 \%$ em 60 minutos. Já no sistema $\mathrm{Fe} \% / E D T A / \mathrm{O}_{2}$ a total oxidação do fármaco foi alcançada somente após 60 minutos de tratamento e remoção de $60 \%$ de COD foi alcançada após 2 horas.

Entretanto, o sistema $\mathrm{Fe} / \mathrm{EDTA} / \mathrm{O}_{2}$ apresenta algumas vantagens em relação ao processo foto-Fenton. A geração de $\mathrm{H}_{2} \mathrm{O}_{2}$ in situ resulta em diminuição dos custos do tratamento uma vez que esse oxidante não necessita ser adicionado ao sistema. O tamponamento do meio e, $\mathrm{pH}$ entre 5-6, próximo à neutralidade, se apresenta como mais uma vantagem pois, elimina a necessidade de ajuste de $\mathrm{pH}$, fator que às vezes torna inviável o tratamento de grandes quantidades de efluentes por processos que necessitem deste ajuste.

A grande concentração de $\mathrm{Fe}^{0}$ necessária para obter os melhores índices de degradação de contaminantes apresenta-se como uma desvantagem do sistema 
$\mathrm{Fe}$-/EDTA/O $\mathrm{O}_{2}$. Além disso, o lodo formado pelos óxidos e hidróxidos de ferro necessita de descarte adequado. Em contrapartida, a utilização de ferro proveniente de rejeitos industriais e afins se mostra uma alternativa promissora. Pereira e Freire (2006) utilizaram um resíduo industrial de ferro metálico para promover a degradação de corantes têxteis, com bons índices de degradação (descoloração de 95\% e remoção de COT de $70 \%$ ). Palha de aço também já foi utilizada como fonte de ferro metálico em processos de degradação de contaminantes (SOUZA; PERALTA-ZAMORA, 2005).

A utilização de EDTA no sistema $\mathrm{Fe} / \mathrm{EDTA} / \mathrm{O}_{2}$ é questionável uma vez que esse composto também é considerado um contaminante (NORADOUN; CHENG, 2005). Entretanto, como esse complexante é utilizado em muitos processos industriais, inclusive na produção de fármacos (FUERHACKER, M.; LORBEER, G.; HABERL, R, 2003) talvez o tratamento por $\mathrm{Fe}^{-0}$ de efluentes que já possuam EDTA em sua composição seja mais recomendado.

Conforme já mencionado, o sistema $\mathrm{Fe}=/ \mathrm{EDTA} / \mathrm{O}_{2}$ promove a degradação de compostos por meio de reações tipo Fenton. Dessa forma, com o intuito de comparar os intermediários de degradação do DZP formados durante os dois processos foram feitas análises de cromatografia líquida acoplada à espectrometria de massas também para amostras do processo $\mathrm{Fe}$-/EDTA/O 2 .

Os dois processos de degradação produzem espécies oxidantes e dessa forma podem gerar intermediários semelhantes. O primeiro indicativo de que os mesmos intermediários eram formados foi a semelhança dos cromatogramas obtidos por CLAEUV para os dois processos (Fig. 53). 


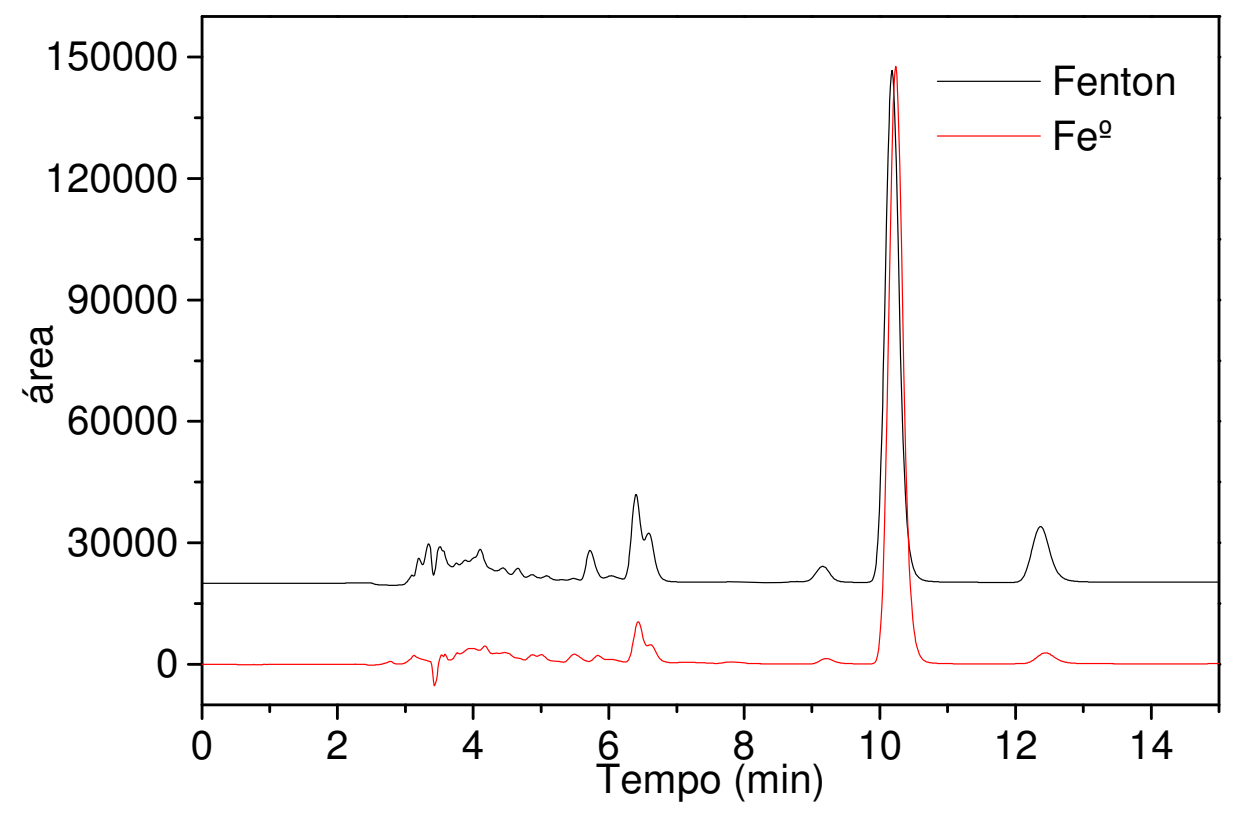

Figura 53. Cromatogramas obtidos por CLAE-UV referentes à amostra retirada do experimento Fenton aos 2 minutos e do experimento $\mathrm{Fe} / \mathrm{EDTA} / \mathrm{O}_{2}$ aos 120 minutos. Fenton Condições iniciais: $[\mathrm{DZP}]=25,0 \mathrm{mg} \mathrm{L}^{-1} ;\left[\mathrm{FeSO}_{4}\right]=0,10 \mathrm{mmol} \mathrm{L}^{-1} ;\left[\mathrm{H}_{2} \mathrm{O}_{2}\right]=1,0 \mathrm{mmol}$ $\mathrm{L}^{-1} ; \mathrm{pH}$ 2,5. Sistema ferro metálico - $[\mathrm{DZP}]=25 \mathrm{mg} \mathrm{L}^{-1} ;\left[\mathrm{Fe}^{-0}\right]=25 \mathrm{~g} \mathrm{~L}^{-1}$, borbulhamento de ar.

Dessa forma, para comparar os intermediários de degradação do DZP, um experimento de degradação de DZP por processo $\mathrm{Fe}$-/EDTA $/ \mathrm{O}_{2}$ foi feito nas seguintes condições experimentais: $\mathrm{Fe}^{-} \mathrm{o}=25 \mathrm{~g} \mathrm{~L}^{-1}$; DZP $=25 \mathrm{mg} \mathrm{L}^{-1}$, borbulhamento de ar porém, na ausência de EDTA para evitar que intermediários provenientes da degradação deste complexante pudessem prejudicar a identificação dos intermediários do fármaco. Foram retiradas amostras em 30, 60, 120 e 180 minutos, pois após esse período não se verificava mais a degradação do fármaco.

Os espectros de massas revelaram que foram formados oito intermediários durante o processo $\mathrm{Fe}$ o/EDTA/O $/ 2,4$ isômeros de relação m/z 301 (Fórmula molecular = $\mathrm{C}_{16} \mathrm{H}_{13} \mathrm{~N}_{2} \mathrm{ClO}_{2}$ ) e 4 isômeros de relação m/z 317 (Fórmula molecular $=\mathrm{C}_{16} \mathrm{H}_{13} \mathrm{~N}_{2} \mathrm{ClO}_{3}$ ). 
Por problemas técnicos do equipamento, não foram obtidos os espectros MSMS e não foi possível estimar onde ocorreu a entrada das hidroxilas nestes isômeros. Portanto, não foi possível confirmar quais isômeros formados no processo foto-Fenton são idênticos aos formados no processo $\mathrm{Fe} / \mathrm{EDTA} / \mathrm{O}_{2}$, sendo possível confirmar apenas que são compostos de relação $\mathrm{m} / \mathrm{z} 301$ e 317 que correspondem provavelmente à entrada de uma e duas hidroxilas na molécula de DZP, respectivamente. Por esse motivo os intermediários de degradação de DZP por processo Feo serão denominados de $D_{7}$ a $D_{14}$.

Os cromatogramas pelo pico base apresentados na Figura 54 mostram a semelhança entre os picos dos intermediários formados durante o processo com ferro metálico (Fig.54A) e o processo foto-Fenton (Fig. 54B).

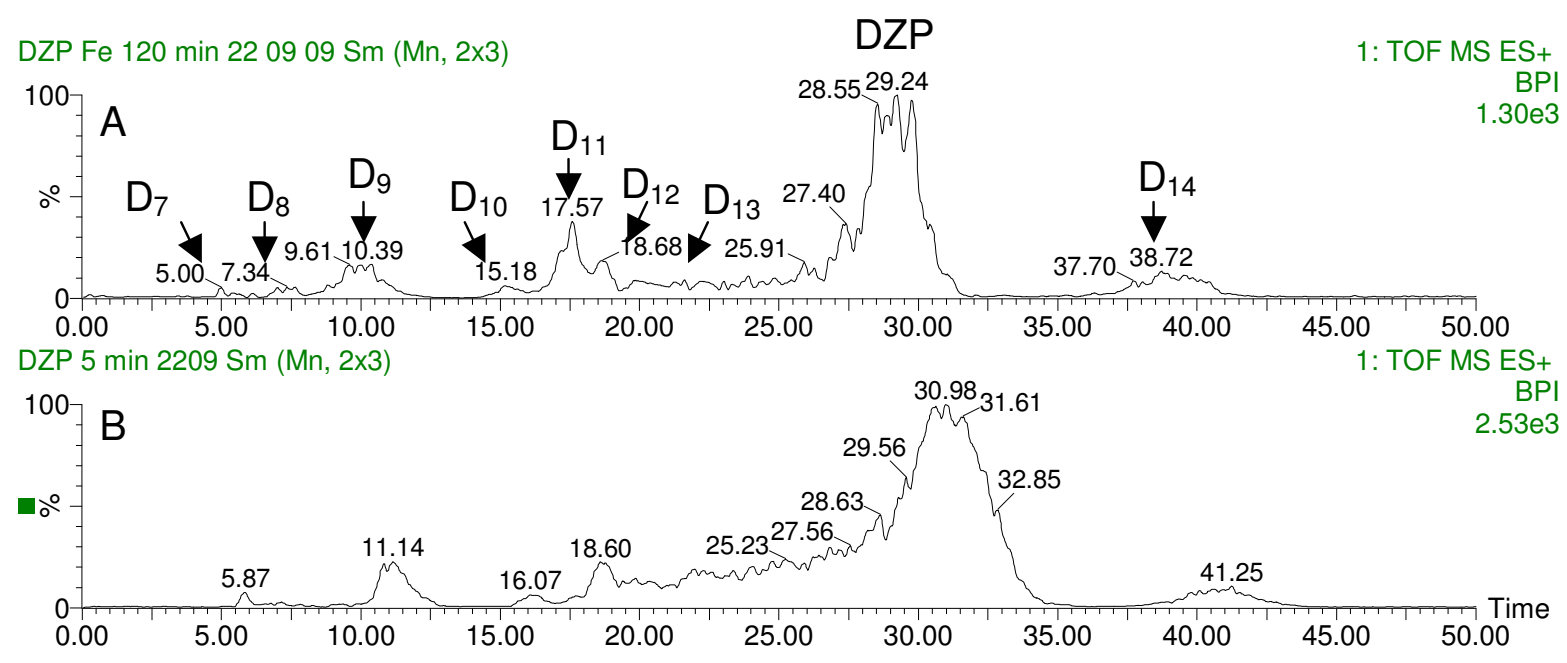

Figura 54. Cromatograma referente aos intermediários formados durante a degradação de DZP pelo $\mathrm{Fe}^{\mathrm{o}}$ - amostra retirada do experimento aos 120 minutos (A) e intermediários formados durante o processo foto-Fenton amostra retirada do experimento aos 5 minutos de experimento (B).

A Figura 55 apresenta os espectros de massas dos intermediários $D_{7}(A), D_{8}(B)$, $D_{9}(C), D_{10}(D), D_{11}(E), D_{12}(F), D_{13}(G), D_{14}(H)$, os quais apresentaram tempos de 
retenção 5,$00 ; 7,34 ; 10,3 ; 15,1 ; 17,5 ; 18,6 ; 21,6$ e 38,7 minutos, respectivamente, formados durante a degradação de DZP por processo $\mathrm{Fe}^{\circ}$.

DZP Fe 120 min 220909241 (4.797) Cm (238:302-61:220)
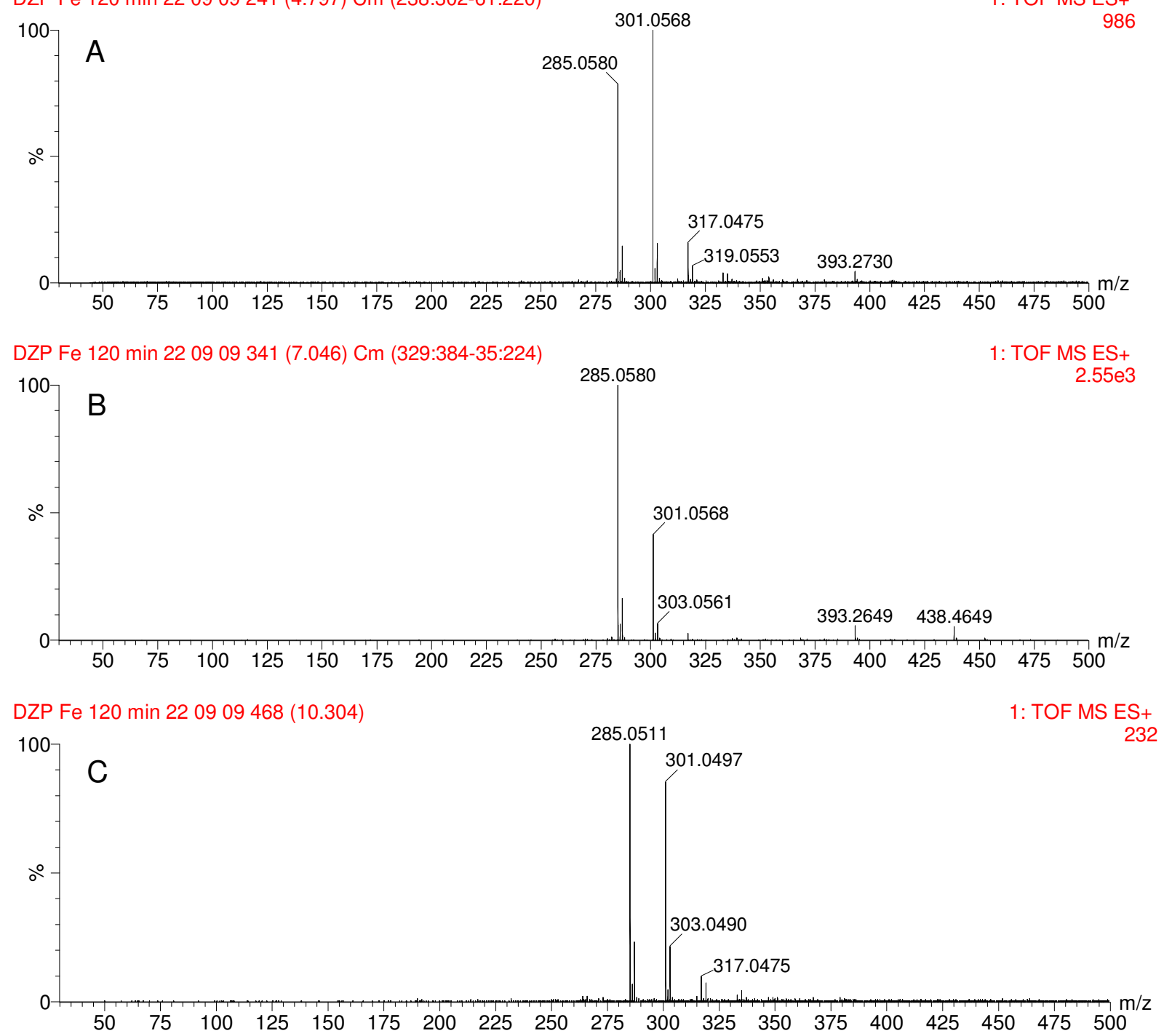

DZP Fe 120 min 220909704 (15.438) Cm (704:746)

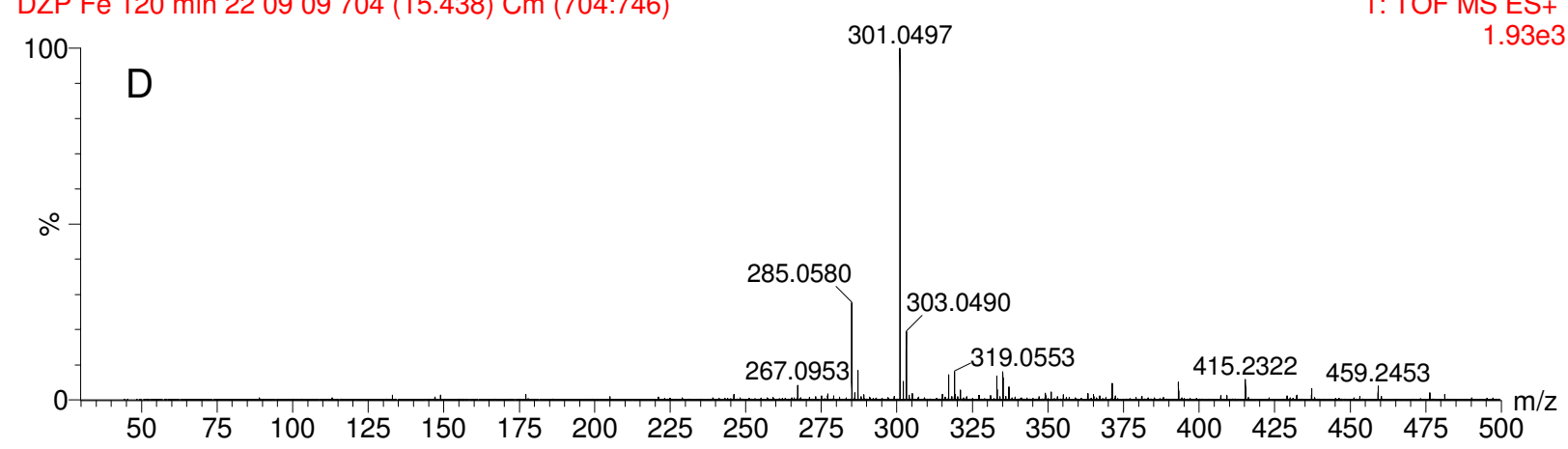


DZP Fe 120 min 220909794 (17.573) Cm (779:813)

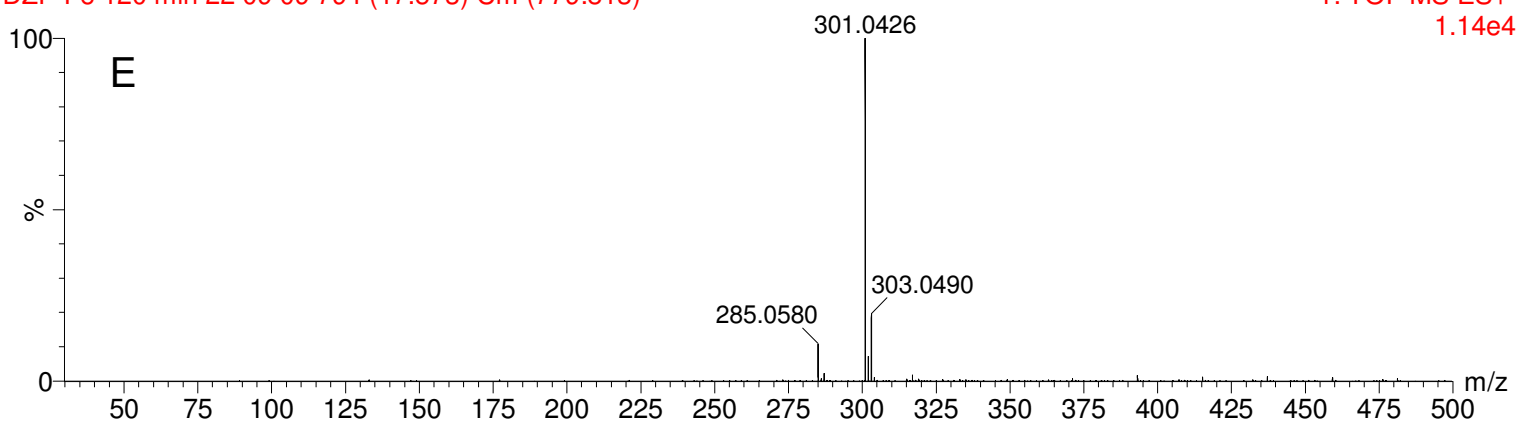

DZP Fe 120 min 220909829 (18.473) Cm (826:864-847:924)

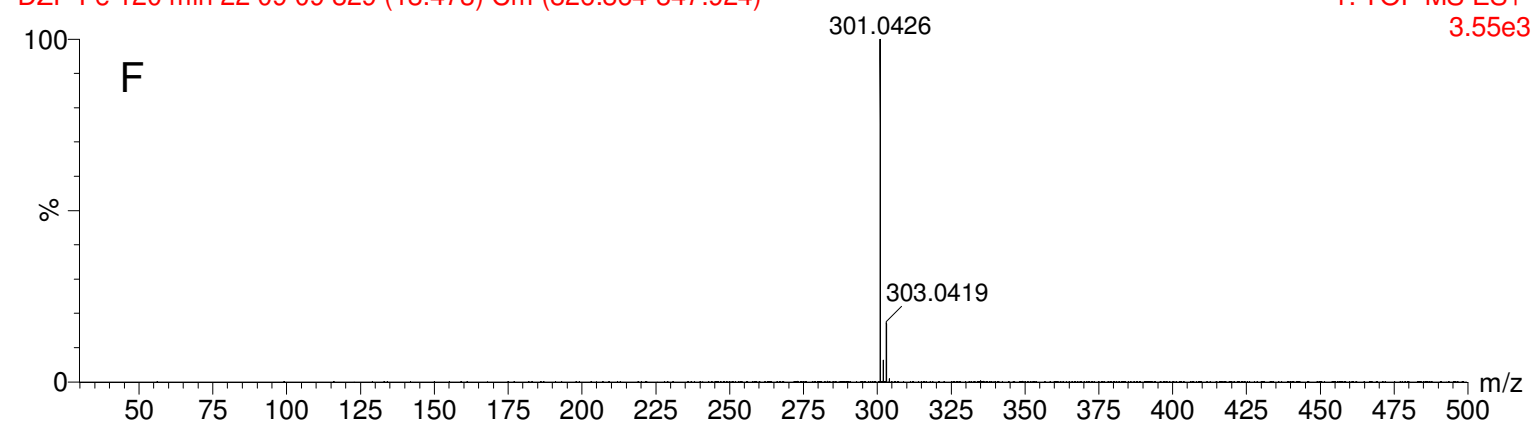

DZP Fe 120 min 220909955 (21.616) Cm (935:968-988:1068)

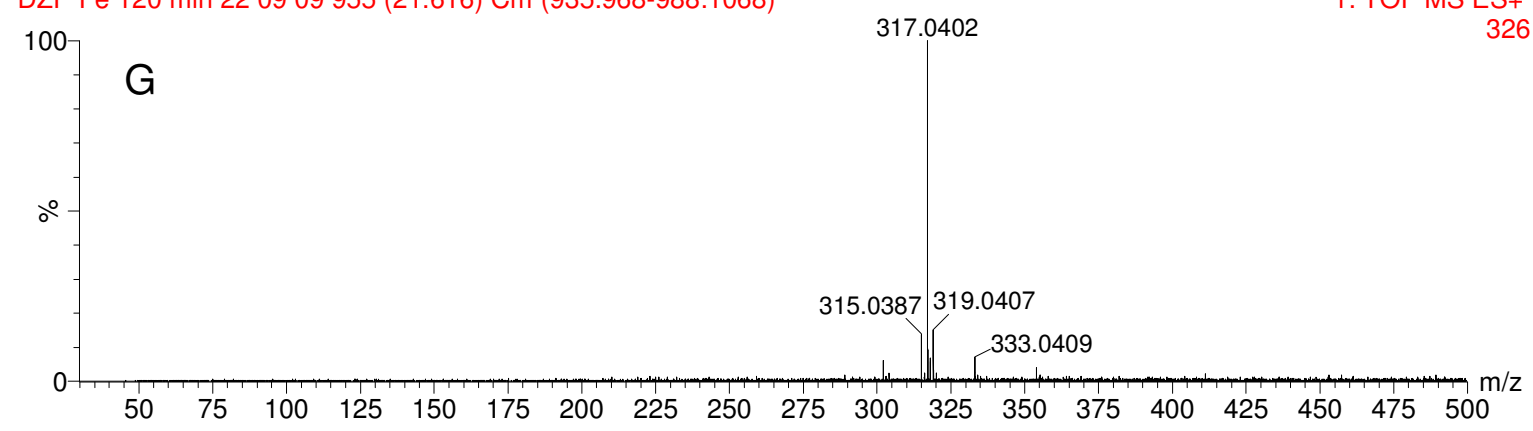

DZP Fe 120 min 2209091707 (38.483) Cm (1661:1791-1871:2056)

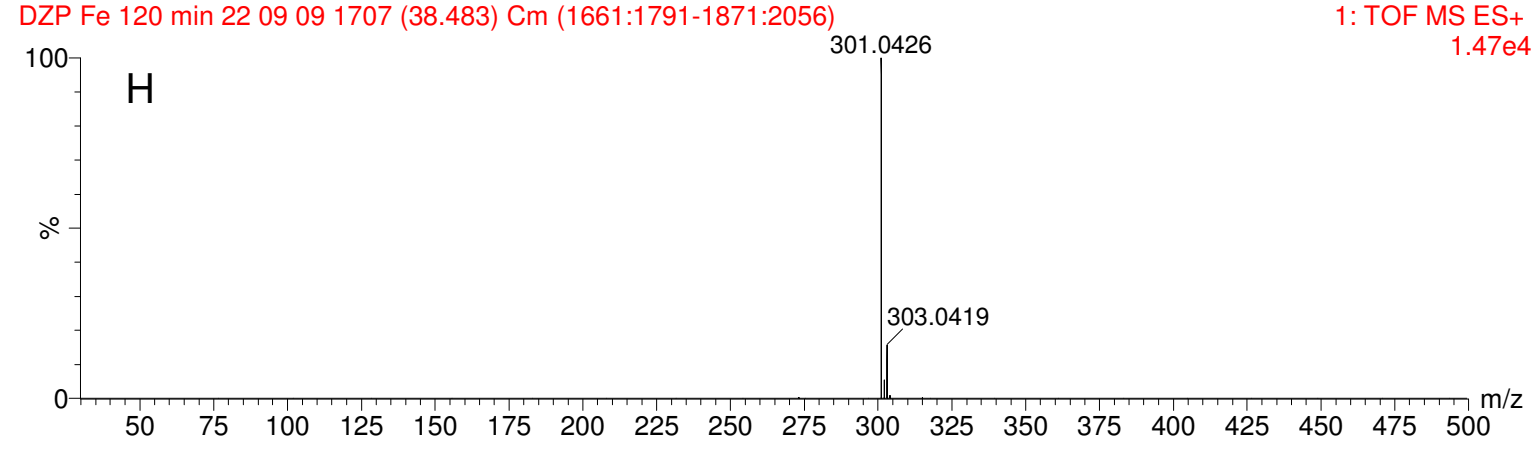

Figura 55. Espectros de massas dos intermediários $D_{7}(A) ; D_{8}(B) ; D_{9}(C) ; D_{10}(D) ; D_{11}(E) ; D_{12}$ $(F) ; D_{13}(G) ; D_{14}(H)$ formados durante degradação de DZP pelo sistema $F e^{\circ}$. 
A Tabela 11 apresenta uma comparação entre os intermediários formados durante a degradação de DZP por processo foto-Fenton e por processo $\mathrm{Fe}^{-}$com seus respectivos tempos de retenção e íons moleculares $[\mathrm{M}+\mathrm{H}]^{+}$.

Tabela 11. Intermediários formados durante degradação de DZP por processo foto-Fenton e sistema ferro metálico

\begin{tabular}{|c|c|c|c|}
\hline & Intermediários & $\begin{array}{c}\text { Tempo retenção } \\
(\min )\end{array}$ & {$[\mathrm{M}+\mathrm{H}]^{+}$} \\
\hline \multirow{7}{*}{$\begin{array}{l}\text { Processo } \\
\text { Foto-Fenton }\end{array}$} & $D_{1}$ & 5,87 & 301,1036 \\
\hline & $\mathrm{D}_{2}$ & 11,1 & 317,1028 \\
\hline & $\mathrm{D}_{3}$ & 16,0 & 317,1101 \\
\hline & $\mathrm{D}_{4}$ & 18,6 & 317,1101 \\
\hline & $\mathrm{D}_{5}$ & 21,9 & 301,1177 \\
\hline & DZP & 30,9 & 285,0718 \\
\hline & $\mathrm{D}_{6}$ & 41,2 & 301,1177 \\
\hline \multirow{9}{*}{$\begin{array}{c}\text { Sistema ferro } \\
\text { metálico }\end{array}$} & $\mathrm{D}_{7}$ & 5,00 & 317,0475 \\
\hline & $\mathrm{D}_{8}$ & 7,34 & 301,0568 \\
\hline & $\mathrm{D}_{9}$ & 10,3 & 317,0475 \\
\hline & $D_{10}$ & 15,1 & 317,1466 \\
\hline & $D_{11}$ & 17,5 & 301,0426 \\
\hline & $D_{12}$ & 18,6 & 301,0426 \\
\hline & $D_{13}$ & 21,6 & 317,0402 \\
\hline & DZP & 29,2 & 285,0718 \\
\hline & $D_{14}$ & 38,7 & 301,0426 \\
\hline
\end{tabular}


Sobre os intermediários de degradação de DZP formados durante degradação com ferro metálico não foi possível concluir que são exatamente os mesmos compostos formados pelo processo foto-Fenton, porém, sem dúvida são compostos isômeros com a entrada de uma ou duas hidroxilas na molécula do DZP. Esse resultado indica que a oxidação no sistema com ferro metálico deve ser promovida pela mesma espécie que promove a oxidação no processo foto-Fenton, o radical hidroxila. 


\section{CONCLUSÕES}

O processo foto-Fenton mostrou-se eficiente na degradação dos fármacos estudados, pois promoveu a oxidação dos mesmos em aproximadamente 8 minutos de tratamento e remoção de matéria orgânica de mais de $80 \%$ após 60 minutos, na melhor condição utilizada.

Na presença de radiação solar os resultados foram ainda mais promissores, pois a total oxidação dos fármacos foi alcançada com uma dose de energia que corresponde a aproximadamente 5 minutos de tratamento e $92 \%$ de remoção de COT ao final do tratamento. A possibilidade da utilização de radiação solar é um atrativo a mais deste processo pois alia eficiência de tratamento com diminuição de custos. Além disso, a mineralização do composto-alvo é importante, pois minimiza a formação de intermediários que possam ser tão ou mais tóxicos que o composto original.

A espécie de ferro demonstrou ter influência no processo de degradação, sendo que FeOx mostrou-se mais eficiente na degradação dos fármacos estudados, tanto sob radiação artificial quanto sob radiação solar. A concentração de $\mathrm{H}_{2} \mathrm{O}_{2}$ também apresentou-se como um parâmetro importante e que requer estudos para a sua definição quando da aplicação do processo. Dentre as concentrações de $\mathrm{H}_{2} \mathrm{O}_{2}$ testadas, a concentração $1,00 \mathrm{mmol} \mathrm{L}^{-1}$ promoveu os menores índices de mineralização dos fármacos.

A enzima catalase demonstrou eficiência na decomposição de $\mathrm{H}_{2} \mathrm{O}_{2}$ interrompendo assim a reação de Fenton, e permitindo que a análise cromatográfica pudesse ser feita em um período de até 40 dias. 
O estudo da influência da matriz foi de grande importância pois permitiu avaliar a eficiência do processo proposto no ambiente em que os fármacos residuais normalmente são encontrados. A oxidação dos fármacos DZP e LCM não foi prejudicada na presença do efluente de ETE, pois em 8 minutos de tratamento a concentração já estava abaixo do limite de detecção dos métodos. Entretanto, a remoção de COD diminuiu na presença do efluente, aproximadamente $10 \%$ para o fármaco LCM, demonstrando que havia substâncias recalcitrantes ao processo. Embora a remoção de matéria orgânica tenha sido prejudicada, os resultados obtidos foram satisfatórios tratando-se de uma matriz extremamente complexa.

Os primeiros intermediários de degradação dos fármacos por processo fotoFenton foram formados por meio de hidroxilação das moléculas, sendo que para o fármaco DZP foram formados seis isômeros estruturais com a entrada de uma e duas hidroxilas na molécula. Os intermediários de degradação do fármaco PPN identificados foram formados por meio da entrada de cinco e sete hidroxilas na molécula e para o fármaco LCM foi possível identificar apenas um intermediário monohidroxilado. Os intermediários de degradação identificados foram condizentes ao processo submetido, porém foram pouco elucidativos no que diz respeito à rota de degradação.

O sistema $\mathrm{Fe}$-/EDTA/O $\mathrm{O}_{2}$ avaliado para a degradação do fármaco DZP também mostrou-se eficiente, entretanto um tempo maior de tratamento foi requerido, pois a total oxidação do composto-alvo foi alcançada após 60 minutos de tratamento e $60 \%$ de remoção de COT em 2 horas.

O pré-tratamento das micropartículas de $\mathrm{Fe}^{-}$não alterou o processo de oxidação de DZP mas promoveu maior remoção de COT. A concentração de Feํo também se mostrou um fator importante pois só utilizando-se altas concentrações $\left(25 \mathrm{~g} \mathrm{~L}^{-1}\right)$ foram 
obtidos resultados consideráveis de degradação. A adição de EDTA ao sistema acelera a oxidação do DZP, entretanto sua utilização para um tratamento deve ser avaliada uma vez que trata-se de um composto tóxico e sua adição representa maior concentração de matéria orgânica no sistema.

$\mathrm{O} \mathrm{Fe}^{-}$mostrou ser de crucial importância na eficiência do processo, pois promoveu $100 \%$ de oxidação de DZP em 120 minutos, quando comparado ao $\mathrm{Fe}^{2+}$ que promoveu somente $23 \%$ de oxidação no mesmo tempo.

A não necessidade de ajuste de $\mathrm{pH}$ e o tamponamento do meio em $\mathrm{pH}$ 5-6 apresentam-se como uma vantagem do processo $\mathrm{Fe}-/ \mathrm{EDTA} / \mathrm{O}_{2}$, pois permite tratar efluentes sem necessidade de ajuste prévio de $\mathrm{pH}$. Foi verificado que a ação tamponante desse sistema não é devida à formação de ácidos orgânicos, como descrito na literatura, mas pode ser devido ao equilíbrio de espécies formadas na hidrólise dos íons metálicos e na oxidação de $\mathrm{Fe}^{\circ}$, considerando que este também ocorre mesmo na ausência de compostos orgânicos.

$\mathrm{Na}$ ausência de $\mathrm{O}_{2}$ ocorre somente $67 \%$ de remoção de DZP e nenhuma remoção de COT em 120 minutos de tratamento, o que demonstra sua importância para a formação de oxidantes. O oxidante formado neste processo provavelmente foi o mesmo formado no processo foto-Fenton, o radical hidroxila, pois oito intermediários de degradação de DZP foram identificados como sendo também compostos mono e dihidroxilados.

Embora o processo Feo/EDTA/O $\mathrm{O}_{2}$ tenha apresentado resultados de degradação inferiores aos obtidos com o processo foto-Fenton, apresenta vantagens, conforme já mencionado anteriormente, que podem torná-lo uma alternativa na degradação de contaminantes orgânicos. 
Esses processos estudados para a degradação de fármacos demonstraram que podem ser aplicados pois apresentam bons resultados de degradação, entretanto necessitam de estudos para avaliar a ecotoxicidade da matéria orgânica remanescente.

Dados de ocorrência e ecotoxicidade de fármacos residuais permitirão o desenvolvimento de legislação que estabeleça concentrações destes contaminantes permitidas no ambiente que não ofereçam riscos nem para humanos tampouco para organismos aquáticos. Neste contexto, os processos de degradação estudados poderão ser aplicados para a remoção deste tipo de contaminante. 


\section{PERSPECTIVAS}

$\checkmark$ Avaliar a ecotoxicidade da matéria orgânica remanescente dos processos fotoFenton e $\mathrm{Fe}$ - $/ E D T A / \mathrm{O}_{2}$.

$\checkmark$ Identificar outros possíveis intermediários formados durante a degradação dos fármacos para elucidação da rota de degradação.

$\checkmark$ Avaliar outros parâmetros do sistema $\mathrm{Fe} / \mathrm{o} / \mathrm{EDTA} / \mathrm{O}_{2}$ como por exemplo, a utilização de outros ligantes, bem como a utilização de rejeitos industriais de ferro. 


\section{REFERÊNCIAS}

ABELLÁN, M. N.; BAYARRI, B.; GIMENEZ, J.; COSTA, J. Photocatalytic degradation of sulfamethoxazole in aqueous suspensión of TiO2. Applied Catalysis B: Environmental, v. 74, n. 3/4, p. 233-241, 2007.

ADDAMO, M.; AUGUGLIARO, V.; PAOLA, A. D.; GARCIA-LOPEZ, E.; LODDO, V.; MARCI, G.; PALMISANO, L. Removal of drugs in aqueous systems by photoassisted degradation. Journal Applied Electrochemistry, v. 35, n. 7, p. 765-774, 2005.

AGÊNCIA NACIONAL DE VIGILÂNCIA SANITÁRIA. Bulário eletrônico. Disponível em: <http://www.anvisa.gov.br/bularioeletronico/default.asp>. Acesso em: 15 nov. 2009.

ANDREOZZI, R.; RAFFAELE, M.; NICKLAS, P. Pharmaceuticals in STP effluents and their solar photodegradation in aquatic environment. Chemosphere, v. 50, n. 10, p. 1319-1330, 2003.

ANDREOZZI, R.; CANTERINO, M.; MAROTTA, R.; PAXEUS, N. Antibiotic removal from wastewaters: the ozonation of amoxicillin. Journal of Hazardous Materials, v. 122, n. 3, p. 243-250, 2005.

ANDREOZZI, R.; CAPRIO, V.; MAROTTA, R.; VOGNA, D. Paracetamol oxidation from aqueous solutions by means of ozonation and $\mathrm{H}_{2} \mathrm{O}_{2} / \mathrm{UV}$ system. Water Research, v. 37, n. 5, p. 993-1004, 2003.

ANDREOZZI, R.; CANTERINO, M.; GIUDICE, R. L.; MAROTTA, R.; PINTO, G.; POLLIO, A. Lincomycin solar photodegradation, algal toxicity and removal from wastewaters by means of ozonation. Water Research, v. 40, n. 3, p. 630-638, 2006.

ANDREOZZI, R.; CAMPANELLA, L.; FRÍASE, B.; GARRIC, J.; GONNELLA, A.; GIUDICE, R.; MAROTTA, R.; PINTO, G.; POLLIO, A. Effects of advanced oxidation processes $(A O P)$ on the toxicity of a mixture of pharmaceuticals. Water Science and Technology, v. 50, n. 5, p. 23-28, 2004.

ARSLAN-ALATON, I. Degradation of a commercial textile biocide with advanced oxidation processes and ozone. Journal of Enviromental Management, v. 82, n. 2, p. $145-154,2007$. 
ATKINS, P.; JONES, L. Princípios de química: questionando a vida moderna e o meio ambiente. 2. ed. Porto Alegre: Bookman, 2001.

AUGUGLIARO, V.; GARCÍA-LÓPEZ, E.; LODDO, V.; MALATO-RODRÍGUEZ, S.; MALDONADO, I.; MARCÍ, G.; MOLINARI, R.; PALMISANO, L. Degradation of lincomycin in aqueous medium: coupling of solar photocatalysis and membrane separation. Solar Energy, v. 79, n.4, p. 402-408, 2005.

AZBAR, N.; YONAR, T.; KESTIOGLU, K. Comparison of various advanced oxidation processes and chemical treatment methods for COD and color removal from a polyester and acetate fiber dyeing effluent. Chemosphere, v. 55, n. 1, p. 35-43, 2004.

BADER, H.; STURZENEGGER, V.; HOIGNÉ, J. Photometric method for the determination of low concentrations of hydrogen peroxide by the peroxidase catalyzed oxidation of N,N-diethyl-p-phenylenediamine (DPD). Water Research, v. 22, n. 9, p. 1109-1115, 1988.

BALMER, M.; SULZBERGER, B. Atrazine degradation in irradiated iron/oxalate systems: effects of $\mathrm{pH}$ and oxalate. Environmental Science and Technology, v. 33, n. 14, p. 2418-2424, 1999.

BAUER, R.; FALLMANN, H. The photo-Fenton oxidation - a cheap and efficient wastewater treatment method. Research on Chemical Intermediates, v. 23, n. 4, p. 341-354, 1997.

BAUTITZ, I. R.; NOGUEIRA, R. F. P. Degradation of tetracycline by photo-Fenton process - solar irradiation and matrix effects. Journal of Photochemistry and Photobiology A: Chemistry, v. 187, n. 1, p. 33-39, 2007.

BENNER, J.; TERNES, T. A. Ozonation of propranolol: formation of oxidation products. Environmental Science and Technology, v. 43, n. 13, p. 5086-5093, 2009.

BENOTTI, M.; TRENHOLM, R.; VANDERFORD, B.; HOLADY, J.; STANFORD, B.; SNYDER, S. Pharmaceuticals and endocrine disrupting compounds in U.S. drinking water. Environmental Science and Technology, v. 43, n. 3, p. 597-603, 2009. 
BENDZ, D.; PAXÉUS, N. A.; GINN, T. R.; LOGE, F. J. Occurrence and fate of pharmaceutically active compounds in the environment, a case study: Höje River in Sweden. Journal of Hazardous Materials, v. 122, n. 3, p. 195-204, 2005.

BOXALL, A. B. A.; KOLPIN, D. W.; HALLING-SORENSEN, B.; TOLLS, J. Are veterinary medicines causing environmental risks? Environmental Science and Technology, v. 37, n. 15, p. 286-294A, 2003.

BRASIL. Ministério do Meio Ambiente. Conselho Nacional do Meio Ambiente. Dispõe sobre a classificação dos corpos de água e diretrizes ambientais para o seu enquadramento, bem como estabelece as condições e padrões de lançamento de efluentes, e dá outras providências. Resolução n. 357, de 17 de março de 2005. Disponível em: <http://www.mma.gov.br/conama/res/res05/res35705.pdf > . Acesso em: 26 nov. 2009.

BRATSCH, S. G. Standard electrode potentials and temperature coefficients in water at 298.15K. Journal of Physical and Chemical Reference Data, v. 18, n. 1, p. 1-21, 1989.

BROWN, K. D.; KULIS, J.; THOMSON, B.; CHAPMAN, T. H.; MAWHINNEY, D. B. Occurrence of antibiotics in hospital, residential, and dairy effluent, municipal wastewater, and the Rio Grande in New Mexico. Science of the Total Environment, v. 366, n. 2/3, p. 772-783, 2006.

BUXTON, G. U.; GREENSTOCK, C. L.; HELMAN, W. P.; ROSS, A. B. Critical review of rate constants for reaction of hydrated electrons, hydrogen atoms and hydroxyl radicals $\left({ }^{\circ} \mathrm{OH} / \mathrm{O}^{\circ}\right)$ in aqueous solution. Journal of Physical and Chemical Reference Data, v. 17, n. 2 , p. $513-886,1988$.

CALAMARI, D.; ZUCCATO, E.; CASTIGLIONI, S.; BAGNATI, R.; FANELLI, R. Strategic survey of therapeutic drugs in the rivers Po and Lambro in northern Italy.

Environmental Science and Technology, v. 37, n. 7, p. 1241-1248, 2003.

CALVERT, J. G.; PITTS, J. N. Photochemistry. New York: John Wiley, 1966.

CALZA, P.; SAKKAS, V. A.; MEDANA, C.; BAIOCCHI, C.; DIMOU, A.; PELIZZETTI, E.; ALBANIS, T. Photocatalytic degradation study of diclofenac over aqueous $\mathrm{TiO}_{2}$ suspensions. Applied Catalysis B: Environmental, v. 67, n. 3/4, p. 197-205, 2006. 
CASTIGLIONI, S.; BAGNATI, R.; FANELLI, R.; POMATI, F.; CALAMARI, D.; ZUCCATO, E. Removal of pharmaceuticals in sewage treatment plants in Italy.

Environmental Science and Technology, v. 40, n. 1, p. 357-363, 2006.

CASTRO, C. M. B. Perturbadores endócrinos ambientais: uma questão a ser discutida. Engenharia Sanitária e Ambiental, v. 7, n. 1/2, p. 4-5, 2002.

CHANG, S.; CHUANG, S.; LI, H.; LIANG, H.; HUANG, L. Comparative study on the degradation of I.C. Remazol Brilliant Blue R and I.C. Acid Black 1 by Fenton oxidation and $\mathrm{Fe}$-/air process and toxicity evaluation. Journal of Hazardous Materials, v. 166, n. 2/3, p. 1279-1288, 2009a.

CHANG, S.; WANG, K.; CHAO, S.; PENG, T.; HUANG, L. Degradation of azo and anthraquinone dyes by a low-cost Fe-/air process. Journal of Hazardous Materials, v. 166, n. $2 / 3$, p. $1127-1133,2009 b$.

CLEUVERS, M. Aquatic ecotoxicity of pharmaceuticals including the assessment of combination effects. Toxicology Letters, v. 142, n. 3, p. 185-194, 2003.

COLEMAN, H. M.; ROUTLEDGE, E. J.; SUMPTER, J. P.; EGGINS, B. R.; BYRNE, J. A. Rapid loss of estrogenicity of steroid estrogens by UVA photolysis and photocatalysis over an immobilized titanium dioxide catalyst. Water Research, v. 38, n. 14/15, p. 32333240, 2004.

COMPANHIA AMBIENTAL DO ESTADO DE SÃO PAULO. Secretaria de Estado do Meio Ambiente. Água, rios e reservatórios. Disponível em:

<http://www.cetesb.sp.gov.br/Agua/rios/informacoes.asp>. Acesso em: 5 dez. 2009.

CURRIE, L. Detection and quantification limits: origins and historical overview. Analytica Chimica Acta, v. 391, n. 2, p. 127-134, 1999.

DANTAS, R. F.; CANTERINO, M.; MAROTTA, R.; SANS, C.; ESPLUGAS, S.; ANDREOZZI, R. Bezafibrate removal by means of ozonation: primary intermediates, kinetics, and toxicity assessment. Water Research, v. 41, n. 12, p. 2525-2532, 2007.

DÍAZ-CRUZ, M. S.; BARCELÓ, D. Trace organic chemicals contamination in ground water recharge. Chemosphere, v. 72, n. 3, p. 333-342, 2008. 
ELMOLLA, E. S.; CHAUDHURI, M. Degradation of the antibiotics amoxicillin, ampicillin and cloxacillin in aqueous solution by the photo-Fenton process. Journal of Hazardous Materials, v. 172, n. 2/3, p. 1476-1481, 2009.

EL-SAHARTY, Y. S. Simultaneous high-performance liquid chromatographic assay of furosemide and propranolol HCL and its application in a pharmacokinetic study. Journal of Pharmaceutical and Biomedical Analysis, v. 33, n. 4, p. 699-709, 2003.

EPOLITO, W. J.; YANG, H.; BOTTOMLEY, L. A.; PAVLOSTATHIS, S. G. Kinetics of zero-valent iron reductive transformation of the anthraquinone dye Reactive Blue 4. Journal of Hazardous Materials, v. 160, n. 2/3, p. 594-600, 2008.

ESPLUGAS, S.; BILA, D. M.; KRAUSE, L. G. T.; DEZOTTI, M. Ozonation and advanced oxidation technologies to remove endocrine disrupting chemicals (EDCs) and pharmaceuticals and personal care products (PPCPs) in water effluents. Journal of Hazardous Materials, v. 149, n. 3, p. 631-642, 2007.

FAUST, B. C.; HOIGNÉ, J. Photolysis of Fe(III)-hidroxy complexes as sources of $\mathrm{OH}$ radicals in clouds, fog and rain. Atmospheric Environment, v. 24, n. 1, p. 79-89, 1990.

FENG, W.; NANSHENG, D. Photochemistry of hydrolytic iron (III) species and photoinduced degradation of organic compounds. A minireview. Chemosphere, v. 41, n. 8, p. 1137-1147, 2000.

FENT, K.; WESTON, A. A.; CAMINADA, D. Ecotoxicology of human pharmaceuticals. Aquatic Toxicology, v. 76, n. 2, p. 122-159, 2006.

FENTON, H. J. H. Oxidation of tartaric acid in the presence of iron. Journal of Chemical Society, v. 65, p. 899-910, 1894.

FOLMAR, L. C.; HEMMER, M.; HEMMER, R.; BOWMAN, C.; KROLL, K.; DENSLOW, N. D. Comparative estrogenicity of estradiol, ethynyl estradiol and diethylstilbestrol in an in vivo, male sheepshead minnow (Cyprinodon variegatus), vitellogenin bioassay. Aquatic Toxicology, v. 49, n. 1/2, p. 77-88, 2000.

FUERHACKER, M.; LORBEER, G.; HABERL, R. Emission factors and sources of ethylene-diaminetetraacetic acid in waste water-a case study. Chemosphere, v. 52, n. 1, p. 253-257, 2003. 
GAGNÉ, F.; BLAISE, C.; ANDRÉ, C. Occurrence of pharmaceutical products in a municipal eflluent and toxicity to rainbow trout (Oncorhynchys mykiss) hepatocytes. Ecotoxicological and Environmental Safety, v. 64, n. 3, p. 329-336, 2006.

GALLARD, H.; LAAT, D. J.; LEGUBE, B. Spectrophotometric study of the formation of iron(III)-hydroperoxy complexes in homogeneous aqueous solutions. Water Research, v. 33, n. 13, p. 2929-2936, 1999.

GALVÉZ, J. B.; RODRÍGUEZ, S. M.; GASCA, C. A. E.; BANDALA, E. R.; GELOVER, S.; LEAL, T. Purificación de águas por fotocatálisis heterogénea: estado del arte. In: BLESA, M. A. Eliminación de contaminantes por fotocatálisis heterogénea. La Plata: Cyted, 2001. Cap. 3, p.51-75.

GAO, H.; ZEPP, R. G. Factors influencing photoreaction of dissolved organic matter in a coastal river of the Southeastern United States. Environmental Science and Technology, v. 32, n. 19, p. 2940-2946, 1998.

GEBHARDT, W.; SCHODER, H. F. Liquid chromatography-(tandem) mass spectrometry for the follow-up of the elimination of persistent pharmaceuticals during wastewater treatment applying biological wastewater treatment and advanced oxidation. Journal of Chromatography A, v. 1160, n. 1/2, p. 34-43, 2007.

GILHAM, R. W. Advances in groundwater poluttion control and remediation. Dordrecht: Kluwer Academic, 1996.

GOGATE, P. R.; PANDIT, A. B. A review of imperative technologies for wastewater treatment II: hybrid methods. Advances in Environmental Research, v. 8, n. 3/4, p. 553-597, 2004.

GÓMEZ, M. J.; BUENO, M. J. M.; LACORTE, S.; FERNÁNDEZ-ALBA, A. R.; AGÜERA, A. Pilot survey monitoring pharmaceuticals and related compounds in a sewage treatment plant located on the Mediterranean coast. Chemosphere, v. 66, n. 6 , p. 993-1002, 2007.

HAAG, W. R.; YAO, C. D. Rate constant for reaction of hydroxyl radicals with several drinking water contaminants. Environmental Science and Technology, v. 26, n. 5, p. 1005-1013, 1992. 
HABER, F.; WEISS, J. The catalytic decomposition of hydrogen peroxide by iron salts. Proceedings of the Royal Society of London: Part A, v. 134, p. 332-351, 1934.

HALLING-SORENSEN, B. Algal toxicity of antibacterial agents used in intensive farming. Chemosphere, v. 40, n. 7, p. 731-739, 2000.

HALLING-SORENSEN, B.; NIELSEN, S. N.; LANZKY, P. F.; INGERSLEV, F.; HOLTEN-LUTZHOFT, H. C.; JORGENSEN, S. E. Occurrence, fate and effects of pharmaceutical substances in the environment: a review. Chemosphere, v. 36, n. 2, p. 357-393, 1998.

HATCHARD, C. G.; PARKER, C. A. A new sensitive chemical actinometer II. Potassium ferrioxalato as a standard chemical actinometer. Proceedings of the Royal Society of London, v. 235, n. 1203, p. 518-536, 1956.

HEBERER, T. Occurrence, fate, and removal of pharmaceutical residues in the aquatic environment: a review of recent research data. Toxicology Letters, v. 131, n. 1/2, p. 5-17, 2002.

HERNANDO, M. D.; MEZCUA, M.; FERNÁNDEZ-ALBA, A. R.; BARCELÓ, D. Environmental risk assessment of pharmaceutical residues in wastewater effluents, surface waters and sediments. Talanta, v. 69, n. 2, p. 334-342, 2006.

HIRSCH, R.; TERNES, T.; HABERER, K.; KRATZ, K. Ocurrence of antibiotics in the aquatic environment. Science of the Total Environment, v. 225, n. 1/2, p. 109-118, 1999.

HUBER, M. M.; CANONICA, S.; PARK, G-Y.; VON GUNTEN, U. Oxidation of pharmaceuticals during ozonation and advanced oxidation process. Environmental Science and Technology, v. 37, n. 5, p. 1016-1024, 2003.

HUBER, M. M.; GOBEL, A.; JOSS, A.; HERRMANN, N.; LOFFLER, D.; McARDELL, C.; RIED, A.; SIEGRIST, H.; TERNES, A. T.; GUNTEN, U. V. Oxidation of pharmaceuticals during ozonation of municipal wastewater effluents: a pilot study. Environmental Science and Technology, v. 39, n. 11, p. 4290-4299, 2005. 
JELIC, A.; PETROVIC, M.; BARCELÓ, D. Multi-residue method for trace level determination of pharmaceuticals in solid samples using pressurized liquid extraction followed by liquid chromatography/quadrupole-linear ion trap mass spectrometry. Talanta, v. 80, n. 1, p. 363-371, 2009.

JOO, S. H.; FEITZ, A. J.; WAITE, T. D. Oxidative degradation of the carbothioate herbicide, molinate, using nanoscale zero-valent iron. Environmental Science and Technology, v. 38, n. 7, p. 2242-2247, 2004.

KATSOYIANNIS, I. A.; RUETTIMANN, T.; HUG, S. J. pH dependence of Fenton reagent generation and As(III) oxidation and removal by corrosion of zero valent iron in aerated water. Environmental Science and Technology, v. 42, n. 19, p. 7424-7430, 2008.

KLAVARIOTI, M.; MANTZAVINOS, D.; KASSINOS, D. Removal of residual pharmaceuticals from aqueous systems by advanced oxidation processes. Environment International, v. 35, n. 2, p. 402-417, 2009.

KEENAN, C. R.; SEDLAK, D. L. Ligand-enhanced reactive oxidant generation by nanoparticulate zero-valent iron and oxygen. Environmental Science and Technology, v. 42, n. 18, p. 6936-6941, 2008a.

KEENAN, C. R.; SEDLAK, D. L. Factors affecting the yield of oxidants from the reaction of nanoparticulate zero-valent iron and oxygen. Environmental Science and Technology, v. 42, v, 4, p. 1262-1267, 2008b.

KIM, I.; YAMASHITA, N.; TANAKA, $\mathrm{H}$. Performance of UV and UV/ $\mathrm{H}_{2} \mathrm{O}_{2}$ processes for the removal of pharmaceuticals detected in secondary effluent of a sewage treatment plant in Japan. Journal of Hazardous Materials, v. 166, n. 2/3, p. 1134-1140, 2009.

KOLPIN, D. W.; FURLONG, E. T.; MEYER, M. T.; THURMAN, E. M.; ZAUGG, S. D.; BARBER, L. B.; BUXTON, H. T. Pharmaceuticals, hormones, and other organic wastewater contaminants in US streams, 1999-2000: a national reconnaissance. Environmental Science and Technology, v. 36, n. 6, p. 1202-1211, 2002.

KÜMMERER, K. Resistance in the environment. In: environment. 2nd ed. Freiburg: Springer, 2004. Cap. 18, 223-231. 
KÜMMERER, K. The presence of pharmaceuticals in the environment due to human use - present knowledge and future challenges. Journal of Environmental Management, v. 90, n. 8, p. 2354-2366, 2009.

LAINE, D. F.; BLUMENFELD, A.; CHENG, I. F. Mechanistic study of the ZEA organic pollutant degradation system: evidence for $\mathrm{H}_{2} \mathrm{O}_{2}, \mathrm{HO}^{\circ}$, and the homogeneous activation of $\mathrm{O}_{2}$ by FellEDTA. Industrial Engineering Chemistry Research, v. 47, n. 17, p. 65026508, 2008.

LAMBROPOULOU, D. A.; HERNANDO, M. D.; KONSTANTINOU, I. K.; THURMAN, E. M.; FERRER, I.; ALBANIS, T. A.; FERNÁNDEZ-ALBA, A. R. Identification of photocatalytic degradation products of bezafibrate in $\mathrm{TiO}_{2}$ aqueous suspensions by liquid and gas chromatography. Journal of Chromatography A, v. 1183, n. 1/2, p. 3848, 2008.

LANGFORD, C. H.; CAREY, J. H. The charge transfer photochemistry of the Hexaaquoiron(III) ion, the Chloropentaaquoiron(III) ion, and the $\mu$-dihydroxo dimer explored with tert-butyl alcohol scavenging. Canadian Journal of Chemistry, v. 53, n. 16 , p. 2430-2435, 1975.

LARSSON, D. G. J.; FICK, J. Transparency throughout the production chain - a way to reduce pollution from the manufacturing of pharmaceuticals? Regulatory Toxicology and Pharmacology, v. 53, n. 3, p. 161-163, 2009.

LARSSON, D. G. J.; PEDRO, C.; PAXEUS, N. Effluent from drug manufactures contains extremely high levels of pharmaceuticals. Journal of Hazardous Materials, v. 148, n. 3, p. $751-755,2007$.

LEGRINI, O.; OLIVEROS, E.; BRAUN, A. M. Photochemical processes for water treatment. Chemical Reviews, v. 93, n. 2, p. 671-698, 1993.

LIAO, C-H.; KANG, S-F.; HSU, Y-W. Zero-valent iron reduction of nitrate in the presence of ultraviolet light, organic matter and hydrogen peroxide. Water Research, v. 37, n. 17, p. 4109-4118, 2003.

LIN, A. Y.; YU, T.; LIN, C. Pharmaceutical contamination in residential, industrial, and agricultural waste streams: risk to aqueous environments in Taiwan. Chemosphere, v. 74, n. 1, p. 131-141, 2008. 
LIN, A. Y.; LIN, C.; CHIOU, J.; HONG, P. K. A. $\mathrm{O}_{3}$ and $\mathrm{O}_{3} / \mathrm{H}_{2} \mathrm{O}_{2}$ treatment of sulfonamide and macrolide antibiotics in wastewater. Journal of Hazardous Materials, v. 171, n. 1/3, p. 452-458, 2009.

LINDQVIST, N.; TUHKANEN, T.; KRONBERG, L. Occurrence of acid pharmaceuticals in raw and treated sewages and in receiving waters. Water Research, v. 39, n. 11, p. 2219-2228, 2005.

LINDSEY, M. E.; MEYER, M.; THURMAN, E. M. Analysis of trace levels of sulfonamide and tetracycline antimicrobials in groundwater and surface water using solid-phase extraction and liquid chromatography/mass spectrometry. Analytical Chemistry, v. 73, n. 19, p. 4640-4646, 2001.

MADDEN, J. C.; ENOCH, S. J.; HEWITT, M.; CRONIN, M. T. D. Pharmaceuticals in the environment: good practice in predicting acute ecotoxicological effects. Toxicology Letters, v. 185, n. 2, p. 85-101, 2009.

MALATO, S.; BLANCO, J.; CÁCERES, J.; FERNÁNDEZ-ALBA, A. R.; AGÜERA, A.; RODRIGUEZ, A. Photocatalytic treatment of water-soluble pesticides by photo-Fenton and $\mathrm{TiO}_{2}$ using solar energy. Catalysis Today, v. 76, n. 2/4, p. 209-220, 2002.

MARTIN, P. D.; JONES, G. R.; STRINGER, F.; WILSON, I. D. Comparison of extraction of a $\beta$-blocker from plasma onto a molecularly imprinted polymer with liquid-liquid extraction and solid phase extraction methods. Journal of Pharmaceutical and Biomedical Analysis, v. 35, n. 5, p. 1231-1239, 2004.

MAURER, M.; ESCHER, B. I.; RICHLE, P.; SCHAFFNER, C.; ALDER, A. C. Elimination of $\beta$-blockers in sewage treatment plants. Water Research, v. 41, n. 7, p. 1614-1622, 2007.

MELO, S. A. S.; BAUTITZ, I. R.; NOGUEIRA, R. F. P. Monitoring pharmaceuticals photo-Fenton degradation process by using solid phase extraction and liquid chromatography. Analytical Letters, v. 41, n. 9, p. 1682-1690, 2008.

MELO, S. A. S.; TROVÓ, A. G.; BAUTITZ, I. R.; NOGUEIRA, R. F. P. Degradação de fármacos residuais por processos oxidativos avançados. Química Nova, v. 32, n. 1, p. 188-197, 2009. 
MULROY, A. When the cure is the problem. Water Environment and Technology, v. 13, n. 2, p. 32-36, 2001.

NAM, S.; TRATNYEK, P. G. Reduction of azo dyes with zero-valent iron. Water Research, v. 34, n. 6, p. 1837-1845, 2000.

NOGUEIRA, R. F. P.; GUIMARÃES, J. R. Photodegradation of dichloroacetic acid and 2,4-dichlorophenol by ferrioxalate $/ \mathrm{H}_{2} \mathrm{O}_{2}$ system. Water Research, v. 34, n. 3, p. 895$901,2000$.

NOGUEIRA, R. F. P.; OLIVEIRA, M. C.; PATERLINI, W. C. Simple and fast spectrophotometric determination of $\mathrm{H}_{2} \mathrm{O}_{2}$ in photo-Fenton reactions using metavanadate. Talanta, v. 66, n. 1, p. 86-91, 2005.

NOGUEIRA, R. F. P.; SILVA, M. R. A.; TROVÓ, A. G. Influence of the iron source on the solar photo-Fenton degradation of different classes of organic compounds. Solar Energy, v. 79, n. 4, p. 384-392, 2005.

NOGUEIRA, R. F. P.; TROVÓ, A. G.; SILVA, M. R. A.; VILLA, R. D.; OLIVEIRA, M. C. Fundamentos e aplicações ambientais dos processos Fenton e foto-Fenton. Química Nova, v. 30, n. 2, p. 400-408, 2007.

NORADOUN, C.; CHENG, I. F. EDTA degradation induced by oxygen activation in a zerovalent iron/air/water system. Environmental Science and Technology, v. 39, n. 18 , p. $7158-7163,2005$.

NORADOUN, C.; ENGELMANN, M. D.; McLAUGHLIN, M.; HUTCHESON, R.; BREEN, K.; PASZCZYNSKI, A.; CHENG, I. F. Destruction of chlorinated phenols by dioxygen activation under aqueous room temperature and pressure conditions. Industrial Engineering Chemistry Research, v. 42, n. 21, p. 5024-5030, 2003.

$\mathrm{OH}$, S.; CHIU, P. C.; KIM, B. J.; CHA, D. K. Enhancing Fenton oxidation of TNT and RDX through pretreatment with zero-valent iron. Water Research, v. 37, n. 17, p. 42754283, 2003.

PACKER, J. L.; WERNER, J. J.; LATCH, D. E.; McNEILL, K.; ARNOLD, W. A. Photochemical fate of pharmaceuticals in the environment: naproxen, diclofenac, clofibric acid, and ibuprofen. Aquatic Sciences, v. 65, n. 4, p. 342-351, 2003. 
PASCOE, D.; KARNTANUT, W.; MULLER, C. T. Do pharmaceuticals affect freshwater invertebrates? A study with the cnidarian Hydra vulgaris. Chemosphere, v. 51, n. 6 , p. 521-528, 2003.

PATEL, B. N.; SHARMA, N.; SANYAL, M.; SHRIVASTAV, P. S. An accurate, rapid and sensitive determination of tramadol and its active metabolite $O$-desmethyltramadol in human plasma by LC-MS/MS. Journal of Pharmaceutical and Biomedical Analysis, v. 49, n. 2, p. 354-366, 2009.

PEREIRA, V. J.; WEINBERG, H. S.; LINDEN, K. G.; SINGER, P. C. UV degradation kinetics and modeling of pharmaceutical compounds in laboratory grade and surface water via direct and indirect photolysis at $254 \mathrm{~nm}$. Environmental Science and Technology, v. 41, n. 5, p. 1682-1688, 2007.

PEREIRA, W. S.; FREIRE R. S. Azo dye degradation by recycled waste zero-valent iron powder. Journal of the Brazilian Chemical Society, v. 17, n. 5, p. 832-838, 2006.

PEREIRA, W. S.; FREIRE R. S. Ferro zero: uma nova abordagem para o tratamento de águas contaminadas com compostos orgânicos poluentes. Química Nova, v. 28, n. 1, p. 130-136, 2005.

PÉREZ, S.; BARCELÓ, D. Application of advanced MS techniques to analysis and identification of human and microbial metabolites of pharmaceuticals in the aquatic environment. Trends in Analytical Chemistry, v. 26, n. 6, p. 494-514, 2007.

PÉREZ-ESTRADA, L. A.; MALATO, S.; AGÜERA, A.; FÉRNANDEZ-ALBA, A. R. Degradation of dipyrone and its main intermediates by solar AOPs. Identification of intermediate products and toxicity assessment. Catalysis Today, v. 129, n. 1/2, p. 207214, 2007.

PÉREZ-ESTRADA, L. A.; MALDONADO, M. I.; GERNJAK, W.; AGÜERA, A.; FERNÁNDEZ-ALBA, A. R.; BALLESTEROS, M. M.; MALATO, S. Decomposition of diclofenac by solar driven photocatalysis at pilot plant scale. Catalysis Today, v. 101, n. 3/4, p. 219-226, 2005.

PIGNATELLO, J. J. Dark and photoassisted $\mathrm{Fe}^{3+}$-catalyzed degradation of chlorophenoxy herbicides by hydrogen peroxide. Environmental Science and Technology, v. 26, n. 5, p. 944-951, 1992. 
PIGNATELLO, J. J.; OLIVEROS, E.; MacKAY, A. Advanced oxidation processes for organic contaminant destruction based on the Fenton reaction and related chemistry. Critical Reviews in Environmental Science and Technology, v. 36, n. 6, p. 1-84, 2006.

POMATI, F.; CASTIGLIONI, S.; ZUCCATO, E.; FANELLI, R.; VIGETTI, D.; ROSSETTI, C.; CALAMARI, D. Effects of a complex mixture of therapeutic drugs at environmental levels on human embryonic cells. Environment Science and Technology, v. 40, n. 7, p. 2442-2447, 2006.

POMATI, F.; ORLANDI, C.; CLERICI, M.; LUCIANI, F.; ZUCCATO, E. Effects and interactions in an environmentally relevant mixture of pharmaceuticals. Toxicological Sciences, v. 102, n. 1, p. 129-137, 2008.

PONDER, S.; DARAB, J. G.; MALLOUK, T. E. Remediation of $\mathrm{Cr}(\mathrm{VI})$ and $\mathrm{Pb}(\mathrm{II})$ aqueous solutions using supported nanoscale zero-valent iron. Environmental Science and Technology, v. 34, n. 12, p. 2564-2569, 2000.

PRADO, M. S. A.; STEPPE, M.; TAVARES, M. F. M.; KEDORHACKMANN, E. R. M.; SANTORO, M. I. R. M. Comparison of capillary electrophoresis and reversed-phase liquid chromatography methodologies for determination of diazepam in pharmaceutical tablets. Journal of Pharmaceutical and Biomedical Analysis, v. 37, n. 2, p. 273-279, 2005.

RADJENOVIC, J.; PETROVIC, M.; BARCELÓ, D. Advanced mass spectrometric methods applied to the study of fate and removal of pharmaceuticals in wastewater treatment. Trends in Analytical Chemistry, v. 26, n. 11, p. 1132-1144, 2007.

RADJENOVIC, J.; PETROVIC, M.; BARCELÓ, D. Complementary mass spectrometry and bioassays for evaluating pharmaceutical-transformation products in treatment of drinking water and wastewater. Trends in Analytical Chemistry, v. 28, n. 5, p. 562580, 2009.

RAVINA, M.; CAMPANELLA, L.; KIWI, J. Accelerated mineralization of drug diclofenac via Fenton reactions in a concentric photo-reactor. Water Research, v. 36, n. 14, p. 3553-3560, 2002. 
REYES, C.; FERNANDEZ, J.; FREER, J.; MONDACA, M. A.; ZAROR, C.; MALATO, S.; MANSILLA, H. D. Degradation and inactivation of tetracycline by $\mathrm{TiO}_{2}$ photocatalysis. Journal of Photochemistry and Photobiology A: Chemistry, v. 184, n. 1/2, p. 141146, 2006.

RIBANI, M.; BOTTOLI, C. B. G.; COLLINS, C. H.; JARDIM, I. C. S. F.; MELO, L. F. C. Validação em métodos cromatográficos e eletroforéticos. Química Nova, v. 27, n. 5, p. 771-780, 2004.

ROBERTS, P. H.; THOMAS, K. V. The occurrence of selected pharmaceuticals in wastewater effluent and surface waters of the lower Tyne catchment. Science of the Total Environment, v. 356, n. 1/3, p. 143-153, 2006.

RODGERS-GRAY, T. P.; JOBLING, S.; KELLY, C.; MORRIS, S.; BRIGHTY, G. WALDOCK, M. J.; SUMPTER, J. P.; TYLER, C. R. Exposure of juvenile roach (rutilus rutilus) to treated sewage effluent induces dose-dependent and persistent disruption in gonadal duct development. Environment Science and Technology, v. 35, n. 3, p. 462470, 2001.

SAFARZADEH-AMIRI, A.; BOLTON, J. R.; CARTER, S. R. Ferrioxalate-mediated solar degradation of organic contaminants in water. Solar Energy, v. 56, n. 5, p. 439-444, 1996a.

SAFARZADEH-AMIRI, A.; BOLTON, J. R.; CARTER, S. R. The use of iron in advanced oxidation processes. Journal of Advanced Oxidation Technology, v. 1, n. 1, p. 8-26, 1996b.

SANCHEZ, I.; STUBER, F.; FONT, J.; FORTUNY, A.; FABREGAT, A.; BENGOA, C. Elimination of phenol and aromatic compounds by zero valent iron and EDTA at low temperature and atmospheric pressure. Chemosphere, v. 68, n. 2, p. 338-344, 2007.

SANTOS, J. L.; APARICIO, I.; ALONSO, E.; CALLEJÓN, M. Simultaneous determination of pharmaceutically active compounds in wastewater simples by solid extraction and high-performance liquid chomatography with diode array and fluorescente detectors. Analytical Chimica Acta, v. 550, n. 1/2, p. 116-122, 2005.

SARMAH, A. K.; MEYER, M. T.; BOXALL, A. B. A. A global perspective on the use, sales, exposure pathways, occurrence, fate and effects of veterinary antibiotics (VAs) in the environment. Chemosphere, v. 65, n. 5, p. 725-759, 2006. 
SAYLES, G. D.; YOU, G. R.; WANG, M. X.; KUPFERLE, M. DDT, DDD, and DDE dechlorination by zero-valent iron. Environmental Science and Technology, v. 31, n. 12, p. 3448-3454, 1997.

SEGURA, P. A.; FRANÇOIS, M.; GAGNON, C.; SAUVÉ, S. Review of the occurrence of anti-infectives in contaminated wastewaters and natural and drinking waters.

Environmental Health Perspectives, v. 117, n. 5, p. 675-684, 2009.

SHEMER, H.; KUNUKCU, Y. K.; LINDEN, K. G. Degradation of the pharmaceutical Metronidazole via UV, Fenton and photo-Fenton processes. Chemosphere, v. 63, n. 2, p. 269-276, 2006.

SEIBIG, S.; VAN ELDIK, R. Kinetics of [Fell(EDTA)] oxidation by molecular oxygen revisited. New evidence for a multistep mechanism. Inorganic Chemistry, v. 36, n. 18, p. 4115-4120, 1997.

SODRÉ, F. F.; LOCATELLI, M. A. F.; JARDIM, W. F. Occurrence of emerging contaminants in brazilian drinking waters: a sewage-to-tap issue. Water Air and Soil Pollution, v. 206, n. 1/4, p. 57-67, 2010.

SODRÉ, F. F.; MONTAGNER, C. C.; LOCATELLI, M. A. F.; JARDIM, W. F. Ocorrência de interferentes endócrinos e produtos farmacêuticos em águas superficiais da região de Campinas (SP, Brasil). Journal of the Brazilian Society of Ecototxicology, v. 2, n. 2, p. 187-196, 2007.

SOHN, K.; KANG, S. W.; AHN, S.; WOO, M.; YANG, S. Fe(0) nanoparticles for nitrate reduction: stability, reactivity and transformation. Environmental Science and Technology, v. 40, n. 17, p. 5514-5519, 2006.

SOUZA, C. R. L.; PERALTA-ZAMORA, P. Degradação de corantes reativos pelo sistema ferro metálico/peróxido de hidrogênio. Química Nova, v. 28, n. 2, p. 226-228, 2005.

SOUZA, S. M. L.; VASCONCELOS, E. C.; DZIEDZIC, M.; OLIVEIRA, C. M. R. Environmental risk assessment of antibiotics: an intensive care unit analysis.

Chemosphere, v. 77, n. 7, p. 962-967, 2009.

SPINKS, J. W. T.; WOODS, R. J. An introduction to radiation chemistry. 3nd ed. Nova York: John Wiley \& Sons, 1990. 504 p. 
STACKELBERG, P. E.; FURLONG, E. T.; MEYER, M. T.; ZAUGG, S. D.;

HENDERSON, A. K.; REISSMAN, D. B. Persistence of pharmaceutical compounds and other organic wastewater contaminants in a conventional drinking water treatment plant. Science of the Total Environment, v. 329, n. 1/3, p. 99-113, 2004.

STUMPF, M.; TERNES, T. A.; WILKEN, R. D.; RODRIGUES, S. V.; BAUMANN, W. Polar drug residues in sewage and natural waters in the state of Rio de Janeiro, Brazil. The Science of Total Environmental, v. 225, n. 1/2, p. 135-141, 1999.

TEIXEIRA, C. P. A. B.; JARDIM, W. F. Processos oxidativos avançados: conceitos teóricos. Caderno Temático, v. 3. Disponível em: <http://lqa.iqm.unicamp.br>. Acesso em: 15 dez. 2009.

TERNES, T.; BONERZ, M.; SCHMIDT, T. Determination of neutral pharmaceuticals in wastewater and rivers by liquid chromatography-electrospray tandem mass spectrometry. Journal of Chromatography A, v. 938, n. 1/2, p. 175-185, 2001.

TERNES, T. A. Occurrence of drugs in German sewage treatment plants and rivers. Water Research, v. 32, n. 11, p. 3245-3260, 1998.

TERNES, T. A.; STUMPF, M.; MUELLER, J.; HABERER, K.; WILKEN, R.; SERVOS, M. Behaviour and occurrence of estrogens in municipal sewage plants - I. Investigation in Germany, Canada and Brazil. The Science of Total Environmental, v. 225 , n. $1 / 2$, p. $81-90,1999$.

TERNES, T. A.; STUBER, J.; HERRMANN, N.; McDOWELL, D.; RIED, A.; KAMPMANN, M.; TEISER, B. Ozonation: a tool for removal of pharmaceuticals, contrast media and musk fragrances from wastewater? Water Research, v. 37, n. 8, p. 19761982, 2003.

TRATA BRASIL. Instituto Trata Brasil divulga ranking do saneamento com avaliação dos serviços nas 79 maiores cidades do País. Disponível em: <http://www.tratabrasil.org.br/novo_site/?id=6747>. Acesso em: 14 jan. 2010.

TROVÓ, A. G.; MELO, S. A. S.; NOGUEIRA, R. F. P. Photodegradation of the pharmaceuticals amoxicillin, bezafibrate and paracetamol by the photo-Fenton process application to sewage treatment plant effluent. Journal of Photochemistry and Photobiology A: Chemistry, v. 198, n. 2/3, p. 215-220, 2008. 
TROVÓ, A. G.; NOGUEIRA, R. F. P.; AGÜERA, A.; FERNÁNDEZ-ALBA, A. R.; SIRTORI, C.; MALATO, S. Degradation of sulfamethoxazole in water by solar photo-Fenton. Chemical and toxicological evaluation. Chemosphere, v. 77 , n. 10 , p. 1292-1298, 2009.

UNITED STATES ENVIRONMENTAL PROTECTION AGENCY. Priority pollutants. Disponível em: <http://www.epa.gov/waterscience/methods/pollutants.htm>. Acesso em: 5 dez. 2009a.

UNITED STATES ENVIRONMENTAL PROTECTION AGENCY. Pharmaceuticals and personal care products (PPCPs). Disponível em: http://epa.gov/ppcp>. Acesso em: 8 dez. 2009b.

VAN DER VEN, K.; DONGEN, W. V.; MAES, B. U. W.; ESMANS, E. L.; BLUST, R. COEN, W. M. D. Determination of diazepam in aquatic samples by capillary liquid chromatography-electrospray tandem mass spectrometry. Chemosphere, v. 57 , n. 8, p. 967-973, 2004.

VOGNA, D.; MAROTTA, R.; ANDREOZZI, R.; NAPOLITANO, A.; ISCHIA, M. Kinetic and chemical assessment of the $\mathrm{UV} / \mathrm{H}_{2} \mathrm{O}_{2}$ treatment of antiepileptic drug carbamazepine. Chemosphere, v. 54, n. 4, p. 497-505, 2004.

WALLING, C.; GOOSEN, A. Mechanism of ferric ion catalyzed decomposition of hydrogen-peroxide - effect of organic substrates. Journal of the American Chemical Society, v. 95, n. 9, p. 2987-2991, 1973.

WANG, S.; BU, S.; LIU, H.; LI, H.; LIU, W. WANG, Y. Separation and characterization of clindamycin phosphate and related impurities in injection by liquid chromatography/electrospray ionization mass spectrometry. Rapid Communications in Mass Spectrometry, v. 23, n. 6, p. 899-906, 2009.

WARDMAN, P. Reduction potentials of one-electron couples involving free radicals in aqueous solution. Journal of Physical and Chemical Reference Data, v. 18, n. 4, p. 1637-1723, 1989.

WERT, E. C.; ROSARIO-ORTIZ, F. L.; SNYDER, S. Effect of ozone exposure on the oxidation of trace organic contaminants in wastewater. Water Research, v. 43, n. 4 , p. 1005-1014, 2009. 
YANG, G.; ZHAO, X.; SUN, X.; LU, X. Oxidative degradation of diethyl phthalate by photochemically-enhanced Fenton reaction. Journal of Hazardous Materials, v.126, n. 1/3, p. 112-118, 2005.

ZEPP, R. G.; SCHIOTZHAUER, P. F.; SINK, R. M. Photosensitized transformations involving electronic energy transfer in natural waters: role of humic substances.

Environmental Science and Technology, v. 19, n. 1, p. 74-81, 1985.

ZHANG, W. Nanoscale iron particles for environmental remediation: an overview. Journal of Nanoparticle Research, v. 5, n. 3/4, p. 323-332, 2003.

ZHENG, H.; PAN, Y.; XIANG, X. Oxidation of acidic dye Eosin Y by the solar photoFenton processes. Journal of Hazardous Materials, v. 141, n. 3, p. 457-464, 2007.

ZHOU, T.; LI, Y.; WONG, F.; LU, X. Enhanced degradation of 2,4-dichlorophenol by ultrasound in a new Fenton like system (Fe/EDTA) at ambient circumstance.

Ultrasonics Sonochemistry, v. 15, n. 5, p. 782-790, 2008.

ZHOU, T.; LU, X.; WANG, J.; WONG, F.; LI , Y. Rapid decolorization and mineralization of simulated textile wastewater in a heterogeneous Fenton like system with/without external energy. Journal of Hazardous Materials, v. 165, n. 1/3, p.193-199, 2009.

ZHU, H.; LUO, J. A fast and sensitive liquid chromatographic-tandem mass spectrometric method for assay of lorazepam and application to pharmacokinetic analysis. Journal of Pharmaceutical and Biomedical Analysis, v. 39, n. 1/2, p. 268274, 2005.

ZORITA, S.; MARTENSSON, L.; MATHIASSON, L. Occurrence and removal of pharmaceuticals in a municipal sewage treatment system in the south of Sweden. Science of the Total Environment, v. 407, n. 8, p. 2760-2770, 2009.

ZUO, Y.; HOIGNE, J. Formation of hydrogen peroxide and depletion of oxalic acid in atmospheric water by photolysis of iron(III)-oxalate complexes. Environmental Science and Technology, v. 26, n. 5, p. 1014-1022, 1992.

ZWIENER, C.; FRIMMEL, F. H. Oxidative treatment of pharmaceuticals in water. Water Research, v. 34, n. 6, p. 1881-1885, 2000. 
ANEXO 1. Resultados da análise da amostra de efluente de ETE.

Coleta: ETE - Araraquara -SP

Data: $11 / 06 / 2008$

Parâmetros

\section{Efluente Padrão efluente}

Demanda Química de Oxigênio (DQO) $\left(\mathrm{mg} \mathrm{O}_{2} / \mathrm{L}\right)$ 378

Demanda Bioquímica de Oxigênio (DBO) $\left(\mathrm{mg} \mathrm{O}_{2} / \mathrm{L}\right)$ 64 $<60^{(a)}$

Remoção DQO (\%) 40

Remoção DBO (\%) 75 $80^{(a)}$

$\mathrm{pH}$

7

Condutividade (us/cm) 728

Sólidos Totais (mg/L) RS

Sólidos Fixos (mg/L) RS

Sólidos Voláteis (mg/L) RS

Sólidos Suspensos Totais (mg/L) RS

Sólidos Suspensos Fixos (mg/L) RS

Sólidos Suspensos Voláteis $(\mathrm{mg} / \mathrm{L})$ RS

Sólidos Dissolvidos Totais (mg/L) RS

Sólidos Dissolvidos Fixos (mg/L) RS

Sólidos Dissolvidos Voláteis (mg/L)

Materiais Sedimentáveis Cone Imhoff 1 hora (mL/L) RS

Substâncias Solúveis em Hexano (mg/L)*

0

RS

$$
5-9^{(a, b)}
$$

Oxigênio Dissolvido $\left(\mathrm{mg} \mathrm{O}_{2} / \mathrm{L}\right)$

0.7

Turbidez (NTU)

385

Cor (Hazen) 1090

Cloreto (mg Cl/L)

53.0

Nitrogênio Amoniacal (mg N/L)

26.0

$<20,0^{(\text {b) }}$

Nitrato ( $\mathrm{mg} \mathrm{N} / \mathrm{L})$

1.20

Nitrito (mg N/L)

0.03

Nitrogênio Total Kjeldahl (mg N/L)

56.00

Fósforo Total (mg P/L)

Remoção Nitrogênio Total (\%)

SR 
Remoção Fósforo Total (\%)

2

27

26

$<40^{(a, b)}$

Temperatura da Amostra $\left({ }^{\circ} \mathrm{C}\right)$

Coliformes Totais (UFC/100mL)

Escherichia coli (UFC/100mL)

Análise do efluente realizada com amostra composta, proporcional à vazão, coletada a cada 2 horas durante 24 horas. RS: análise realizada uma vez por semana; SR: sem remoção.

Análise segundo Normas da $20^{a}$ ed. do Standard Methods for examination of water and Wastewater e CETESB.

Obs. ${ }^{(A)}$ Decreto Estadual 8468/76 art. 18; ${ }^{\text {(B) }}$ Resolução CONAMA 357/2005 Art. 34;

Substâncias solúveis em hexano incluem óleos minerais, vegetais e gorduras animais.

\section{Fonte: DEPARTAMENTO AUTÔNOMO DE ÁGUA E ESGOTOS}

Laboratório Físico-Químico e microbiológico

Rua Domingos Barbieri, 100 - Caixa Postal, 380 - Telefone: (16) 3324-9555

CEP 14802-510 - Araraquara - SP CNPJ 44.239.770/0001-27

e-mail-ete@daaeararauqara.com.br 